
REGENERACIÓN URBANA

PROPUESTAS PARA EL BARRIO DE SAN PABLO, ZARAGOZA

\section{URBAN REGENERATION}

PROPOSALS FOR SAN PABLO NEIGHBORHOOD, ZARAGOZA 
PRESENAACION
PRESETATION

6 José Manuel Alonso

Ayuntamiento de Zarago:za
Zaragoza Town Council

8 Javier Monclús

Escuela de Ingeniería Arquutectura. Universidad de Zaragozza
School of Engnineering and Architecture, Zaragozaz University

10 REGENERACION URBANA INTEGRADA INTEGRATED URBE
Javier Monclús

OBSERVACIONES ELEMENTALES SOBRE ELL LUGAR

Massimo Fortis

54 La GESTIÓN DE LA REGENERACIÓN URBANA INTEGRAL

Julio Tejedor Bielsa

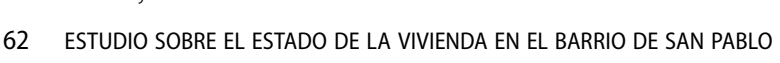

STUDY ON THE STATE OF HOUSIIG IN THE SAN PABBO NEGGHOPHOOD

Juan Rubio y Sergio García

SAN PABLO / LUIS BUÑUEL

José Javier Gallardo

88 REForMAS URBANAS EN ZARAGOZA

INER URBAN RENEWAL IN ZARAGOZA

98 ANALIISI DE REEORMAS URBANAS
ANALISSS OF URBAN REFORMS

Luciac. Perezz, coordinacion

106 ReHABLLITAR Un LoCAL PARA REVITALIZAR Un BaRrIO: APRENDIZAAE BASADO EN UN CASO REAL
REVURBSSING PREMIES TO HELP REVITALSE A NEIGHBORHOOD: REAL CASE-BASED LEARIING

Beqoña Genuay Belinda López-Mesa

114 PROPUESTAS PARA UN LOCAL

18 TALLER SAN PABLLO-ZGZZ UNA EXPERIENCIA ACADÉMICA DE REGENERACIÓN URBANA

TALLER SAN PABLO-ZGG. UNA EXPERRENCAA ACADEMICA DE REGENERACON URBANA
SAN PABLO (ZARAGOZA) WORKSHOP. AN ACADEMIC EXERRIENCE IN URBAN REGENERATION Francisco Berruete, Pablo de la Cal y Miriam García

130 PROYECTOS DE URBANIZACION

Enique Cano y Juan Antonio Ros

34 PROPUESTAS PARA EL BARRIO DE SAN PABLO
PROPOSALS FOR THE SAN PABLO NEIGHBORHOOD

178 ANEXO. ESCUELA DE ARQUTTECTURA Y POLITICA MUNIIIPALL UNA CONCLUSION FINAL A RALZ DE LA MOCIÓN PRESENTADA EN EL AYUNTAMIENTO
PARA ABRRIR LOS JARDINES DEL EDIFICIO PIGNATELLI 
In recent years the City Council of Zaragoza has been promoting social and urban revitalisation policies and strategie in various parts of the city's Historic Centre. Many of the planned interventions have become part of the Integral Plans for the Historic Centre (PICH 1997-2004, 2005-2012, 2013-2020, the latter was approved recently), and we have als identified Integral Rehabilitation Areas in the Historic Centre within the framework of state and regional Housing and Rehabilitation Plans. We have even encouraged an overall analysis of the various roles the Historic Centre plays. Transforms the Centre study.

The Integral Plan for the Historic Centre Office has collaborated with other municipal departments to contribute to the revitalisation of this part of the city by promoting a project involving several intervention proposals on different levels - architecture, urban development and landscape - put forward by the School of Engineering and Architecture the University of Zaragoza. The Council of Zaragoza signed an agreement with the University to produce a documen as part of the 2013-2014 Master of Architecture academic year, mostly in the course integrated urban and landscape designs workshop, although later other additional approaches were added for rehabilitation, redevelopment, heritage and urban planning management contents. The result of this agreement is a product of collaboration between both institutions, with specific backing from the public society Zaragoza Vivienda, which provided several documents for the project managers.

The book you are holding in your hands will not give you complete solutions to the complex problems found in the San Pablo district or the Historic Centre of Zaragoza. Nevertheless, this document, produced by a team of Master Architecture students and tutors from the University of Zaragoza, with some external collaboration, explores the not situations characterising the district to identify opportunities for urban intervention in this essential p.
Historic Centre of Zaragoza and to propose urban regeneration proposals of varying scope and complexity.

This is, therefore, a series of thoughts and proposals which will undoubtedly help the council to rethink its future urban strategies in collaboration with private initiative and citizen organisations. Some of the proposals might seen utopian, yet a succinct narrow view of everyday life would end up being wanting. Only through dialogue can you strike a balance between different proposals.

José Manuel Alonso

City Councillor and Head of the Committee for the Historic District of Zaragoza
Durante los últimos años, el Ayuntamiento de Zaragoza viene desarrollando políticas y estrategias de revitalización social y urbanística en diferentes ámbitos del Centro Histórico de la ciudad, a través de sucesivos instrumentos de planificación e intervención plasmados, entre otros, en los sucesivos Planes Integrales del Centro Histórico (PICH 997-2004, 2005-2012, 2013-2020, este último recientemente aprobado), así como mediante la declaración de Áreas de Rehabilitación Integral del Centro Histórico (ARCH) en el marco de los Planes estatales y regionales de Vivienda y Rehabilitación, o incluso propiciando la reflexión global sobre las diferentes funciones y carencias del Centro Histórico que, con ocasión de la candidatura de Zaragoza a la Capitalidad Europea de 2016, dieron lugar al estudio "La cultura transforma el centro"

En esta línea, la Oficina del Plan Integral del Casco Histórico (PICH), en colaboración con otras áreas municipales y en aras a contribuir en el proyecto de revitalización en esta zona de la ciudad, ha impulsado un trabajo sobre posibles propuestas de intervención a nivel arquitectónico, urbanístico y paisajístico, desarrolladas desde la Escuela de Ingeniería y Arquitectura de la Universidad de Zaragoza. El Ayuntamiento de Zaragoza firmó un convenio con la Universidad con el objetivo de elaborar un documento en el marco del Máster Universitario de Arquitectura que se desarrolló durante el curso 2013-14, especialmente en la asignatura Taller Proyectos Urbanos y Paisaiisticos Integrados, si bien posteriormente se incorporaron otras visiones complementarias correspondientes a los contenidos de rehabilitación, reurbanización, patrimonio o gestion urbanistica. El resultado de ese convenio es así un producto de la colaboración entre ambas instituciones, con el apoyo especifico de la Sociedad Municipal Zaragoza Vivienda, que ha aportado diversa documentación a los responsables del trabajo.

En el libro que el lector tiene en sus manos no se encontrarán soluciones acabadas a los complejos problemas que se plantean en el barrio de San Pablo ni en el centro histórico zaragozano. Sin embargo, en el documento elaborado por el equipo de estudiantes y profesores del Máster Universitario en Arquitectura de dicha Escuela, con otras colaboraciones externas, se exploran a fondo diversas situaciones que caracterizan al barrio, tratando de identificar oportunidades de actuación urbanística en esa pieza esencial del centro histórico de Zaragoza y efectuando propuestas de regeneración urbana de distinto alcance y de complejidad variable.

Nos encontramos, por tanto, ante una serie de reflexiones y propuestas de naturaleza urbanistica que, indudablemenee, resultarán de gran utilidad para repensar las estrategias que podria impulsar el Ayuntamiento en colaboración con que permita conciliar propuestas de distinta índole.

José Manuel Alonso

Concejal Presidente de la Junta de Distrito de Casco Historicico de Zaragoza 


\section{Urban perspectives and proposals for the San Pablo neighborhood in Zaragoza}

During the autumn term of the academic year 2013-2014, Master of Architecture students from the University of Jarazoza reflected on whan regeneration in historic centres in general, and proposed a series of improvements for the San Pablo district in the city in particular.

The core idea in this course was to collate a variety of approaches to the intricate processes involved in this regeneration by focusing on a specific aspect, yet without losing the overall cross-sectional perspective; in other words, we looked at a specific case from a rigorous academic standpoint, analysing complicated situations with the investigative and experimental skillset that postgraduate courses require. Our aim was to achieve results that, firstly, benefit the education of our students, and, secondly, help to transfer our knowledge of the subject to local government.

In our opinion the city should be redesigned taking residents' views into consideration. However, we also realise that in a field as complex as this one, architectural and urban visions must complement those from related sectors, such as sociology and economics. Although our differing specialisms within the School of Engineering and Architecture led us to emphasise specific curriculum-related approaches in each subject, we are convinced of the need to addres projects comprehensively to fully benefit from the synergies among the various disciplines.

The method we followed throughout the course reviewed several debates, references and experiences that form part of international architectural and urban culture. At the same time, our workshops explored several approaches to urban design, landscape, construction and management aspects. This required coordination of the teaching programmes of he following Master's subjects: integrated urban an s a cultural landscape, and urban management.

Our starting point was the socioeconomic diagnoses forming the basis of the Comprehensive Plan for the Historic Centre of Zaragoza as well as materials produced for specific sectors or occasions (such as the candidacy for the European Capital of Culture 2016); but we also used the workshops" "self-diagnoses" based on the possible intervention strategies that had been proposed: urban renewal, redevelopment, restoration, rehabilitation, revitalisation, improvements in habitability, to facilities, public spaces, traffic, etc. In short, all the aspects we can include in urban regeneration in the broad sense of the term.

We believe that the document we are presenting here meets the twofold objective we set ourselves: giving students Wractice in highly complex real cases, and at the same time adding design considerations, strategies and proposals to the urban debate to ensure it is as rigorous and all-encompassing as possible.

\section{Javier Monclús}

he University Master of Architecture and Head of the Department of Architecture at the School of Engineering

and Architecture. University of Zaragoza

\section{Perspectivas urbanísticas y propuestas para el barrio de San Pablo de Zaragoza}

Durante el semestre de otoño del curso 2013-14, en el marco del Máster Universitario en Arquitectura de la Universidad de Zaragoza se ha afrontado una reflexión general sobre la regeneración urbana en los centros históricos, aconpañada de una serie de propuestas para el barrio zaragozano de San Pablo.

La idea fuerza de este curso ha sido la de reunir aproximaciones diversas a los complejos procesos que se manifiestan en el centro histórico, focalizadas en un ámbito concreto aunque sin renunciar a una perspectiva global y transversal. Partimos de una vision academica pero centrada en un caso específico. Es decir, con una aproximación rigurosa que

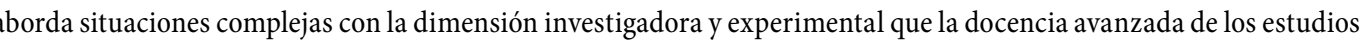
Máster demanda. La intención es la de conseguir unos resultados que, en primer lugar, redunden en beneficio de la formación de nuestros estudiantes, y en segundo, contribuyan a la transferencia de conocimiento disciplinar a la administración municipal.

Estamos convencidos de que la ciudad debe repensarse con los ciudadanos. Pero también de que en un campo tan complejo, las visiones arquitectónicas y urbanísticas deben ser complementarias a las que provienen de otros campos afines, como la sociología o la economía. A pesar de que el énfasis en cada asignatura lo hemos puesto en planteamientos disciplinares y especificos por nuestras respectivas especializaciones dentro de la Escuela de Ingeniería y Arquitectura, estamos convencidos de la necesidad de visiones globales e integradoras y del aprovechamiento de las sinergias entre las diferentes disciplinas.

Esta aproximación nos ha permitido repasar, durante el desarrollo del curso, diversos debates, referentes y experiencias que forman parte de la cultura arquitectónica y urbanística internacional. En paralelo, se han planteado diversas aproximaciones en los correspondientes talleres que han profundizado en aspectos urbanisticos, proyectuales, pai-

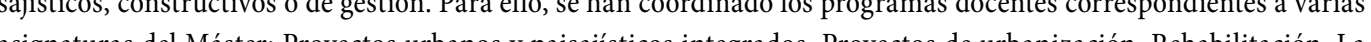
asignaturas del Máster. Proyectos urbanos y paisuific

Los diagnósticos socioeconómicos que sirven de base al Plan Integral del Centro Histórico (PICH) así como diversos materiales generados en ambitos u ocasiones especificas (como la candidatura para la capitalidad cultural de 2016) se han utilizado como punto de partida; pero también los "propios diagnósticos" efectuados en los talleres en función de las posibles estrategias de intervención que se plantearon: renovacion urbana, reforma, recuperacion, rehabilitación, revitalización, reciclaje, mejoras en la habitabilidad, en los equipamientos, en los espacios públicos, en la circulación, etc. En definitiva, todos aquellos aspectos que, bajo un concepto amplio, podemos incluir en el ámbito de la regeneración urbana.

Nos parece que el documento que aquí se presenta cumple con el doble objetivo que nos habíamos marcado: ejercitar a tuales que pueden contribuir a un debate urbano lo más riguroso y vasto posible.

\section{Javier Monclús}

Coordinador del Mäster Universitario en Arquitectura y director del Departamento de Arquitectura 


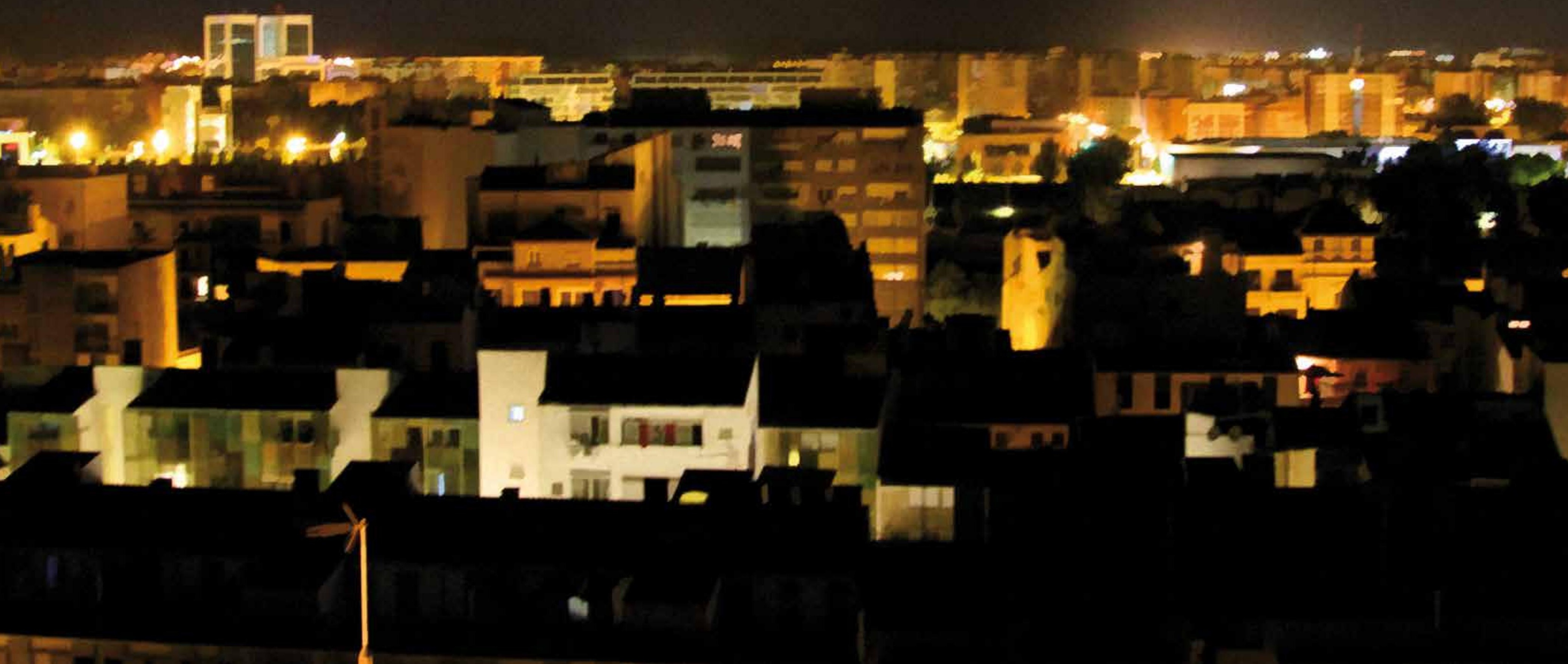




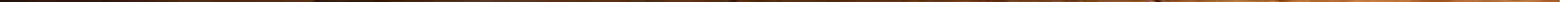

REGENERACIÓN URBANA INTEGRADA

INTEGRATED URBAN REGENERATION

Javier Monclús 


\section{Integrated Urban Regeneration: concepts and strategies}

In the "Declaration of Toledo" - one of the most important documents published by the European Commission (2012) -integrated urban regeneration is set out as "a planned process that must transcend the partial ambits and approaches that have been the norm until now, in order to address the city as a functioning whole and its parts as components of the whole urban organism, with the objective of fully developing and balancing the complexity and diversity of social, economic and urban structures, while at the same time stimulating greater environmental eco-efficiency."3

The ambiguity of the definition of this concept carries certain risks that trivialise it and use it as theoretical support for interventions that are very different to each other, and even conflicting. Although the term is too generic, it is however useful because it refers to objective and interesting strategies, tested extensively over recent years, despite the dange that it can mask some operations of a purely substitutive nature and the radical renovation of historic areas 4 . However for some time now, this concept has been had an effect on international Planning
studies and agreements that have been developed with remarkable systematisation ${ }^{5}$.

It is important to consider the broad field of references and experiences that are part of international urban cultur regarding reform, urban renewal and regeneration. In a book published more than forty years ago, Anthony Sutcliffe analysed the processes that he called the "decline and failure of central Paris". What the author pointed out was in response to the particular case of Paris, in a given period, from the mid-19th century until 1970. Sutcliffe explained with laudable clarity the change in the strategies applied to the centre of this city in recent years, especially since the Sixties of the last century. from modernisation to preservation'. "Before 1914, the survival of the historic centre of Paris was threatened primarily by city authorities, and its partial survival was due to the practical impossibility of destroying it; in fact, there was no doubt about the willingness of doing that. When Parisians finally understand tha they will have to coexist with the city centre, they will finally like it, "warts and all"... preservation gradually replaced modernisation as the urban planning goal for the centre of Paris". Sutcliffe wrote the book (1970) precisely when the decisive "Battle of Les Halles" began, resulting in the central market eventually being demolished. Anthony Sutcliffe's conclusion was premonitory: "Preservation and restoration may even seem to be the most effective, cheapest an the cause for preservation has triumphed in the centre of Paris"s

M. Hebbert, W. Sonne, "History Builds the Town: On the Uses of History in Twentieth-century City Planning", en J. Monclús, M. Guardia (eds.), Culture, Urbanisme and Planning, Ashgate, Londres, 2006, 1 4.

B. Secchi, La città dei i richie la città dei poveri, Laterza, Bari, 2013

Toledo Informal Ministerial Meeting On Urban Development Declaration Toledo 22 June 2000

4L. Moya, A. Diez, “La intervención en la ciudad construida: acepciones terminológicas", Urban NS04, 2013, pp. 113-123.

5 . Roberts, H. Sykes (eds.), Urban Regeneration. A Handbook, Sage, Londres, 2008.

The Autumn of Central Paris: the Defeat of Town Planning 1850-1970, E. Arnold, London, 1970

We recall the process by which certain sectors and neighbourhoods of the city were preserved, and in a way, "ossified" or "frozen", as was suc case of the Maralis after the "Mal raux law" of 1962), while in other neighbourhoods radical urban renewal interventions were planned res, and 18,000 inhabitants who would have to be evicted A. Sutcliffe, op cit., p. 301 .

8A. Sutcliffe, op. cit., p.323. About Les Halles and the problem of the Paris centre: Paris contemporaine. De Haussmann a nous jours une A. Autclifte, op. citt, p.323. About Les Halles and the prob
capitale a 'ére des métropoles, Parigramme, Paris, 2005.
"Entre la ciudad y las diversas disciplinas se deberían construir nuevas alianzas. Los urbanistas, pero también los economistas y los sociologos, deberian volver a discutir con los gedgrafos, los botanicos, los ingenitios."

(B. Secchil)

Regeneración urbana integrada: concepciones y estrategias

En la "Declaración de Toledo", uno de los documentos más relevantes publicados por la Comisión Europea (2012), la regeneración urbana integrada se concibe como "un proceso planificado que ha de trascender los ámbitos y enfoques parciales hasta ahora habituales para abordar la ciudad como totalidad funcional y sus partes como componentes del organismo urbano, con el objetivo de desarrollar plenamente y de equilibrar la complejidad y diversidad de las estructuras sociales, productivas y urbanas, impulsando al mismo tiempo una mayor ecoeficiencia ambiental'’.

La ambigüedad en la definición de este concepto, conlleva ciertos riesgos de banalización y utilización del mismo como soporte térico de actuaciones muy diferentes entre sí, o incluso contrapuestas. Aunque el término es excesivamente genérico, sin embargo resulta útil porque alude a objetivos y estrategias interesantes, ampliamente ensayados en los últimos años, a pesar del peligro de que pueda llegar a encubrir operaciones de pura sustitución y renovación radical de áreas
históricas4. En cualquier caso, desde hace un tiempo este concepto ha conseguido imponerse en ámbitos internacionales, dando lugar a un conjunto de estudios y tratados que se han ido desarrollando con una notable sistematización 5 .

Es importante tener en cuenta el extenso campo de referentes y experiencias que forman parte de la cultura urbanística internacional relativa a la reforma, renovación o regeneración urbana. En un libro publicado hace ya más de cuarenta años, Anthony Sutcliffe analizaba los procesos por los cuales se produce lo que él denominaba el "ocaso y fracaso del centro de París" ( $\mathrm{o} \mathrm{el} \mathrm{"fracaso} \mathrm{del} \mathrm{urbanismo",} \mathrm{en} \mathrm{la} \mathrm{versión} \mathrm{original} \mathrm{inglesa).} \mathrm{Lo} \mathrm{que} \mathrm{el} \mathrm{autor} \mathrm{apuntaba} \mathrm{res-}$ pondía, lógicamente, a la especificidad del caso de Pariśs, en un periodo determinado, el que va de mediados del siglo XIX hasta 1970 . Sutclife explicaba con una claridad encontible cl cambio en las estrategias aplicadas en el centro de esta ciudad en los últimos años, especialmente desde la década de los sesenta del siglo pasado: de la modernización a la preservación6. "Antes de 1914, la supervivencia del centro histórico de París estaba amenazada principalmente por las autoridades de la ciudad; y su supervivencia parcial fue consecuencia de la práctica imposibilidad de destruirlo, más bien no se planteaba ninguna duda sobre la deseabilidad de hacerlo así. Y finalmente, conforme los parisienses comprenden que tendrán que convivir con el centro, al final llega a gustarles: "con verrugas y todo"... la preservación gradualmente sustituyó a la modernización como objeto de planificación del centro de Paris"s". Cuando Sutcliffe acaba de escribir el libro (1970) es, precisamente, cuando comienza la decisiva "batalla de Les Halles", con la consecuencia de que el mercado central sería finalmente demolido. La conclusión de Anthony Sutcliffe resulta premonitoria: "La pre-

"A planner with a one sided sense of history is almost as dangerous as one with none at all", M. Hebbert, W. Sonne, "History Builds the Town: On the Uses of History in Twentieth-century City Planning", en J. Monclús, M. Guardia (eds) Culture, Urbanisme and Planning,

ricchi e la città dei poveri, Laterza, Bari, 2013.

3 Declaración de Toledo (2012) http:///ec.europa.eul/regional_policy/archive/newssroom/pdf/201006_toledo_declaration_es.pd

4L. Mova, A. Díez, "La intervención en la ciudad construida: acepciones terminológicas", Urban NS04, 2013, pp. 113-123.

5 P. Roberts, H. Sykes (eds.), Urban Regeneratition. A Handbook, Sage, Londres, 2008.

6A. Sutclifie, Ocaso y fracasso del centro de París, G. Gili, Barcelona, 1973, p. 319 vv. . The Autumn of Central Paris: the Defeat of Town Plan(5)

"conserecordar el proceso por el cual determinados sectores y barrios de la ciudad fueron preservados y, en cierto modo, "osificados" o "congelados", como fue el caso del Marais (con la "ley Malraux" de 1962), mientras en otros se planificaban operaciones radicales de reno-
vación urbana, el caso de Les Halles, con el concurso de 1970 para un àrea que incluáa el Mercado y su entorno, más de 15 Ha, con 18.000 habitantes que deberian ser desalojados: A. Sutclifie, op. cit., p.301. 


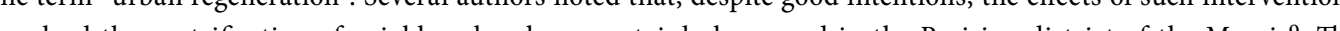
inolved che virtue of Sutchles systematic study of central Paris was that instead of presenting an inlexible explanation of such processes, he rased questions about the effectiveness of conservation and renewa strategies: "Is the survival of the "

What does what happens in Paris have to do with the processes that historic centres of European cities of a differen developed back then, from the fifties to the seventies, compare with the ones that determine trends now in a historic centre such as Zaragoza's? Since Paris has been a viable model for almost every European city for a long time ${ }^{11}$, it would not be an exaggeration to himk hat it has had a more or less direct influence. Perhaps a number of more convincing parallels may be found with other European cities, which while sharing the desire to modernise their historic centres, see preservationist views come to the fore. Myriad episodes, both successes and faiures, record the advantages an disadvantages of both the urban renewalist and the preservationist views. The matters treated by Anthony Sutcliffe therefore are applicable, in one way or another, to almost every European city.

Only with this dual international and retrospective perspective will the drift of urban centres be understood and a more complex and thorough diagnosis be established that can be useful to address the problems, challenges and opportunities that are now presented by our cities. The 2013-14 Master's Degree in Architecture has focused on the topic of comprehensive urban regeneration embracing this dual approach. Rather than starting from "s the topic of comprehensive urban regeneration embracing this dual approach. Rather than starting from
"simple formulas for compact cities" it seemed necessary to rethink some of the arguments that are at the heart of "simple formulas for compact cities" it seemed necessary to rethink some of the arguments that are at the heart of and other cities. With this core idea, our theoretical and methodological philosophy is structured around a series of axes and key strategies:

Debate for and against urban change. Modernising visions of "inner city reform" as a response to processes of urban degradation and obsolescence versus conservation and "freezing" strategies for Historic Centres Town planners and urban historians have argued for and against urban reform, gving rise to two opposing vision or strategies between supporters of "modernising" and transforming city centres, and those who wish to try an
"preserve" them "preserve" them no matter what. This is a "classic" debate encompassing a wide series of experience with mixed results,
This experience ranges from "internal reform" to urban renewal. Historical experience provides ample material for in in expth analysis and rethinking the characteristics of these processes and planning strategies. From the mid-19th in-depth analysis and rethinking the characteristics of these processes and planning strategies. From the mid-19th century and well into the 20th century, most European cities experienced interventions that illustrate this oppositional
struggle "for and against urban change,"12 The case of the reform of Barcelona's city centre, with the first proposals put forward by Cerdá as part of his 1859 Plan de Ensanche [Extension Planlis sufficiently illustrative. An example of put forward by Cerda as part of his 1859 Plan de Ensanche [Extension Planlis sufficiently illustrative. An example of
the inertia of this "long and intermittent" operation was the Via Layetana, included in Cerdá's blueprint but actually the inertia of this "long and intermittent" operation was the Via Layetana, included in Cerda's blueprint but actually
begun in 1908 and ended a century after its conception in $1958^{13}$. It should be pointed out that other operations of city centre reform carried out in various Spanish cities and executed in parallel to the Planes de Ensanche, went on into the mid-20th century almost until the approval of the $1956 \mathrm{Zoning} L a w$ (Ley del Suelo). The creation of some of the wide

9 R. Kain, “Conservation Planning in France: policy and practice in the Marais, Paris", in R. Kain (ed.), Planning for conservation, Manshell, Londres, 1981.

10 A. Sutclifie, op. cit., p. 11

11 S. Ward, "Cities as Planning Model"," Planning Perspectives, 28, 2, 2013, http://dx.doi.org/10.1080/20265433.2013.774572

$12 \mathrm{M}$. Wagenaar, "Centros monumentales, alrededores pintorescos:contrastes entre paisajes urbanos y diferentes usos del sulo en seis

capitales europeas, 1850-1914", Historia Urbana, 4, 1997.

13 E. Nasarre, A. Ortiz, L L reforma interior de Barcelona, segles XIX XXX, Barcelona, 28 i 29 de setembre de 2001

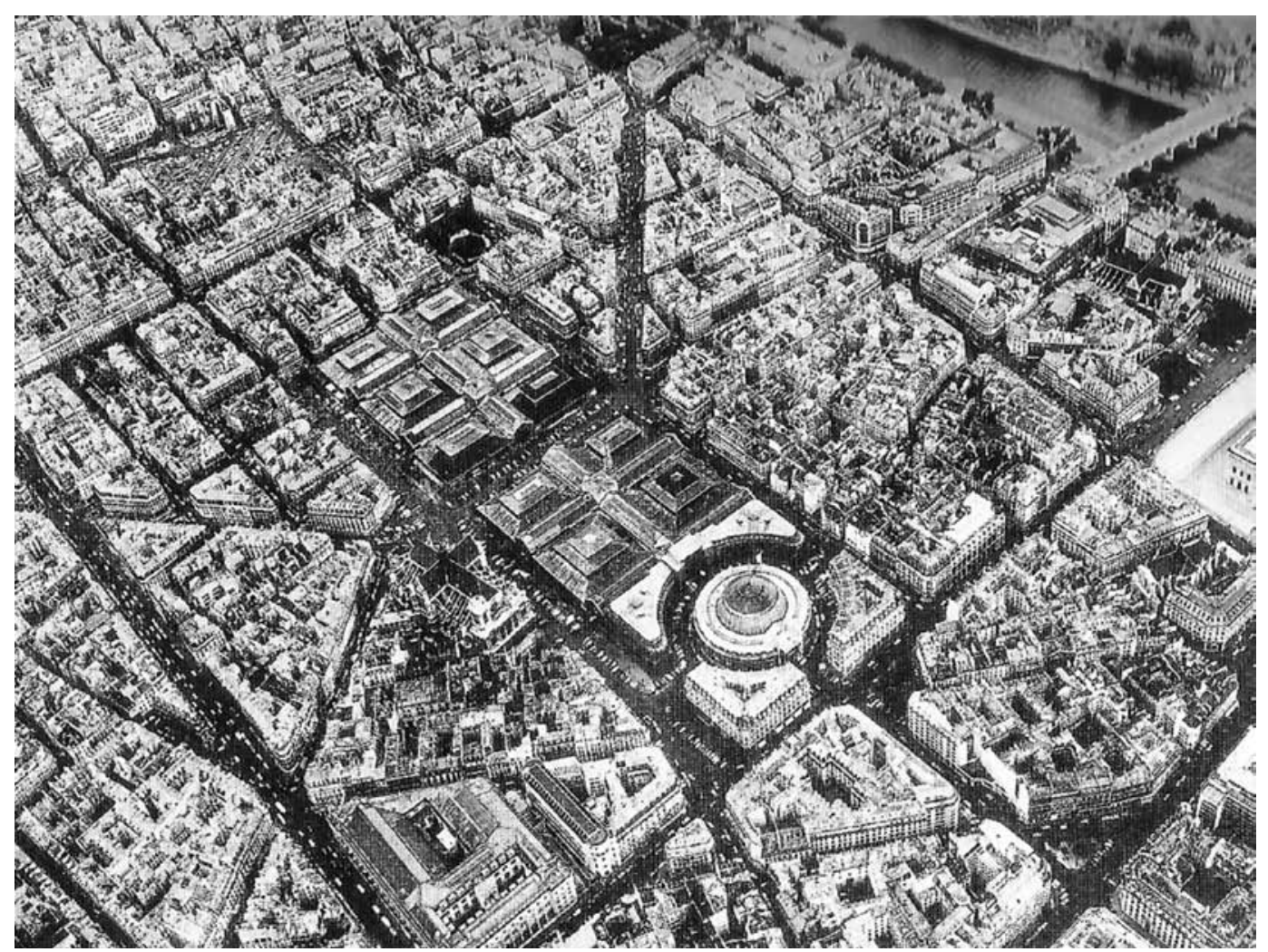

servacion y restauración bien pudieran aparecer incluso como la forma más efectiva, barata y rápida de reconstrucción del centro de la ciudad. Por

El debate se prolonga en los años siguientes y resume las cuestiones que se plantean en torno a las distintas acepciones del término "regeneración urbana". Diversos autores constatan que, a pesar de las buenas intenciones, los efectos de del termino "regeneración urbana". Diversos autores constatan que, a pesar de las buenas intenciones, los efectos de
ese tipo de intervenciones conllevan la gentrificación o aburguesamiento de los barrios, tal como, sin duda, sucede en el barrio parisino del Marais9. La sistemática exploración del centro de París desarrollada por Sutcliffe tiene la virtud de que, en lugar de presentar una explicación cerrada de este tipo de procesos, plantea interrogantes sobre la efectivi-

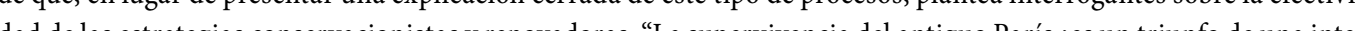
ligentecos socioeconómica cultural $y$ discilinar si se pretende responder a la complejded de que "cambio "y "continuidad" son palabras clave.

Qué tiene que ver lo que ocurre en París con los procesos a los que están sometidos los centros históricos de otras ciudades europeas de distinta naturaleza, como por ejemplo, el centro histórico de Zaragoza? ¿Cómo pueden compararse los procesos de transformación urbana o las estrategias que se desarrollaron entonces -desde los años cincuenta a los

8. Sutclifie, op. cit., p.323. About Les Halles and the prot capitale a l'ère des métropoles, Parigramme, París, 2005. 9R. Kain, "Cons
Londres, 1981 . 10 A. Sutcliffe, op. cit., p. 11. 


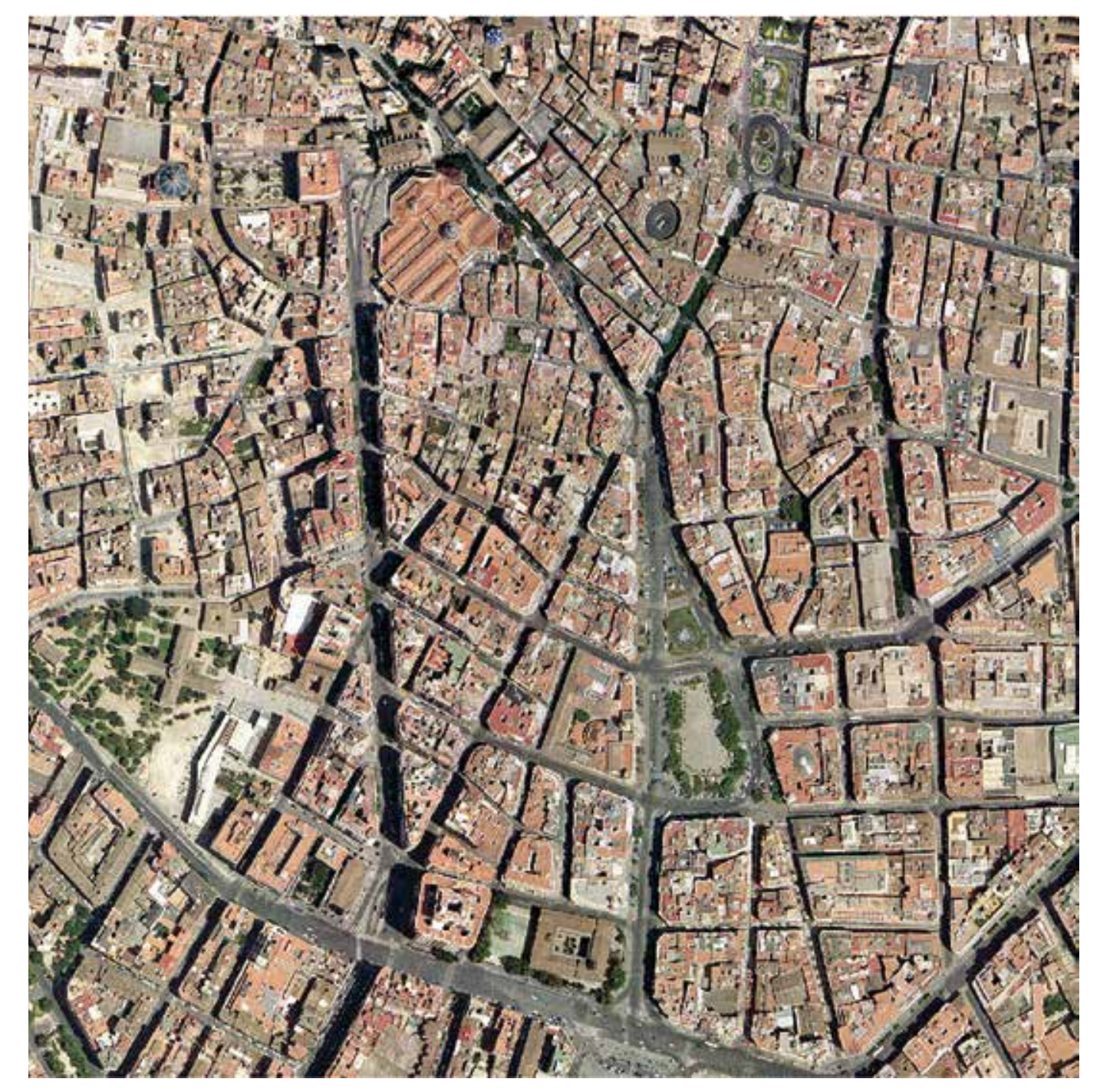

avenues

Urban renewal and modern urban planning. Visions of modern urban planning and critical views. Jane Jacobs versus Robert Moses

Once again we find valuable material in history for reconsidering recent problems. This is the case of the so-called Once again we find valuable material in history for reconsidering recent problems. This is the case of the so-called
"Urban renewal" that many American cities underwent, followed by European ones during the Sixties of the last "Urban renewal" that many American cities underwent, followed by European ones during the Sixties of the last
century. Despite obvious differences, the reconstruction of European cities from the Fifties onwards was done keeping century. Despite obvious differences, the reconstruction of European cities from the Fiffties onwards was done keeping
the complexity of historic city centres, while American cities underwent tertiarisation and a demographic shift which the complexity of historic city centres, while Ameris
led to the decentralisation of all kinds activities.

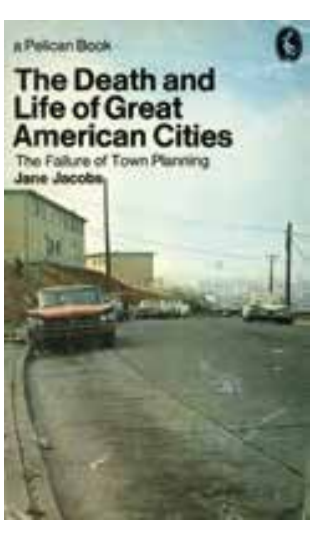

setenta- con los que ahora determinan las tendencias de un casco histórico como el de Zaragoza? Dado que París ha sido, durante un largo periodo, un auténtico modelo para casi cualquier ciudad europea ${ }^{11}$, no sería exagerado pensar que hubiera podido tener una influencia más o menos directa. Pero quizás resulten más convincentes los paralelismos que se pueden establecer con diferentes ciudades europeas que, a la vez que comparten el deseo de modernización de tros históricos, ven avanzar visiones más preservacionistas. Multitud de episodios, exitosos o fallidos, registran los costes y beneficios de ambas posturas, la renovadora y la preservacionista. Las cuestiones que se planterbAnthony Sutcliffe, como vemos, son aplicables, de un modo u otro, a casi todas las ciudades europeas.

Sólo con esta doble perspectiva, internacional y retrospectiva, seremos capaces de entender la deriva de los centros

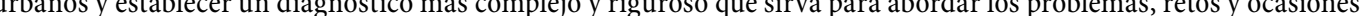

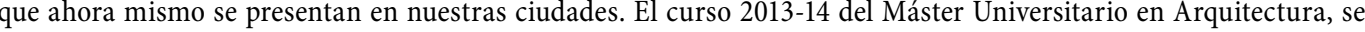
ha centrado en el tema de la regeneración urbana integral, con esa doble aproximación. Más que partir de "recetas simples para la ciudad compacta, parecia necesario repensar algunos de los argumentos que están en la base de las intervenciones que se han levado a cabo en distintos contextos y situaciones urbanas, en el pasado y en el presente, en Un bests seller del urbanismo: Jane
Jacobs, The Death and lifeoff freat Jacobss, the Death and
American Cities (1961). Zaragoza y en otras ciudades. Con esta idea fuerza, nuestra reflexión teórica y metodológica se articula en torno a una serie de ejes y estrategias esenciales:

Debate a favor y en contra del cambio urbano. Visiones modernizadoras de la "reforma interior" como respuesta a los procesos de degradación y obsolescencia urbana, frente a las estrategias conservacionistas y de "congelación" de los centros históricos

Urbanistas e historiadores urbanos han argumentado a favor o en contra de la reforma urbana, dando lugar a dos visiones o estrategias que oponen a los partidarios de "modernizar" y transformar el centro a los que tratan de "preservarlo" a toda costa. Se trata de un debate "clasico" sobre el que se dispone de un abanico extenso de experiencias con resultados desiguales. Esas experiencias van desde la llamada "reforma interior a la renovación urbana. Las las caracteristicas de esos procesos y estrategias uristicas. Desde medindos del siglo XIX y hasta bien entrado el XX casi todas las ciudades europeas exper contra del cambio urbano"l. El caso de la Reforma interior de Barcelona, con las primeras propuestas proyectadas por Cerdá como parte de su Plan de Ensanche de 1859, es suficientemente ilustrativo. En ese sentido, se ha destacado la inercia de una operación "intermitente y larga", como la Vía Layetana, que se incluía en el proyecto de Cerdá pero que comienza efectivamente en 1908 y finaliza un siglo más tarde de su concepción, en $1958^{13}$. Hay que señalar que en otras operaciones de reforma interior llevadas a cabo en distintas ciudades espanolas y ejecutadas en paralelo a los ensanches, se prolongan hasta mediados del siglo XX, prácticamente hasta la aprobación de la Ley del Suelo de 1956. Algunas de las Grandes Vías que protagonizan el urbanismo de la primera mitad del siglo XX son una buena muestra de esas visiones modernizadoras ${ }^{14}$

Renovación urbana y urbanismo moderno. Visiones del urbanismo moderno y críticas a la totalidad. Robert Moses versus Jane Jacobs

De nuevo encontramos en la historia un valioso material para reconsiderar problemas recientes. Es el caso del llamado 作 ricanas primero y, con ciertas variantes, más tarde también las europeas. Salvando las distancias, la reconstrucción de las ciudades europeas a partir de los años cincuenta se realizó manteniendo la complejidad de los centros históricos,

11 s. Ward, "Cities as Planning Models," Planning Perspectives, 28, 2, 2013, http://dx.doi.o.rg/10.1080/02665433.2013.774572 12 M. Wagenaar, "Centros monumentales, alrededores pintorescos:contrastes entre paissjes urbanos y diferentes usos del sulo en seis
capitales europeas, 1850-1914", Historia Urbana, 4,1997 .

13 E. Nasarre, A. Ortiz, La reforma interior de Barcelona, segles XIX $i X X$, Barcelona, 28 i 29 de setembre de 2001.

14 F. Taberner, "La Gran Via del Deste de Valencia. Tres etapas para un proyecto", en R. Sanchez Lampreave, J. Monclús, I. Bergera., La Gran Vía de Zaragoza y otras grandes vias, Lampreave, Madrid-Zaragoza, 2011 . 


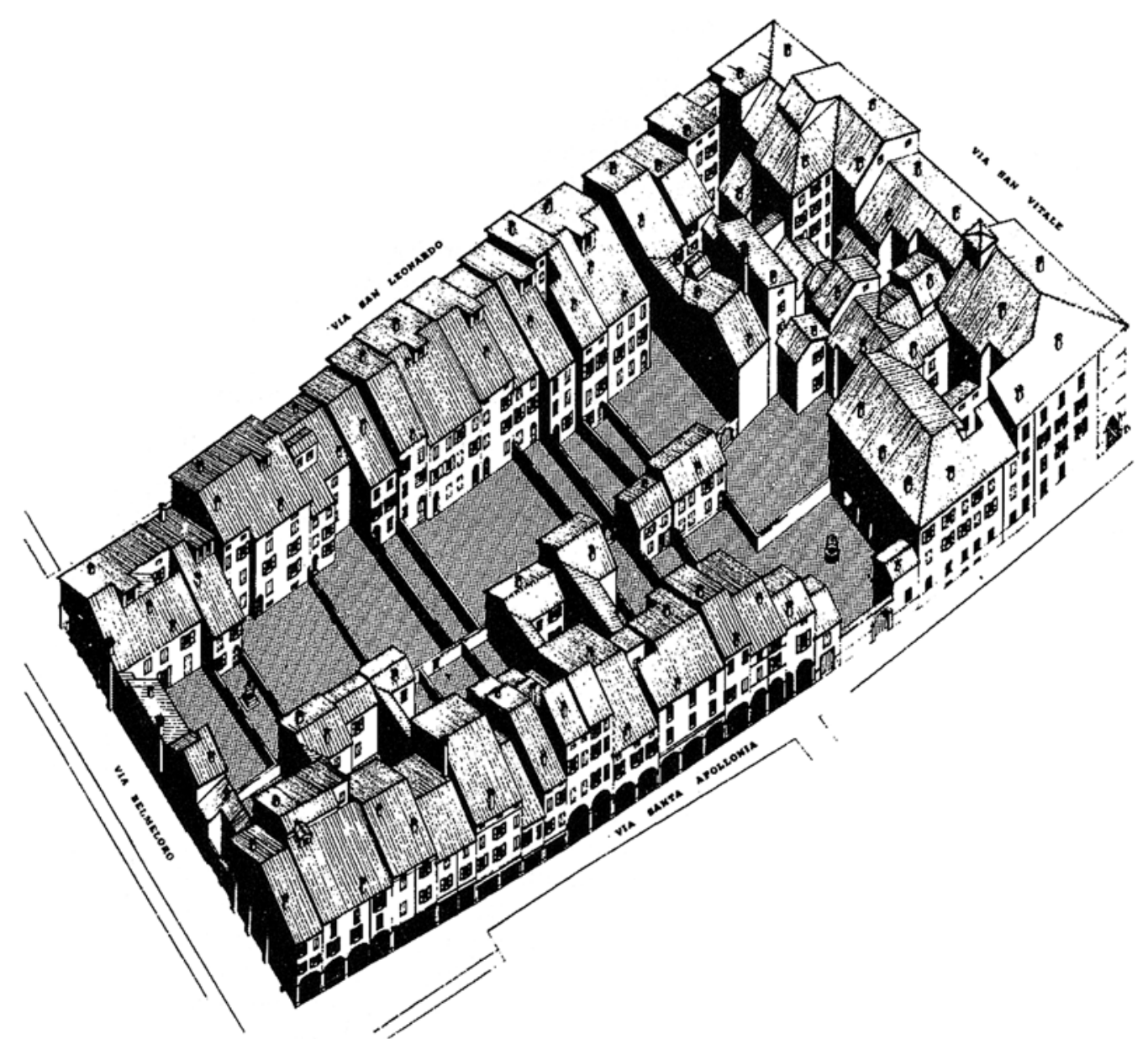

The debate between Robert Moses - the arrogant "czar" of New York's Urban Planning department - and Jane Jacobs - an activist who was opposed to urban renewal - author of one of the few best sellers on 20 th century urban planning literature 15 is not only relevant now but must be kept in mind when the foundations of urban moderniationing

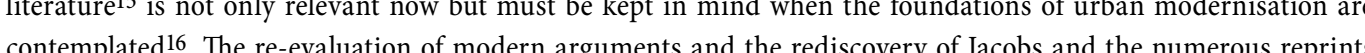
of her book show the relevance of this debate. Thus, a recurring theme of the book - now deeply entrenched in contemper s. contenpor ses chaldings diverity in the of types of activity concenty bed in specife areas, tct? Marshall Berman - one of the most brilliant modern writers on this debate - has an interesting take on it. Along Dronx New York, suffering the radical urban renewal interventions of those years, offers an extraordinary perspective for

15. Jacobs, The Death and Life of Great American Cities, Vintage Books, New York, 1961.

16 D. Schubert (ed.), Contemporary Perspectives on Jane Jacobs: Reassessing the Impacts of an Urban Visionary, Ashgate, 2014.

17 Jacobs introduced some new concepts: Slumming y Unslmumming, see: R. Moreno, A. Sanchez, "Jane Jacobs en la Red" (2006),
http://habitat.aq.upm.essboletin/n34/nred.html mientras las norteamericanas vivieron un proceso de terciarización y vaciamiento demográfico que condujo a la descentralización de todo tipo de actividades.

El debate entre Robert Moses (el prepotente "zar" de los servicios de urbanismo de Nueva York) y Jane Jacobs (la activista que se opone al urban renewal y autora de uno de los escasos best sellers del urbanismo del siglo XX15 no sólo resulta ahora relevante sino que, como muestran las numerosas reediciones de los textos y la recuperación de esta última figura, debe tenerse en cuenta cuando se plantean las bases mismas de la modernizacion urbanna ${ }^{16}$. La reconsideración de los argumentos modernos y las numerosas reediciones del libro de jane Jacobs muestran la actualidad de ese debate. Asi, un tema recurrente del libro -ahora un lugar común de la teoría urbanística contemporánea- es la ráneos: diversidad social y económica entre habitantes; diversidad en formas y tamaños de los edificios; diversidad de tipos de actividad concentrados en áreas acotadas, etc. ${ }^{17}$

Es interesante conocer la posición de Marshall Berman, uno de los autores más lúcidos de la modernidad en este debate. Junto a las vicines globales de la modernizción de los añs sesenta la experiencia personal de Berren como habitante de un bario panoram etraction ma paradignátice en la ciudad de Nueva York pero, con varintes, tombén en otras muchas ciuddes not esmericanas 18. De nuevo, frente a posiciones que ignoran o califican de "populistas" la filosofía de Jane Jacobs sobre los procesos de degra(a) de aplicar las "recetas Jacobs" en un contexto differente, estarían los que se esfuerzan por actualizar esas concepciones.

De la restauración morfológica a la rehabilitación residencial. El centro histórico como lugar representativo y como espacio social con prioridad para los residentes

Otra línea de reflexión, una de las más intensas que se plantean en la cultura arquitectónica y urbanística desde los años sesenta, se corresponde con la renovada atención a lugar y a la "ciudad como arquitectura, con posiciones más sensibles a los valores de la ciudad historica. Por un lado, cabe destacar las ideas que, en paralelo, se desarrollan durante los años sesenta sobre la ciudad como actusulacion historica y creación cultural, desde Ungers en Alemania a Hertzberber en Holanda y, sobre todo, Aldo Rossi y la Escuela de Venecia en Italia' ${ }^{1}$, con las renovadas concepciones

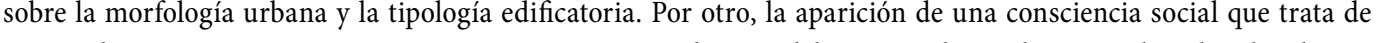

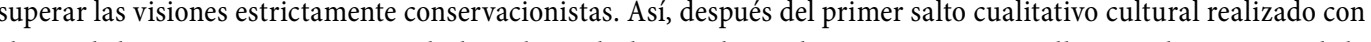
el paso de la concepción monumental a la ambiental, el segundo y todavía más importante llegó con la extensión de la visión morfológica al horizonte más amplio de la visón social y funcional20.

Todas esas reflexiones confluyeron en la experiencia de Bolonia, cuyo Plan regulador del Centro Histórico (1971) se convirtió en un hito y en una referencia indiscutida para la denominada rehabilitación urbana integral. El Plan se planteaba como objetivo el mantenimiento de los componentes estructurales del tejido urbano pero también la rehabilitación de viviendas con objeto de mantener el uso residencial del centro, invirtiendo el éxodo poblacional. Posteriormente se fueron elaborando otros planes con objetivos realmente ambiciosos para ese momento, al plantear

15J. Jacobs, The Death and Life of Great American Sities, Vintage Books, New York, 1961 (v. esp. Muerte y vida de las grandes cindades, Madrid, Ediciones Peninsula, 1961; 1967; 1973.

16D. Schubert (ed.), Contemporary Perspectives on Jane Jacobs: Reassessing the Impacts of an Urban Visionary, Ashgate, 2014

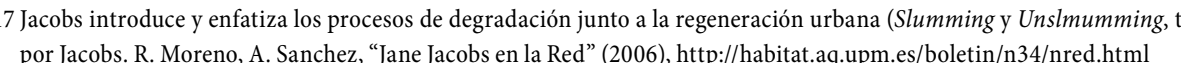
18 M. Berman, Todo lo sólido se desvanecce en el aire. La experiencia de la modernidad, (1982), Siglo XXI, Madrid, 1991. 19 M. Fortis, Place and Such Things A l la recherche du lieu perdu, en este mismo volumen, (v. italiana e inglesa en Zarch n.l, 2013). 20 P. Cervellati. R. Scannavini, Bolonia. Politicica y metodologia de la restauración de centros historíicos, G.Gili, Barcelona, 1973; G. Campos Venuti, F. Oliva (coords.), Cincuenta años de Urbanisitica en Italia, 1922-1992, Universidad Carlos III de Madrid- B.O.E., Madrid, 1994. 
$\begin{array}{ll}\text { Regeneración urbana integrada } & \text { Again, in opposition to views that disregard or describe Jane Jacobs's philosophy on the processes of degradation and } \\ \text { lntegrated rbhan Regeneration } & \text { loss of vitality of the old historic city centres as "populist" or, on the contrary, those who take a historicist position and }\end{array}$ try to apply "Jacobs's formulas" to a different context, there are others who strive to update these conceptions.

From morphological restoration to residential rehabilitation. The historic city centre as a representative place and social space with priority for residents

Another line of thought, one of the most intense that arose in the architectural and urban culture in the Sixties, corresponded to the renewed attention given to place and to the "city as architecture", with more sensitive attitudes to the values of historical city centres. On the one hand, a number of parallel ideas developed during the Sixties envisioning cities as a historical accumulation and cultural creation should be pointed out; examples such as Ungers in Germany and Hertzberber in Holland, and in particular Aldo Rossi and the School of Venice in Italy ${ }^{19}$, with their renewed concepts of urban morphology and building typology. And on the other hand, the emergence of a social consciousness that tried to overcome strictly conservationist visions. Thus, after the first qualitative cultural leap from monumental concepts to an environmental discourse, the latter - and most important one - came with the extension of morphological vision to social and functional horizons ${ }^{20}$.

All these thoughts came together in the experience of Bologna, whose Historic City Centre Plan (1971) was a milestone and became an undisputed benchmark for so-called integrated urban rehabilitation. The Plan aimed to maintain the structural components of the urban fabric but also rehabilitate housing in order to maintain the city centre residential and reversing population migration. Later, other plans were developed with very ambitious goals for the time; addressing the conservation of land use, regarding both the resident population as well as building typology. The historic city centre thus went from being understood as representative to becoming a social space with priority for residents.

The Bologna Plan was hugely influential on strategies developed in other old historic cities and this was also the case in Spain, where cities including Barcelona and Vitoria addressed the issue from the late Seventies onwards 21 . In the Eighties, other forms of integrated intervention in historic city centres, such as that of Santiago de Compostela, become landmark feats for Spanish and international urban culture ${ }^{22}$

Degradation, urban regeneration and gentrification: exemplary actions and changes for people living in urban city centres

Some key issues on urban regeneration, housing rehabilitation and so-called gentrification are raised here. This refers to the trend of replacing the less affluent resident population with other social groups with more purchasing power, leading to the gentrification of certain sectors in old historic city centres.

As previously mentioned, the debate is not new. Basically, the dichotomy between preservation and urban modernisation only changes in its specific manifestations. Referring to London, Peter Bishop firmly believes in

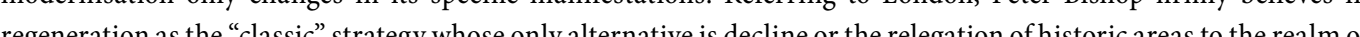

18 M. Berman, Al that is solid melts into the air. The experience of modernity, (1982).

19 M. Fortis, Place and Such Things À la recherche du lieu perdu, Zarch 1, 2013.

20 P. Cervellati. R. Scannavini, Bolonia. Politica y metodologia de la restauración de centros historicics, G.Gili, Barcelona, 1973; G. Campos Wenut, F. Iliva (coords.), Cincuenta años de Urbanistica en Italia, 1942-1992, Universidad Carlos III de Madrid- B..O.E., Madrid, 1994. 21 G. Campos Venuti, Quince años de experiencias urbanissticas en Bolonia, Dossier urbano. Conferencias de Nuno Portas, Campos Venuti Luis López, Seminario de Urbanismo, Cátedra de Urbanismo, ETSAB, 1974

22 J.L. Dalda, "Planes y politicas urbanas. La experiencia Uantstia de Santiago de Compostela desde 1988", Urban 12, pp. 102-12.5.

23 Peter Bishop (2012), “Approaches to regeneration", A.D., 01.2012; M. Frasser, “The Global architectural influences on London, A.D., 01.2012

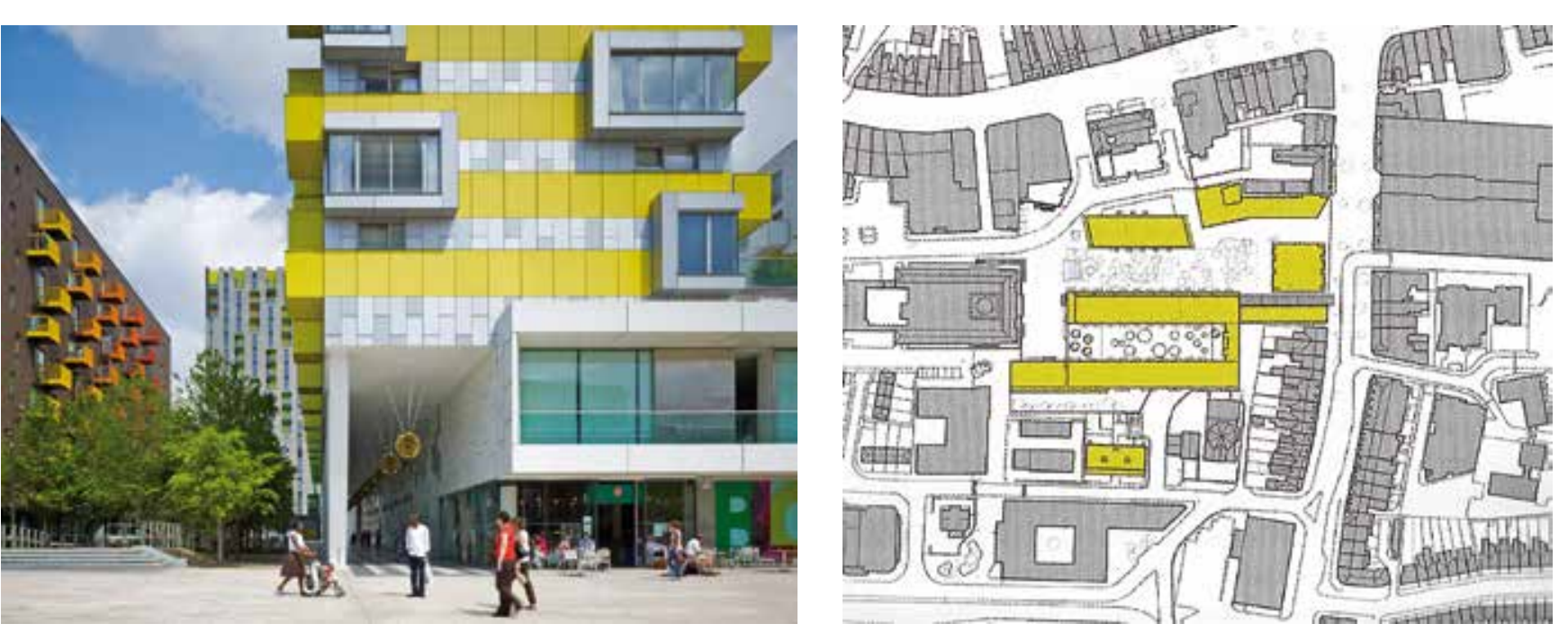

Londres, renovación urbana:
Barking Central, East London) London, urban renewal: Barking Central, East Londo (M. Fraser, A.D. la conservación de usos, de la población residente y de la tipología edificatoria. El centro histórico pasó entonces de entenderse como lugar representativo a un espacio social con prioridad para los residentes.

La influencia del Plan de Bolonia fue indudable en las estrategias desarrolladas en otros centros históricos. También en España, desde Barcelona hasta Vitoria y a otras muchas ciudades que abordaron el tema desde finales de la década de los años setenta ${ }^{21}$. A partir de los años ochenta, otras formas de intervención integrada en centros históricos, como las de Santiago de Compostela, se han convertido en referentes obligados para la cultura urbanística española e internacional ${ }^{2}$.

Degradación, regeneración urbana y gentrificación: actuaciones ejemplares y cambios en la población residente en los centros urbanos

Aquí se plantean algunas de las cuestiones clave en torno a la regeneración urbana, la rehabilitación residencial y los denominados procesos de gentrificación. Es decir, las tendencias a la sustitución de la población residente de escasos recursos por otros grupos sociales de mayor poder adquisitivo, con el consiguiente aburguesamiento o "litización" de determinados sectores en los centros históricos.

Como se ha indicado, el debate no es nuevo. En el fondo, la dicotomía entre preservación y modernización urbana solo cambia en sus manifestaciones concretas. Con referencia a Londres, Peter Bishop apuesta claramente por la regene-
ración como estrategia "clásca" que sólo tiene como alternativa el declive o la relegación de áreas históricas al ámbito ración como estrategia "clásica" que sólo tiene como alternativa el declive o la relegación de áreas históricas al ámbito
de la "industria del patrimonio" (heritage industryy23. El caso de Barcelona reviste especial interés, concretamente el barrio del Raval, pues los procesos urbanos que ahí se producen pueden considerarse un buen laboratorio de lo que puede suceder en otros barrios de los centros históricos, como el de San Pablo de Zaragozaz ${ }^{24}$

21 G. Campos Venuti, Quince eños de experiencias urbanisticas en Bolonia, Dossier urbano. Conferencias de Nuno Portas, Campos Venuti, Luis López, Seminario de Urbanismo, Cátedra de Urbanismo, ETSAB, 1974.

22 J.L. Dalda, "Planes y politicas urbanas. La experiencia urbanistica de Santiago de Compostela desde 1988", Urban 12, pp. 102-125. 23 Peter Bishop (2012) "Approaches to regeneration", A.D., 01.2012; M. Frasser, "The Global architectural influences on London", A.D., 01.2012

24 Una de las actuaciones más discutidas, la remodelación del área central del barrio con importantes demoliciones que permitieron la configuración de la nueva plaza del Raval, responde a una estrategia enunciada de forma contundente por Oriol Bohigas en 1985. "Way muchos porque el aprovechamiento aunque sea parcial es econónicamente insostenible o porque la degradación del ámbito urbano y unifinonivel porque e laprovechamiento aunque sea parcial es económicamente insostenible o porque la degradacion del ámbito urbano y su infimo nivel
de habitabilidad es incorregible sin un cambio radical Hay que tener la valentía de destruir escogiendo bien los objetivos" 0 . Bohigas Reconstrucción de Barcelona, 1985. M. Fiori (ed.), Revivirel centro historico. Barcelona, La Habana, Ciudad de México y Quito, UOC, Barcelona, 2013. 

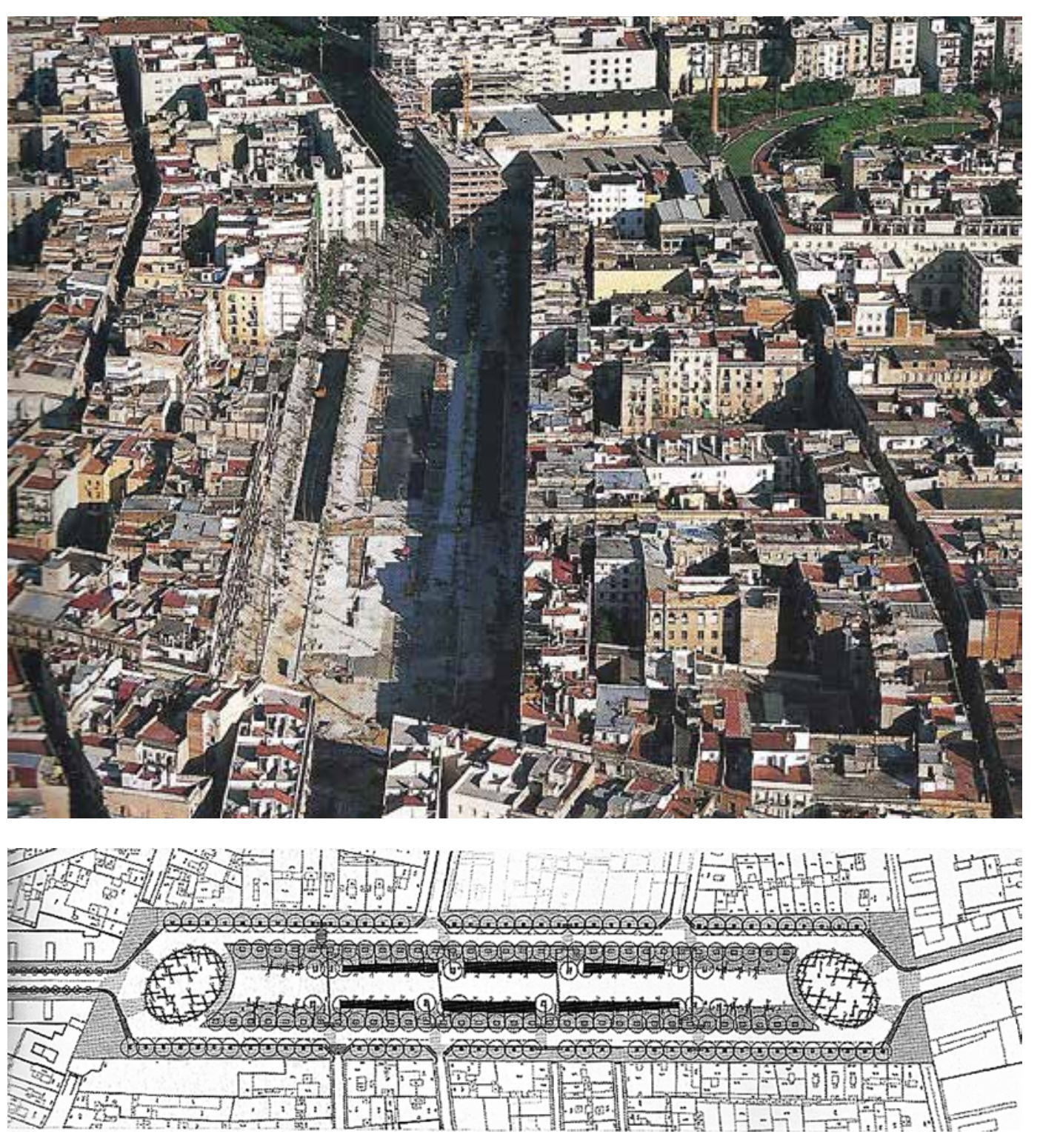

processes that took place there can be considered a good testing ground for what can happen in other neighbourhoods of old historic city centres such as that of San Pablo de Zaragoza ${ }^{24}$

Although the debate still continues, critical analysis is in agreement that there has not been a significant return to the Although the debate still continues, critical analysis is in agreement that there has not been a significant return to the
city centre by the upper classes that once abandoned it, nor a general migration of the residents of the centre. In Ciutat

24 One of the most controversial actions, the renewewal of the central area of the neighbourhood following significant demolition to allow the crea-
tion of the new Plaza del Raval corresponds to strategy enphatically explaned Oriol Bohigas in 1995 " "There are many tion of the new Plaza de Raval, corresponds to a strategy emphatcally explaned Orio Bohigas in 1985 . "here are many areas of Barcelon

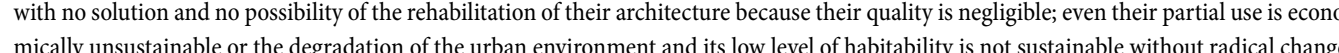

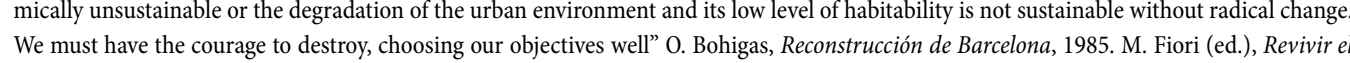
centro historico. Barcelona, La Habana, Ciudad de México y Quito, UOC, Barcelona, 2013.
Aunque el debate continúa, análisis críticos coinciden en señalar que no se ha producido un retorno al centro a gran escala por parte de las clases más pudientes que antaño lo habín abandonado, ni tampoco se da una expulsión generalizada de los residentes de dicho centro. En Ciutat Vella, la segregación es vigente los núcleos de pobreza y los de riqueza no conviven. Las áreas elitizadas están muy localizadas, en zonas estratégicas; se trata de un proceso de "microgentrificación" 25.

Se puede advertir, por tanto, que esos procesos de gentrificación constituyen una tendencia que no tiene por qué darse necesariamente en cualquier situación urbana. No ha sido éste, por ejemplo, el caso del barrio de San Pablo en el centro histórico de Zaragoza, al menos hasta ahora. A este respecto, Horacio Capel matiza en referencia a las ciudades españolas que, en general, los procesos de gentrificación han sido bastante limitados²6.

La recualificación del espacio público y del paisaje urbano como argumento esencial de regeneración urbana. Recuperación de las calles y las plazas, peatonalización del centro

En este ámbito de reflexión no sólo cultural, sino también técnica y funcional, se cuenta con experiencias notables y con un corpus disciplinar amplio. En los últimos años, el esfuerzo por llevar a cabo un tratamiento unificado de edificios, infraestructuras y espacios públicos ha contribuido a mejorar las condiciones urbanísticas de ciertas áreas urbanas, en particular las de determinados centros históricos. Ciudades como Barcelona27, Lyon o Copenhague han liderado un auténtico movimiento de recuperación de espacios públicos mediante intervenciones de recualificación urbana y paisajistica28. Copenhague, por ejemplo, fue pionera en Europa en la aplicación de estrategias de peatonalización de su centro y continua ahora con estrategias de recualificación urbana. La continuidad y la innovación en el tratamiento integrado de sus espacios publicos han sido ampliamente reconocidas. El trabajo de Jan Gehl y su equipo ha dado lugar a una profunda teorizacion y puesto de manifiesto las oportunidades que subyacen en ese campo ${ }^{29}$. En cierto modo, se puede decir que esas estrategias de "humanización del espacio urbano" se inscriben en los principios de Jane Jacobs y los prolongan, sobre todo en sus propuestas de permeabilización, transparencia, conexión entre calle y edificios, activación de las plantas bajas, etc.

Esa es también una de las apuestas principales del Proyecto Madrid Centro, una propuesta que parte de la transformación y reciclaje de la ciudad existente, con el espacio público como "sistema organizativo, referencia identitaria y elemento mediador entrel a ciudad y sus habitantes 30 . A peser de las difcultades de gestín es interes te nencionar

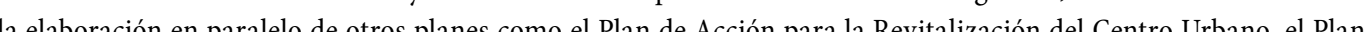
Madrid Río o el Proyecto Recoletos Prado, etc. 3

25 M.A. Sargatal (2009). El barrio del Raval de Barcelona (1999-2008). Transformaciones urbanas y nuevos enfoques metodologicicos para el estudio del centro historicico (The district of el Raval in Barcelona (1999-2008). Urban transformations and new methodological approaches to the study of the historic centrele. Bim
http://www.ub.es/geocrit/b3w-824.htm

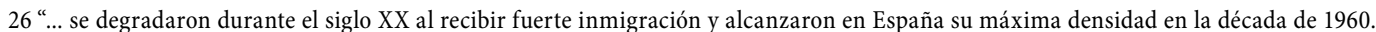

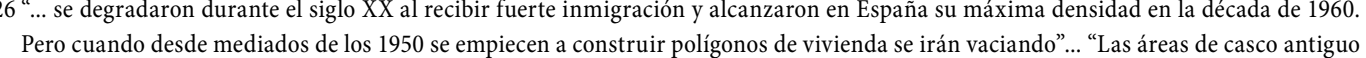
han podido acentuar su proceso de envejecimiento del caserio paralelelamente a la huida de los grupos burguesese y su conversión en barrios populares, o dar lugar a procesos de renovación reciente (con intervenciones municipales de renovación, gentrificación, etc.). Pero, en

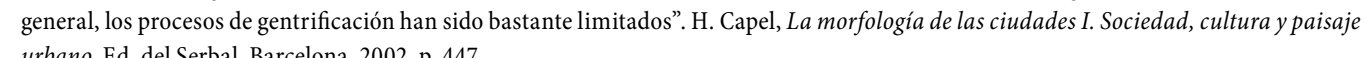

27 Proyecto BCN, Actar, Barcelona, 2007.

28 Es interesante referirse a algunas experiencias europeas innovadoras. I. Velazquez, C. Verdaguer, Regeneración urbana integral. Tres W

29. Gehl Life between buildings. Using Public Space, The Danish Architectural Press, 2011 ( 4 edición); I. Gehl, , La humanización delespacio urbano. La vida social entre los ediffcios. Estudios Universitarios, Ed. Reverté, Barcelona, 2006 (reimp. 2009); I. Gehl et al Close encounters with buildings, URBAN DESIGN International (2006) 11, 29-47.

30 Proyecto Madrid Centro, http://ezquiagaarquitectura.com/2012/proyecto-madrid-centro/

31 Memoria del Plan de Acción para la Revitalización del Centro Urbano (Madrid, 2009): http://www.madrides/UnidadWeb/Contenidos/ Publicaciones/TemaUrbanismo/MemoGest22009/5RevitalizacionCentroUrb/2plandeaccion.pdf 


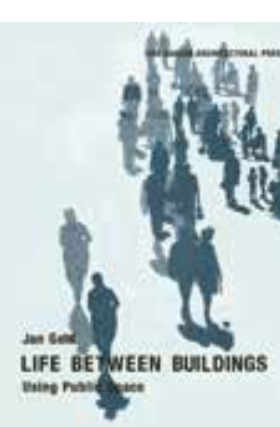

La "Escuela de Copenhague":" (1971). The "School in Copenhagen".Jan
Gehl, LLifebetween buildings (1971).
Vella (Old Town) this segregation is obvious and areas of poverty and wealth do not coevist. Centrified areas are very calised in strategic places and this process is called "microgentrificación"

It should be pointed out, however, that these gentrification processes do not necessarily occur in every urban situation For example, it has not been the case of the San Pablo neighbourhood in the historic city centre of Zaragoza, at leas until now. In this regard, studies by Horacio Capel on Spanish cities show that, generally speaking, gentrification has been quite limited26.

\section{Improving public spaces and the urban landscape as an essential issue for urban regeneration. Recovery of} streets and squares, pedestrianisation of city centre

This topic, which is not only cultural but also technical and functional, brings together much remarkable knowledge and work from a wide range of disciplines. In recent years, the effort to carry out a unifying treatment for buildings, infrastructure and public spaces has helped improve the conditions of a number of urban areas, particularly in certain old historic towns. Cities like Barcelona ${ }^{27}$, Lyon and Copenhagen have spearheaded an important movement of recovering public spaces via interventions of urban and landscape improving 28 . Copenhagen, for example, was a pioneer in Europe with the implementation of pedestrianisation strategies for its city centre and this is now continuing with urban rezoning strategies. Continuity and innovation in the comprehensive treatment of its public spaces have been widely recognised. The work of Jan Gehl and his team has resulted in in-depth theorising and revealed the underlying opportunities of this topic'29. In a way, it can be said that these strategies of "humanising of urban spaces" conform to the principles established by Jane Jacobs, especially with their ideas of permeabilisation, transparency connection between streets and buildings, active use of ground floors etc.

This is also one of the main goals of the Madrid Centro Project, a plan at whose heart is the transformation and recycling of the existing city, with public spaces as an "organisational system, mark of identity, and a mediating element between

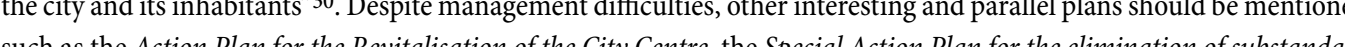
housing the Quality Plon for Urban Landscapes the Mudrid Rio Project and the Recoletos Prado Project etc.31

In a way, the renewal of approaches to landscape converges with the expansion of concepts regarding heritage and cultural landscape, with the emergence of new paradigms, such as that of "historic urban landscape" 32 . The creation

25 M.A., Sargatal (2009). El barrio del Raval de Barcelona (1999-2008). Transformaciones urbanas y nuevos enfoques metodologicos para el estudio del centro historico [The district of el Raval in Barcelona (1999-2008). Urban transtormations and new methodological approaches to the study of the historic centrel. Bible 3 .

.... decay during the twentieth century with a high influx of immigration, reaching its peak in Spanish cities in the 1960s. But when the been accelerating in tandem with the migration of the middle class and their settling into popular neighbourhoods; or has led to recent renewal processes (with municipal interventions of renewal, gentrification, etc..). But overall, gentrification has been rather limited" H. Capel, La morfologia de las ciudades I. Sociedad, cultura y paisaje urbano, Ed. del Serbal, Barcelona, 2002, p. 447.

27 Proyecto BCN, Actar, Barcelona, 2007.

28I. Velazquez, C. Verdaguer, Regeneracación urbana integral. Trese xxperiencias europeas innovadoras: Ile de Nantes, Coin Street y Barrio de

29 J Gehl, Life between buildings. Using Public Space, The Danish Architectural Press, 2001 (4 edición)) J. Gehl, La humanización del espacio urbano. La vida social entre los ediffcios, Estudios Universitarios, Ed.

30 Proyecto Madrid Centro, http://ezquiagarquitectura.com/2012/proyecto-madrid-centro/

31 Memoria del Plan de Acción para la Revitalización del Centro Urbano (Madrid, 2009); http://www.madrid.es/UnidadWeb/Contenidos

32F. Bandarin, R. van Oers, The historic urban landscape. Managing heritage in an urban century, Wiley-Blackwell, 2012; Sobre la emergencia de paradigmas paisajisticos: J. Monclús, "El Proyecto LIFE Teruel como estrategia de regeneración urbana y paisajistica”, en I.

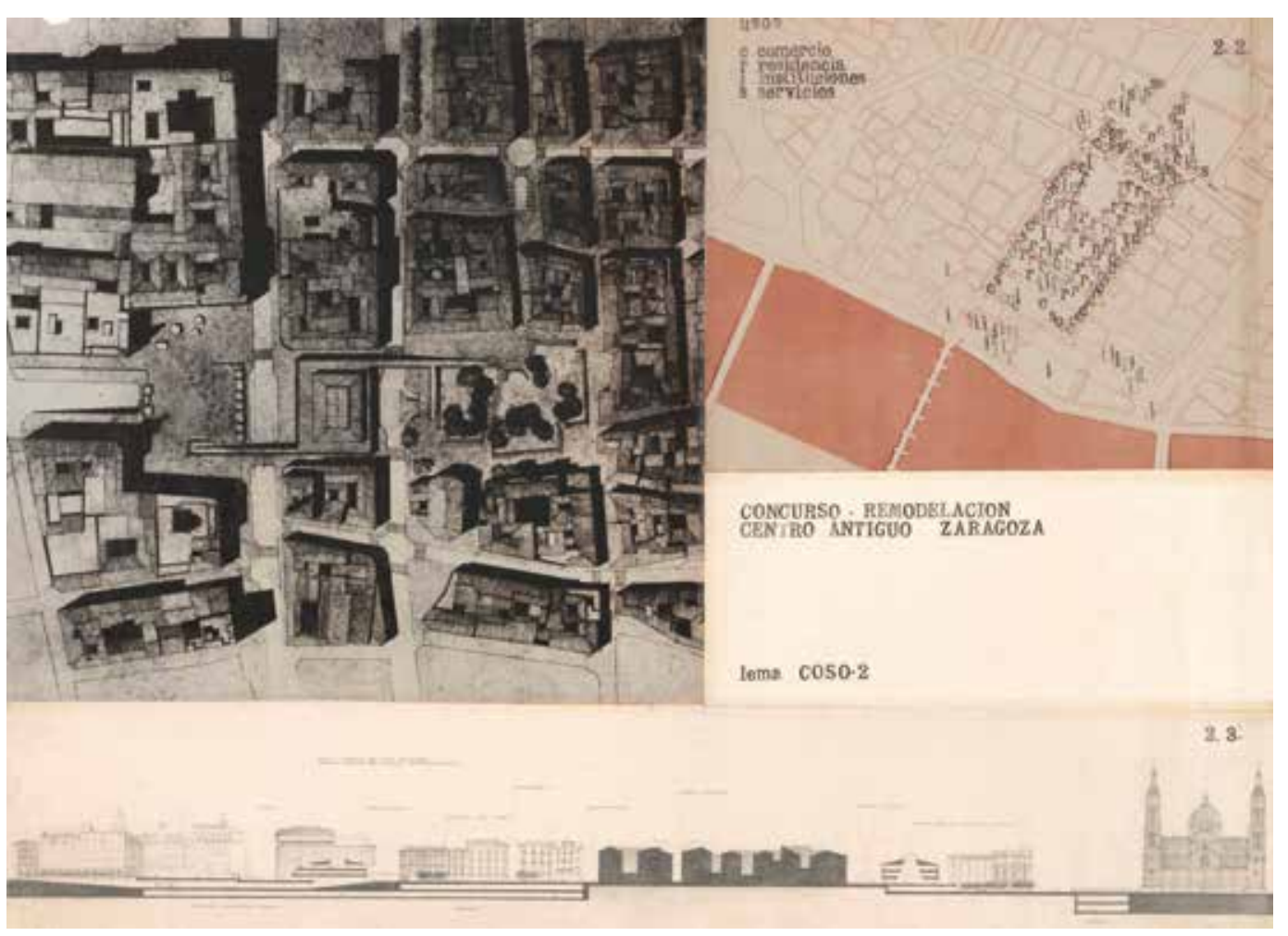

En cierto modo, la renovación de las aproximaciones paisajisticas viene a confluir con la ampliación de las concepciones sobre el patrimonio y los paisajes culturales, con la emergencia de nuevos paradigmas, como el del "paisaje urbano histórico"32. El desarrollo novedoso de ese concepto ha permitido, por ejemplo, la puesta en marcha de planes de gestión de centros históricos como el de Salamanca, con una integración más avanzada de los enfoques urbanísticos
con los patrimoniales33.

Repensar la regeneración urbana, repensar el barrio de San Pablo

El análisis comparado de esos debates y experiencias internacionales y la contraposición con el caso zaragozano permite replantear una serie de presupuestos y estrategias que, de un modo u otro, han caracterizado el devenir de su mite replantear una serie de presupuestos y estrategias que, de un modo u otro, han caracterizado el devenir de su
centro histórico. Como en otras ciudades europeas, también en Zaragoza continúa desde mediados del siglo XIX la dicotomía entre reformas centrales y extensiones urbanas, preferentemente en forma de "ensanches parciales". Y también aquí se podrían comprobar las resonancias de casi todas las cuestiones que se plantean en aquellas ciudades: Renovación urbana y urbanismo moderno; degradación, regeneración urbana y gentrificación; la rehabilitación residencial; recualificación del espacio público y del paisaje urbano, etc.

Con esa perspectiva, se puede reinterpretar la situación que se plantea hacia 1970, es decir, cuando en París comienza la demolición de Les Halles. Y cuando en Zaragoza se detiene la amenaza de actuar radical mente en el centro histórico.

$22 \mathrm{~F}$. Bandarin, R. van Oers, The historic urban landscape. Managing heritage in an urban century, Wiley-Blackwell, 2012; Sobre la emer-

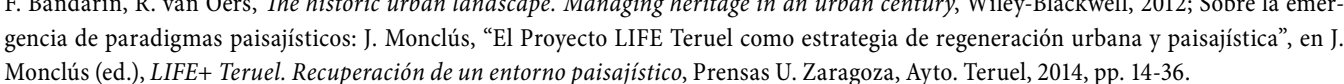
33. L. de las Rivas, “EI paisaje urbano historico de la 'ciudad vieja' de Salamanca, claves para un plan de gestión”, Ciudades, 14, 201 . 
The comparative analysis of these debates and international experience and their comparison with the case of Zaragoza allows a range of strategies to be reconsidered which, one way or another, have characterised the evolution of its historic centre. As in other European cities, from the mid-19th century onwards, Zaragoza has also continued to deal with the dichotomy between inner city reforms and urban Ensanches, with an emphasis on "partial Ensanches". The echoes of almost all he issues raised in those illes can be seen here. Urban Renewal and Modern Urbanis andscapes, etc.

With this perspective, the situation that arose in about 1970 can be reinterpreted; in other words, when in Paris the demolition of Les Halles began, and when the threat of radical action to be taken on Zaragoza's historic city centre was stopped. In this regard, it is worth remembering that it was the urban and social decay of the city centre which caused the mobilisation of the commercial sector and a proposed revitalisation of the city to the Town Hall, giving rise to the important open call in 1969/1970 for the urban renewal of the old city centre. This raised many intervention possibilities for the historic centre, from radical renewal, with an extension of the Paseo de la Independencia, to the conservation of the city centre with actions of less impact 34 .

Regarding this issue, it is interesting to look back at the proposal by the Moneo and Solà-Morales team (2nd prize). In a spirit of recognition of the values of the historic centre and with special architectural sensibility in the treatment of the proposed actions, they reflected on the different hypotheses which were then raised, avoiding both the radical remodelling of the centre and also a "freeze of the entire neighbourhood" because in urbanistic terms "urba immobility equals death". To tackle this, that the team addressed the main problems they detected: a disconnect between the historic city centre and the Ensanches, inefficient traffic flow and the degradation of the historic city centre. A strategy therefore that considered the main elements of the urban structure, but focused on how to manage the project's position regarding urban interventions, carefully raising the questions of: "How do you establish spaces and relationships between volumes so that, whilst highlighting the building's value, they do not lose their meaning in a more combined and overall understanding of the whole?"35.

Despite the weakness or absence of an actual plan, it is important to consider both the socioeconomic diagnoses underpinning the Comprehensive Plan for the Historic Centre (CPHC) ${ }^{36}$ and the various legacies generated in specific

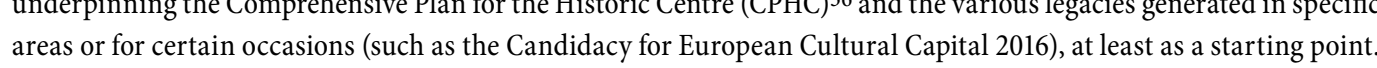

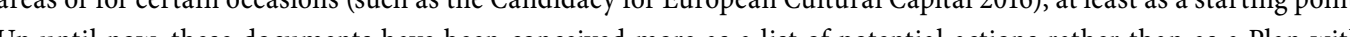

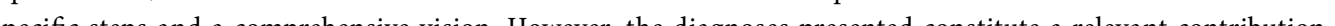
som

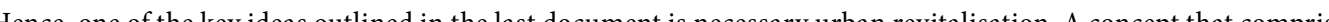
ve d's vitality"37.

As generic conclusion of this review of the topics analysed during the course, we would like to make reference to the proposals of the Urban Design Workshop which are included at the end of this book. They explore specific situations in

33J. L. de las Rivas, "El paisaje urbano histórico de la 'ciudad vieja' de Salamanca, claves para un plan de gestión”, Ciudades, 14, 201 L. $34 \mathrm{E}$. Martinez Litago, "El concurso de ideas de 1969 para la remodelación urbanistica del centro antiguo de Zaragoza", Zarch 1, 2013, pp. $362-381$.

35 C. Díz Medina, "Conversacion con Rafael Moneo", Zarch 1, 2013, pp. 353

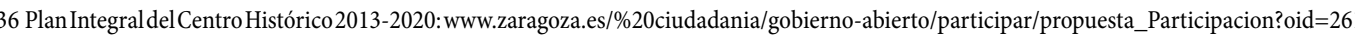
37 La Cultura transforma el Casco Histórico, Zaragoza 2016. Z arquitectura, 1617, 2012.

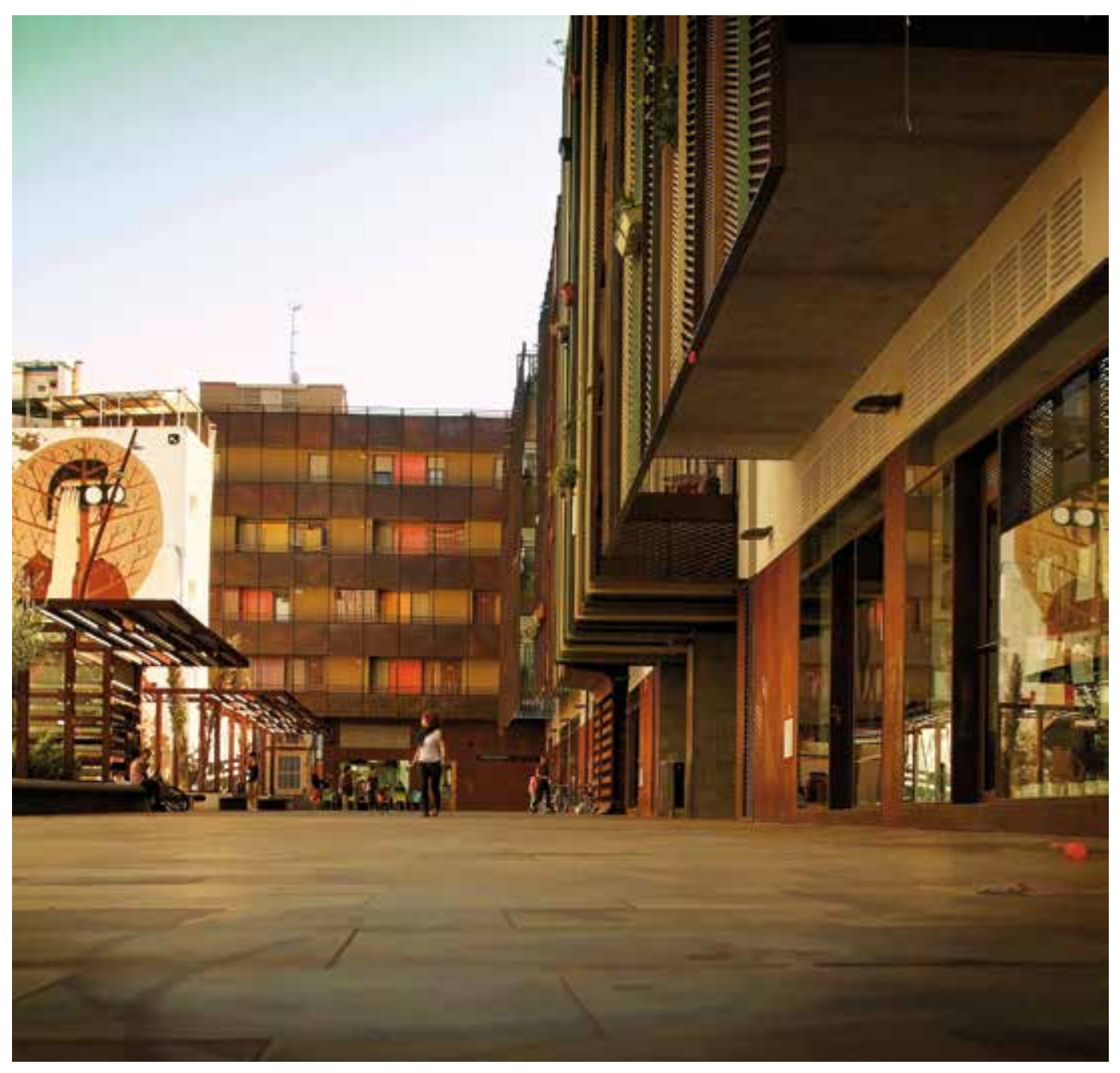

En ese sentido, conviene recordar que es la decadencia urbanística y social del centro lo que provoca la movilización del sector comercial, "proponiéndose al Ayuntamiento su revitalización", lo cual da lugar a la convocatoria del importante concurso de $1969 / 70$ para la remodelación urbanística del centro antiguo. Se plantean así diversas posibilidades de intervención en el centro histórico, desde la remodelación radical, con la prolongación del Paseo de la Independencia, hasta la conservación del centro, con actuaciones menores ${ }^{34}$

En este sentido, es interesante revisar la propuesta del equipo de Moneo y Solà-Morales (2॰ premio). Con un espíritu de reconocimiento de los valores del centro y con especial sensibilidad arquitectónica en el tratamiento de las actuaciones propuestas, se reflexiona sobre las distintas hipótesis que entonces se planteaban, evitando la remodelación radical del centro, pero también "la congelación de todo un barrio", pues "urbanisticamente, inmovilidad urbana equivale a muerte". Para ello, se abordaban los principales problemas que el equipo detectaba: desconexion entre casco antiguo y ensanche, mal funcionamiento del tráico o degradación del centro histórico. Una estrategia, por tanto, que tenía n cuenta con mayor o menor acierto los elementos fundamentales de la estructura urbana, pero que enfatizaba la di34E. Martinez Litago, "El concurso de ideas de 1969 para la remodelación urbanistica del centro antiguo de Zaragoza”, Zarch 1, 2013, pp.
362-381. 

(blocks, buildings, public, collective and private spaces). As noted in the Declaration of Toledo on integrated urba regeneration, it is not a matter of just thinking about joint actions on physical space and social space, but also about

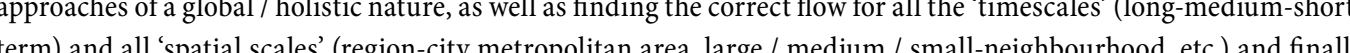
the conjunction between the two.

Of course it is essential to overcome the usual ways of city-making with tools that are now obsolete, in other words forms of conventional planning and management, based on what are still traditional zoning Plans, in particular in difficult areas such as this one, the San Pablo neighbourhood as part of Zaragoza's historic centre: a neighbourhood th could recover and increase its complexity, in line with new forms of urban intervention that are generally required 3 . mensión proyectual de las intervenciones urbanísticas, al plantear cuidadosamente esas cuestiones: "¿cómo establecer los espacios y relaciones de modo que, acentuando el valor de los edificios, no pierdan su sentido en una lectura más a y más global de todo?"35.

A pesar de la debilidad o ausencia de un auténtico plan, es importante considerar tanto los diagnósticos socioeconómicos que sirven de base al Plan Integral del Centro Histórico (PICH) ${ }^{36}$, como diversos materiales generados en ámbitos u ocasiones específicas (como la Candidatura para la capitalidad cultural de 2016), al menos como punto de partida. Hasta ahora, esos documentos se han concebido mass bien como un listado de actuaciones posibles que como un plan con etapas específicas y con visión integradora. En cualquier caso, los diagnosticos que ahi se presentan constituyen ya una aportación relevante, por lo que supone de reconocimiento de determinados procesos de forma relativamente integrada. Así, se constata la pérdida de vitalidad de determinadas áreas. De ahí que una de las nociones clave utilizada en el último documento sea la de la necesaria revitalización urbana. Un concepto que incluye actuaciones diversas, entre otras las relativas a la reactivación de la oferta comercial "con el convencimiento de que el comercio es el mejor reflejo de la vitalidad del barrio"37.

Como conclusión genérica de esta revisión de los materiales analizados durante el curso, podemos referirnos a las propuestas del Taller de Urbanismo que se incluyen al final del volumen. Se trata de exploraciones sobre situaciones
concretas en las que es posible y deseable plantear intervenciones especificas en el barrio y en determinados sectores urbanos (mas qua es posibios y espaciob públicos, colectivos y privados). Como apunta el Documento de Toledo sobre la regeneración urbana integrada, no sólo se trata de penser en actuciones simultánecs sobre el espacio fisico y el la regeneración urbana integrada, no solo se trata de pensar en actuaciones simultaneas sobre el espacio fisico y el ticulación de todas las 'escalas temporales' (largo-medio-corto plazo) y de todas las escalas espaciales' (región-área ticulación de todas las 'escalas temporales' (largo-medio-corto plazo) y de todas las escalas espaciales' (reg
metropolitana-ciudad grande/mediana/pequeña-barrio, etc.) y, finalmente, la conjunción de ambas entre sí.

Claro que para ello resulta fundamental superar las formas habituales de hacer ciudad mediante instrumentos que resultan ahora obsoletos, es decir, las formas de planeamiento y gestión convencionales, basadas en lo que todavía es el Plan de zonificación tradicional. Sobre todo en ámbitos difíciles como el que nos ocupa, el barrio de San Pablo como parte del centro histórico zaragozano: un barrio que podría recuperar e incrementar su complejidad, en la línea de las
nuevas formas de intervención urbanística que se reclaman de forma generalizada ${ }^{8}$. 


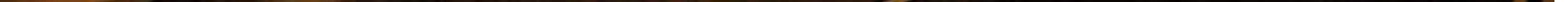




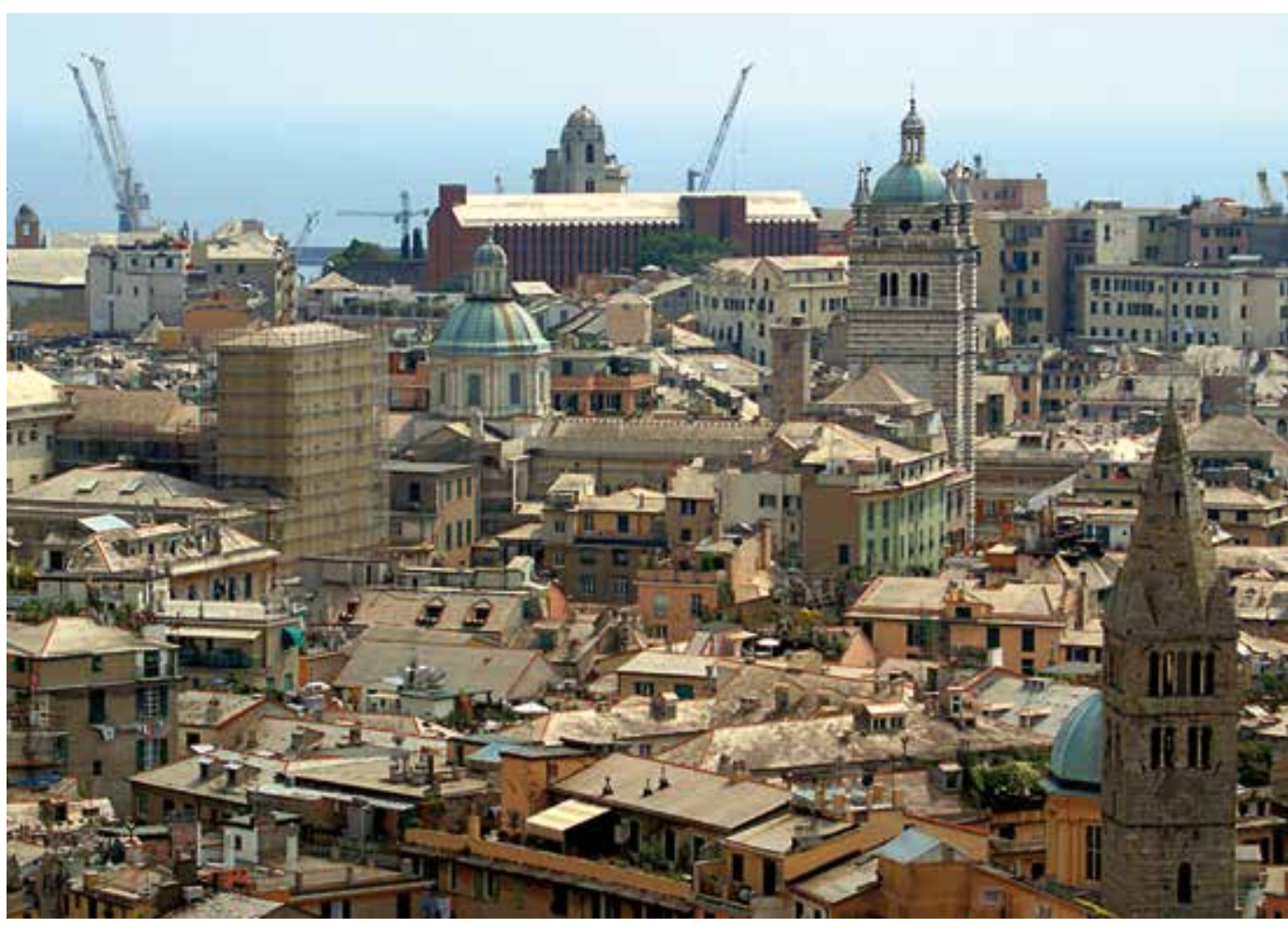

À la recherche du lieu perdu

Como colofón de su Historia crítica de la arquitectura moderna, publicada en Londres en 19801, Kennet Frampton presentaba en el último capítulo, "Lugar, producción y arquitectura: hacia una teoría crítica de la construcción", un texto que, a partir de algunos proyectos de arquitectura recientes, recapacitaba sobre las tendencias por aquel entonces en boga. Tras subrayar la ineficacia que el urbanismo operativo - por el que parecia mostrar una cierta indiferenciahabia demostrado a la hora de conferir forma fisica a los asentamientos, el autor dingla la mirada hacia las potenciale promesas del diseno urbano, apuntando: «There is, as Hans Sedlmayr has pointed out, a moment when place an

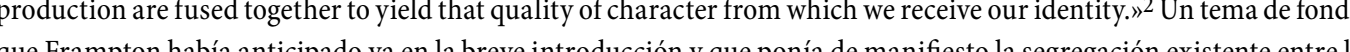
que Frampton habia anticpado ya en a beve introductiony que ponta de manilfesto la segregacion existente entre a

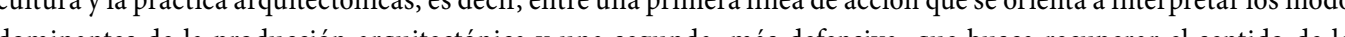

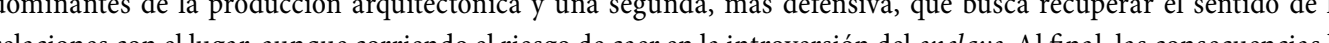
a

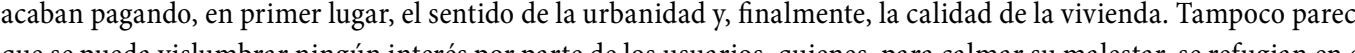

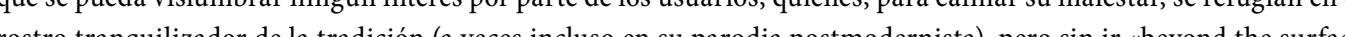
yet creative redefinition of the concrete qualities of the built domain., ${ }^{3}$

1 Kennet Frampton, Modern Architecture: a critical history, Thames and Hudson, London, 1980. Edición en castellano: Historia critica de la arelona, Gustavo Gili, 1981 2 Ibidem, p. 297. En la edicíón en castellano: "Como ha indicado Hans Sellmayr, hay un momento inescapable en el que lugar y yroducción
se funden para producii esa calidad de carácter de la que eventual mente obtenemos nuestro sentido de la i identidad", op. cit, p. 301.

3Ibidem, p. 10. En la edición en castellano: " "más alláde la la cuestión superficial del estillo para pedir que la práctica arquitectónica se reoriente
hacia la cuestión de la creación de lugar, hacia una redefinición crítica pero creativa, de las cualidades concretas del entorno edificado", op. cit, p. 10 .
A distancia de más de treinta años, podemos hoy preguntarnos si la esperanza en el proyecto de arquitectura que las palabras del historiador suscitaban ha conseguido consolidar, más allá del legado del pensamiento teórico, una estela de "buenas prácticas" arquitectónicas en el ejercicio de la actividad profesional y académica. Una pregunta

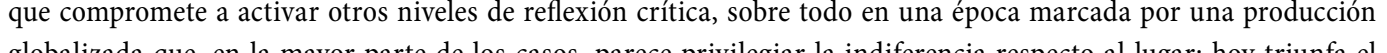

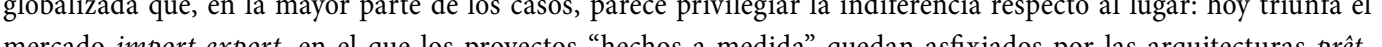
mercado mportexpon, en el que los proyectos "heces a nedida quedn asxas por las anquitectras pret-

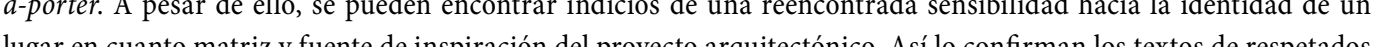
lugar en metodologías didácticas al uso.

Por el contrario, podemos también preguntarnos si la atención -enf́ática en el momento de la publicación del libro de Frampton- prestada a las sugestiones morfogenéticas de un determinado contexto no constituye en realidad un subterfugio frente a la reconocida incapacidad de la arquitectura de "hacer ciudad" 0 , en otro sentido, de proponer una fisionomía estilística compartida.

Le lieu retrouvé (en théorie)

Las muestras de la intolerancia a la internacionalización del lenguaje y a la estandarización de los modelos de asentamiento, imputada con o sin raźn ána producción post-bélica del Movimionto Moderno (incluyendo una crítica implicita a sus principios teóricos $s^{4}$ ) no tardaron en aparecer en el debate cultural de los años cincuenta y sesenta. La
inter a polémica que contrapuso a Ernesto N. Rogers-Casabella y a Reyner Banham-Architectural Review es una historia demasiado conocida como para dedicarle más que una mención. Lo que es importante subrayar es que el reclamo de las "preexistencias ambientales", además de la referencia a la contiunidad de las tradiciones contenía, implícitamente, la invitación a prestar mayor atención al valor de los lugares, bien en sentido histórico o topográíco. Un camino, por otro lado, ya emprendido por arquitectos de primer orden, como Albini, Gardella y Ridolfi en lo que respecta a Italia o Sostres y Coderch en lo que se refiere a España, que estaban explorando en su obra construida aspectos que diferían de los modelos de la modernidad, tratando fundamentalmente de injertarse en las coordenadas contextuales de la trama urbana. En otro orden de cosas, el tema de la relación con el paisaje natural caracteriza, en clave de poética espacial, la contribución de Alvar Aalto (y no solo la suya, pero se le cita aquí por la influencia que ejerció en la arquitectura española en las décadas sucesivas).

Los años sesenta registraron una notable producción de estudios teóricos orientados a engranar el proyecto de arquitectura en una trama más amplia de relaciones que abarcaba los sistemas urbanos y territoriales: se pueden recordar desde el libro de Vittorio Gregotti, que a partir de una visión antropogeografica terminó abogando por la preeminencia del principio de asentamiento, a los trabajos de Kevin Lynch, destinados a explorar los aspectos de a percepción de los paisajes urbanizados 5 . Con La arquitectura de la ciudad de Aldo Rossi quedan enunciados dos horizontes a traves de los cuales el proyecto de arquitectura se hace participe de la construccion del ambiente físico: por una parte, Rossi tiene en cuenta la estructura general de los "hechos urbanos" (Jatti urbanil) y sus transformaciones en el tiempo; por otra, llama la atención sobre el carácter de irrepetible unicidad que los lugares parlantes irradian. De aquí parten dos líneas de trabajo: la primera de ellas, denominada "Análisis urbano y proyecto arquitectónico", pretende que el estudio de los hechos arquitectónicos y el estudio de la ciudad, al considerarse fenómenos de la misma naturaleza, se recompongan en un cuadro unitario a partir de una sistemática científica; la segunda, por otro lado, se aplica a contextos urbanos o paisajisticos densos de sugerencias morfológicas o de sedimentaciones históricas.

4 Una critica precipitada, tal y como argumenta Giorgio Grassi en su introducción a la antologia italiana de la revista Das Neue Frankfurt Una critica precipitada, tal y como argumenta Giorgio Gasst en su introduccion a la antologia italiana de la revista Das Neue Frankfurt tinuidad con la axperiencia historica de las ciudades alemanas.

5 Vittorio Gregotti, Il territorio dell'architettura, Feltrinelli, Milano, 1966. Edición en castellano: El territorio de la arquitectura, Gustavo Gili, Barcelona, 1972. Veanse tembién los trabajos, desarrollados desde posiciones antiteteticas, de Christopher Alexander y Colin Rowe. 

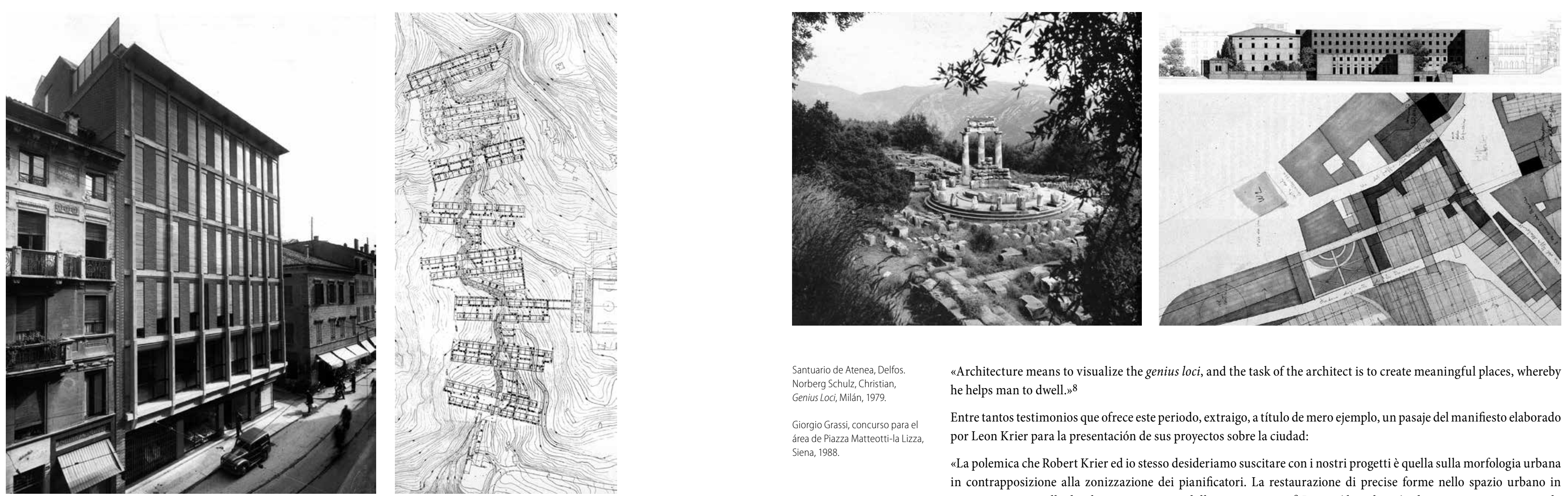

Santuario de Atenea, Delfos,
avrberg Schulz, Chistian,

Grius Loci, Milán, 1979 .

Giorgio Grassi, concurso para el
àrea de Piazza Matteotti-la Lizza,

A distancia de alounos decenios, podemos hoy admitir el fracaso de la primera de estas dos líneas como procedimiento para orientar la transformación urbana, razón que induce a Pierluigi Nicolin a escribir en uno de los últimos números de Lotuse «Dopo il fallimento dell'ultimo tentativo di stabilire un accordo tra l'architettura e la città con le proposte di morfologia urbana avanzate da Rossi, Aymonino, Quadroni, Huet, ecc. di nuovo, perlomeno a partire dagli ann Ottanta del Novecento, c’è il convincimento di dover tener conto una volta per tutte dell' incapacità dell'architettura di fare città, di costituirsi in morfologia urbana significativa $[. .].]^{6}$. Y aún podríamos añadir que «[...] Da quando è comunemente accettato che larrchitettura della città si realizzi tramite una sequela di oggetti indipendenti abbandonando definitivamente l'illusione di determinare attraverso una morfologia urbana il ground ${ }^{7}$, la acción proyectual encaminada a restituir una cierta semblanza de urbanidad parece haber pasado a las manos del nuevo paisajismo o de otras estrategias de asentamiento. Por el contrario, la atención prestada a la especificidad de un determinado lugar, sobre todo si éste se distingue por disponer de una singular aura natural o artificial, parece haber sido destinada a gozar de mayor fortuna, avivada por la aparición de textos como Genius Loci, que al final de los años
sesenta contribuyó a propagar una especial sensibilidad hacia este tema mediante el eslogan:

6Pierluigi Nicolin, "Urban Landscape", Lotus international, n. 150, 2012, p. 80. «Tras e el fracaso del último intento de establecer un acuerd

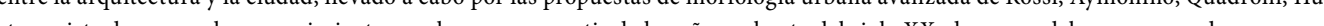
todas la incepacidad de la arquitectura para hacer ciudad, para constituirse en morfologia urbana significativas. Traducción $C$ Diez$7 \mathrm{Ibídem}$. «Desde el momento en que se ha aceptado de forma generalizada que la arquitectura de la ciudad se construye a través de u secuencia de objettos independientes, abandonando definitivamente la li liusión de que una determinada morfología permita determinar ef ground [.... . T. Traducción C. Díez
«Architecture means to visualize the genius loci, and the task of the architect is to create meaningful places, whereby he helps man to dwell.»8

Entre tantos testimonios que ofrece este periodo, extraigo, a título de mero ejemplo, un pasaje del manifiesto elaborado por Leon Krier para la presentación de sus proyectos sobre la ciudad:

«La polemica che Robert Krier ed io stesso desideriamo suscitare con i nostri progetti è quella sulla morfologia urbana in contrapposizione alla zonizzazione dei pianificatori. La restaurazione di precise forme nello spazio urbano in contrapposizione alla desolazione provocata dalla zonizzazione „9 De aquí la redacción de proyectos que, partiendo de la configuración y de la estratificicaión histórica de las áreas de intervención, proponen una especie de crecimiento mimético de la estructura preexistente, como sucede en el proyecto con carácter de manifiesto para el liceo de Echternach, o también en el proyecto con valor demostrativo desarrollado con J. Stirling para el Derby City Hall de 1970. En este caso, es la ruptura de la continuidad urbana la que ofrece la inspiración para proponer una estructura que, en lugar de imponer un modelo tipológico/funcional propio, encuentra la razón de la forma en la voluntad de saldar la brecha existente (constriñendo las funciones en el interior del trazado morfológico), al mismo tiempo que crea un lugar inédito: la nueva plaza enmarcada por la galería

Tampoco se pueden olvidar, en otro mundo figurativo, las prácticas extractivas llevadas a cabo por Giorgio Grassi con el fin de identificar en la estructura del lugar l a razón y el sentido del proyecto. Una actitud que se manifiesta explícitamente en el plano metodológico, por ejemplo, en la memoria del provecto de reconstrucción de Teora, el pueblo destruido a raíz del último terremoto sufrido en 1980, y desarrollada mediante una serie de proyectos de concurso, entre los que destaca la propuesta elaborada para Siena como demostración experimental de un dispositivo de interpolación entre construcción y lugar -entre lo viejo y lo nuevo- en el que la impronta tipológica parece disolverse.

Otros autores expresan los términos de una poética que ha llegado a convertirse en argumento: de Aldo Rossi («Ho sempre affermato che 1 luoghi sono piu forti delle persone, la scena fissa e piu forte della vicenda» 0 « Io penso sempre

8 Christian Norberg Schulz, Genius Loci. Towards a Phenomenonlogy of Architecture, Rizzoli, New York, 1980, p. 5. «A A Arquitectura significa vist 9 Leon Krier, "Progetti sulla città//Projects on the city", in Lotus international, n. 11, 19761, p.72. «L La polemica que Robert Krier y yo mismo los urbanistas, en la restauración de formas bien definidas en el espacio urbano en contraposición con la desolación provocada por la zonificación.» Traducción C. Díez. 


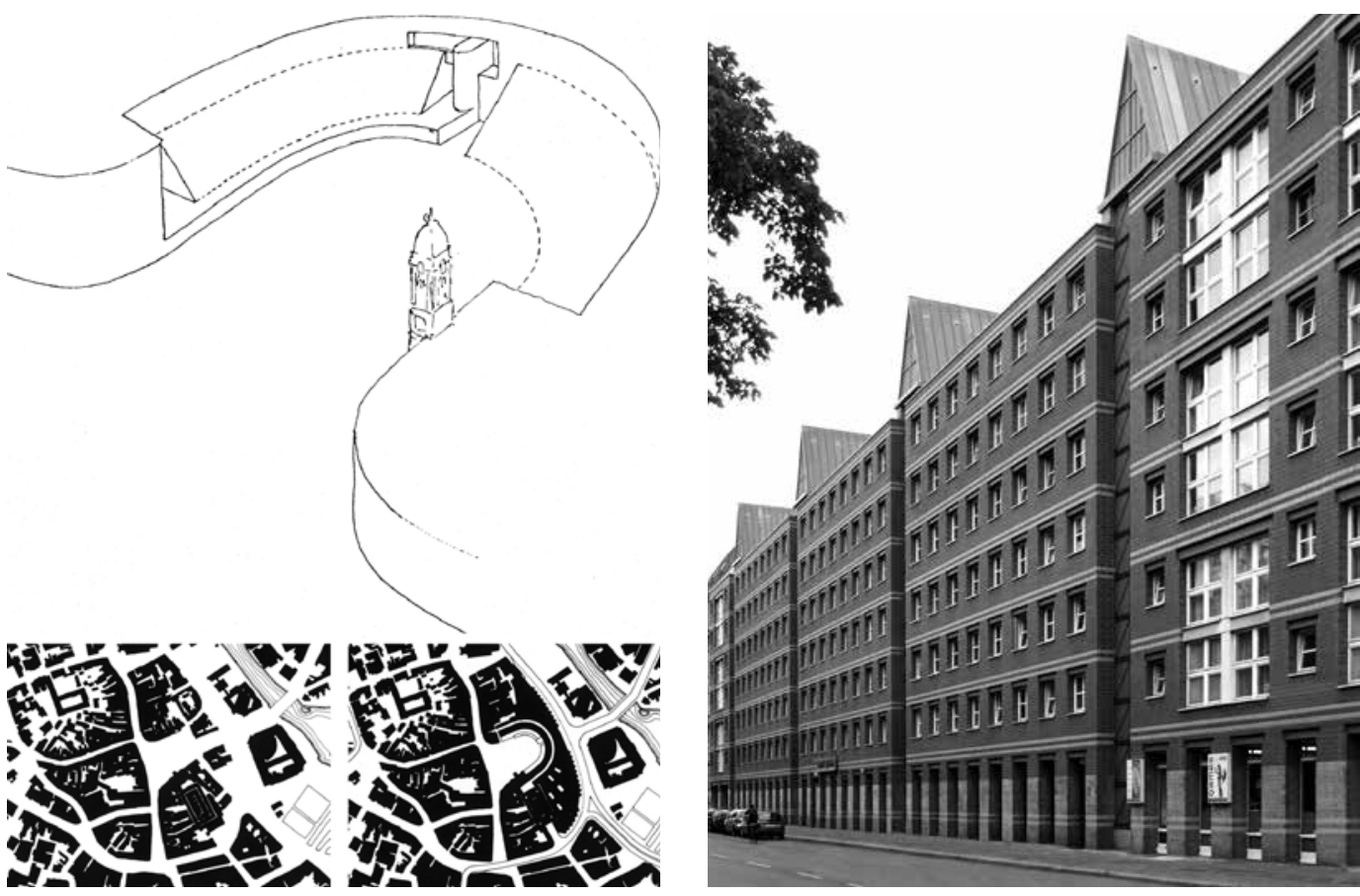

in qualche modo ad un luogo. Certamente in ogni luogo si riassumono molte cose, il luogo si presenta come un risultato 10 ) a Rafael Moneo, que en el texto On Site, Time and Specificity in Architecture condensa las ideas principales de su reflexión arquitectónicall

De estos y otros escritos se pueden extraer algunos postulados elementales, cuya obviedad puede entenderse como evidencia objetiva:

- el lugar, aunque metafórico o ficticio, constituye un elemento esencial para el proyecto de arquitectura, es la materia prima: «Therefore, it is the site, with all of its tangential implications, that composes the first material manifestation of any construction» $\mathrm{e}$ «Thus, the site participates in determining the character and significance of the architecture that is or will be grounded upon it.»12

- la arquitectura transforma a su vez el lugar mismo, lo hace especifico, discierne «what existing conditions of the site must be ignored, eliminated, augmented, or transformed»13 y, allí donde no hay nada más que un terreno desnudo hace aparecer un lugar;

10 Aldo Rossi, Autobiografa a scientitica, Pratiche Editrice, Parma, 1990, pp. 63, 69. Edición en castellano: Aldo Rossi, Autobiografía cientifi ca, MIT 1981, G.Gili, Barcelona, 1984, 1988. « Siempre he afirmado que los lugares son màs fuertes que las personas, el escenario más que el acontecimientol.,y, $\mathrm{p}$.63. « De una forma u otra, siempre estoy pensando en el lugar. En verdad, en cada lugar se resumen muchas cosas

11 Rafael Moneo, On Site, Time and Speciffcity in Architecture, Conferencia, Doctorado Honoris Causa, Universidad Católica de Lovaina, 2

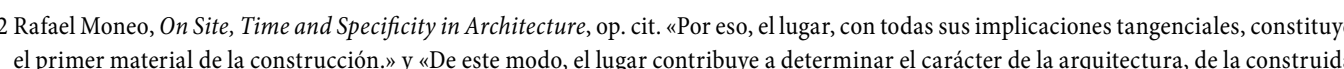
el primer material de la construcción., y «De estent
o de la se levantará en él., Traducción C. Díez.

33 Ibídem, «cuáles de las condiciones existentes en un lugar han de ser ignoradas, eliminadas, reforzadas o transformadas.» Traducción $C$ Dier. -el lugar es una pre-condición necesaria para el proyecto, pero no suficiente: el principio de la pertenencia es estéril si no aparece reforzado por las cualidades formales que, en arquitectura, provienen del sentido de la propia "cosa", ya sea una institución o una casa, y también de sus propiedades constructivas.

Es difícil para quien escribe trazar un panorama actualizado con los desarrollos teóricos más recientes, que parecen eza filosófica y de inmersiones extradisciplinares: seguramente las contribuciones publicadas en este número proveerán de coordenadas más precisas para orientarse en los complejos caminos del concepto de lugar. Personalmente me limito a proponer algunas reflexiones de orden genérico que este argumento me ha sugerido.

Minima localia: reflexiones en orden disperso sobre el tema del lugar

\section{Arquitectura y ciudad o proyecto y lugar}

«Come esiste un rapporto autentico, circostanziato, con la città in cui costruiamo? Esso esiste solo nella misura in cui l'architettura riporta a motivi della sua stessa progettazione i caratteri generali della città.,114 Así se expresaba Aldo Rossi en un ensayo de 1972. En efecto, la ambición de ser capaz de establecer una correspondencia entre el carácter arquitectónico de la obra de arquitectura y esa armonía en el conjunto que percibimos como propia de una determinada ciudad es el hilo conductor de la investigación proyectual del autor y queda expresada explícitamente en las memorias que acompañan sus proyectos para Turín y para Berlín.

Conviene especificar que se trata de una correspondencia biunívoca: si, por un lado, la búsqueda de una sintonía con el âme de la cité pretende hacer resonar o condensar en la fábrica arquitectónica la estructura general de una ciudad o sus connotaciones dominantes sedimentadas a lo largo de la historia, también es verdad que cada nuevo injerto contribuye a precisar o a variar la tonalidad sinfónica del concierto urbano; en algunos casos, añadiendo nuevas notas domintes, cono dentestra la inhuencia de la obra de Mansart en el rostro trbano de Paris, ola herencia del trío Rastrelli-Quarenghi-Rossi en San Petersburgo. Una ambición que involucra al arquitecto en cuanto intelectualartista, es decir, en cuanto persona en grado de percibir el core cultural de una determinada ciudad; pero también en

14 Aldo Rossi, "Architettura e città. Passato e presente", en Scritti scelti sull architettura e la città, 1956-1972, clup, Milano, 1975, p. 475

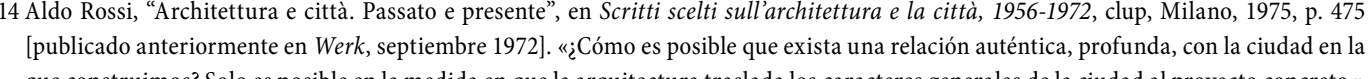

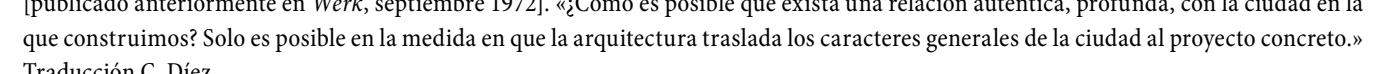



a inserción forzada en las ciudades de organismos arquitectónicos "apátridas"-desde esta perspectiva, esto ocurre (on vin la luz de esta categoría interpretativa

Zoom out - zoom in: si en el panorama internacional prevalecen las interacciones entre color global y color local ${ }^{15}$ a las que se oponen las experiencias maduradas en el ambito de las escuelas regionales, en general el proyecto culto parece privilegiar el tema de la relación con el lugar, con las peculiaridades ligadas a su conformación física, a las estratificaciones historicicas, a las construcciones circundantes. El proyecto se convierte en primera respuesta al lug específico: o, dicho de otro modo, el lugar en sí mismo se convierte en el tema del proyecto: ya sea en clave poética con el fin de dar vida a una nueva trama de relaciones espaciales y sociales activada entre los elementos que compone la escena. Volveremos a comentar brevemente estas interpretaciones más tarde, tomando como ejemplo alguna experiencias desarrolladas en el área cultural de la Península ibérica.

Conviene señalar, en cualquier caso, que no han faltado en los últimos decenios del pasado siglo arquitecturas capaces de registrar puntual mente la especificidad del lugar y de reflejar, al mismo tiempo, su integración con el carácter global
de la ciudad en la que se asientan. Un ejemplo convincente de edificio double range es la Facultad de Arquitectura de

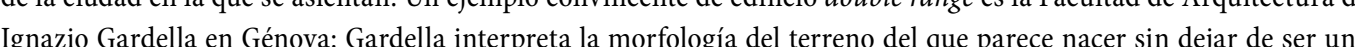
construcción exquisitamente genovesa.

\section{Paradise lost}

En el mismo escrito de Aldo Rossi antes citado, encontramos más adelante un pasaje que merece nuestra atención. Después de haber apreciado la sabiduría de Le Corbusier al utilizar la sección del terreno para insertar en él el Convento

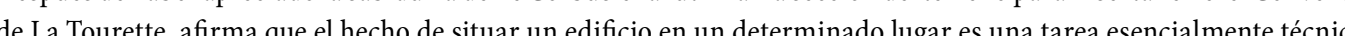
y añade: «Im a y anade. In precedenti si cof for trusca; volerlo rendere nei termini contempont

Podemos recoger aquí el guante de una polémica anti-organicista o, dicho más sencillamente, de una actitud de desconfianza frente a aquellas posiciones "ambientalistas" llevadas a mimetizar la arquitectura en el paisaje natur o construido. En verdad, los desarrollos teóricos sucesivos han aportado claves interpretativas más sofisticadas par intentar comprender la naturaleza íntima de los lugares, desde Norberg Schulz a Espuelas, y nuestro bagaje filosófico en esta materia parece hoy más rico.

Por otro lado, se ha abierto camino la aspiración -anticipada ya en las formulaciones teóricas del Movimiento Modernoa reunificar de nuevo el habitar con la naturaleza, un anhelo reeditado bajo la forma de ecologismo redentor. El pasaje citado, independientemente de cómo se quiera considerar, nos lleva a reflexionar sobre el sentido artificial y terrenal de la construcción humana. La negación de este carácter artificial que pretende restablecer una relación de fusión primigenia con las cosas de la naturaleza se presenta como una ilusión, una vez roto el pacto que vinculaba hombres, lugares y cosas en un sentimiento de común animismo. La separación de la divinidad que habitaba ubicuamente el paisaje -en una migración al parecer concluida al final del periodo Neolíitco, cuando los dioses y lo sagrado abandonaron los bosques las aguas y las rocas para transferirse al Olimpo, o incluso más arriba- tiene un valor fundamental para la historia del hombre y de sus asentamientos. Es ésta una fractura irremediable que sirve de fondo a las reflexiones mitológicas

15 La expresión hace referencia a los análisis desarrollados por Marc Ausect

16 Aldo Rossi, “Architettura e città. Passato e presente”, op. cit,. p. 476. «Imaginar una relación con el paisaje más compleja que la que se

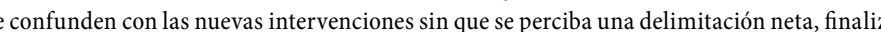
turaleza o las construcciones preexistentes se confunden con las nuevas intervenciones sin que se perćba un
con la arquitectura griega y yetrusca; querer extrapolarla a la contemporaneidad es irreal.» Traducción C. Díe.

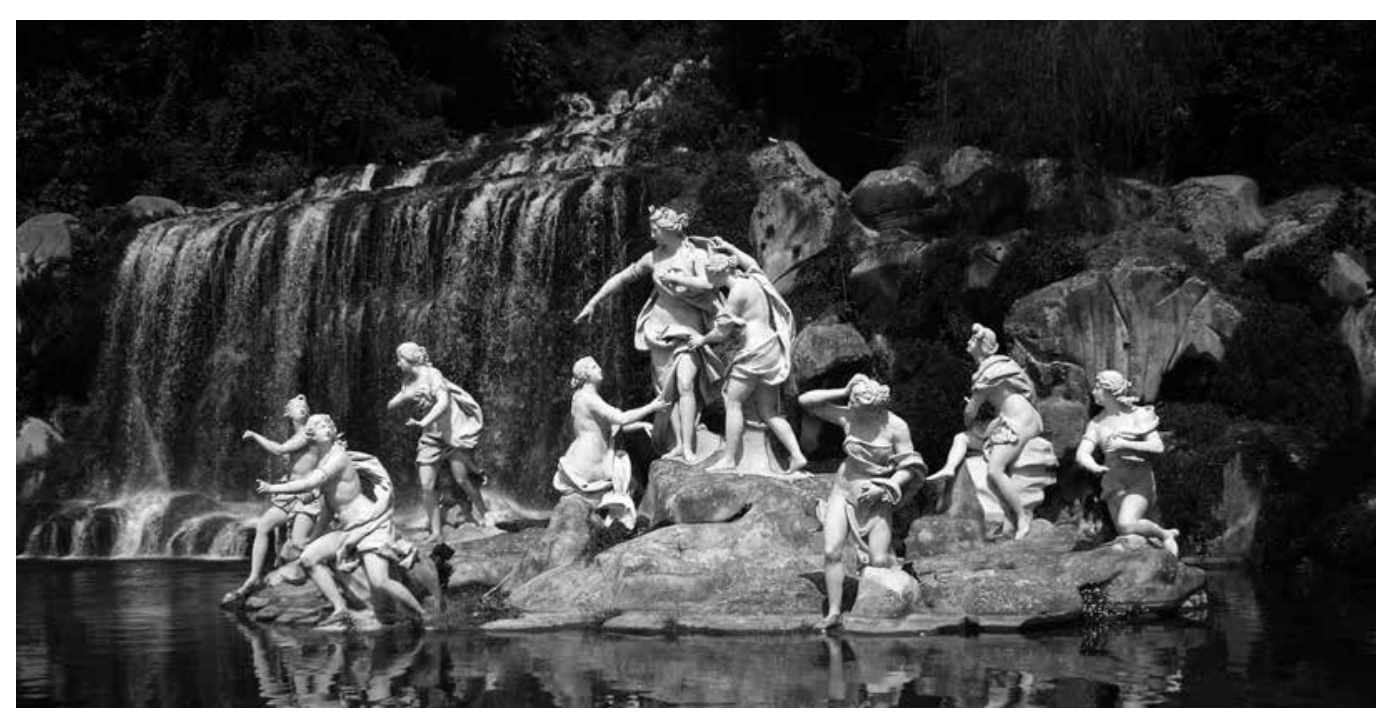

propuestas por Cesare Pavese en sus Dialoghi con Leucò, en los que uno de los motivos dominantes es la transición desde e estado de coágulo caótico -de una naturaleza todavía indiferente- al nuevo orden impuesto por los dioses olímpicos, que señala el inicio de las acciones humanas caracterizadas por la consciencia del límite-

- «Ĺacqua, il vento, la rupe e la nuvola non son più cosa vostra, non potete più stringerli a voi generando e vivendo. Altre mani ormai tengono il mondo. [...] non puoi più mischiarti a noialtre, le ninfe delle polle e dei monti [...] È mutato il destino. - «Adesso i luoghi sono come erano prima di loro. [...] Ammetterai che sul sentiero non si incontrano più dèi.»

«A quel tempo la bestia e il pantano eran terra d'incontro di uomini e dèi. La montagna il cavallo la pianta la nube il torrente - tutto eravamo sotto il sole.,...17

Pero la separación de la naturaleza y el alejamiento de las nuevas divinidades, a una distancia inescrutable, si bien han producido la herida con la que hemos de cargar, singular y colectivamente, constituyen también la semilla doliente que da origen a la civilización de los hombres:

«Sono poveri vermi ma tra loro tutto è imprevisto e scoperta. Soltanto vivendo con loro e per loro si gusta il sapore del mondo ... è vero tutto quello che toccano diventa tempo. Diventa azione. Attesa e speranza. [...] Come i vignetic che han

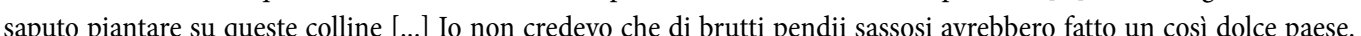
Cosi è del grano, cosi dei giardini. Dappertutto dove spendono fatiche parole nasce un ritmo un senso, un riposo „18 El anhelo de retorno está presente en las teorizaciones del Movimiento Moderno, con Le Corbusier como autorizado paladín. En este sentido, Giancarlo Consonni comenta

17 Cesare Pavese, Dialoghi con Leucò, Einaudi Editore, Torino, 1953, pp. 11-12, 212, 35. Edición en castellano: Cesare Pavese, Diallogos con

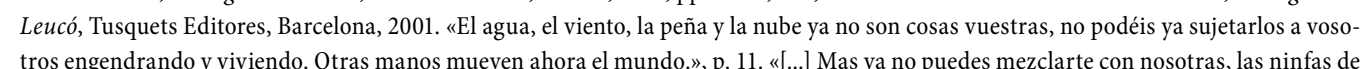

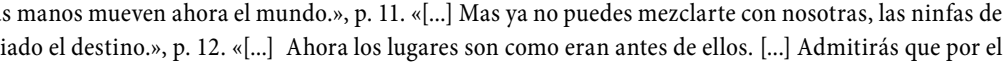
sendero ya no se encuentran dioses., p. . 192. «..... En aquel tiempo la bestia y el pantano eran tierra de encuentro de hombres $y$ de dioses. tam $18 \mathrm{bidem}$, «[Los hombres] Son pobres gusanos, mas todo entre ellos es descubrimiento e imprevisto. [...] Solamente viviendo con ellos $y$ por ellos se disfrutata del sabor del mundo.n, p. 166 . «.... is cierto, todo lo que tocan se convierte en tiempo. Se convierte en acción. Espera una tierra tan dulce. Lo mismo con el trigo, y con los jardines. Por doquiera que gastan fatigas $y$ palabras nace un ritmo, un sentido, un reposo.., p. $16 \%$ 


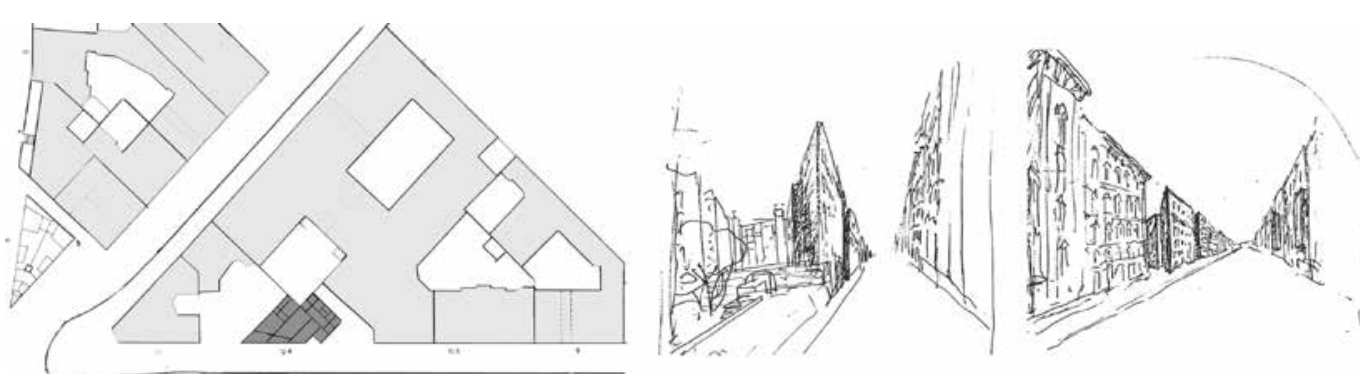

«La natura è vista come un fatto primigenio, da creazione del mondo. L.C. ritiene possibile un presunto stato originario, di cui si cura di preservare, attraverso la tecnica, il carattere virginale. Non conta che la tecnica sia nata dalla necessità rendere abitabile la terra e sia evoluta in un processo in cui artificio e natura si sono fusi dando luogo a realtà inscindibili,y

Por esto nos preguntamos si los intentos de (literalmente) "re-animación" de la primigenia relación con la naturaleza buscada a través de rituales pseudo-verdosos, no está destinada a ser engañosa, desde el momento en el que la consciencia del tiempo ha evidenciado a ouson que no se deba demostrar el méximo respeto por la naturaleza y por la tierra o que no se pueda disfrutar de las agury de las selvas o la ciudad, los lugares del habitar y los viñedos.

\section{Ningún lugar. En ningún sitio. (Kein Ort. Nirgends)}

La cultura arquitectónica autorizada parece obsesionada por la preocupación de reivindicar la inmanencia del lugar como puerta de ingreso principal al proyecto. Sobre todo desde que la noción de tipo ha dejado entrever que no goza de buena salud tras ser acusado de ser incapaz de interpretar las dinámicas de las transformaciones territoriales ${ }^{20}$, a pesar de la apasionada defensa de Carlos Martit, encaminada a demostrar la intrínseca vitalidad de los estatutos tipológicos²1. Parecería que al fina
del siglo XX la tríada vitruviana se ha transformado en un cuadrilátero, donde el cuarto vértice podría denominarse relatio. Muchos de los autores interpelados insisten en afirmar que cualquier proyecto de arquitectura parte de presuponer un lugar, un "estar", como condicion primaria para la existencia de la arquitectura; e incluso cuando se trata de proyectos ilustradamente más abstractos -más centrados en el concepto, en la figuración o representación de activo, si bien implíitamente, a veces entre bastidores22. Y todo ello sucede independientemente de que se trate de 1 ciudad burguesa, en el caso de los edificios-modelo de Durand, o de los escenarios proyectuales de las metrópolis en desarrollo, como ocurre en los "avances" experimentales de MVRDV o de Rem Koolhaas.

19 Giancarlo Consonni, La bellezza civile. Splendore e crisi dell a città, Maggioli Editore, S. Arcangelo di Romagna, p.124, «La naturaleza se por preserar nado en un proceso en el que artificio y naturaleza se funden, dando lugar a realidades inescindibles.» Traducción C. Diez

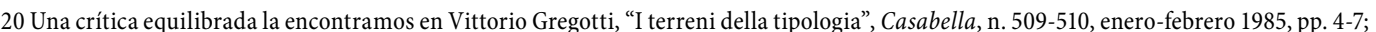
otras contribuciones críticas más concretamente referidas a la noción de tipo provienen de Peter Eisenman y de Rafael Moneo. Rafa Moneo, "On typology", Oppositions 13, 1978. Edición en castellano: Rafael Moneo, Sobre el concepto de tipo en arquitectura, Curso de Composición H. Escuela de Arquitcent

21 Carlos Marti Aris, Le variazioni dell identitat. Il tipo in architettura, clup, Milano, 1990; Edición en castellano: Las variaciones de la identidad. Enssayo sobre el tipo en arquitectura, ediciones del Serbal, Colegio de Arquitectos de Cataluña, 1993. Prefacio de Giorgio Grass

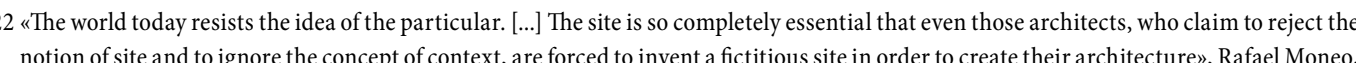
On Site, Time and Specificity in Architecture, op. cit. «El mundo de hoy se resiste a la idea de lo especifico. [.].] [Sin embarsol El El lugar est esencial que incluso aquellos arquitectos que insisten en rechazar la noción de lugar y en ignorar el concepto de contexto están obligados a inventar un lugar ficticio para crear su arquitectura.» Traducción C. Diéc.

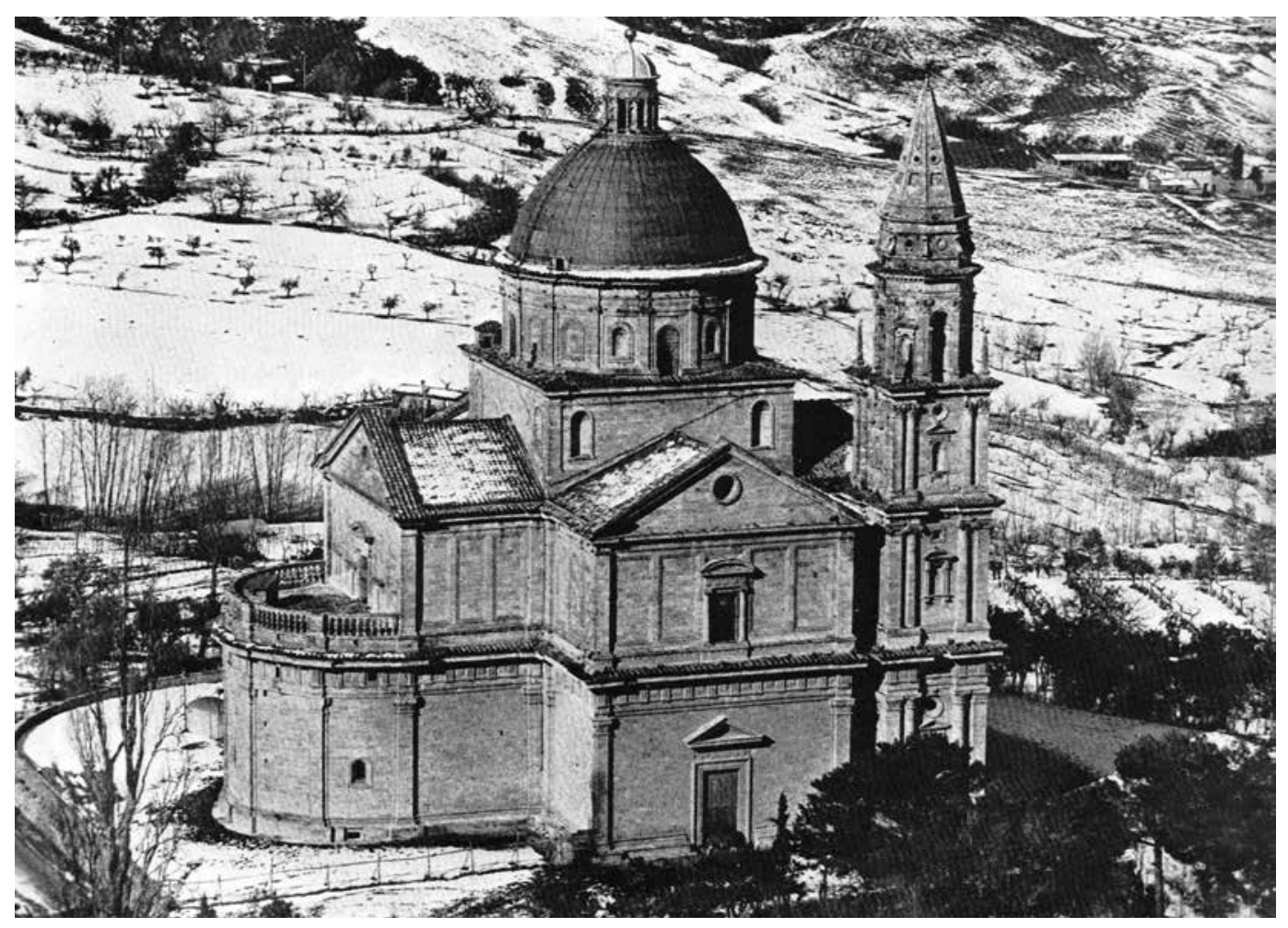

La imperiosa voluntad de entender el lugar como vestíbulo del proyecto puede estar motivada, por un lado, por la urgente necesidad de oponer una barrera cultural a la tendencia generaliz da a catapultar objetos autorferenciales hacia diversas partes del globo. Sin embargo, este hecho no nos debe hacer olvidar que, en arquitectura, el sentido que deriva de la representación de la función civil y también del hecho de construir es, en gran medida, independiente de las connotaciones de lugar, por lo que, en mas de un caso, la arquitectura opone al lugar una cierta resistencia. Por el contrario, si la realidad concreta de los lugares se sustituye por la indeterminación de los paisajes metafóricos, surge el riesgo de que se lleven a cabo operaciones fraudulentas en las que el escenario venga utilizado para legitimar fantasías plásticas que poco tienen que ver con la naturaleza de los asentamientos.

En cualquier caso, es un hecho que cada arquitectura, construida por fuerza -y por suerte- de cosas, debe hacer referencia a un lugar concreto, a un territorio. Incluso cuando el lugar se manifiesta af́́sico y carente de particulares sugerencias para el proyecto. Y también en aquellos casos en los que la obra es fruto de una elaboración en términos abstractos, en cuanto dotando de un nuevo carácter al mismo23. En otros casos nos encontraremos frente a una relación "por contraste", como sucede frecuentemente en la convivencia de villas de matriz clasicita con jardinerís naturalistas/romántices donde es

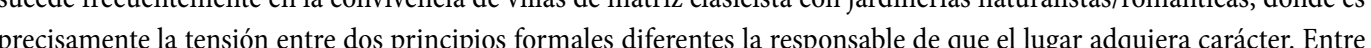
los ejemplos pardi néticos por Antos d Sangllo il por la autoridad de la tratadística se posa en un contexto de campos cultivados y de bosques24.

23 Potencia de la arquitectura: entret 24 En este caso ayuda también la ub

significativas con el paisaje circundante. 


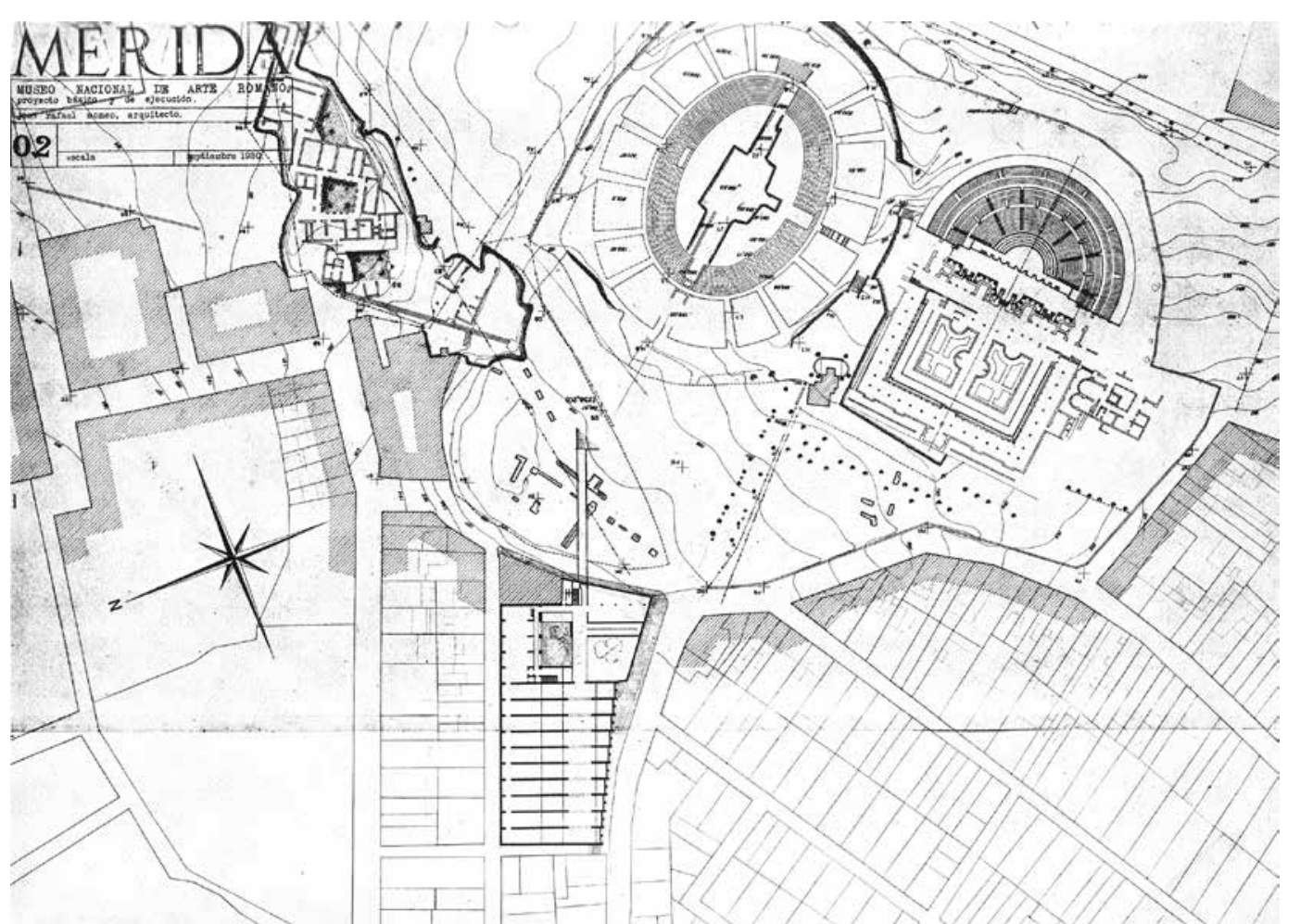

Poética/as del espacio: paradigmas ibéricos

En 1981 Pierluigi Nicolin resaltaba en la revista Lotus, en su comentario a tres proyectos de Álvaro Siza para el barrio del Kreuzberg en Berlín redactados en el marco del programa de la IBA, el valor específico que el arquitecto portugués atribuye al concepto de manzana, entendida ésta no como elemento serial de una estructura urbana con connotaciones generalizables, sho
actuar; y y continuación añadía:

«If we were to describe the effects of this particular sensibility towards topography we should have to focus on Sizás attention to the phinary, pre-linguistic elemments of urban construction, such as the division of property (with boundary walls and blind walls), heterogen ily of use, co-presence of different types of object, layering of a history of occupation. Materials are used in a refined strategy, a subtle means to arrange the insertion of new buildings.,25 Nicolin ofrecía a continuación un elenco de sietes puntos que condensan, en forma de ábaco/recetario, las microestrategias empleadas por Siza para dar forma a sus edificios a partir de una trama germinativa que es resultado de una "no convencional" interpretación del lugarar. En efecto, si observamos la planta de la pequeña intervención (no

25 Pierluigi Nicolin, "Alvaro Siza: tre progetti per Kreuzberg / Alvaro Siza: three projects for Kreuzberg", in Lotus international, n. 32, 1981/

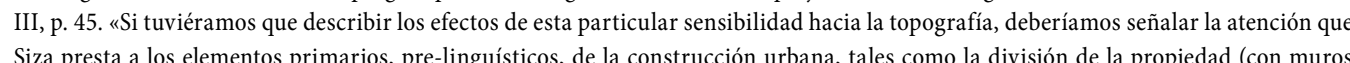
Siza presta a los elementos primarios, pre-linguísticos, de la construcción urbana, tales como la división de la propiedad (con muros
ciegos y medianeriass, la heterogeneidad de uso a convivencia de diferentes tipos de objetos o la superposición de las capas históricas de la ocupación. Los materiales se usan con una estrategia refinada, como un medio sutil para resolver la inserción de los nuevos edificios en el contexto., Traducción C. Dié,

26 Rafael Moneo, On Site, Time and Speciffcity in Architecture, op. cit. «[.... a pprender a escuchar el murmullo del lugar es una de las experiecias más necesarias en la educación del arquitecto.». Traducción C. Diez. realizada) en Kottbusserstraße, que ocupa parcialmente un vacío del frente del edificio hacia la calle, descubrimos que la urdimbre plan enca se adecua al desarrollo accidental del limite interior del solar, resolviendo la geometria de

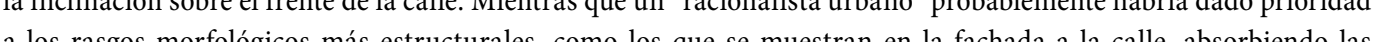

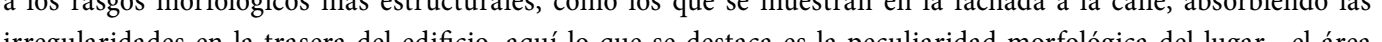

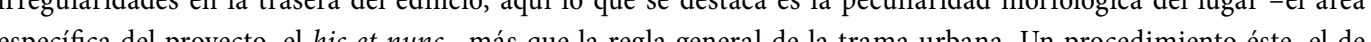

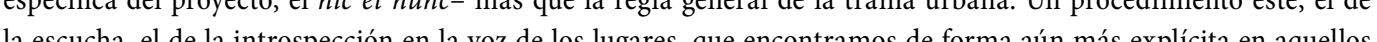

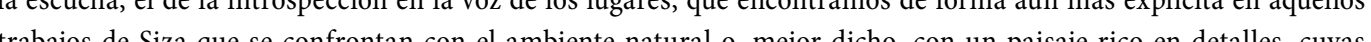
Irabajos de Sya huse chas trazas secte una pre-fundación del proyecto.

En cualquier caso, hay que decir que las obras de Siza, aunque demuestran ser sensibles a las sugerencias del lugar, mantienen sin embargo un aura de continuidad estilistica que se perpetua más allá de las ocasiones concretas. Un discurso similar podria hacerse tambièn, aunque en referencia a un registro expresivo completamente distinto, a

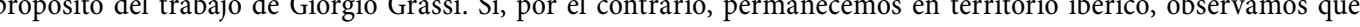
la investigación llevada a cabo por Rafael Moneo parece exponer en más de un caso una actitud más atrevida y desprejuiciada. Comparando el Ayuntamiento de Murcia con el Kursaal de San Sebastian -dos proyectos que el autor justifica con abundancia de argumentos analiticos elaborados como respuesta a las condiciones contextuales-, tenemos que reconocer que el binomio tema/lugar conduce a resultados arquitectónicos tan distintos unos de otros que difícilmente podremos adscribirlos a la mano de un mismo arquitecto. Tampoco hay que olvidar que, en ambos casos, el aspecto de la construcción, en términos de respuesta referida al lugar, está bien presente, hasta el punto de que se convierte en un aspecto distintivo de la obra.

Escribe Moneo: «[... to learn to listen to the murmur of the site is one of the most necessary experiences in an architectural

\section{¿A qué lugar perteneces?} Hagamos un pequeño experimento: situémonos frente a la planta de Mérida en la que aparece insertada la planta del Museo de Arte Romano proyectado por Rafael Moneo e imaginemos no conocer la obra construida. Con seguridad, deformación del lado sur que se adapta al quiebro de la calle el cambio en el frente que registra, como una especie de

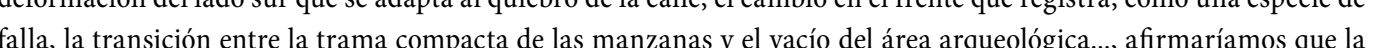
falla, la transición entre la trama compacta de las manzanas y el vacio del area arqueologica.... afirmariamos que la intervención parece estar cosida a medida a la topografia urbana. Imaginemos ahora transportar esta misma planta de un edifico de época remana, una de aquellas estructuras de servicio, como los horrea, en las que se aplicaba el de un edifico de época romana, una de aquellas estructuras de servicio, como los horrea, en las que se aplicaba el
sistema constructivo de muros en su versión simplificada y exenta de ennoblecimientos arquitectónicos. La conjetura sistema constructivo de muros en su version simplificada y exenta de ennoblecimientos arquitectonicos. La conjetura
se confirma plenamente al observar el edificio realizado, que explicita en sus alzados internos y en la narración constructiva una referencia casi literal a la arquitectura de la antigua Roma.

Diremos pues que el proyecto se dispone sobre dos lugares diferentes: uno real, el fragmento de la ciudad de Mérida al que se adapta dócilmente, y uno electivo, el territorio de la arquitectura antigua al que declara su voluntad de pertenecer en términos figurativos y constructivos. Que se trate de lugares de la historia o del espiritu poco importa; probablemente se trata de ambos. Y tampoco es cuestión de citar el ideal de la arquitectura renacentista o evocar las dislocaciones transtemporales (eexcavaciones en el tiempo?) llevadas a cabo por Louis Kahn. Aquí tiene más sentido confrontar, la propensión -por lo demás expresada por los representantes de la cultura académica- a situar en un contexto temporal más amplio el proyecto de arquitectura y el de lugar con la práctica que vincula el proyecto 27 Tal punto de vista aparece formulado en el ensayo de Rafael Moneo "Otra modernidad", publicado en Arquitectura y ciuddad, Madrid,
Ediciones del Circulo de Bellas Artes, 2007 . 


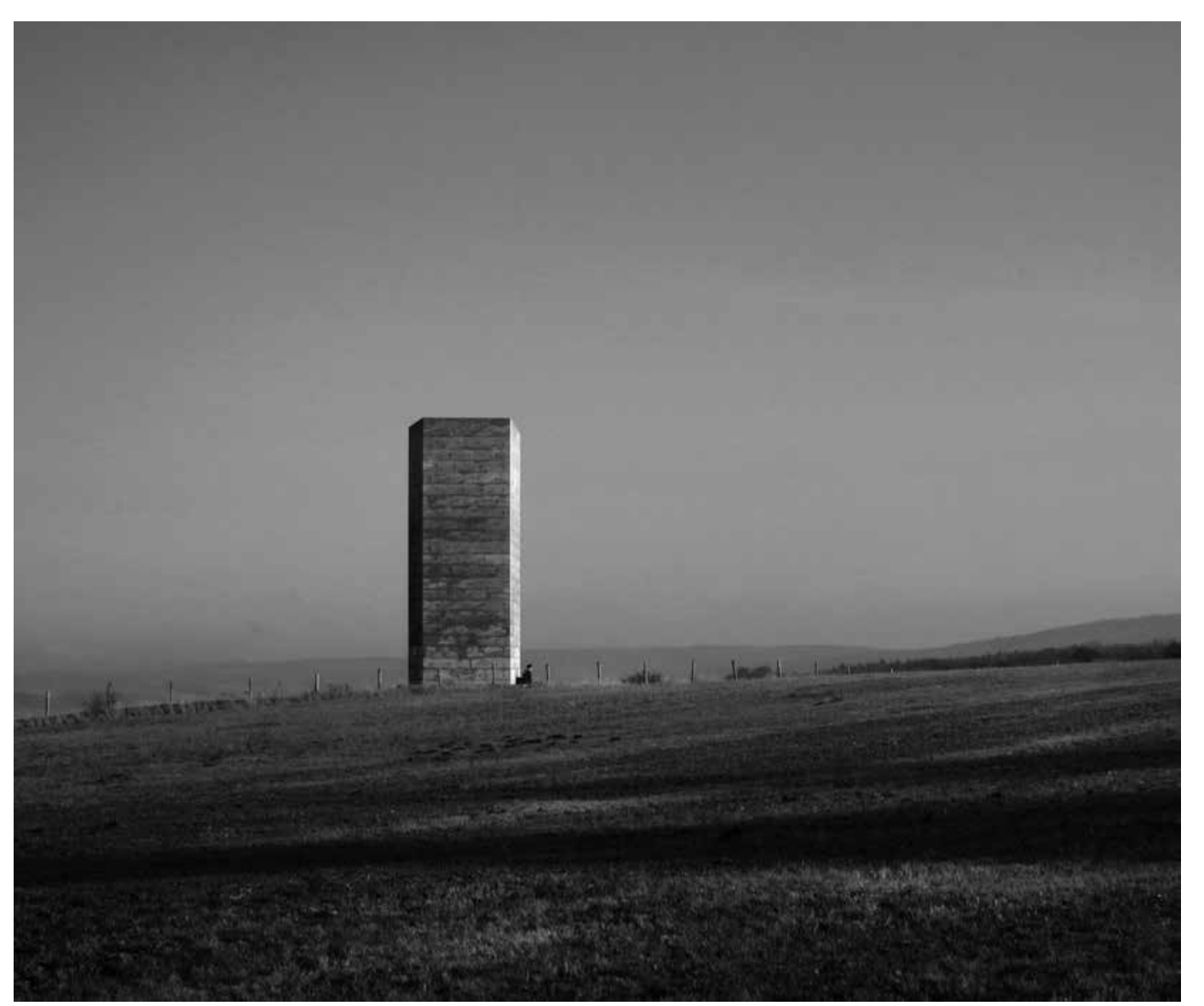

directamente con el presente y que pretende recuperar sin mediación alguna las vocaciones de los lugares y el espiritu del tiempo. En el primer caso, el riesgo que se corre es el de resultar "decadente", es decir, el de no conseguir expresar las formas del propio tiempo, debiendo tomar prestadas representaciones elaboradas en otros momentos culturales en los que el binomio lugar-tiempo tenía un valor distinto; en el segundo caso, la componente "barbárica", implícita en el action-design, si bien resulta eficaz en términos de impacto expresivo, comporta el riesgo de agotarse en su misma inmediatez, de no enraizarse en los contextos $y$, en definitiva, de no dejar huellas.

Identificar una tercera vía ${ }^{27}$ no resulta fácil, pero quizá ahí esté precisamente el desafí; si se me pregunta de qué lado estoy, si de Brunelleschi o de Alberti, responderé sin dudarlo: de Brunelleschi.

\section{Seducciones atmosféricas}

Entre las declinaciones teóricas del presente ha encontrado espacio una línea de investigación que podría resumirse bajo la denominación de "aproximación atmosférica", cuyas premisas filosóficas se fundamentan en autores como

28 Y también Herman Schmitz; un encuadre en el lámbito de la investigación en clave filosófica lo ofrece Tonino Grififero, Atmosferologia. Estetica degli spazzi emozionali, Editori Laterza, Roma-Bari, 2010; en el campo de la arquitectura, el argumento lo aborda, además de

Incluso sndo cierto que no faltan algunos ejemplos en los que el planeaneamiento ha contribuido a dejar una profunda huella en $\mathrm{l}$ corporeidad propia de una ciudad, como es
por Rem Koolhas en Delirious New York).
Gernot Bhöme o Jürgen Hasse; en el ámbito de la disciplina arquitectónica, una importante contribución procede de Peter Zumthor con su Atmósferas. Las cosas a mi alrededor (2003)28. La atención prestada a aquellas "semi-cosas" denominadas atmósferas coloca en primer plano las interacciones perceptivas entre sujeto y objeto y, por tanto, las

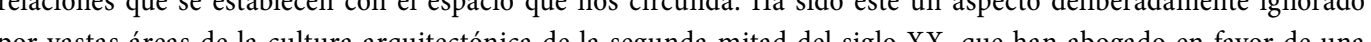

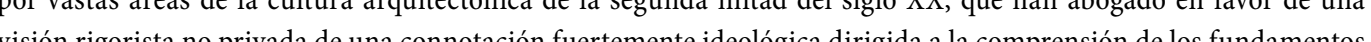

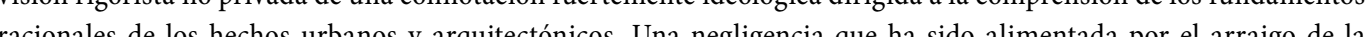
racionales de los hechos urbanos y arquitectoricos. Una neglgenta que ha sido allmentada por el arigo de la

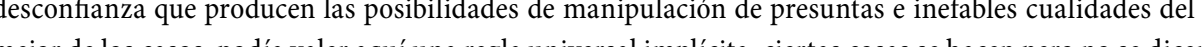

Con la perspectiva que dan los años puedo serenamente admitir que en aquel momento se llevó a cabo una amputación intelectual excesivamente drástica y que, con una vision retrospectiva, fue un error exorcizar las relaciones de naturaleza perspectiva y sensorial y a de las de la arquitectra (sibien yo prefiero hablar de cole sensuale, una práctica ampliamente frecuentada en el curso de los siglos). Que las ciudades - $y$ en un grado inferior los lugares- posean una carga atmosterica propia que repercute en sus habltantes y en los forasteros, en sentido positivo o negativo, es una experiencia demasiado comun como para no aceptarla como un hecho comprobado. En la mayoria de las ocasiones se trata más del resultado de un proceso lento de estratificación histórica mediante el cual se sedimentan formas, olores, sonidos, colores, rostros, etc., que de un proceso de planificacion pre-establecid ${ }^{29}$. Sin embargo, mientras que es posible analizar y describir expost la cualidad atmosferica de un lugar (me gustaria senalar aqui que quiza las mejores descripciones del mood de una ciudad son las que proceden de los escritores), es bien distinto controlar ex ante las repercusiones atmosterica de un proyecto, entre otras cosas porque no se puede -ni se debe- pretender gobernar las relaciones perceptivas de los usuarios.

En la práctica común el problema está en decidir si debemos afinarnos -y cómo podríamos hacerlo-con la entonación de un determinado lugar, es decir, en qué medida debemos sintonizarnos con su longitud de onda atmosférica. Sabiendo que, tanto si se trata de un edificio o de un conjunto urbano, el provecto arquitectónico es, inevitablemente, un proyecto de lugar. Y sabiendo también que incluso la sola presencia de un único objeto perfecto, completo en sí mismo, en un determinado lugar, lo hemos dicho ya, lo altera.

Entonces, iquiere esto decir que el proyecto destinado a un ambiente natural debe asumir una especie de cauta neutralidad y evitar expresar su propia emocionalidad potencial? Si aceptamos la tesis formulada por Griffero, que sugiere «di attribuire non a tutti i sentimenti ma sicuramente a quelli atmosferici, spaziali in senso non metaforico, unesistenza esterna e semi-oggettivaw 30 , se perfilla ante nosotros un campo de accion prometedor, incluso para quien, como quien escribe, siempre ha buscado en el objeto arquitectonico sus cualidades propias, evitando proyectar en él percepciones subjetivas. La actitud de cautela de la que me consideraba representante se basaba en la convicción de que el constructor debería intentar trabajar con las cualidades propias y primeras del objeto arquitectonico, teniendo en "de atta inercia atmosterica que un exterior o un interior parecen testimoniar. No se trata de un verdadero proyecto cle atmosteras, sino en realidad de $u$ na especie de pre-condicion (pre-sentimiento), grabada en el cuerpo mismo de la (a) stait danim fi es posible concebir el espacio cremente

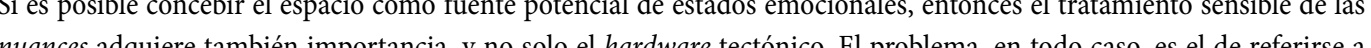
nuances adquiere tambien mportancia, y no solo el hardwar teetonico. El problema, en todo caso, es el de referirse a diapasones lse en sentido metafórico), una existencia externa y semi-objetiva., Traducción C. Diez 


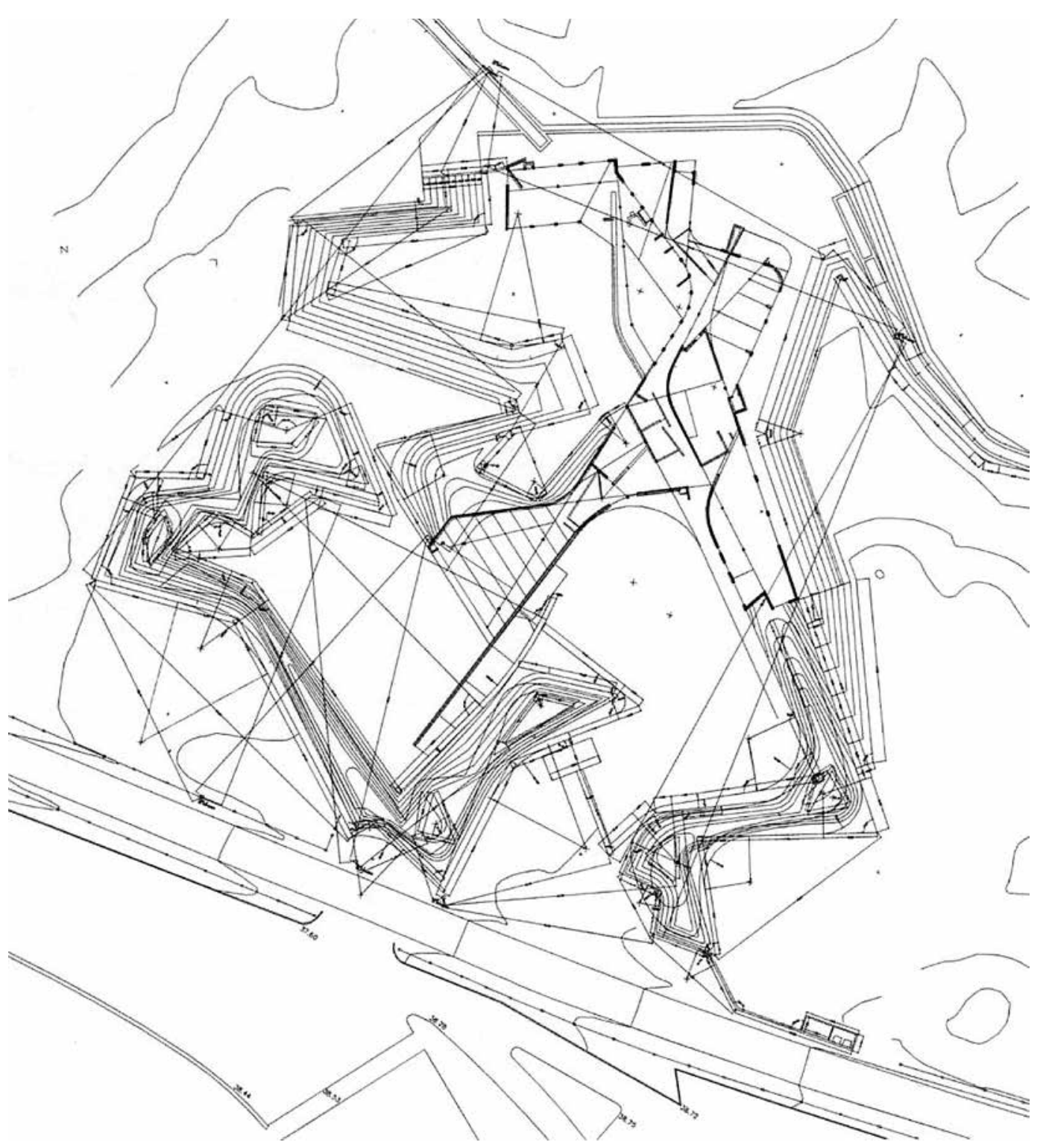

arquitectura queda reducida a evento o forma de espectacularización impositiva. Y conscientes, en cualquier caso, de que la arquitectura, aunque no está exenta de una componente teatral escenográfica, no debe confundirse con una instalación.

\section{Sobrecargas topológicas}

Sucede a menudo que nos encontramos en las páginas de las revistas y en las mesas de las universidades proyectos de arquitectura, edificios o lugares públicos cuya matriz formal se deriva de la lectura analítica de los rasgos morfológicos del lugar. En particular, si se pregunta a un estudiante: "por qué propones esto?", la mayoría de las veces alegara argumentos que parten de interpretaciones, más o menos fundadas, de la topografía, de las estratificaciones históricas, de las exigencias locales, etc. Las respuestas, en todos los casos, aparecerán sólidamente armadas con exquisitas y elocuentes justificaciones acerca de las decisiones tomadas, que se presentarán como resultado de una manipulación de las presuntas vocaciones contextuales.
Deducir de la especifica área de intervención más de lo que ésta pueda ofrecer, como si la génesis de la forma dependiese exclusivamente de tal relacion, dejando en un segundo plano los estatutos propios del edificio, sus

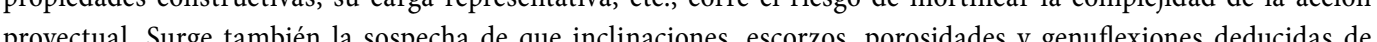

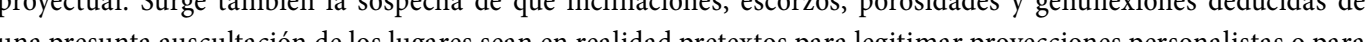
ofrecer cor ciecer con chis cor sin prestar atención a los lares de la historia, iel potencial de lo barbáricol

Volver a pensar que una arquitectura deba oponer una cierta resistencia al lugar puede constituir una premisa teórica diálogo capaz de hacer que la abstracción del esquema propositivo pueda acoger la especificidad y los colores de aquel específico contexto -variantes morfológicas, orientación, paisaje, materias- en un proceso de adaptación que confiere al hecho arquitectónico un carácter propio derivado de la adecuación al entorno.

En fin, hay que decir también que, si el intervenir en la Plaza de Murcia o en otro lugar específico implica realizar una interpretación sofisticada de la trama de relaciones sedimentadas en el tiempo, entonces, en la mayor parte de las
ocasiones, proyectar en aquel determinado lugar significaría dar forma a lugares ausentes, silenciosos o fáścicos. Ésta

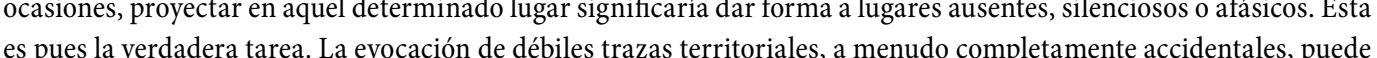
revelarse como síntoma de una sustancial falta de ideas.

Se perfila pues la oportunidad de reconstruir una ética de los lugares en oposición a aquellas visiones proyectuales que pretenden obtener provecho de la naturaleza de las cosas para dar fundamento a morfemas personalistas. La invitación, aparentemente provocadora: “'VOlvamos a ser topógrafos!", puede revelarse como una práctica saludable. Significa, sobre todo, prestar una atenta consideración a las condiciones materiales que acompañan a la inserción de un edificio en un lugar: el control de la escala, el adecuado anclaje con el suelo, el respeto al desarrollo planialtimétrico, etc., sin olvidar nunca que tan saludable como estas actitudes es, parafraseando a Loos, "volver a ser albañiles, a ser posible sabiendo latín", conscientes de que se puede responder a las preguntas del lugar mediante el

\section{Intentos de reunificación urbana}

Entre la casa y la ciudde En la práctica habitual del urbanismo, en buena parte heredero de las teorías del Movimiento Moderno -en especial en lo referente a la postulación racionalista de distinción entre los objetos que componen el espacio destinado a vivienda-, ha triunfado la separación de los volúmenes edificados. Frente a esta actitud no faltan en el repertorio europeo reciente intentos de insistir en el concepto de contigüidad y en la interrelación entre el edificio y el sistema de espacios públicos, con el fin de ratificar la pertenencia a la fábrica urbana de los lugares destinados a vivienda ${ }^{32}$. Se puede constatar, casi por descontado, que las operaciones de cosido y recomposición de la ciudad físicamente fragmentada encuentran un terreno fértil y predispuesto allí donde la urdimbre urbana -se podría decir del "plan urbanístico"- se reconoce aún como tejido bien definido y vital, como es el caso de Barcelona; en contextos con tejidos urbanos más informes este tipo de actuación se revela, en efecto, ardua. Lo cual no impide que, considerando una perspectiva temporal más dilatada, y suponiendo que las transformaciones estarán orientadas más a la reconstrucción que a las nuevas expansiones, al menos aqui en Europa, tales estrategias puedan encontrar un extenso campo de aplicación.

Lo que parece vincular esta variedad de soluciones, dictadas en función de contextos y ocasiones diversas, es el reto compartido de resolver la oposición, claramente ejemplificada en la manzana decimonónica, entre el frente a la calle/ espacio público y las zonas interiores/espacio más privado. Todas ellas exploran dispositivos espaciales capaces de

32 Ver, en referencia a este tema: Bruno Melotto, Simona Orsina Pierini, Housing Primer. Le forme della residenza nella città contemporanea,

Maggiol Edittore, Santarcangelo di Romagna, 2012; la observacion ani
cargo del autor de este articiculo, titulado "Invarianze e perturbazioni ' 
Observaciones elementales
sobreellugar

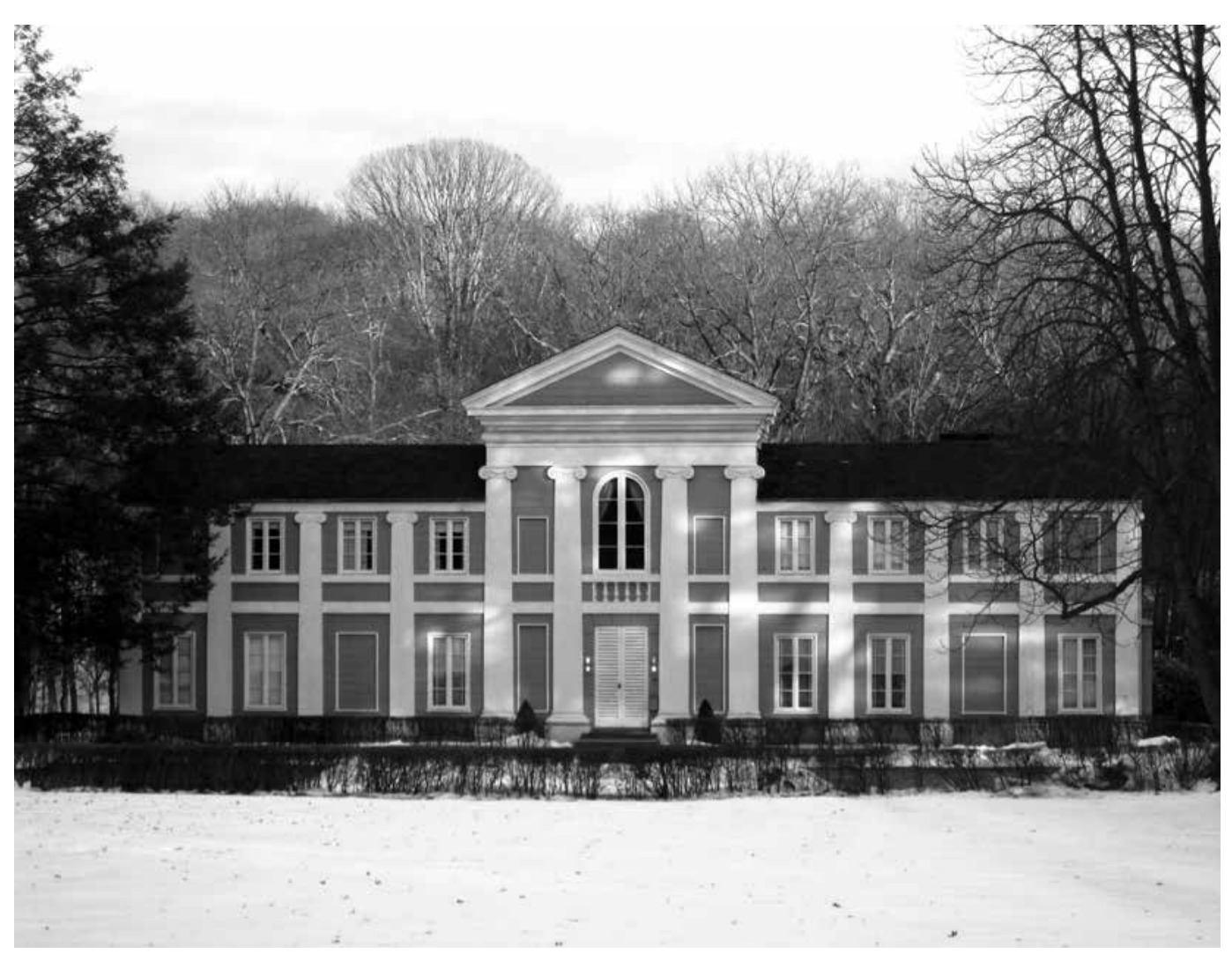

una figura recurrente que aflora en los campos ingleses, en las llanuras rusas y entre los campos de algodón de Luisiana a pesar de que algunas veces lo que se ha heredado es solo el lenguaje arquitectónico y no de la estructura.

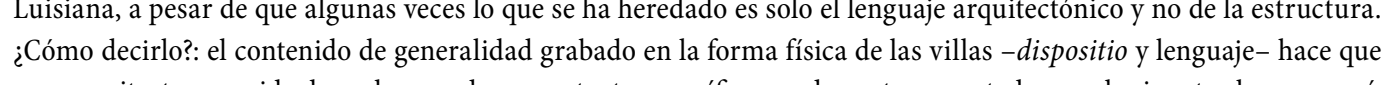
¿Cómo decirlo?? el contenido de generalidad grabado en la forma fisica de las villas - dispositio y lenguaje- hace que
una arquitectura nacida de un lugar y de un contexto específico pueda ser transportada a cualquier otro lugar; eso sí, manteniendo un contenido evocativo análogo. Una especie de emancipación posible gracias a la fisonomía dual de las villas palladianas. Un destino éste que parece valer para todas las grandes arquitecturas: concebidas para responder a una condición de hic et nunc y, al mismo tiempo, ciudadanas del mundo. Vale la pena señalar aquí la diferencia entre una arquitectura apátrida y una arquitectura cosmopolita.

\section{Lugares en el tiempo}

«...l’affidarsi al luogo, a ciò che più lentamente muta.,.33 $\mathrm{A}$ pesar de que la rapidez y virulencia de las transformaciones operadas sobre el territorio durante el último siglo han sometido a una dura prueba el concepto de permanencia relativa del valor de los lugares, caracterizados por la continuidad secular, todavía podemos reconocer en ellos la existencia de una componente inercial, cuando menos si se acepta que la escena parece ser más estable que el mutable aparecer de personajes y de acciones. Sin embargo, ésta tambièn cambia con mayor 0 menor lentitud. Es dificil tener esto en cuenta project, cuyo alcance parece agotarse en el breve tiempo del consumo rápido. Quien diseña un jardin, o un parque, 


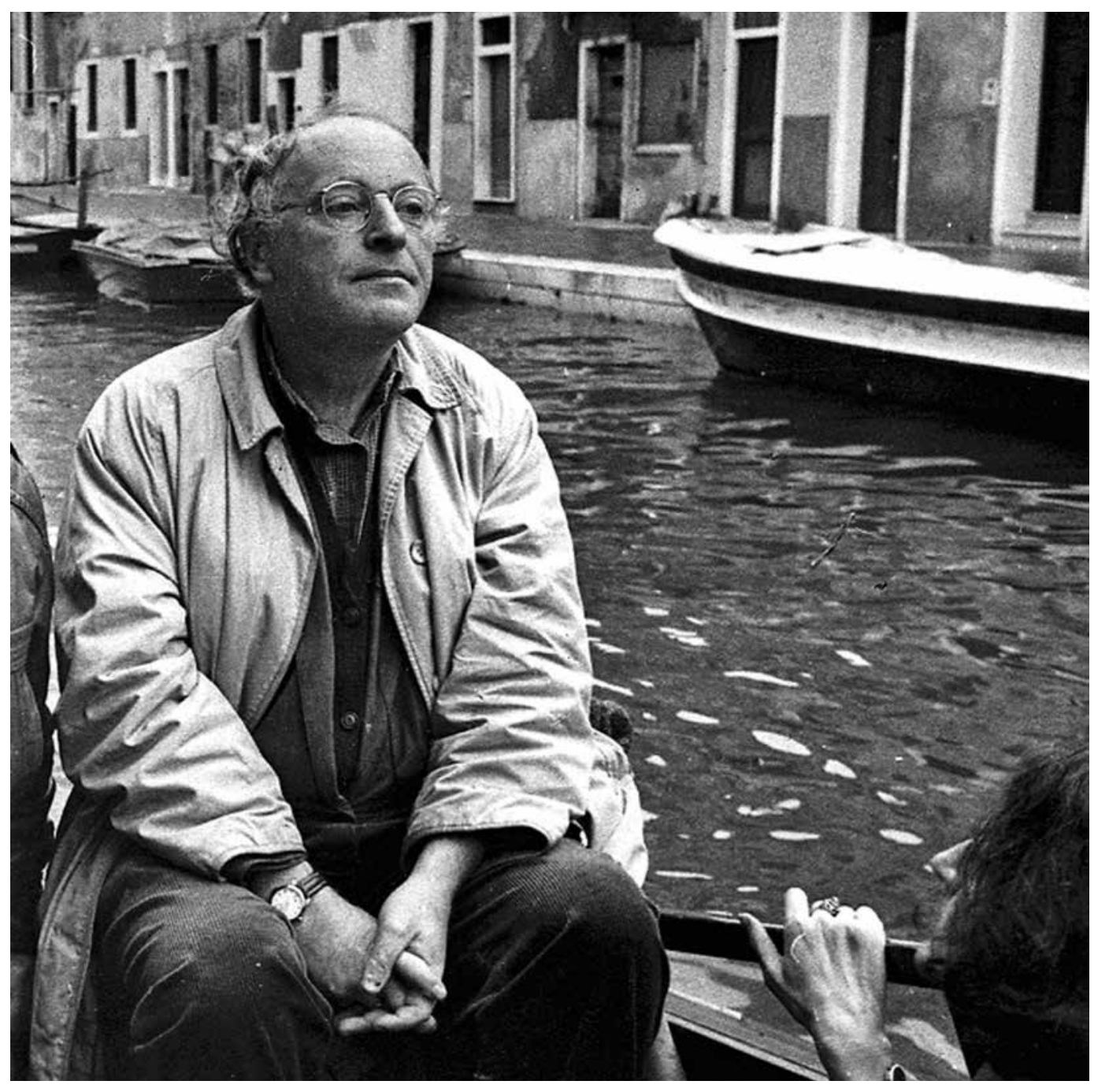

debe saber "ver" con antelación el efecto de lo que ha sido su crecimiento vegetal en el curso de los sucesivos decenios, exceptuando obviamente aquellas intervenciones posteriores que han conllevado transformaciones no previsibles saber llevar a cabo esta tarea competentemente es una de las claves esenciales del oficio: un work in progress por definición. Más difícil resulta imaginar las mutaciones temporales de los lugares en el ámbito arqutiectónico-urbano, no solo por lo imprevisible de las variaciones futuras, sino por causa de la naturaleza artificial, menos vulnerable o, si se quiere, más resistente respecto al devenir, a las transformaciones en el tiempo. Un edificio, por ejemplo, contribuyea definir el carácter de una calle o de una plaza en una condición de sustancial estabilidad: pueden cambiar las relaciones con su entorno, puede envejecer y corromperse, pero su identidad sigue siendo la misma. Esta doble condición -la de ser al mismo tiempo inevitable representación del presente y, a la vez, participar en la "construcción lenta"34 de espacio habitado - debería implicar una actitud que permitiera avanzar un cierto pronóstico, independientemente de la esperanza de vida de un edificio. Respetar las condiciones permanentes de las que habla Auguste Perret y no solo las momentáneos, que también hay que cumplir, puede ser un primer consejo saludable. Este discurso quizá no valga para la gran arquitectura, en grado de irradiar el lugar, o de dominarlo incluso en una situación de espléndido aislamiento Para la arquitectura en prosa, cuya convivencia con el espacio de lo cotidiano es condición imprescindible de existencia, el entender dónde estamos, reprimiendo las ansias de protagonismo, puede ser una buena norma para encontrar en la discreta dinámica de los lugares.

Al comienzo de los años ochenta se me presentól la ocasión de construir un hotel en el centro de una ciudad de provincia: el resultado fue modesto -también por causa de algunas visitudes de diferente nad aleza, no solo por la impericia del arquitecto-, pero estaba soldannte construldo y reflejaba, en sumater local de una ciudad que se habia tradicionalmente decantado por ofrecer, frente a la plenitud de los diferentes estilos históricos, una version mas contaminada, o quiza menos ostentosa, en algunas ocasiones casi contenida, en otras podriamos decir que hibridada. Asi que me dije: "Bueno, no es una gran cosa, pero con el tiempo podría llegar a

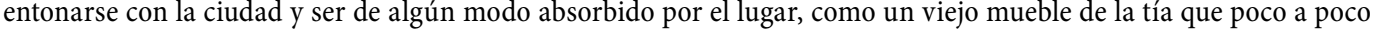
entra a formar parte del mobiliario de la casa, como si siempre hubiera estado alli." $Y$ así ha sucedido, mientras que en otros edificios cuyo lenguaje era más rotundo, manifiestan ahora su condición de objetos ajenos al contexto. Queda, en cualquier caso, la tremenda responsabilidad de desarrollar el proyecto de arquitectura poniéndolo en

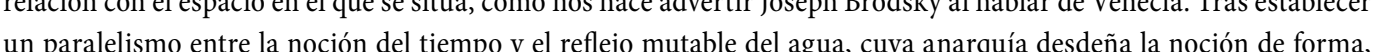
añade:

ut is as thought space, cognizant here more than anyplace else of its inferiority to time, answers it with the only property time doesn't possess: with beauty. 35

Es verdad, Venecia es única, pero el deseo de oponernos al paso del tiempo es de todos, y puede que, en el proyecto que se convierte en obra, no exista nada más que esa batalla aunque perdida contra el tiempo. Contra el tiempo huidizo de la cotidianidad y contra aquel otro tiempo inminente que atraviesa nuestra existencia. ¿Qué otra cosa podemos hacer sino recurrir a la estrategia -jay, qué perecedera! - de enfrentarnos a él en un ámbito fuera de su jurisdicción, buscando la forma en el espacio y en la materia?

35 Joseph Brodsky, Watermark: An Essay on Venice, Penguin Classics, London, 2013, p. 22. Edición en castellano: Joseph Brodsky, Marca
de agua, Ediciones Siruela, Madrid, 2005, 2008, «Es como siel espacio más consciente aquicion se su inferioridad frente al tiempo, le respondiera con la única propiedad que éste no posee: con la belleza., p. p. 40 .

Massimo Fortis Nace en Novara en 1944 y se gradú en Arquitectura en el Politécnico de Milán en 1969 . Fue colaborador de Aldo Rossi, Giorgio Grassi y Antonio Monestiroli al inicio de los años setenta. Desde 1974 enseña Composición Arquitectónica. Es Catedrático en el Departamento de Arquitectura y Urbanismo del Politécnico de Milán, donde fue Director del Departamento de Ar-

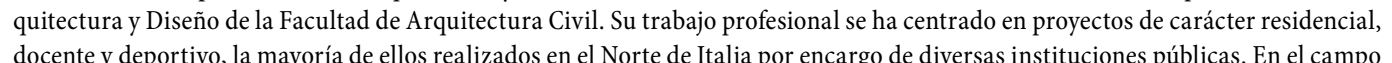

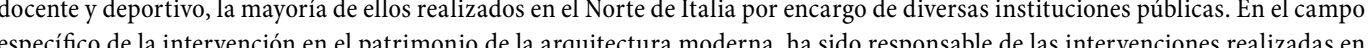
específico de la intervención en el patrimonio de la arquitectura moderna, ha sido responsabble de las intervenciones realizadas en
el Edificio “D” del conjunto de Monte Amiata, de Aldo Rossi, asi como del provecto de restauración y rehabilitación funcional del Instituto Marchiondi, de Vittoriano Viganò. 


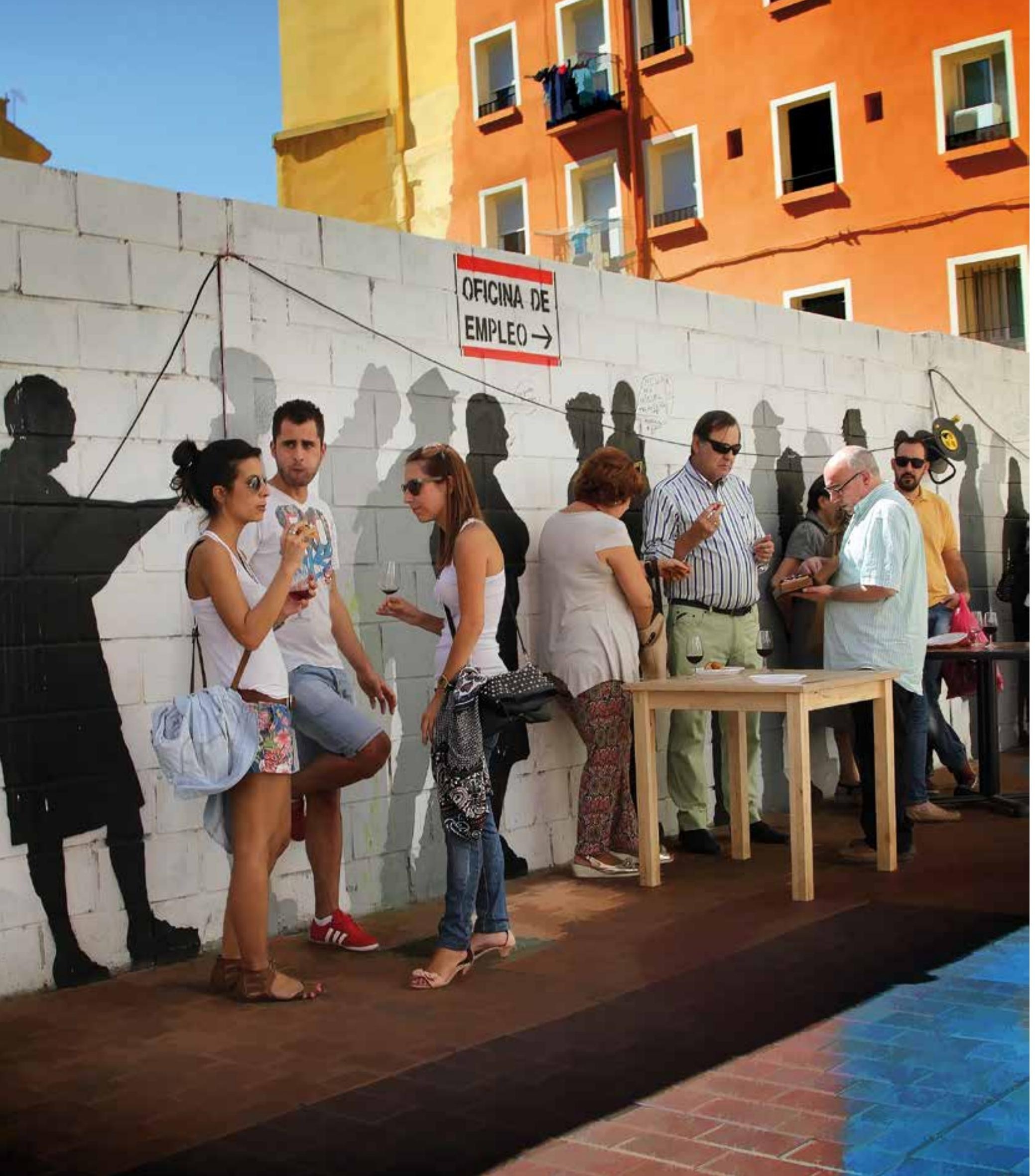




\section{La regeneración urbana integral como concepto que desborda lo urbanístico}

Resulta sorprendente comprobar la lentitud con la que los legisladores estatal y autonómicos están afrontando la regulación de la intervención sobre la ciudad y la edificación existentes. Desde los conceptos mismos de rehabilitación urbana o regeneración urbana integral, que desbordan ampliamente conceptos urbanisticos con los que pudieran pretender compararse, como el de actuación urbanística integrada, hasta la regulación de aspectos instrumentos de tales procesos, o de los de rehabilitación edificatoria, atinentes al aprovechamiento urbanístico, la ocupación de elementos comunes o privativos o la de espacios libres de titularidad pública.

El amplio ordenamiento urbanístico, legal y reglamentario, desarrollado en una miríada de instrumentos de plaeamiento, ha venido dedicando una atención marginal a las cuestiones atinentes a la intervención sobre la ciuda difrièndola a planes especiales escasamente regulados, relativamente flexibles en parámetros de reservas y aprove-

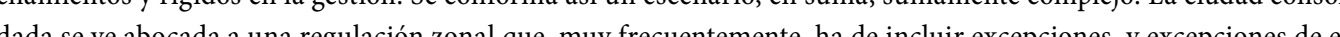
dada se ve aboada a na regulación zonal que, muy frecuenter

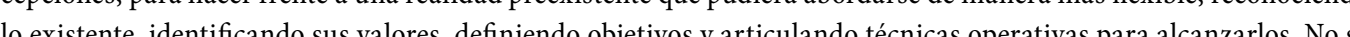
lo exiras. No hilitacie o arquitectónica, entre otras.

El concepto mismo de regeneración urbana es reciente. Dejando al margen las volatilies, instrumentales e imprecisas referencias que al mismo vienen realizando los planes estatales de fomento de la rehabilitacion (1), 0 las norm fagmentarias aprobadas entre 2009 y 2012 (2), desde una perspectiva sustantiva se ha incorporado a nuestro ordenamiento en fechas recientes. Ciertamente, existian elaboraciones y experiencias previas muy notables (3), pero se incorporaron al ordenamiento juridico y, en gran medida, quedaron soterradas tras el urbanismo expansivo de más reciente burbuja inmobiliaria. Lo más relevante, a priori, del proceso de construcción del concepto de regeneración urbana es precisamente su afán integrador, el propósito de incluir los múltiples intereses y faces que presenta ciudad y de actuar con metodologías renovadas, que incluyan a la población actual y se basen procesos ampliamente participativos e inclusivos. La regeneración, rehabilitación o reciclaje urbanos, desde esta perspectiva, es tan compleja y tan rica como el propio tejido urbano sobre el que se trata de actuar. Como ha afirmado Rubio de Val (4) "las diversas dimensiones -medioambientales, económicas, sociales y culturales- de la vida urbana están interrelacionadas yeléxit del desarrollo urbano solo puede lograrse a través de un enfoque integrado. Las medidas que atañen a la renovación física de las ciudades deben combinarse con medidas que promuevan la educación, el desarrollo económico, la inclusión social y la protección del medio ambiente. Asimismo, el desarrollo de una sólida cooperación entre los ciudadanos locales, la sociedad civil, la economia local y los diversos estamentos gubernamentales constituye un requisito previo", No ha sido hasta la Ley 8/2013, de 26 de junio, de rehabilitación, regeneración y renovación urbanas (L3R), cuando se ha incorporado a nuestro ordenamiento, superando algún precedente inmediato anterior mucho más confuso, concepto de actuación de regeneración o renovación urbanas integradas (5). Si “las actuaciones sobre el medio urbano se definen como aquéllas que tienen por objeto realizar obras de rehabilitación edificatoria, cuando existan situaciones de insuficiencia o degradación de los requisitos básicos de funcionalidad, seguridad y habitabilidad de las edificaciones, y de regeneración y renovación urbanas, cuando afecten, tanto a edificios, como a teid dos urbanos, pudiendo llegar a incluir obras de nueva edificación en sustitución de edificios previamente demolidos", "las actuaciones de regeneración cluir obras de nueva edificación en sustitución de edificios previamente demolidos", "las actuaciones de regeneración
renovación urbanas tendrás, además, carácter integrado cuando articulen medidas sociales, ambientales y económicas renovación urbanas tendrás, además, carácter integrado cuando articulen medidas sociales, ambientales y economicas se ha afrontado el régimen jurídico de la rehabilitación, regeneración y renovación urbanas.

El histórico abandono de la ciudad consolidada a las fuerzas del mercado ha provocado el deterioro de los cascos his tóricos y la falta de renovación generacional de sus habitantes. En la ciudad histórica existen viviendas con programa aboletos o inadecuados, en edificios con redes $y$ servicios deteriorados o inservibles, sin ascensores, en entornos urbanos con su urbanización envejecida y equipamientos limitados o que no responden a las necesidades de una población que ha cambiado sus características por el transcurso del tiempo. Además, la población residente en dichos entornos suele estar incluida en grupos en riesgo de exclusión y, frecuentemente, es de avanzada edad y escasos recursos. En municipios en situación de regresión demográfica la situación todavía es más grave pues, simplemente, los cascos históricos están vacíos $y$ un gran número de vivieda abu

En el tejido urbano existente nos encontramos ante problemas complejos que requieren soluciones complejas, que han de diseñarse e implementarse integralmente. La necesidad de un conjunto renovado de técnicas de ordenación y gestión se confirma cada vez que se afronta con ánimo regenerador el estudio de la ciudad existente. El estudio del barrio de San Pablo objeto de esta obra y el intento de programar su regeneración integrada permiten alcanzar también esa misma conclusión. Transferencias de aprovechamientos en unidad discontinua, intervención sobre la edificación, alteración de los elementos comunes de edificios en propiedad horizontal, generación de espacios privados de uso público, intervención sobre la ocupación de manzanas y conexión entre las edificaciones que las conforman generando nuevas relaciones jurídicas, y, ocasionalmente, ocupación de dominio público para viabilizar actuaciones de rehabilitación, colaboración público-privada para la financiación y ejecución de concretas actuaciones, entre otras cuestiones, confluyen de manera combinada en el barrio de San Pablo.

II. Un déficit regulatorio evidente sobre la ciudad existente

No esta de mass, antes de examinar sucintamente las técnicas de intervención que al servicio de la rehabilitación y la regeneración urbana incorpora la más reciente normativa, realizar alguna referencia a las magras previsiones de la normativa urbanistica desde la triple perspectiva, ya clásica, que la estructura, la de ordenación, la de gestión y la de disciplina. La ordenación del suelo urbano en el planeamiento general, dejando al margen las determinaciones impuestas por la normativa de patrimonio historicico o cultural, ha de incluir el señalamiento de aquellas áreas en las que se prevean operaciones de reforma interior que requieran un plan especial, fijando explíitamente los objetivos de la reforma y, como mínimo, los usos e intensidades resultantes.

Los planes especiales, en todo caso, además desarrollar la reforma interior en los supuestos previstos en el planeamiento general, o aun en otros no previstos en el mismo, podrán también tener por objeto la protección, conservación miento gental, a ann en otros no previstos en el mismo, podran tambièn tener por objetola protectón, conservación y mejra del medo suletoria mativa estatal hy supletra la aprobacion de noras especiales para la catalogacion, cos tras a

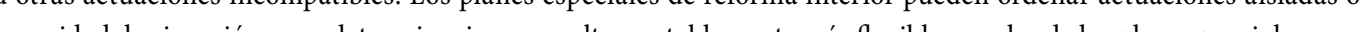
en unidad de jectán y sas deter a

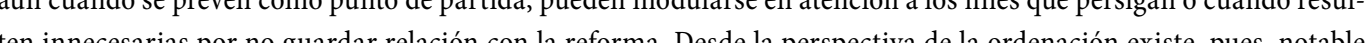
ten incesarias por no guardar

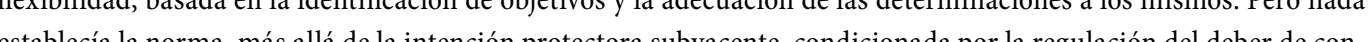
establecia la norma, mas alla de la intencion protectora sabyacente, condicionada por la regulación del deber de conservacion h ha ha par a

Flexibilizada la ordenación, la gestión mediante unidades de ejecución se desarrollaba en términos prácticamente idénticos a los previstos para la gestión de la expansión urbana. Ciertamente, la reparcelación, cuando resultase precisa, podía desarrollarse en su modalidad de reparcelación economica o mixta o incluso, cuando era voluntaria, en unidad discontinua. Pero el procedimiento en sí, una vez determinado el sistema de actuación, se regía por las reglas ordinariamente aplicables. Como única alternativa aparecen las actuaciones aisladas, sin necesidad de unidad de ejecución, que comportan ordinariamente la expropiación forzosa de los terrenos precisos para ejecutar el planeamiento. Las cesiones obligatorias derivadas de las alineaciones fijadas, por ejemplo, expresamente reguladas en normas autonómicas, plantearon siempre el problema de su delimitación de la vinculación singular con las correspondientes 

ialmente en actuaciones aisladas, podía tener sobre los espacios públicos o privados preexistentes. Se regularon, eso sí, los derechos de realojo y retorno de los habitantes afectados por la actuación en determinados supuestos.

No es de extrañar, en ese contexto, que algunos planeamientos incorporasen técnicas como las transferencias de aprovechamiento urbanístico, potenciasen las reparcelaciones económicas como instrumento operativo o previesen el pago de expropiaciones mediante aprovechamiento (voluntario en el caso de la expropiación forzosa, no en los supuestos de ocupación directa). Sin embargo, la falta de una cobertura legal explícita y adecuada hacía que estos procedimientos resultasen inseguros cuando no eran aceptados por los afectados y suscitasen, por ello, una litigiosidad que, a la postre, acababa bloqueando o haciendo inviables las actuaciones con demoledores efectos sobre la ciudad o la trama urbana existente. El bloqueo de actuaciones de regeneración o renovación urbanas resultante de la inseguridad jurídica, frecuentemente derivado de la tensión entre normativa cultural protectora y normativa y práctica urbanísticas permisivas, es una de las causas que generan la pérdida de patrimonio edificado y la degradación urbanística, edificatoria y social de entornos urbanos.

III. Bases del nuevo régimen jurídico integral de la rehabilitación urbana

La L3R distingue los supuestos en los que ha de alterarse la ordenación urbanística de aquellos otros en que no ocurra sí. Para los primeros garan urbanas que impliquen la necesidad de alterar la ordenacion urbanistica vigente, observaran los trámites procedimentales requeridos por la legislacion aplicable para realizar la correspondiente modificacion", si bien, con proposito flexbilizador y agilizador, "tal legislación podrá prever que determinados programas u otros instrumentos de ordenación aprueben de forma simultanea a aquella modificacion, o independientemente de ella, por los procedimientos de aproba-. ción de las normas reglamentarias, con los mismos efectos que tendrían los propios planes de ordenación urbanistica". Para los segundos establece que "las actuaciones que no requieran la alteración de la ordenación urbanistica vigent precisarán la delimitación y aprobación de un ámbito de actuación conjunta, que podrá ser continuo o discontinuo, o la identificación de la actuación aislada que corresponda, a propuesta de los sujetos mencionados en el artículo anterior y a elección del Ayuntamiento" (art. 10.1 L3R).

El acuerdo de delimitación, preciso también en ambos supuestos, resulta clave para el proceso de gestión e incluirá el avance de equidistribución y el plan de realojo temporal y definitivo, y de retorno a que dé lugar, en su caso (art. avance de equidstibuc

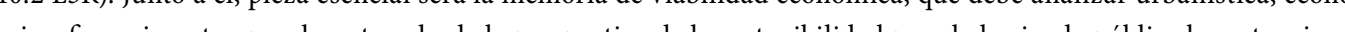

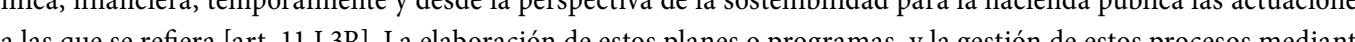
a

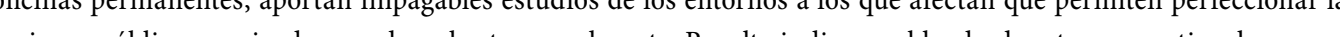
列

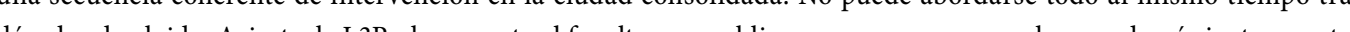

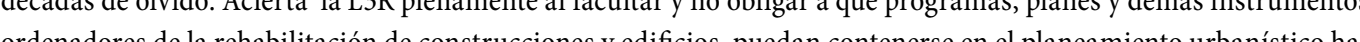
bil reglamentarias sumamente más ágil que los procedimientos de aprobación de planeamiento urbanistico.

Para gestionar la ejecución de las actuaciones de rehabilitación edificatoria y las de regeneración y renovación urbanas ta administración podrà utilizar todas las modalidades de gestion directa e indirecta admitidas por la legislación de regimen juridico, de contratacion de las Administraciones publicas, de régimen local y de ordenacion territorial y urbanistica" (art. 13.1 L3R). En cualesquiera supuestos de iniciativa publica o en los de ejecución subsidiaria cabra pues gestión directa o indirecta, si bien el art. $14.3 \mathrm{~L} 3 \mathrm{R}$ regula especialmente ésta última imponiendo los concursos públicos para la ejecución de estas actuaciones, abiertos a cualquier persona interesada, sin preferencia para los propietarios. Podrán suscribirse convenios de colaboración entre las Administraciones Públicas y las entidades públicas adscritas dependientes de las mismas, que tengan como objeto, entre otros, conceder la ejecución a un Consorcio previamente

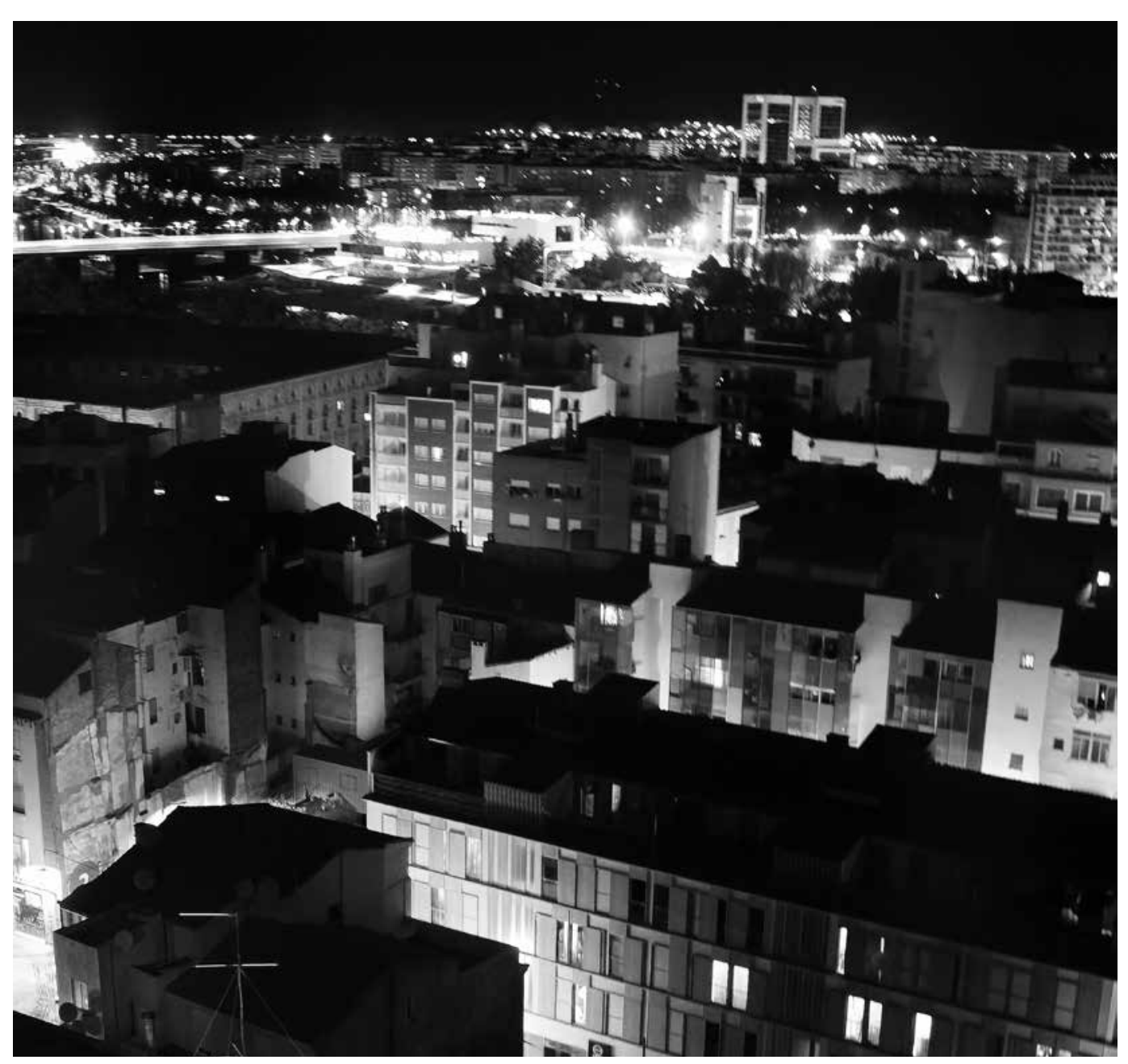

creado, 0 a una sociedad de capital mixto de duración limitada, o por tiempo indefinido, en la que las Administraciones Públicas ostentarán la participación mayy

en su funcionamiento (art. 14.3 in fine $\mathrm{L} 3 \mathrm{~B}$ ).

a tuaciones de conservación, mejora y regeneración, directamente o aplicando cualesquiera otras fórmulas de reacción administrativa a su elección, pudiendo ampliarse en estos supuestos el alcance del deber de conservación, si así lo establecía la normativa autonomica, hasta el setenta y cinco por ciento del coste de reposición de la construccion o el edificio correspondiente (9.2 LS). Tras la L3R, la LS parece ampliar excesivamente la facultad de la administración de imponer actuaciones sobre al deber de conservación (art. 9.2 LS). Tal prevision, no obstante, debe modularse teniendo presente que mal podrá dictarse orden de ejecución en relación con actuaciones sobre el medio urbano si no se dan los presupuestos legales

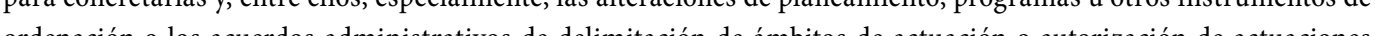

También la normativa de propiedad horizontal ha sido sustancialmente modificada (disposición final primera L3R). Se han incluido entre las obras obligatorias, que no requieren acuerdo previo de la Junta de Propietarios, las que impli- 

públicas o solicitadas a instancia de los propietarios, "los trabajos y las obras que resulten necesarias para el adecuad antente cluyendo en todo caso [.... cualesquitra orras derradas de la imposition, por parte de la Administracion, del deber leg

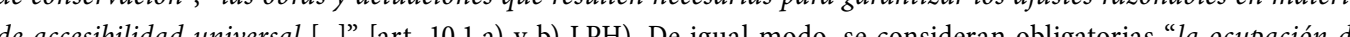

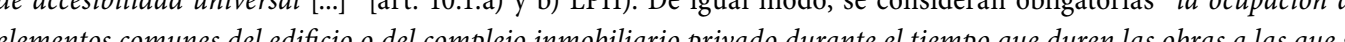
celementos comunes del eificico o del complejo inmobiliario privado durante el tiempo que duren las obras a las que se

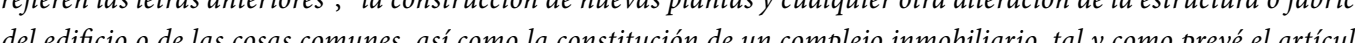

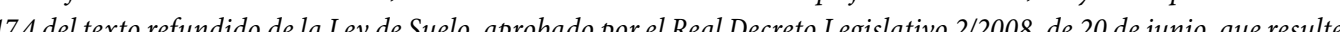
17.4 del texto refundido de la Ley de Suclo, aprobado por l Real Decro Legislanvo 2/2008, de 20 de juno, que resulten

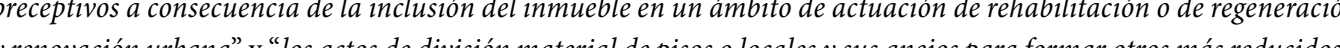
independientes ela segregación de alguna parte realizados por voluntad y a instancia de sus propietarios, cuando toles actuaciones ser posibes a con a

De manera coherente con la previsión de la ejecución de estas actuaciones en régimen de distribución equitativa de beneficios y cargas [art. 15.2 y 10.2.a) L3R], se ha previsto la afección real directa, inmediata y con la misma preferenc y prioridad que la afección al pago de cuotas de urbanización, de las fincas constitutivas de elementos privativos de regímenes de propiedad horizontal o de complejo inmobiliario, cualquiera que sea su propietario, al cumplimiento del deber de costear las obras derivada de la conformidad o autorización administrativas del proyecto técnico o, en $s$ caso, la orden administrativa de ejecución que las ordene [art. 12.2 L3R o 10.2.c) LPH]. Además, se han regulado un régimen especial de ocupación de los elementos comunes del edificio o el complejo inmobiliario privado por obras instalaciones de rehabilitación (art. 15.3.) ) L3R], y la declaración de unildad publca o interes social de la expropiación de elementos pri 15.3.g) L3R]

Desde la perspectiva urbanistica y patrimonial pública existen también relevantes novedades tales como la regulación de la desclasificación, desafectación y enajenación a la comunidad de propietarios de espacios libres o de dominio público para la instalación de servicios comunes que, siendo legalmente exigibles, estén previstos en planes, programas instrumentos de rehabilitación [art. 12.1.b) L3R]; las reglas especiales de cómputo de aprovechamiento y de distancias mínimas a linderos, otras edificaciones o la vía pública por ocupación de suelo por las instalaciones del ascensor, tales como vestíbulos, descansillos y acceso a viviendas derivados de la instalación, así como del subsuelo y vuelo corres pondientes, objeto de la desclasificación como espacio libre y, en su caso, desafectación del dominio público (art. 10.3 L3R): y la posibilidad de pago obligatorio en especie de los justiprecios expropiatorios [art. 13.2.a) L3R].
(1) IGLESIAS GONZÁLEZ, Felipe. "Régimen jurídico de la protección pública a la rehabilitación", en el volumen colectivo 2013, pp. 147-164.

(2) TEJEDOR BIELSA, Julio. Derecho a la vivienda y burbuja inmobiliaria. De la propiedad al alquiler y la rehabilitación. La Ley, Madrid, 2012, pp. 210-246.

3) RUBIO DE VAL, Juan (coordinador). La politica de rehabilitación urbana en España. Evolución, experiencias y efectos. Instituto del Territorio y del Urbanismo, Madrid, 1990. (4) RUBIO DE VAL, Juan. "La rehabilitación integral de algunos conjuntos urbanos de Zaragoza. Una oportunidad para el
reciclado sostenible de la ciudad", en el volumen colectivo Rehabilitiación y regeneración urbana en España. Situación actual yperspectivas, dirigido por Julio Tejedor Bielsa, Zaragozaz, 2013, p. 275.

(5) Además del volumen colectivo ya citado, sobre la L3R vid. VV.AA., Monográfico sobre la "Ley de rehabilitación, renovación y regeneracióón" de la Revista de Derecho Urbanistico y Medio Ambiente, no. 285, 2013; y A. Menéndez Rexach
(coordinador), "Por la rehabilitación, la regeneración y la renovación urbanas", monográfico de Ciudad y Territorio. Estudios (coordinador), "Por la reha,
Julio Tejedor Bielsa. Profesor Titular de Universidad de Derecho administrativo en la Facultad de Derecho y en la Escuela de Ingeniería y Arquitectura de la Universidad de Zaragoza Doctor en Derecho (1997) con la tesis titulada La necesaria redefinición del modelo urbanisticic en el Estado autonómico, tras completar estudios en la Universidad Paris I (Panthéon-Sorbonne). Imparte docencia dos voliersidad de Zaragoza desde 1992. Autor de seis monografía y de más ochenta publicaciones científicas y coordinador de dos volímenes colectivos, sobre la reciente reforma bancaria y sobre la Ley de rehabilitación y regeneración urbana, en la que ha

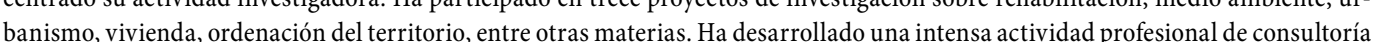
para administraciones públicas y particulares, redactado numerosos anteprovectos normativos y desempeñado cargos públicos en el ámbito del urbanismo y la politica de vivienda. 


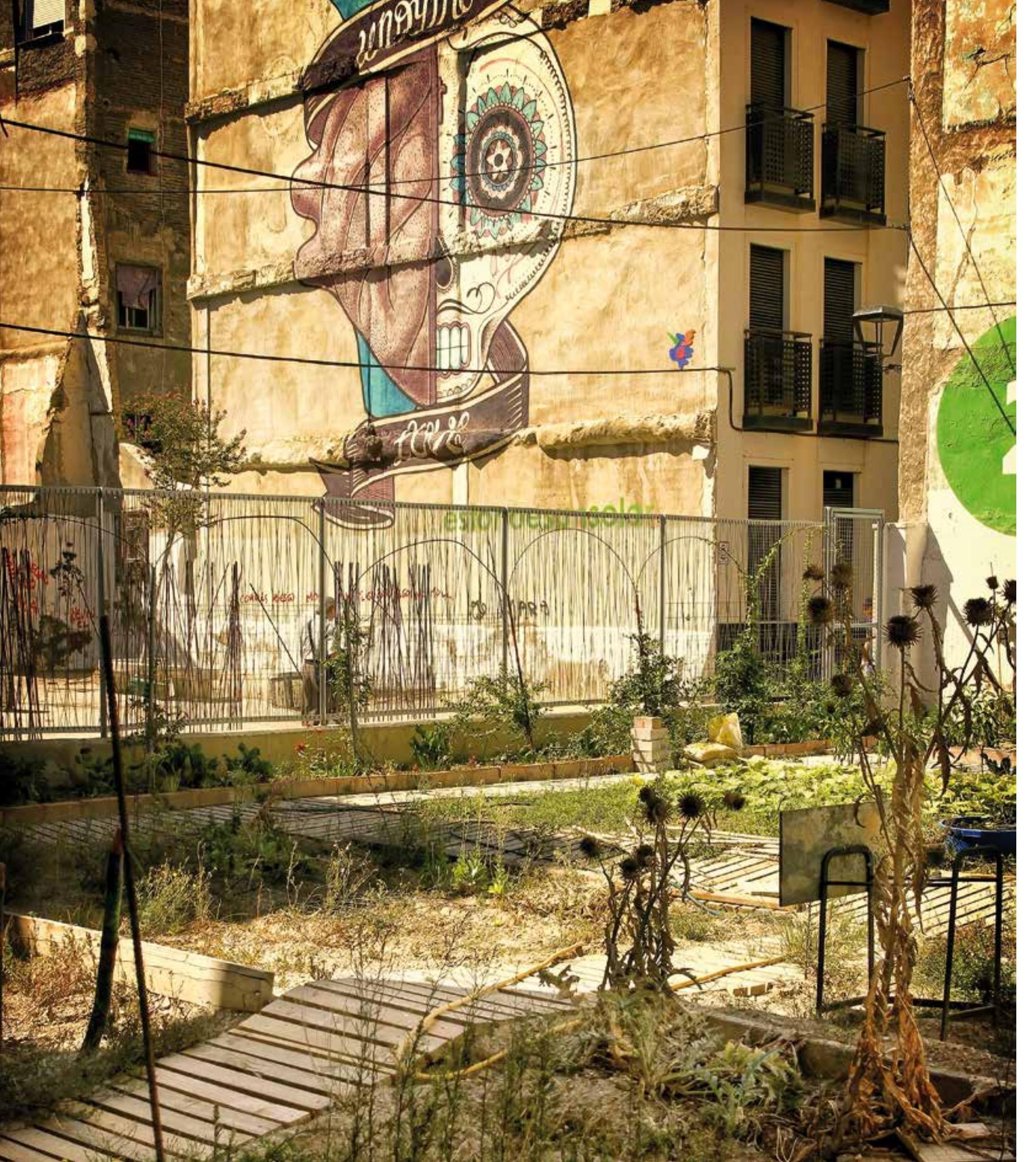

EN EL BARRIO DE SAN PABLO

STUDY ON THE STATE OF HOUSING

IN THE SAN PABLO NEIGHBORHOOD

Juan Rubio del Val

Sergio García Pérez 


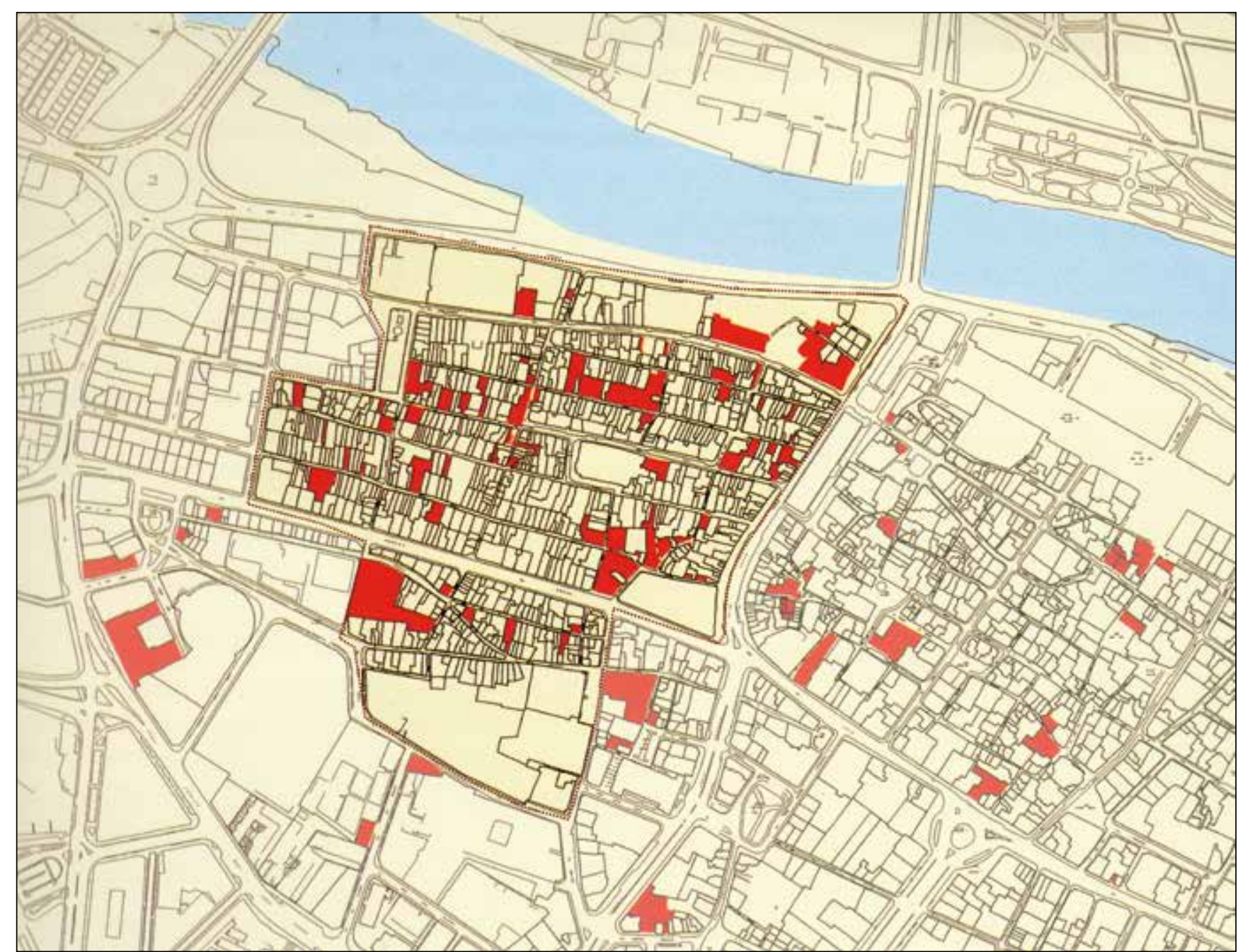

Solarese existentes en e lámbito
de estudio en 1997 . Fuente: Plan Integral de Cascc Plots in the study area in 1997 Source: PICH (Integral Plan fort
Historic Centrel $1997-2004$.

\section{Need for the study. Diagnosis of the housing situation}

At the public society Zaragoza Vivienda (known by the acronym SMZV in Spanish), we like to talk about housing And that's because, as our manager, Nardo Torguet, so aptly puts it, the right to housing is one of our citizens' primary needs.

When we speak about housing, we are, therefore, speaking about a central component of urban habitability (although not the only one), since it can be considered part of the main core guiding all the variables in the complex reality of our modern city (society, public space, financial activities, and so on).

If you know the housing stock, then you know the society that lives there. You know who is walking along the streets using the spaces and who forms a district. And you need to know this to make the right decisions, to establish strategies and courses of action that help perform the exciting work involved in improving the life of a district's residents. That's why this article presents the work performed on housing in the San Pablo district to date and the criteria behind the decisions to identify strengths and weakness. These, together with a new diagnosis, will help us to come up with ideas on how to improve and regenerate the historic structures forming the district.
Necesidad de la realización de un estudio. Diagnóstico de la situación de la vivienda

En la Sociedad Municipal Zaragoza Vivienda gusta hablar de vivienda. Y es que, como bien dice Nardo Torguet, gerente de la sociedad, el derecho a la vivienda recoge una de las necesidades prioritarias de los ciudadanos.

Hablar de vivienda, es por lo tanto hablar de un pilar de la habitabilidad urbana, (aunque no el único), ya que se puede consider como constituyente del núcleo principal sobre el que pilotaran tas las variables que comprenden la realidad compleja que se entiende por ciudad (sociedad, espacio público, actividades económicas,...).

Conocer el tejido residencial es conocer a la sociedad que allí habita. Conocer pues quién camina por sus calles, quién usa sus espacios, y quín constrye a bario. Conocer para poder tomar dectisones certeras, para poder establecer estrategias y líneas de acción que ayuden al apasionante trabajo que supone la mejora de la vida de los ciudadanos de un barrio. Por ello, el presente artículo reflexiona sobre el trabajo realizado en materia de vivienda en el barrio de San Pablo hasta ahora, y bajo los criterios con los que fue planteado, para detectar las fortalezas y debilidades que junto a un nuevo diagnóstico, sea capaz de arrojar ideas sobre la posibilidad de mejora y de regeneración del tejido histórico que constituye el barrio.

Dinámicas

De forma pionera y desde 1989, el Ayuntamiento de Zaragoza, gracias a la Ordenanza Municipal de Fomento a la Rehabilitación Privada de Viviendas trabaja en la recuperación de un tejido que se ha visto dañado por el resultado del urbanismo desarrollista. Con el Avance del Plan Especial de Casco Histórico (redactado en 1981 por el arquitecto Alfonso Fernández Castro) se comenzó un trabajo que sigue desarrollándose hoy en día.

En este Plan Especial, cuyo objetivo era, a partir de la declaración del Casco Histórico como Conjunto Histórico-Artístico, explicitar que normas de protección debian desarrollarse: se realizó una exhaustiva catalogación del patrimonio edificado para poder dete

La línea de actuación planteada, basada en reflexiones ceñidas al campo físico en su valoración histórico-artística fue pronto reformulada bajo una nueva visión en 1997 cuando decide intervenirse de forma integral gracias a la figura del Plan Integral de Casco Histórico.

\section{Primer Plan Integral}

En un primer periodo, desde 1997 hasta 2004, se trabaja bajo una mirada transversal que reconoce importancia y programas de actuación en la línea de la vivienda, con especial interés tanto en los solares vacíos, como en la rehabilitación del parque edificado. Sin embargo, las propuestas que se plantean no se realizan tras análisis exhaustivos a priori del estado de la vivienda sino que se realizarán posteriormente con la delimitación de Áreas de rehabilitación integral (ARI), en las áreas más degradadas del Casco Histórico, contando así con un mecanismo capaz de definir zonas de actuación preferente, concentrando mayores esfuerzos, ayudas e incentivos.

Los programas previstos resultan interesantes al incluir la adquisición de solares y edificaciones para la inversión pública y el incentivo tanto de construcción de viviendas de protección oficial y libre como de rehabilitación pública y privada. Los años posteriores son años de trabajo intenso por parte de la Sociedad Muicipal de Rehabilitación Urbana, tanto en materia de edificación de nueva planta, como en rehabilitación de edificios propios, así como en la gestión de las ayudas para la rehabilitación privada. Un total de 207 viviendas de nueva planta, junto a 56 rehabilitadas y habiendo incentivado la rehabilitación privada en 1.344 viviendas, en el barrio de San Pablo.

\section{Segundo Plan Integra}

En 2005, finalizado el periodo de vigencia del Plan Integral de Casco Histórico se decide ampliarlo con una nueva etapa que durará otros 8 años llegando hasta el 2012. Esta etapa detecta dificultades en los modelos de inversión privada propuestos, no habiendose cumplido los objetivos ni para obra de nueva planta ni para rehabilitación. 


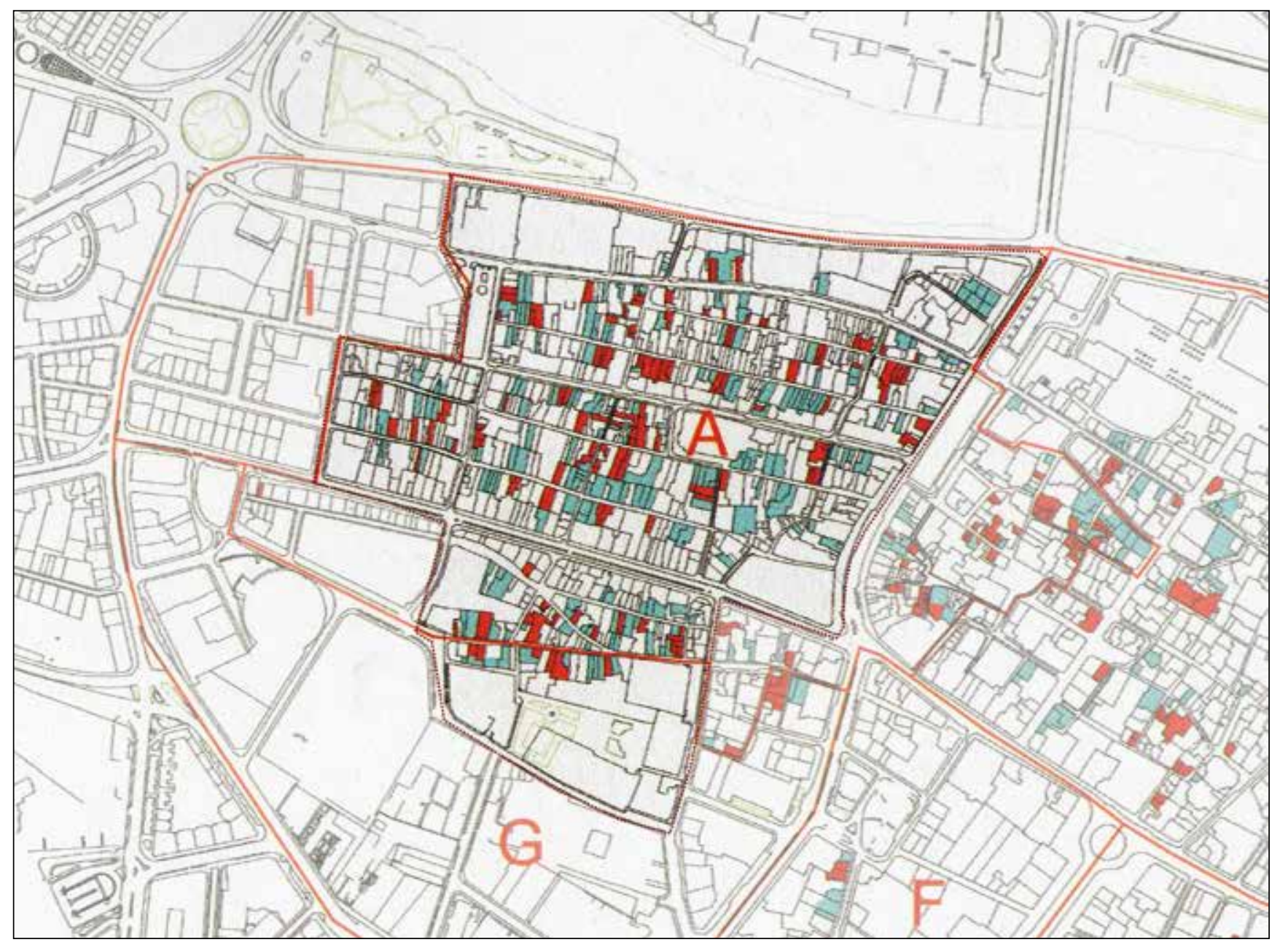

Estado de la edificación en e Fuente: Plan Integral de Casco

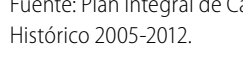
State of buildings in the study
area in 2005 . Source: PiCH (Integral Plan for
Historic Centre) 2005-2012.
Dynamics

Since 1989, the City Council of Zaragoza, as a result of the Municipal Ordinance of Development for the Private Rehabilitation of Housing, has taken the pioneering step of working to restore buildings that have been damaged by the outcome of urban development. Based on the Special Plan for the Historic Centre (drafted in 1981 by the architect Alfonso Fernández Castro), they began a project that is still ongoing today.

After declaring that the Historic Centre was a Historic and Artistic Complex, the purpose of this Special Plan was to explain which protection regulations should be set in place: an exhaustive catalogue of the built heritage was compiled cable, the grants available for improvement works. The course of action proposed, based on the physical assessment of their historic and artistic value, was soon revamped in a new vision in 1997 when the Integral Plan for the Historic Centre called for an intervention in the centre as a whole.

\section{First Integral Plan}

In the first period, from 1997 to 2004, a cross-sectional viewpoint recognised the importance of housing and, therefore, included programmes for it, especially targeted at empty plots and the rehabilitation of the housing stock. However,
El nuevo PICH actúa bajo la filosofía de las ARI del plan anterior, ahora denominadas Áreas de Rehabilitación de Casco Histórico (ARCH). En esta ocasión si existe una diagnosis de todo el estado físico de la vivienda en el ámbito delimitado por el plan. Este se realiza mediante inspección ocular del edificio con la que se otorga una calificación de regular o mal estado, adjuntando un cálculo estimativo de los costes de las obras de mejora, en función de la catalogación recibida y la superficie construida.

Existe un interés en el estudio por los solares vacíos, los edificios catalogados, la situación de infravivienda, y la accesibilidad. Para ello se cuenta con estudios específicos basados generalmente en la información que el censo de 2001 refleja.

En esta ocasión se sigue trabajando en la línea de la revitalización desde una perspectiva más integral y coordinada entre diferentes áreas municipales. Una de las dinámicas que cambia el rumbo de trabajo es la evolución poblacional en la que está inmerso el barrio en estos años, modificando sobretodo los modelos de rehabilitación privada ${ }^{1}$

Durante este periodo, en el ámbito analizado en este articulo, se realizan 144 viviendas de obra nueva para alquiler o se otorgan ayudas a la rehabilitación privada a 738 viviendas, con una inversión final en estas últimas actuaciones de 8.125.232 €.

A la finalización de este periodo, dentro de la evaluación PICH realizada, no se concreta ni se valora la mejora del estado de la vivienda, al no poder utilizar estadísticas basadas en la información generada por el censo 2011, al no ser este todavía público. Sin embargo, las encuestas si detectan una buena acogida por las entidades. instituciones y ciudadanía en las líneas de trabajo llevadas a cabo.

\begin{tabular}{|l|c|c|c|}
\hline & Anteriores a 1997 & PICH 1997-2004 & PICH 2005-2012 \\
\hline Renovación SMZV edificios nuevva planta & 104 & 207 & 144 \\
\hline Rehabilitación edificios SMZV & 19 & 56 & 17 \\
\hline Rehabilitación privada con ayydads pubblicas & 285 & 1.344 & 738 \\
\hline
\end{tabular}

Tabla resumen. Actuaciones en el barrio de San Pablo (en no de viviendas). Fuente: elaboración propia

\section{Situación actual}

Conocidas las dinámicas hasta la fecha, es el momento ante la inexistencia de un estudio especifico sobre la situación actual de la vivienda, de realizar un diagnostico y propuestas sobre ello. El estudio que realizamos trata de conocer el estado físico de la vivienda desde sus condiciones y posibilidades de adaptación a las características básicas de habitabilidad exigibles hoy en día a una vivienda.

\section{Edad de la edificación}

En primer lugar conocer el año de construcción de la edificación ayuda a determinar su comportamiento energético. El reto que España debe plantearse de cara a la eficiencia energética es vital, y además en esta área queda mucho más justificado conociendo las características sociales de los habitantes². Se distinguen principalmente dos tipos de edificaciones: anteriores a 1980 y posteriores a dicha fecha, cuando la construcción con aislamiento térmico comenzó a ser obligatoria de gestión previstos, ante esta nueva perspectiva

2 La pobreza energética es una realidad latente en el barrio, ya que afecta a la sociedad más vulnerable.

3 Cuando el Plan Estatal de Vivienda 2013 -2016 comience a ser operativo, otorgará ayudas a las edificaciones construidas antes de 1981, 


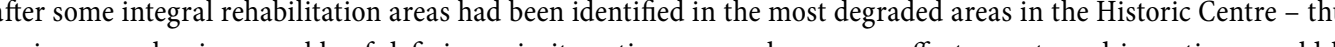

The planned programmes are interesting as they include the acquisition of plots and buildings for public investment and the incentive to construct subsidised and non-subsidised housing, as well as rehabilitate public and private properties.

In the years following this period, the Public Society for Urban Rehabilitation worked hard on new builds, rehabilitating its own buildings and managing grants for private rehabilitation. A total of 207 new homes were built, 56 were rehabilitated and incentives were given for the private rehabilitation of 1,344 in the San Pablo district.

\section{Second Integral Plan}

The Integral Plan for the Historic Centre was extended in 2005 for another eight years to 2012 after its initial period had come to an end. This stage detected difficulties in the proposed private investment models as the objectives for new build and for rehabilitation had not been met.

The new plan (known by the acronym PICH in Spanish) was based on the philosophy of the integral rehabilitation areas in the previous plan, which were now termed rehabilitation areas in the Historic Centre. This time the scope of the plan did include a diagnosis of the overall physical state of the housing. This comprised a visual inspection of the building to rate the condition as satisfactory or deficient and to allocate an estimate of the costs for the improvemen works depending on its classification and floor area.

There was interest in studying empty plots, classified buildings, sub-standard housing and accessibility. For that purpose specific studies were used generally based on information in the 2001 census.

On this occasion, work continued on revitalisation from a more integral and coordinated perspective among several municipal departments. One of the dynamics that changed the course of the work is the residential development the district was undergoing at the time, which above all changed private rehabilitation models.

During this period, within the scope of this article, 144 new homes were built for rent or sale under a subsidised scheme, 17 homes were rehabilitated in buildings owned by Zaragoza Vivienda and grants were given for the private rehabilitation of 738 homes. The final investment in the latter work was $€ 8,125,232$.

At the end of this period, the integral plan's assessment did not specify or value the improvement in the condition of the housing as the statistics based on the information generated by the 2011 census could not be used as it was not yet in the public domain. However, the surveys did detect that entities, institutions and the general public welcomed the work that had been performed.

\begin{tabular}{|l|c|c|c|}
\hline & Before 1997 & PICH 1997-2004 & PICH 2005-2012 \\
\hline SMZV renewal of newly constructed buildings & 104 & 207 & 144 \\
\hline Rehabilitation of SMZZ buildings & 19 & 56 & 17 \\
\hline Private rehabilitation with public subsidies & 285 & 1.344 & 738 \\
\hline
\end{tabular}

Summary table. Work in the San Pablo district (in number of housing units). Source: author's own.

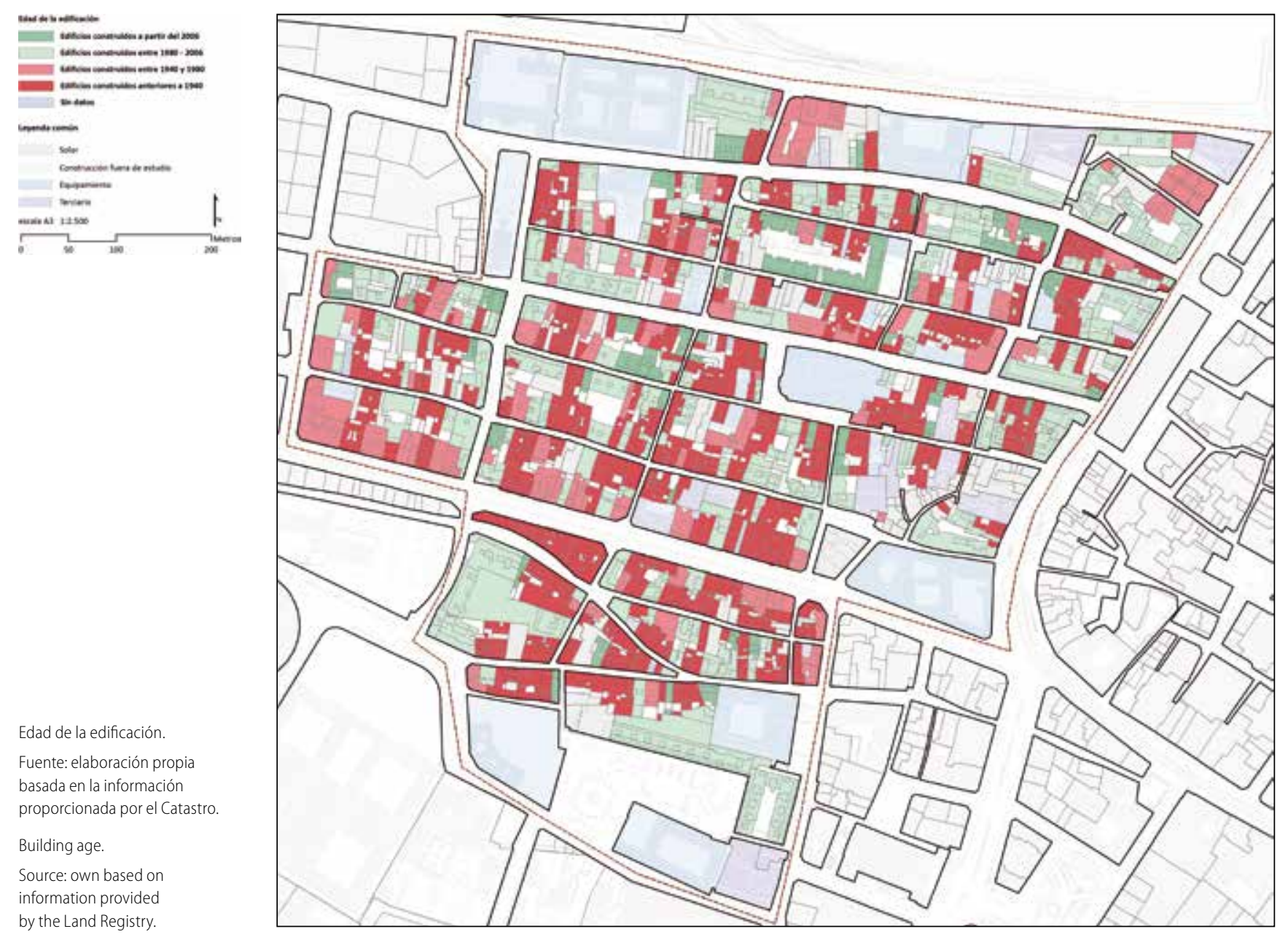

Los resultados demuestran dos tipos de tejidos diferenciados en el barrio. La existencia de un parcelario medieval ${ }^{4}$ que posee la mayor cantidad de construcción anterior a 1981 en convivencia con otros modernos, resultado de la agrupación de los anteriores y que corresponden a las construcciones más modernas del barrio.

Accesibilidad de los edificios y viviendas

En segundo lugar, conocer el grado de accesibilidad de la edificación permite saber si existe exclusión de colectivos sociales en el barrio5. Para la realización del estudio se han definido los siguientes conceptos:

- accesibilidad total: el edificio posee ascensor y este es accesible desde la cota de la calle.

-accesibilidad parcial: el edificio posee ascensor, sin embargo existe un tramo de escalones en el exterior o en el interior del edificio (y además no existen elementos que los salven) que no permiten la accesibilidad total desde la cota de la calle. - accesibilidad nula: el edificio no posee ascensor.

El parcelario medieval se caracteriza por poseer una crujiáa estrecha, que concentra la edificación principal a la calle junto a patios y construcciones auxiliares a li interior de la manzana. El tiempo ha hecho que la configuración inicial de la parcela se vea ahora modificada por
una altura en ocasiones excesiva de la construcción principal junto a una gran concentración de construcciones auxiliares, mermando las capacidades espaciales que en origen poseía el patio trasero.

Un barrio pocc accesible condiciona dinámicas de atracción a la parte de la población más pobre, y resulta una condición excluyente de la buscada diversidad social, al no ser atractivo a familias jóvenes, ancianos. 
As there is no specific study on the current housing situation, now is the time to analyse it and make proposals taking all the dynamics to date into account. The study we have conducted aims to discover the physical state of housing based on its condition and the possibility of adapting it to the basic habitability characteristics current housing needs to have

\section{Building age}

Firstly, knowing the year when the building was constructed helps to determine its energy performance. It is vital that Spain takes up the energy efficiency challenge, and this is far easier when we know residents' social characteristics.2 Primarily there are two types of buildings: before 1980 and after that date when building with thermal insulation became obligatory. ${ }^{3}$

The results show two different types of structures in the district. A medieval site 4 , containing the most constructions prior to 1981, next to other modern sites, resulting from the grouping of the former and which contain the most modern buildings in the district.

\section{Accessibility of buildings and housing}

Secondly, discovering the level of accessibility of the buildings tells us if there is any exclusion of social groups in the district. 5 The following concepts have been defined to perform the study:

- full accessibility: the building has a lift, which is accessible from street level.

- partial accessibility: the building has a lift; however, there is flight of stairs outside or inside the building (and there are no elements to avoid them) which does not enable full access from street level.

- no accessibility: the building does not have a lift.

Only buildings with more than four storeys have been considered, since it is important to analyse the cost-benefit of the investment of installing a lift in a block with fewer than three floors, in a building with two flats per floor.

The results show that the most accessible flats are in new buildings, which seems logical. Furthermore, these are concentrated along typical corridors or the most representative places, such as Predicadores Street, San Blas Street, Mayoral Street (which together with San Blas had a Special Plan), San Pablo Square and, lastly, the buildings formin the district wall (Conde Aranda, Avenida Cesar Augusto and Paseo Echegaray y Caballero)

The largest number of buildings with no accessibility is inside the district; it also has the highest concentration of buildings with up to three storeys, so any work to improve accessibility in any of these buildings would be very costly 6

\section{Zaragoza Vivienda projects in the area}

Thirdly, we wanted to investigate the work the SMZV had performed over the years, some within the two stages of the Integral Plan for the Historic Centre.

We have differentiated between projects the SMZV promoted - either new build or rehabilitation of own stock - on the one hand, and improvement works private owners have undertaken using public grants, on the other.

2 Energy poverty is a latent situation in the quarter since it affects the most vulnerable members of society

3 When the 2013-2016 State Housing Plan comes into effect, it will provide grants to buildings constructed before 1981, and energy efficiency will be one of its $p$

4 The medieval site is characterised by having a narrow bay, concentrating the main building next to the street, and courtyards and ancill constructions inside the block. Over time the initial layout of the plot has been modified and the main building is sond
high, while the concentration of ancillary buildings reduces the space capacities that the original back courtyard had.

5 A district that is not very accessible conditions the dynamics to attract the poorest section of the population, and it excludes the soughafter social diversity as it does not attract young families, the elderly, and so on

6 This refers not only to the cost of installation, but also to the cost of maintaining the installation for the rest of its working life.

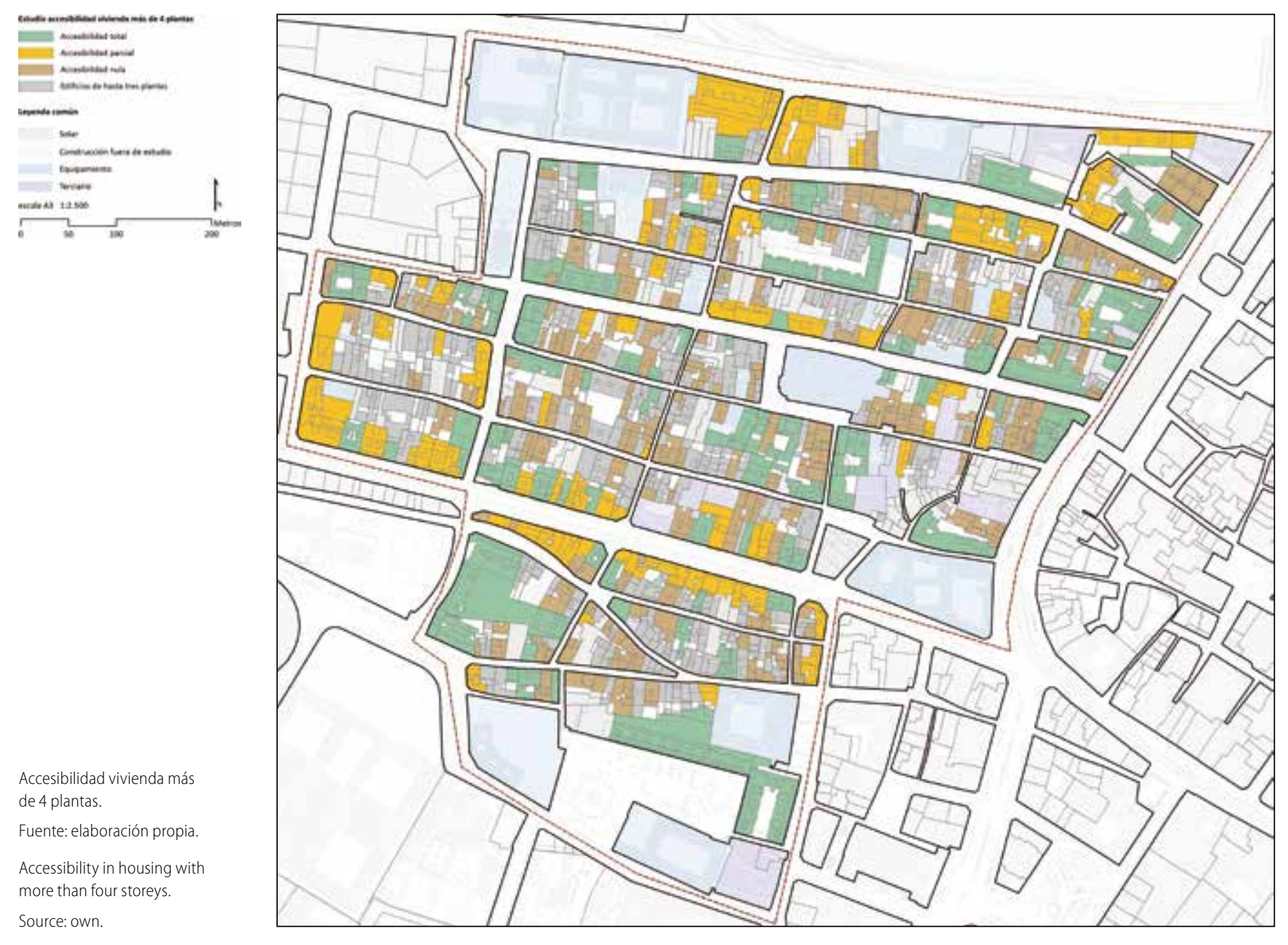

Además, sólo se ha considerado la edificación que cuenta con más de 4 plantas, ya que es importante considerar el coste-beneficio de la inversión que supone un ascensor en una vivienda de menos de 3 plantas, en una escalera con dos viviendas por planta.

Los resultados revelan que las viviendas más accesibles corresponden a la nueva edificación como parece lógico. Además, esta se concentra en ejes característicos o lugares de mayor representación como son la calle Predicadores, la calle San Blas, la calle Mayoral, (que junto a San Blas contó con un Plan Especial), la Plaza de San Pablo y por último las edificaciones que configuran la muralla del barrio (calles Conde Aranda, Avenida Cesar Augusto y Paseo Echegaray y Caballero). El interior del barrio, concentra la mayor cantidad de edificios de accesibilidad nula, y cuenta además con la mayor concentración de edifícios de hasta tres plantas, por lo que la actuación de mejora puntual de la accesibilidad en cada
uno de estos edificios resultaría muy costosa ${ }^{6}$.

\section{Actuaciones de Zaragoza Vivienda en el área}

En tercer lugar hemos querido conocer las intervenciones realizadas durante estos años de trabajo de la Sociedad Municipal Zaragoza Vivienda, algunas de ellas enmarcadas dentro de las dos etapas de vida del Plan Integral de Casco Históricico.

6 No se referer tan sólo a un coste de la instalación, sino también al coste de mantenimiento de la instalación para el resto de vida útil de la mism 


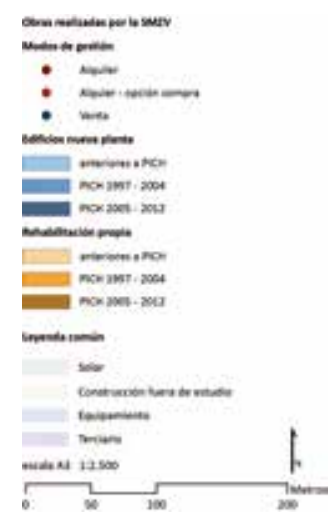

.

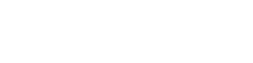

Obras realizadas por la Sociedad Fuente: elaboración propia Projects performed by the SMZV
(Sociedda Municipal Zaragoza Vivienda).
Source. own.

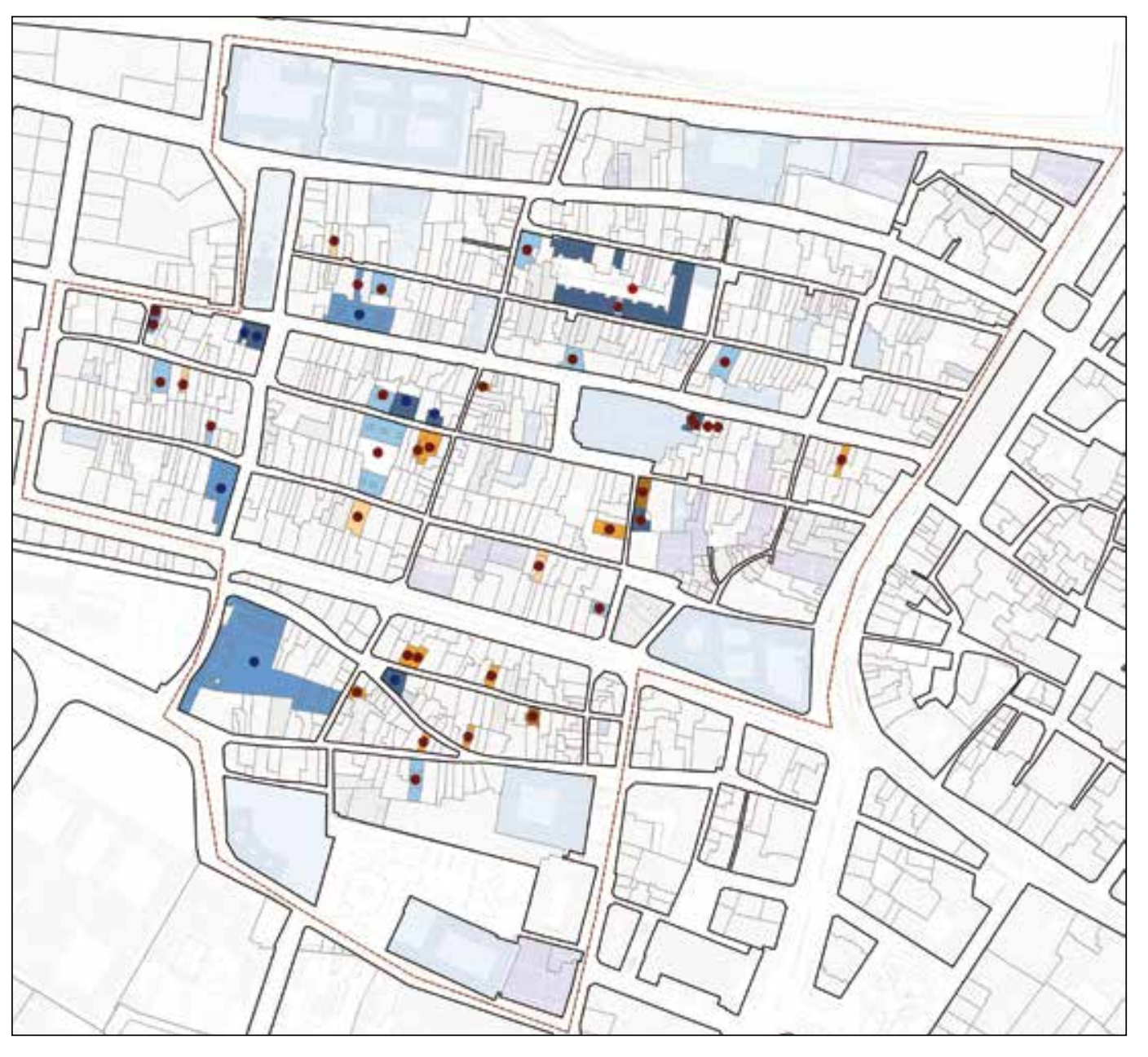

The former took place on plots and in properties which the SMZV acquired and then managed, thus promoting properties to rent or buy under a subsidised scheme within the Historic Centre. These works are sometimes easy to identify (above all the new-build ones) since they comply with current standards (accessibility, insulation, etc.).

\section{Subsidised private rehabilitation works}

While private rehabilitation works have addressed the most serious structural and habitability problems inside the flats, they have not always solved functional deficiencies, such as accessibility or energy efficiency (insulation and facilities). This is confrmed by the fact that average quotes for rehabilitation works using public grants bardy amont to 100 euros per square metre of floor area. This indicates that very few private interventions improve the building's enclosure and accessibility (at least comprehensively) as their costs exceed those described?

The limits set for the rehabilitation areas in the Historic Centre, adopted to define the destination of the grants and management efforts, have helped to considerably further this type of action in more vulnerable areas. We have even come across quite a few actions outside these areas, with fewer public incentives, which proves the positive or knockon effect of these initiatives in other less vulnerable parts of the city.

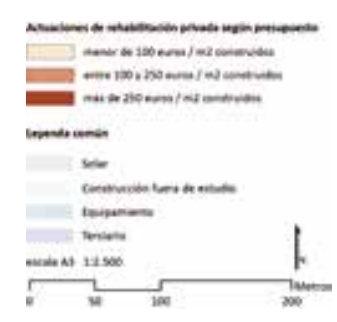
Fuente. elaboracion propla. Source: own

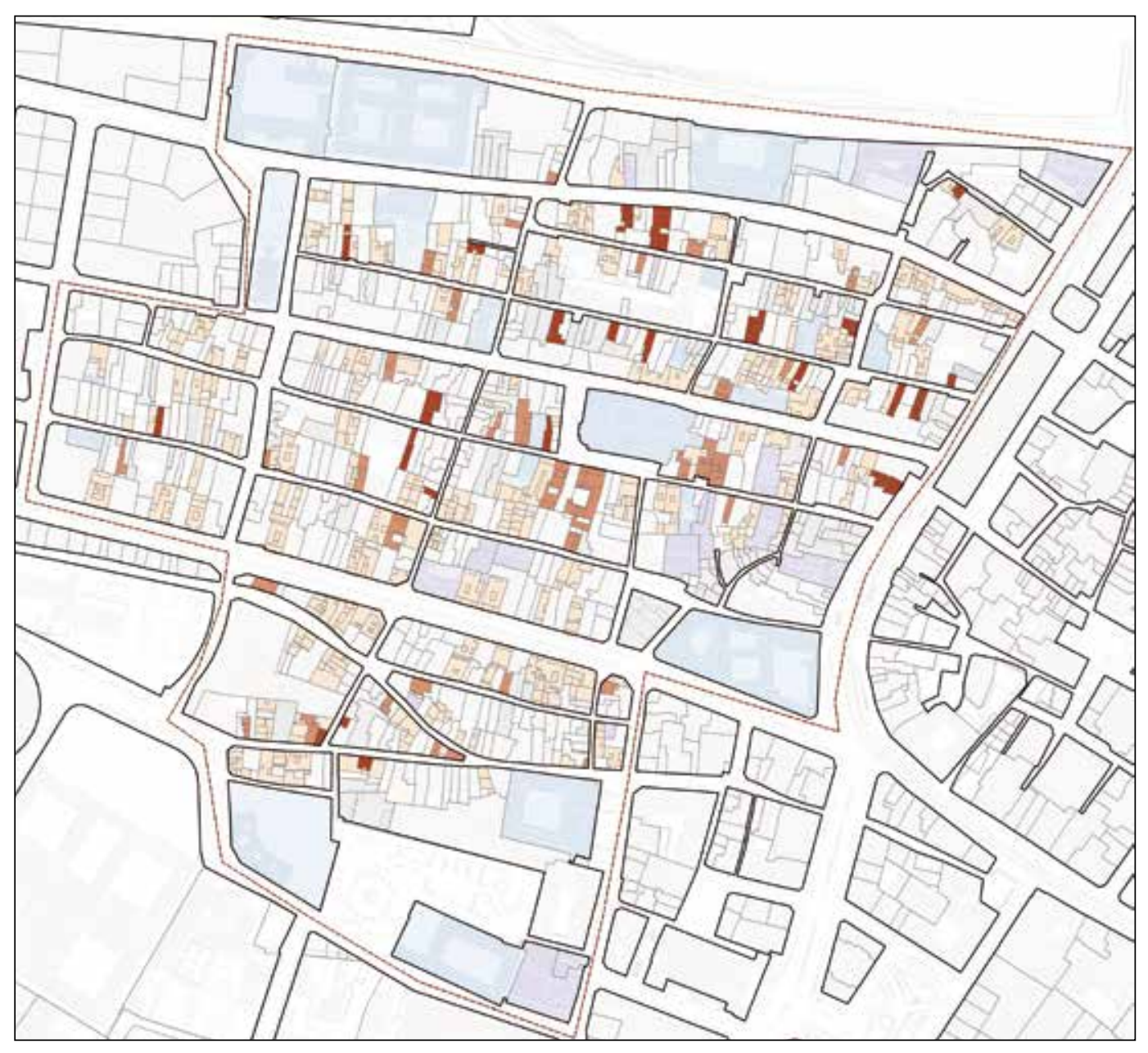

Se diferencian actuaciones por una parte promovidas por la Sociedad Municipal, bien sean de nueva planta o de rehabilitación propia y por otra, las obras de mejora llevadas a cabo por propietarios privados y que han contado con ayudas publicas. Las primeras, se han llevado a cabo sobre los solares e inmuebles que la Sociedad ha adquirido y gestionado posteriormente, fomentando así el alquiler y la promoción pública de VPA en venta dentro del casco histórico. Se trata de obras en ocasiones fácilmente identificables (sobre todo las referidas a nueva planta), ya que se realizan con arreglo a los estándares actuales (accesibilidad, aislamiento, etc.).

\section{Actuaciones subvencionadas de rehabilitación de iniciativa privad}

Mientras que en las de rehabilitación privada, se han resuelto los problemas más graves de carácter estructural y de habitabilidad en el interior de las viviendas, no siempre se ha dado respuesta a otras deficiencias funcionales, como la accesibilidad o la eficiencia energética (aislamiento e instalaciones). Esto se confirma viendo como la media de presupuestos de las actuaciones de rehabilitación con ayudas publicas no llega a los $100 \mathrm{euros} / \mathrm{m}^{2}$ construido, poniendo de manifiesto que son escasas las intervenciones privadas que mejoran la envolvente y la accesibilidad de la edificación (al menos de modo integral) cuyas obras suponen costes más altos que los descritos?.

Estudio de elaboración propia que ha tenido en cuenta los presupuestos totales de obra de los expedi
Municipal de Zaragoza Vivienda, yla superficie construida de los edificios según datos catastrales. 


\section{And now what?}

Having recognised the need to preserve the historic medieval sector as a direct witness to history and the district's heritage base, and as no intervention method has been able to adapt it so far8 8 , the questions we need to ask are, on
the one hand, how can we adapt the historic sector to current habitability requirements for buildings and housing without losing their identifying characteristics (width of their structural bays, interior courtyard at the back without losing their identifying characteristics (width of their structural bays, in courtyard at the back, an people living there?

Neither can we ignore other sustainability criteria, which must be in keeping with the district's situation and its social morphological and heritage characteristics. A good strategy in this sector must always seek to take advantage of the resources on offer, and this is the main purpose of the possibility proposed here.

When speaking of accessibility, and the cost-benefit of the investment, we did not consider buildings with fewer than four storeys since the work would not be viable from a financial point of view, not just due to the high cost of the investment and maintenance (a cost that owners can often not afford), but also the small number of homes one lift can reach. But how can we rule out improving accessibility in a district where $40 \%$ of the housing is inaccessible and $18 \%$ (1,111 homes) are in the historic sector?

\section{How can we make these improvements in habitability (including accessibility) viable?}

If, instead of considering the viability of the investment based on building height, we think about the sustainability of the model based on an increase in the number of homes the same lift reaches without needing to increse the height (horizontal growth), we can group them together and thus lower investment and maintenance costs. As a result of the layout of the blocks, the buildings contain courtyards by using this resource, not only can we reorganise distribution but also a space at the back that was previously wasted.

This would be possible with the new Law 8/2013 on Urban Rehabilitation, Regeneration and Renewal which proposes interventions by establishing a new type of management called "administrative association". Based on the concept of compensation boards, it can group communities of property owners together for the shared improvement project of group of several buildings rather than just one in isolation

If at the same time they manage to improve the characteristics of the building's envelope, which is a priority in almost all the buildings we are referring to here, they will also reduce expenditure on energy in the long-term, which some social spheres in the district cannot always afford due to energy poverty.

The fact that there are still some free plots in the district could be beneficial for the possibility put forward here, since Combined rehabilitation and new-build projects could solve many of the problems that just rehabilitation can present (lack of shared spaces, lack of motivation to invest, and so on).

In short, our proposal includes preserving the built heritage, going beyond isolated interventions in buildings, which has been the norm so far, and proposes grouping works together in a new urban perspective, one that focuses on the as delimitaciones de Áreas de Rehabilitación de Casco Histórico (ARCH), como figura adoptada para la concentración de ayudas económicas y de esfuerzos de gestión, han servido para incrementar notablemente este tipo de actua-

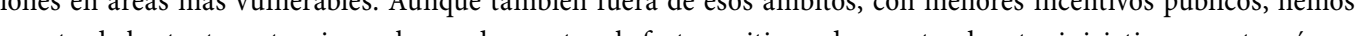

En definitiva, la situación actual del barrio de San Pablo presenta una edificación heterogénea, donde conviven tipologias actuales, resultados de agregacion de parcelas historicas, con un mayor grado de habitabilidad, eficiencia y confort; junto a tipologias que derivando de estructuras medievales se han visto fuertemente modificadas y que no poseen tan buenas características de habitabilidad como las anteriores, a pesar de haber concentrado esfuerzos económicos y de gestión en el fomento de su rehabilitación. Son estas construcciones de gran valor patrimonial (más por la trama sobre la que se asientan, que por el resultado visible fuertemente mutado) el objeto sobre el que se deben centrar los esfuerzos en los años que vienen, si realmente quiere adoptarse una estrategia capaz de aunar conservación y renovación.

Detectada la necesidad de conservación de la trama histórica medieval, como testigo directo de la historia y base patrimonial del barrio, y ante la inexistencia de un método de intervención que haya podido adaptarla hasta la fecha ${ }^{8}$ la pregunta que se debe formular es icómo poder adaptar la trama histórica a las exigencias actuales de habitabilidad de los edificios $y$ las viviendas, sin perder sus características identitarias de anchura de crujia, patio interior al fondo, etc., que la hacen excluyente a parte de la población, y por otra, cómo dar respuesta a las necesidades de la población que alli habita?

En la actualidad, no podemos eludir también otros criterios de sostenibilidad, que no deben alejarse de la realidad del barrio, de sus características sociales, morfológicas y patrimoniales. Una buena estrategia en este campo debe buscar siempre conocer y aprovechar los recursos sobre los que se trabaja, y ese es el objeto principal de la posibilidad que aquí se plantea.

Cuando se ha hablado de la situación de la accesibilidad, y el beneficio-coste de la inversión, no se tenían en cuenta los edificios menores de 4 plantas, al ser, desde un punto de vista económico, una intervención inviable, no sólo por el alto

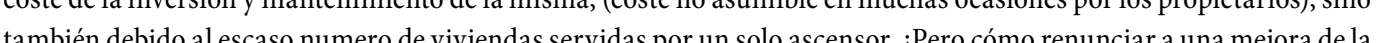
(1) en las tramas históricas?

\section{Cómo lograr hacer viables estas operaciones de mejora de la habitabilidad (accesibilidad, incluida)?}

Si en vez de pensar en la viabilidad de la inversión en función de la altura de la edificación, se piensa en la sostenibilidad del modelo basada en un aumento del número de viviendas servidas por un mismo ascensor sin necesidad de aumentar la altura (un crecimiento horizontal), podemos plantear agruparlas y disminuir así los costes de inversión mantenimiento Además, gracias a la morfología de las manzanas, se cuenta con la existencia de patios en la edificación, donde aprovechando este recurso, no sólo se consigue distribuir, sino reordenar lo que antes era un espacio trasero residual.

Esto seria posible con la nueva Ley 8/2013 de Rehabilitación, Regeneración y Renovación Urbana que propone intervenciones mediante la constitución de una nueva figura de gestión denominada "asociación administrativa", que basándose en el concepto de las juntas de compensación, puede agrupar a comunidades de propietarios para el proyecto común de la mejora, no ya de una edificación aislada, sino la agrupación de varias de ellas.

8 Como se ha detectado, frente a métodos de intervención estudiados y llevados a cabo con éxito en otro tipo de parcelario, las ayudas a la rehabilitación privada que han sido la forma de ayuda mas generalizada en esta tipologia edificatoria aun que han resultado efectivas para la
conservación y mejora parcial de l a habititabilidad, no han resultado un mecanismo eficaz de rehabilitación desde un punto de vista integral 


\section{JUAN RUBIO DEL VAL
SERGIO GARCIA PEREZ}

\section{Estudio sobre lestado dela
vivienda en} Study on the state ef fousing take advantage of all the resources in the San Pablo district.

\section{REFERENCES}

AAVV. 25 años de la Sociedad Municipal de Rehabilitación Urbana de Zaragoza. Torguet, Nardo; Lallana, Juanjo and Vallés, Paco (coord.) Zaragoza. Sociedad Municipal de Rehabilitación Urbana de Zaragoza, S.L., 2008.

AAVV. El Plan Integral del Casco Historico. Júlvez, Manuel and Navarro, Miguel Ángel (coord.). Zaragoza. Centro Municipa de Ordenación del Territorio, 1998

AAVV. Renovación del Plan Integral del Casco Histórico de Zaragoza 2005-2012. Zaragoza. Gerencia de Urbanismo, Servicio de Estudios Urbanos y Planes Integrales, 2007. AAVV. Evaluación del Plan Integral del Casco Histórico. PICH 2005-2012. Diagnóstico del barrio y Propuestas de Futuro.
Gómez Quintero, Juan David (coord.) Zaragoza. Oficina PICH, Ayuntamiento de Zaragoza y Universidad de Zaragoza, 2013.

uan Rubio del Val (1951). Town planner who qualified at the School of Architecture of the University of Navarra in 1976. He start his career drafting town plans and providing advice on urban development to small and medium municipalities in the provinces of Zaragoza and Huesca. He was the coordinator of the first ten Regional Rehabilitation Offices in Aragon from 1984 to 1985 . As a Urban Rehabilitation in Spsin (1986-1989). Since 1989 he has been responsible for the Urban Rehablilitution Dentiter The Politics of Urban Rehabilitation in Spain (1986-1989). Since 1989 he has been responsible for the Urban Rehabilitation Department of the pu
blic society Zaragoza Vivienda and since 2003 he has also been in charge of Residential Innovation Projects a section that prome urban rehabilitation in Zaragoza and actively participates in several European projects related to the rehabilitation of traditions districts. Besides his professional work, he has also been the Chairperson of the Zaragoza Branch of the Association of Architects of Aragon (1990-1995), a representative of the national development company Vallehermoso in Aragon (1995-2000), and a founding member and current board member of the Foundation for Ecology and Development (1995).

Sergio García Pérez. Student of the Master's Degree in Architecture. EINA. Universidad de Zaragoza. 2013-14
Si la vez, se consiguen mejorar las características de la envolvente del edificio, necesidad prioritaria en casi todos los dificios a los que estamos refiriéndonos, se estará además reduciendo el gasto a laroo plazo de energía a veces inasumible por las condiciones de pobreza energética que las características sociales del barrio presentan.

Además, la existencia todavía de algunos solares en el barrio resulta favorable a la posibilidad propuesta, ya que si se trataran acciones combinadas de rehabilitación junto a nueva planta, podrían solucionarse muchos problemas que la rehabilitación aislada hoy en día puede presentar (falta de espacios comunes, falta de motivación en la inversión...)

En definitiva, la apuesta que proponemos pasa por la conservación del patrimonio edificado, superando la intervención aislada en la edificación que se ha llevado hasta ahora, apostando así por la agrupación de las mismas bajo una The

dispone el barrio de San Pablo.

\section{BIBLIOGRAFIA}

AAVV. 25 años de la Sociedad Municipal de Rehabilitación Urbana de Zaragoza. Torguet, Nardo; Lallana, Juanjo y Vallés, Peo (coord) Zaragoza. Sociedad Municipal de Rehabilitación Urbana de Zaragoza, S.L., 2008.

AAVV. El Plan Integral del Casco Historico. Júlvez, Manuel y Navarro, Miguel Ángel (coord.). Zaragoza. Centro Municipal de Ordenación del Territorio, 1998.

AAVV. Renovación del Plan Integral del Casco Histórico de Zaragozza 2005-2012. Zaragoza. Gerencia de Urbanismo, Servicio de Estudios Urbanos y Planes Integrales, 2007. AAVV. Evaluación del Plan Integral del Casco Histórico. PICH 2005-2012. Diagnóstico del barrio y Propuestas de Futuro.
Gómez Quintero, Juan David (coord.) Zaragoza. oficina PICH, Ayuntamiento de Zaragoza y Universidad de Zaragoza, 2013.

Juan Rubio del Val (1951). Arquitecto Urbanista titulado por la E TS. A. de Navarra (1976). Comienza su actividad profesion redactando planeamiento urbanístico y asesorando urbanisticamente a pequeños y medianos municipios de Zaragoza y Huesca. Coordinador de las primeras 10 Oficinas Comarcales de Rehabilitación en Aragón (1984-85). Ha dirigido y coordinado, por encargo del MOPU, la realización de un estudio de ámbito nacional titulado “La Politica de Rehabilitación Urbana en España”" (1986-89). Desde 1989 es responsable del Area de Rehabilitación Urbana de la Sociedad Municipal Zaragozaz Vivienda y desde el 2003 tam-
bién de Proyectos de Innovación Residencial, desde donde viene impulsando la rehabilitación urbana en Zaragoza y prticipando activamente en diversos proyectos europeos relacionados con la rehabilitación de los barrios tradicionales. Además de su actividad estrictamente profesional, ha sido Presidente de la Delegación de Zaragozad del Colegio de Arquitectos de Aragón (1990-1995),
delegado en Aragón de la promotora nacional Vallehermoso (1995-2000) y miembro fundador y actual Consejero de la Fundación Ecologia y Desarrollo (1995)

Sergio García Pérez. Estudiante del Máster Universitario en Arquitectura. EINA. Universidad de Zaragoza. 2013-14. 


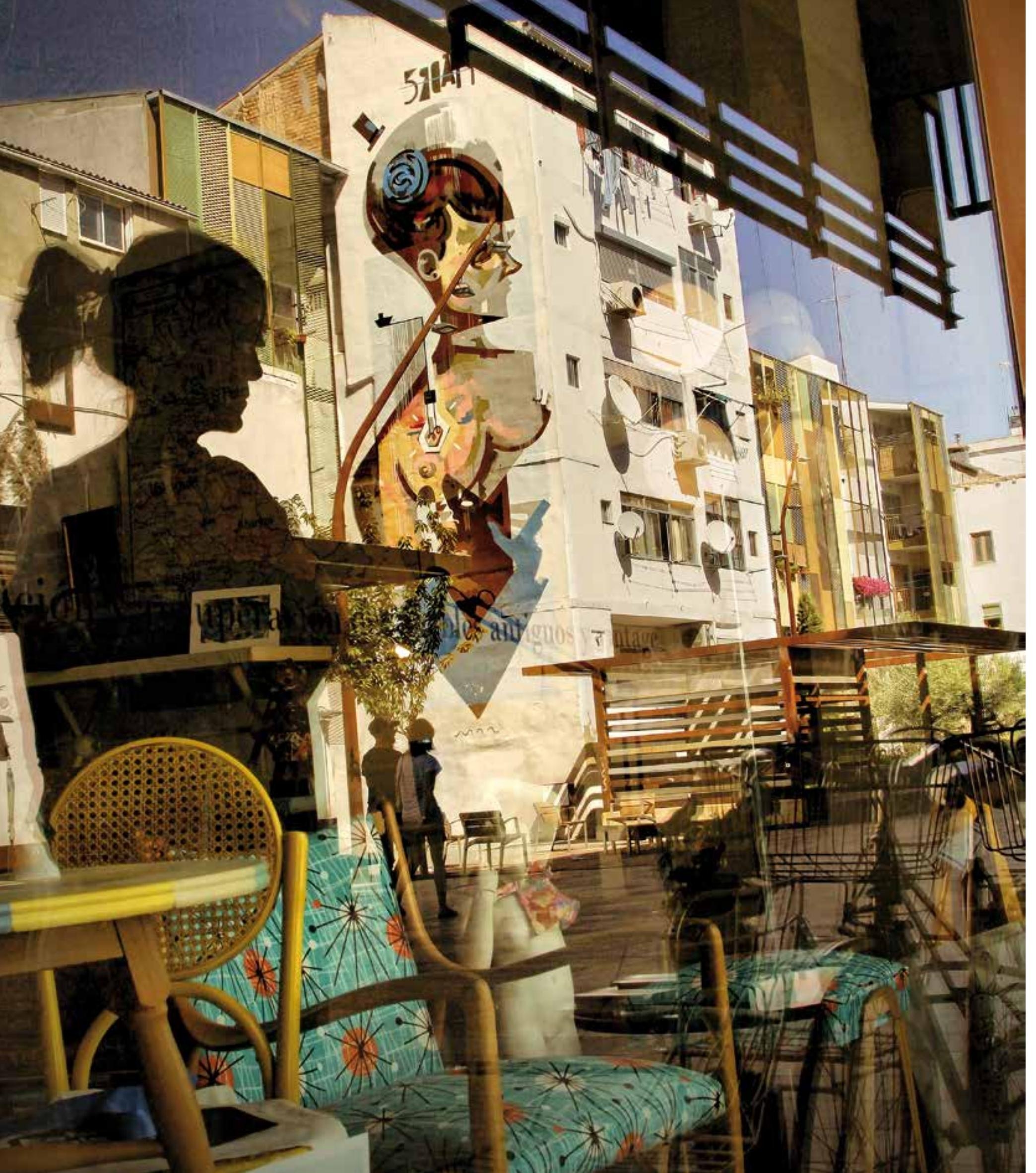




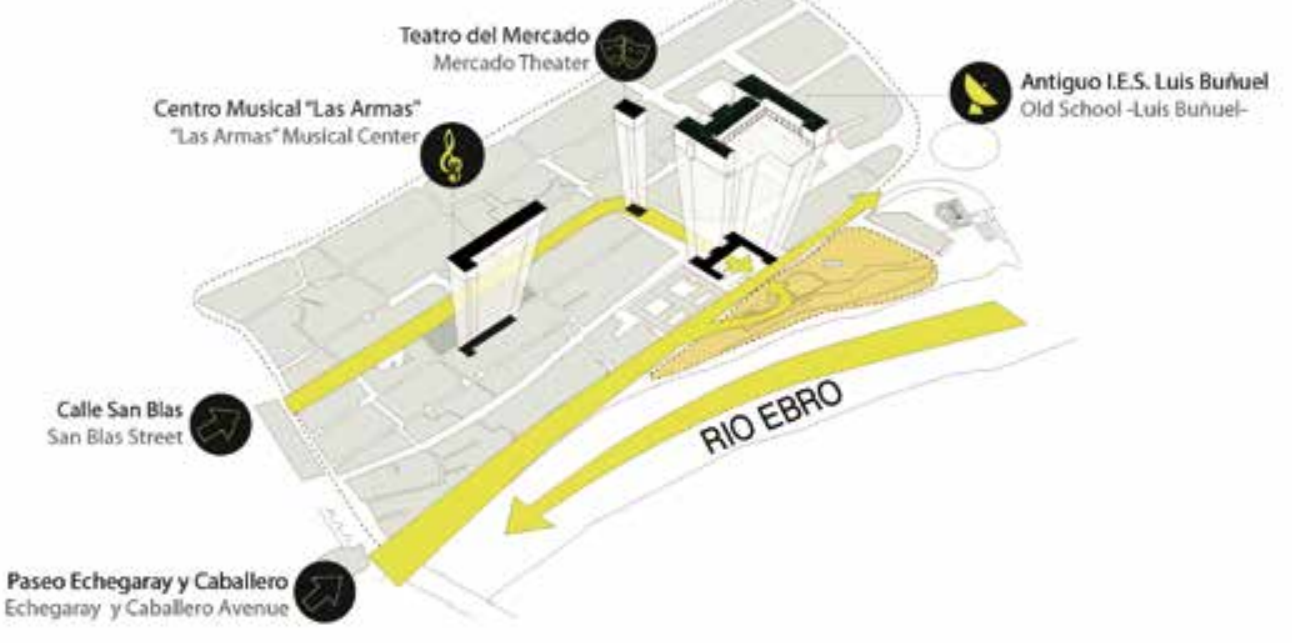

Una cuestión de Perogrullo... el Barrio de San Pablo es un tejido cuya configuración heredada debe ser adaptada y renovada constantemente para permitir su evolución, evitando la obsolescencia y la degradación. Sin embargo, como los espacios libres existentes no bastan para cumplir con las necesidades demandadas, suplir esta carencia manteniendo la morfología urbana implica actuar sobre los espacios vacantes.

Pero ¿a qué viene esto?

Por un lado, San Pablo posee un enorme patrimonio construido que abarca desde la propia morfología urbana hasta múltiples ejemplos de edificaciones civiles y religiosas; y se han impulsado o están en proceso de desarrollo diversa actuaciones en torno a los sectores Sann Pablo/rgnatell, tratando de aportar cohesion cultural [Centro Musical "Las Armas', Locales para Artistas, Distrito Erasmus... Al mismo tiempo, el barrio incorpora identidad y caracter propio su historia y acusada multiculturalidad han provocando una ica presencia de movimientos sociales y culturales que facilita la captación de individuos, colectivos y entidades vinculadas con el mundo del arte, la cultura y la propuesta social. En definitiva, existe un "sentido de barrio" apoyado en todo un entramado asociativo.

Por otro lado, la coyuntura económica y social contemporánea no permite el impulso de actuaciones complejas; si embargo, lo que podría entenderse como un hándicap es la oportunidad de intervenir el Antiguo I.E.S. Luis Buñue con el objetivo de recuperar, con gasto mínimo, el patrimonio vacante y el espacio público asociado, entendiendo el nuevo equipamiento como la puerta de entrada al Barrio de San Pablo, en conexión con la escala de la ciudad yel eje fluvial. La permeabilidad del edificio será el eslabón que permitirá el enlace de los espacios públicos y de los contenedores existentes.

Al tema... planteemos los siguientes Objetivos, Metodología, Herramientas y Etapas, encaminados a estructurar un Centro Social Comunitario?... aunque el apellido sea lo de menos.

Antes nos detenemos en el recuerdo de su historia. El antiguo I.E.S. Luis Buñuel es un equipamiento vacante situado en la Plaza de Santo Domingo del Barrio de San Pablo. El edificio original fue construido entre los años 1880 y 1890 en una parte del solar del Convento de los Dominicos. Fue Colegio Preparatorio Militar, Museo Provincial de la ciudad, Escuela de Bellas Artes y desde 1911, durante cincuenta años, Ayuntamiento de la ciudad. Meses después de su desalojo fue rehabilitado como Instituto de Bachillerato Luis Buñuel. El edificio quedó deshabitado en 2004 y actualmente es un contenedor en desuso cuyo período de deterioro ha sido paralelo a numerosas propuestas de intervención que han carecido de continuidad.

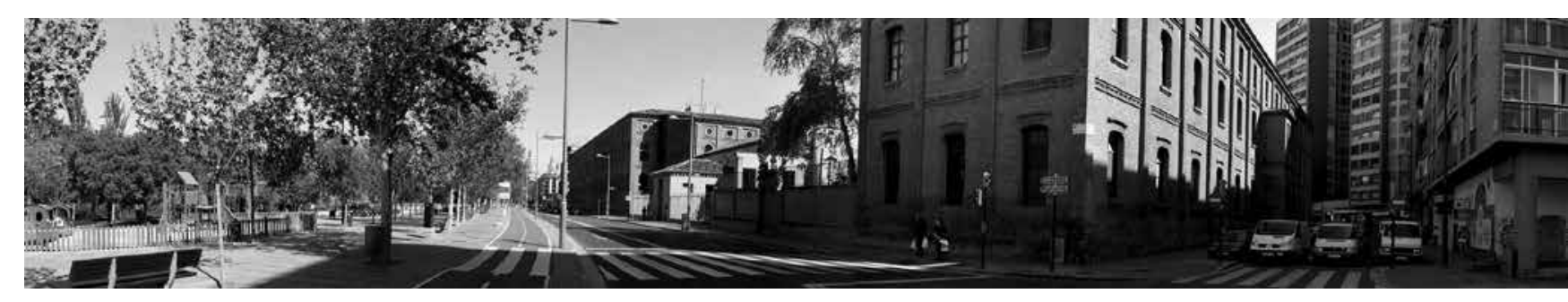

Luis Bunuel-Echegaray.

1. Objetivos

El usuario

La arquitectura no se hace para los arquitectos o para los gestores públicos y, en consecuencia, cuando lo proyectado se valora únicamente por la coherencia entre las primeras ideas y las realizaciones posteriores, estamos pasando por alto las nuestras. Es importante reivindicar y meditar cuál es el espacio de representación en el que el usuario pueda tener la palabra, pensando en una dimensión política del lugar que es el derecho que tiene cada uno a utilizarlo, a apropiarse de él y a que le represente legítimamente.

\section{Gastar tierra}

Supuestamente, tenemos un espacio arquitectónico que es nuestro porque somos arquitectos o gestores públicos y hemos venido al mundo para construir y ocupar la tierra. La filosofía que hay detrás de todo esto nos recuerda que disponemos de un lugar y entonces lo dividimos, lo loteamos, hacemos habitaciones con el, lo compartimentamos... pero no es éste un acto antoposito bastante phmano?. Fr.ne a todo ello, lo que se propone son acciones respetuosas

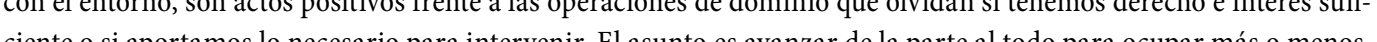
dence si ap o de accislo con aspectos frif

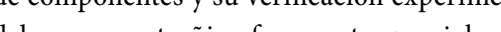

\section{Sostenibilidad}

El concepto sostenibilidad es una estrategia que va de lo individual a lo colectivo y que debe contener una actitud activa y al mismo tiempo reivindicativa. Esta es la forma de transmitir el concepto sostenibilidad, con la acción... y

\section{Método}

Micro-urbanismos. Re-habilitación urban

Cada vez es más frecuente observar en nuestras calles y plazas realidades que siempre habíamos considerado domésticas. Al contrario también pasa, todos los días vivimos en nuestras casas situaciones que implican relacionarnos con personas que no son de nuestro núcleo familiar. El diseño doméstico de nuestras ciudades y el urbanismo del diseño de interiores parecen herramientas oportunas en el mundo que nos ha tocado vivir. Esto nos lleva a pensar que los espacios públicos y privados son términos simplificados, definidos en base a conceptos de propiedad para organizar la ciudad. En cambio, sus usos, gestión y comportamientos se han complejizado, distorsionando la terminología convencional hasta hacerla completamente obsoleta.

La propuesta es iniciar proyectos de acupuntura, probetas en las que no exista la posibilidad de error puesto que son procesos, no situaciones estáticas. Dinámicas adaptables a cualquier tipo de ciudadano, a saber:

- Haciendo ciudad donde no la hay: proponemos habitar propositivamente los vacíos urbanos. 


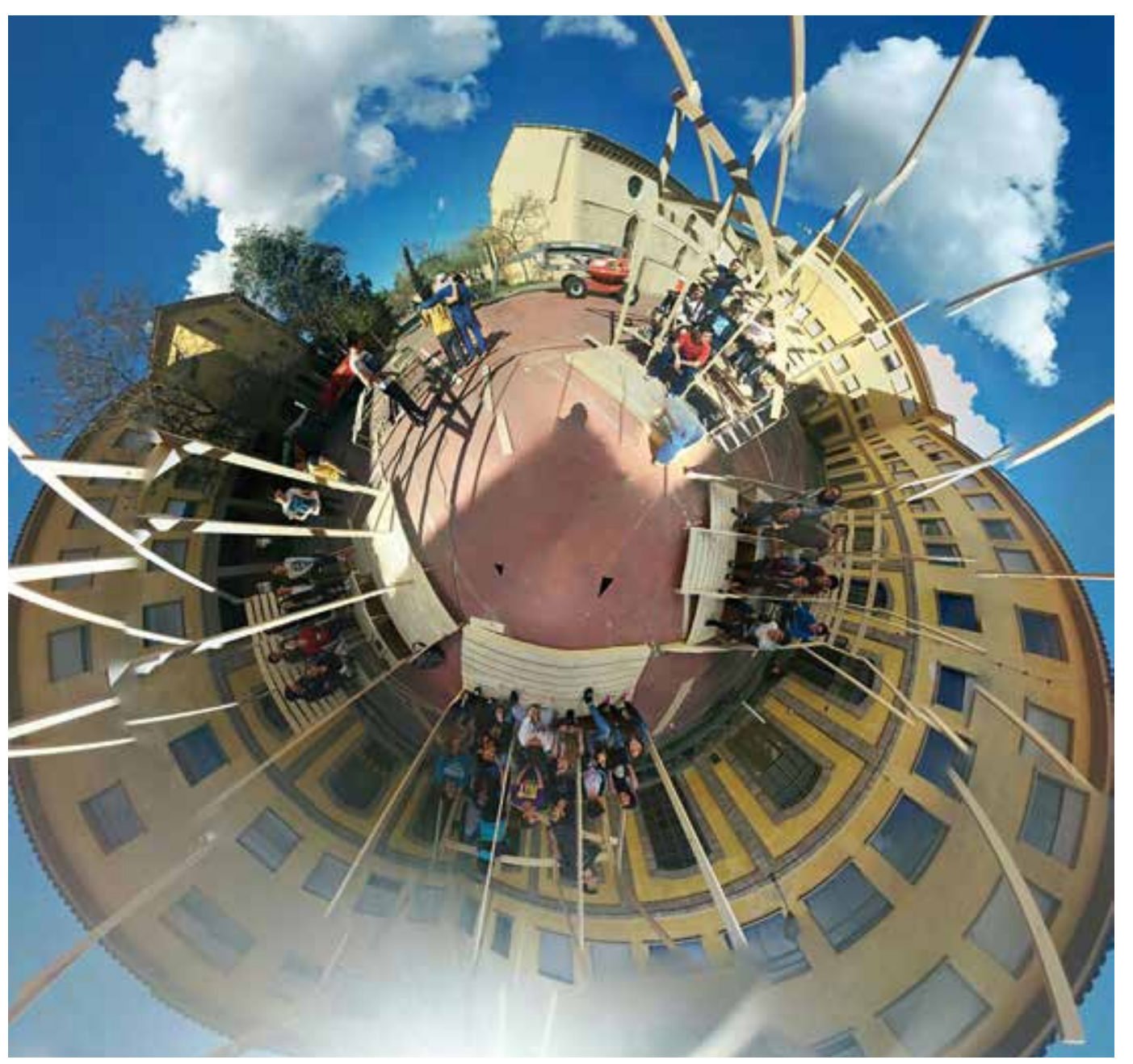

- Necesidad de habitar el conflicto: el cambio nace gestionando la controversia sin intentar simplificarla Mind the gap: buscamos incluir al mayor número de agentes posibles en las tomas de decisiones, tendiendo puentes con la administración.

Las reglas del juego: entendemos el espacio público como un espacio complejo, los procesos deberán incluir regla mentaciones, puertas y horarios

Autonomía ciudadana: investigar de qué manera se pueden abrir las infraestructuras a la ciudadanía

- Ciudad híbrida: ciudad transmediática y multiformato con espacios públicos que favorecen la comunicación, la participación, la gestión y la financiación.

- Espacio crítico participado: empoderamiento ciudadano que permite la transformación a partir de procesos bottom-up. Urbanismo eventual: contemplar la ciudad como el gran contenedor de prácticas culturales, activador de relaciones sociales

La ciudad nunca se inauguró: y nunca se va a dar por concluida, con procesos de transformación que contemplen otros márgenes temporales.

Commons sense: recuperación en la vida cotidiana de las regulaciones cualitativas del sentido común y de la escala de barrio
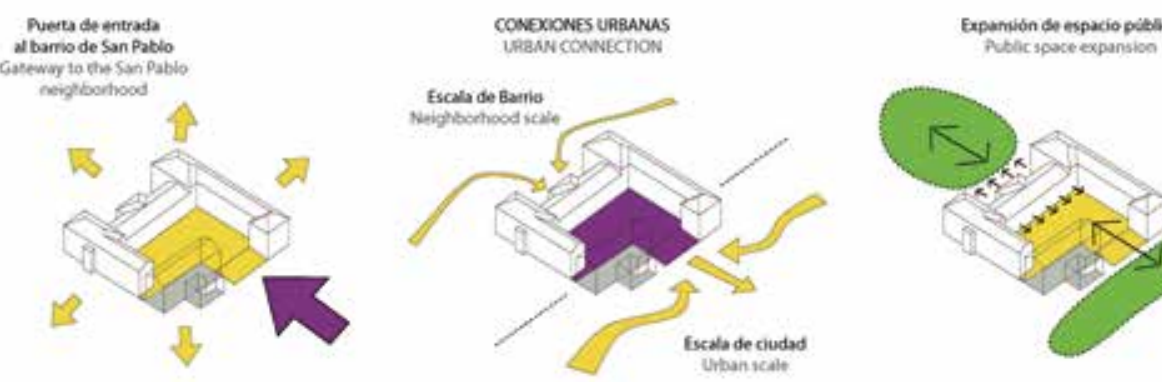

Siv
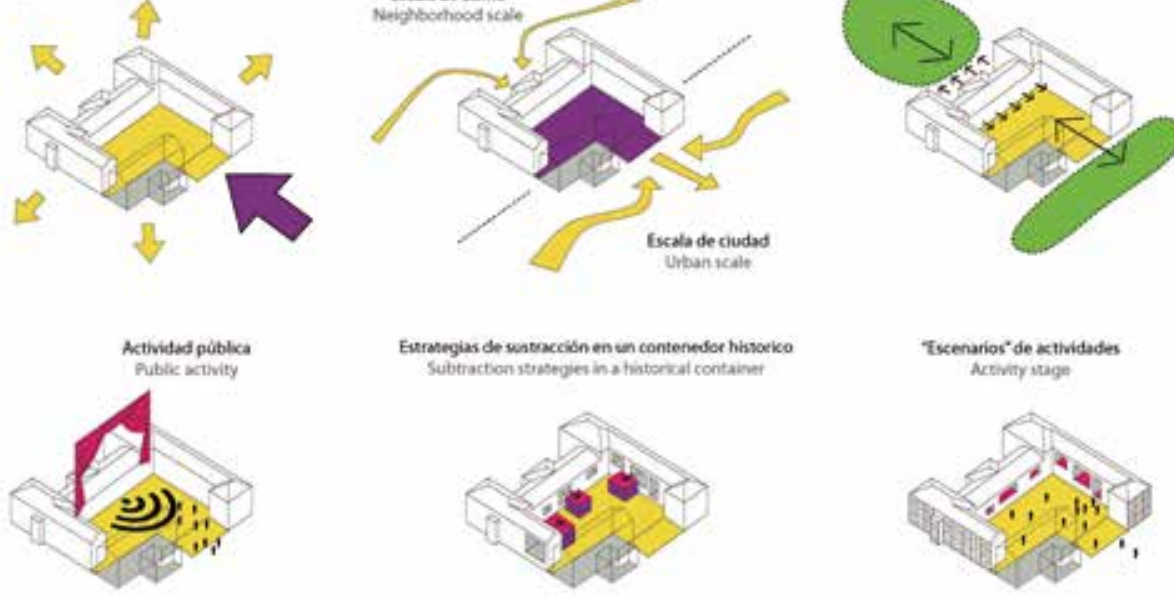

Ciudad open source: espacios con licencias Creative Commons de código abierto; con la vocación de réplica, adapta bilidad y evolución

Hand made urbanismo: construcción del espacio a través de procesos directos y entornos pedagógicos; transparenciu y open data; comunicación explicita y transparente de todos los procesos que suceden.

Revisión de las autorías: dinámicas de diseño capaces de hacer partícipes a todos los usuarios.

- Infraestructura para el resto de la ciudad: intervenciones en lugares puntuales que se convierten en un espacio útil para plantear nuevos procesos ciudadanos.

- Mobiliario a medida para el ciudadano/cuidador: diseñando soportes para nuevas formas de utilizar la ciudad, permitiendo roles ciudadanos basados en el cuidado y la curadoría de lo urbano.

Optimización de recursos materiales: con políticas de segundas vidas y reutilizaciones.

Los nuevos contratos del arquitecto: nuevos roles como diseñadores de servicios y no solo de productos.

- Herramienta altavoz: espacio de construcción de redes en contextos internos y externos que permiten amplificar las opiniones ciudadanas para capacitar su escucha.

\section{Re-ocupación/Re-construcción}

Se trata, en esencia, de analizar las propuestas que pretenden reutilizar o re-construir una estructura en desuso para prestar servicio a la comunidad y frenar su deterioro.

En aras de conseguir la sostenibilidad económica y funcional se deberán tomar decisiones capaces de adaptarse, con t tiempo, al desarrollo de las diferentes actividades que los espacios propuestos acojan. Se analizará la sostenibilidad e haciol

La edificación recuperada la imaginaremos permeable, permitiendo una acusada relación con circulaciones de entorno. De esta manera, el edificio funcionara coexistiendo con su conflictiva situación y no pretenderá ordenarla, sino sólo permitirá cosas. No impondrá situaciones totalmente determinadas, convirtiéndose en un contenedor flexible despojado de un lenguaje codificado.

Enlaces urbanos

Deberemos analizar el éxito de estas acciones de acuerdo a su grado de implicación con el resto de dotaciones equivalentes, creando una red de continuidad y acción que evite su caducidad y permita crear enlaces de actividad. 


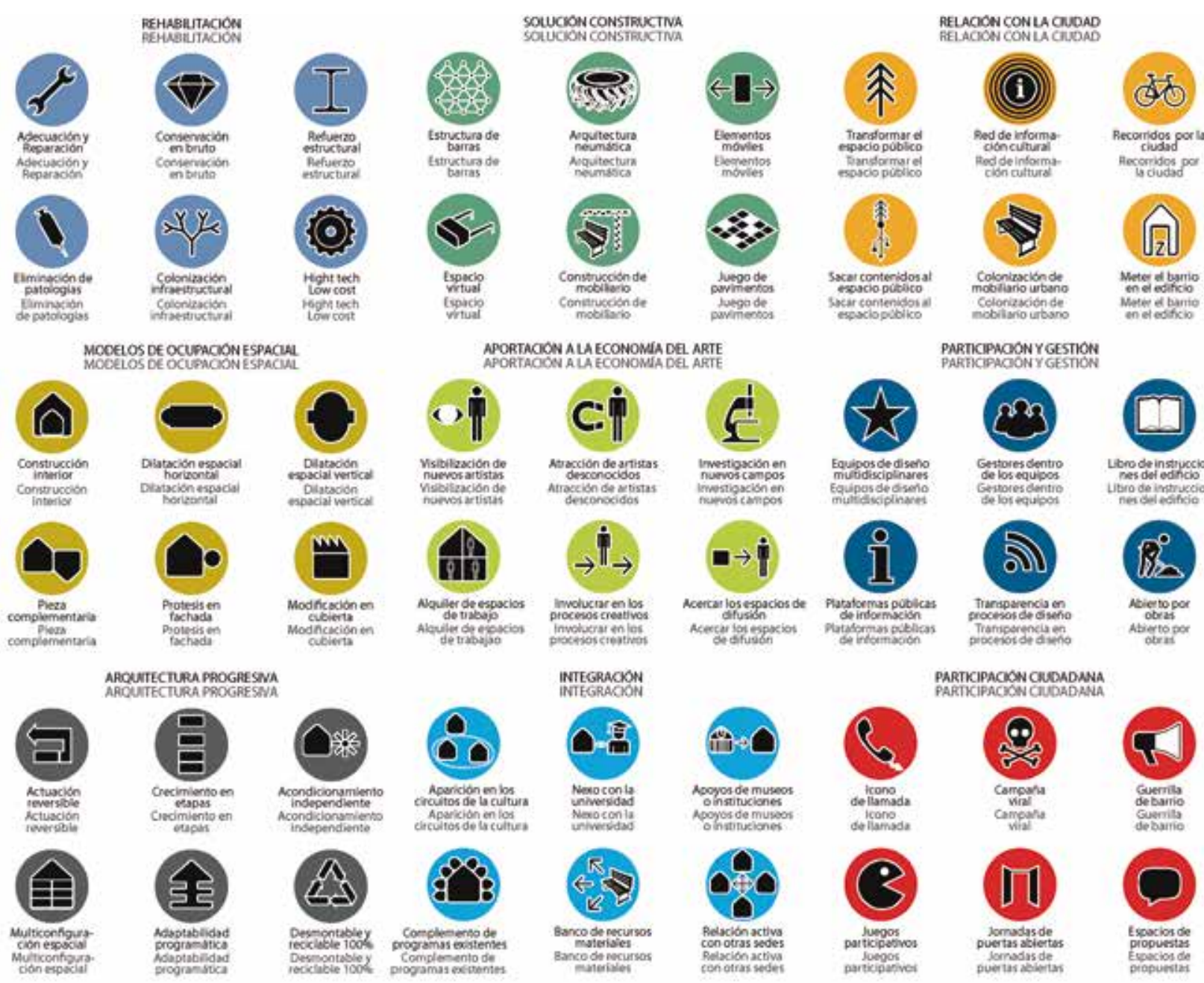

Se trata de 'Pensar la Ciudad' y adaptar las estrategias urbanas existentes a través del análisis selectivo de datos abstractos que serán interpretados para describir las características estructurales generales. Estas exploraciones analititractos que serán interpretados para describir las caracteristi
cas nos revelarán estructuras invisibles de nuestra sociedad.

3. Herramientas

Para desarrollar la metodología es necesario un catálogo de herramientas arquitectónicas que unirán todas las propuestas analizadas. Un contexto de estrategias comunes que permitirá describir con los mismos códigos cualquier acción urbana.

4. Etapas

Micro-urbanismos

Se propone legitimar el patio del 'Luis Buñuel' a través de talleres ciudadanos, con sistemas constructivos que permitan la creación colectiva y el diseño producido con múltiples cabezas pensantes, pretendiendo construir la ciudad

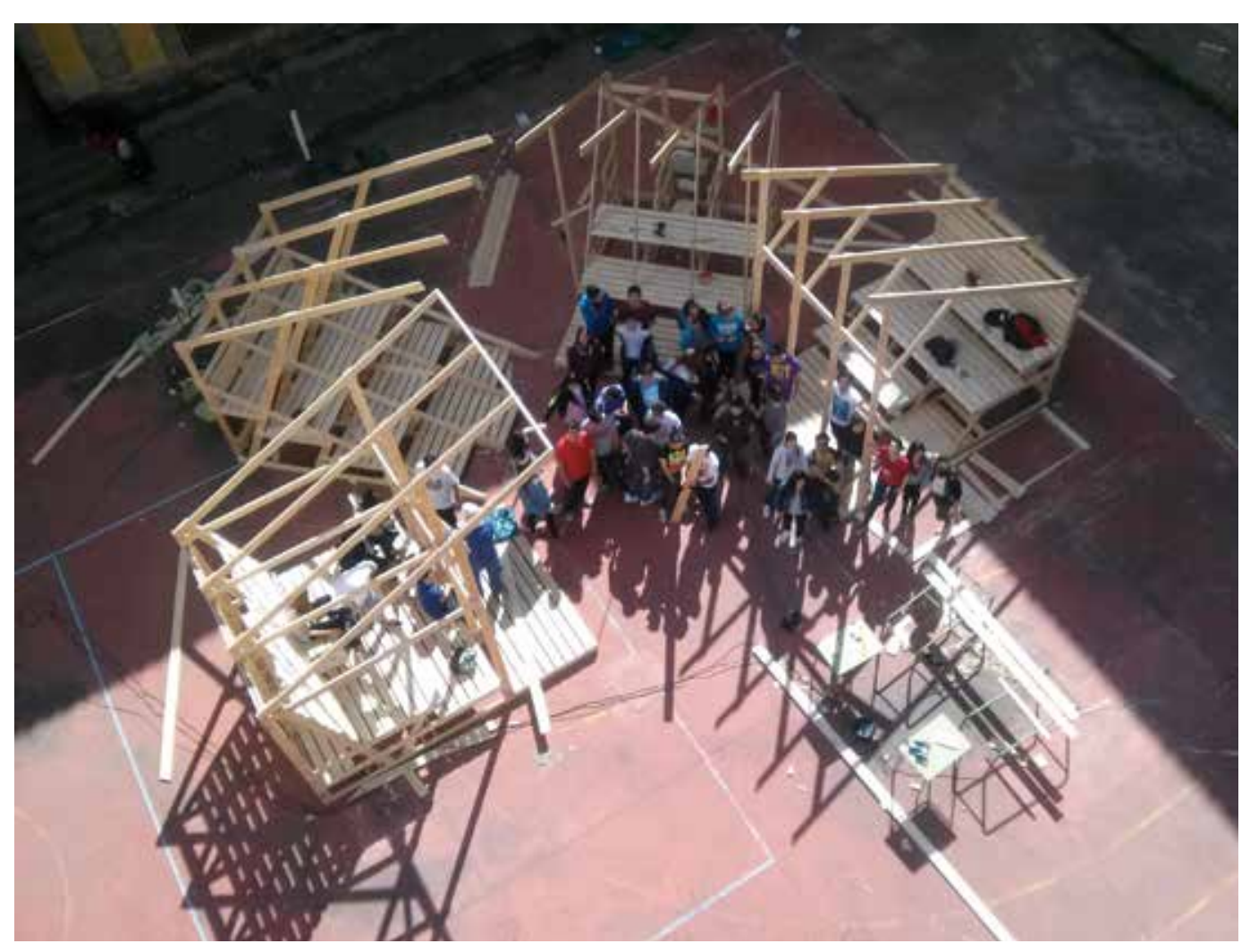

desde lo que es muy pequeñito para poder pensarla desde la escala muy grande. Estas iniciativas tratarán de investigar y analizar proponiendo, nos adentrará mucho más en las redes de proveedores, en el conocimiento local constructivo y en las condiciones de contorno. El objetivo es la configuración de talleres docentes, con institutos de investigación, universidades, asociaciones vecinales o socios locales. Los formatos pedagógicos permitirán involucrar a muchos agentes en el conocimiento de herramientas y procesos, trabajando desde la hibridación entre el conocimiento técnico yel popular.

En este momento, el patio del Buñuel está siendo testigo de una rica actividad participativa a través de talleres, eventos culturales y sociales ${ }^{\star}$. Es un ejemplo, la celebración del taller participativo [UNIZAR / PICH / red.prospección. urbana / Colectivos] urban.outcast.festival.

El objetivo... comprobar, a través de la verificación experimental, si merece la pena que vayamos más allá, proponiendo la Re-ocupación//Re-construcción de los contenedores o espacios en desuso asociados a la actividad. Esta cuestión implica, necesariamente, la captación del interés y la atención de los poderes administrativo y empresarial.

\section{Re-ocupación/Re-construcción}

Se apostará, en primera fase, por la rehabilitación de la planta baja del antiguo instituto, con la finalidad de incorporar la cota cero al espacio público del barrio, contemplando: la sostenibilidad funcional relacionada con soluciones de programas entrelazados de activación independiente o simultánea; el control de los recursos constructivos y la previsión de los costes de conservación futuros.

El objetivo... determinar la rentabilidad social y/o cultural en relación con los recursos económicos invertidos, valorando el éxito de la intervención; cuestión de la que podría derivarse la propuesta de rehabilitación de las plantas alzadas, escenificando el proceso de avance de la parte al todo para ocupar más o menos, de acuerdo con aspectos funcionales $y$ de eficiencia. 


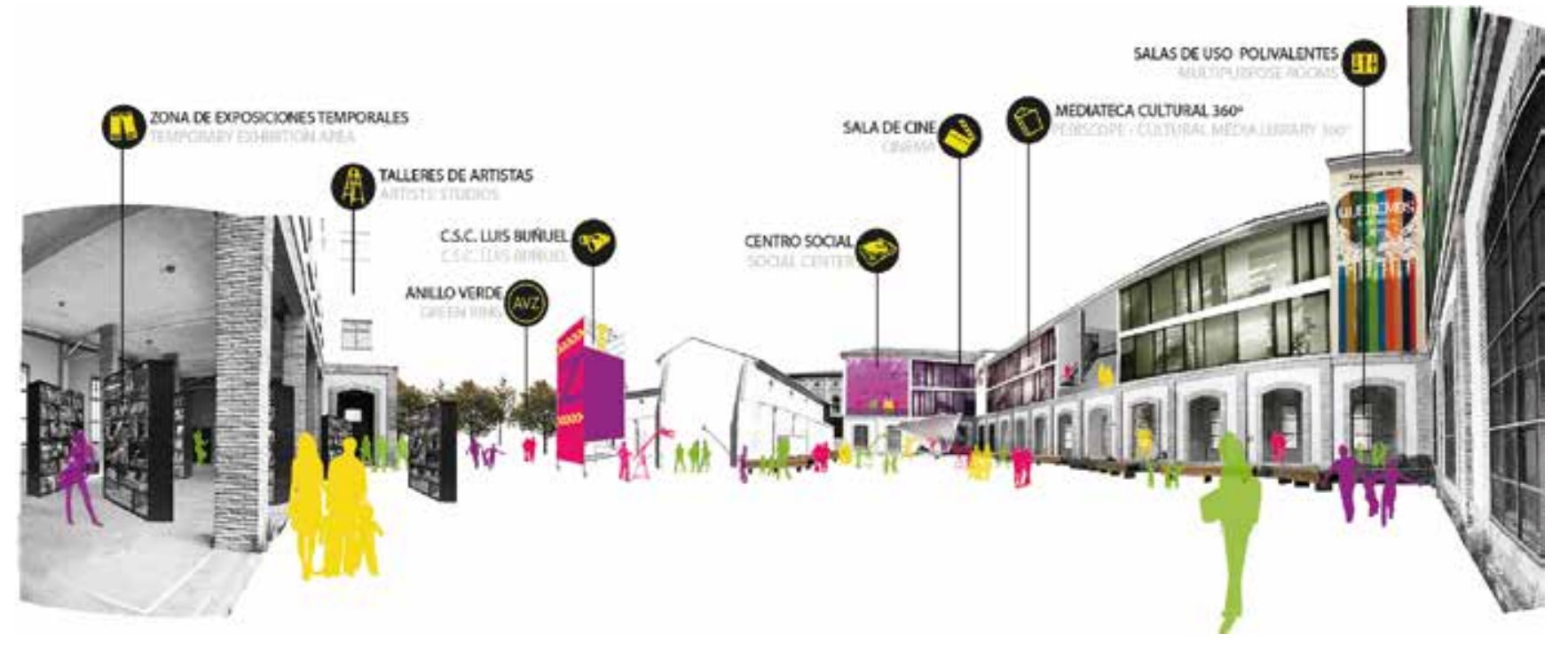

Enlaces urbanos

La integración de la cota cero en el espacio público existente permitirá el enlace urbano 'escala barrio' a través de la Plaza de Santo Domingo y la conexión escala ciudad' a través del eje 'Patio/Echegaray/Ribera'.

El objetivo... la incorporación de redes ciudadanas, imprescindibles para impulsar: la innovación social enfocada a un desarrollo sostenible, inclusivo y creativo; y la creatividad/producción cultural como generadora de nuevas economía a través del emprendizaje cultural. De este modo, San Pablo se podrá conffgurar como un punto de intercambio de economia cultural, aunque la clave estara en trabajar a través de las pequenas iniciativas de emprendizaje para dota-

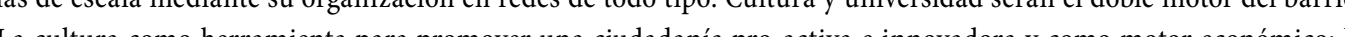

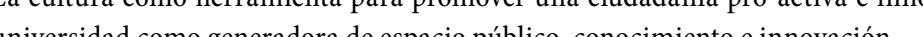

losé Javier Gallardo Ortega. Arquitecto y Urbanista por la Universidad Politécnica de Valencia. Ha sido profesor de la ETS Ar tectura de Universidad de Valencia; Miembro electo Comisión Cientifico-Técnica de Universidad de Valencia; arquitecto del Ayurtamiento de Valencia; becado por el Ministerio de Educación y Ciencia como investigador en el CSIC, Instituto Eduardo Torroja de Zaragoza deste 1990 . Zaragoza desde 1990, responsable de Conservación Patrimonio, Oicina Proyectos I y arquitecto del Area Cultura, Educación, Medio (OMA, UNSTUDIO Y y jurado en concursos de arquitectura nacionales e internacionales. Su obra ha obtenido diversos premios nacionales e internacionales IGarcía Mercadal, Palacio Congresos Zaragoza, Wan Awards 21 X 21, Puerto Mangalia Rumanía, ABarcelona, Hospital Neuropsiquiátrico Granollers, Lamp, X BEAU, Unidad Discapacitados Conductuales... y ha sido ampliamente difundida en congresos, medios escritos y audiovisuales (TVE, California TV, El Pais, El Croquis Editorial, Arquitectura Viva, AV Un UNIZAR; director y fundador de la revista del COAA $Z$ arquitectura; fundador $y$ CEO de urban prospection network y fundador/ director de urban.outcast.festival
Una experiencia contada por el colectivo "Dale Vida al Luis Buñuel"

El proyecto "Dale Vida al Luis Buñuel" surge de la convergencia de varios factores: el estallido del movimiento social 15M ante la situación socioeconómica actual, la creación de una asamblea de barrio que se reúne en la AVV LanuzaCasco Viejo, la necesidad de un espacio en el que los colectivos y proyectos sociales de la ciudad puedan encontrarse y tejer redes, y el interés por el trabajo comunitario como herramienta de politización y empoderamiento de la ciudadanía.

El proyecto de construcción de un Centro Social Comunitario (CSC) ha sido desarrollado desde metodologías participativas que nos han permitido recoger las demandas de las personas que de alguna manera han querido sumarse

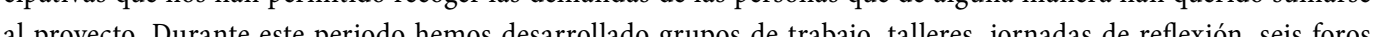
participativos y cientos de asambleas.

El principal objetivo del proyecto ha sido, y es, construir comunidad, generando nuevas formas de relación, de trabajo, de comunicación, de participación, de cooperación.

El proyecto se genera con el fin de rehabilitar un edificio público abandonado, dotando al distrito del Casco Histórico de un nuevo equipamiento abierto y participativo en el que se realicen actividades propuestas y gestionadas por el mis-
mo vecindario. Del mismo modo, se pretende favorecer la actuación en red de los distintos entes socioculturales del

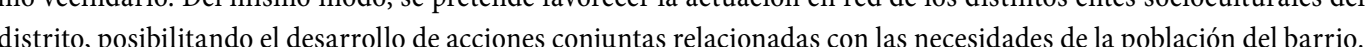
Hemos reflexionado mucho en torno al modelo de gestión que queremos para el CSC Luis Buñuel. Nos hemos empapado de muchas otras experiencias de gestión colectiva de lo público, y desde allí hemos empezado a construir el modelo que mejor se corresponde a nuestros valores, objetivos y sueños.

Planteamos la Gestión Compartida del espacio. Nuestra intención es generar un diálogo con las administraciones. Decidimos dar un paso como personas que viven en la ciudad y quieren implicarse en pensar qué tipo de espacios queremos crear y cómo.

Nuestro modelo de gestión plantea la Asamblea como organismo soberano de toma de decisiones en relación a los objetivos y acciones del proyecto. Las asambleas son abiertas e inclusivas, lo cual facilita que cada persona pueda objetivos y acciones del proyecto. Las asambleas son abiertas e inclusivas, lo cual facilita que cada persona pueda
decidir libremente cómo y cuándo se implica en el provecto. Asimismo se estructura en base a varios ejes de trabajo que contemplan diversidad de aspectos, desde la gestión de uso cotidiano, hasta la proyección política, pasando por el trabajo relacional.

Planteamos el proyecto como un servicio comunitario abierto al barrio y la ciudad. Las personas que formamos parte del grupo motor de gestión del edificio trabajan en la creación de estructuras de participación y en el desarrollo de proyectos y actividades de interés social y cultural de forma voluntaria y gratuita.

Desde el CSC Luis Buñuel queremos ser escuela de participación democrática. Un espacio donde todo el mundo pueda llegar a ver, escuchar, proponer, participar, aprender, cuestionar 



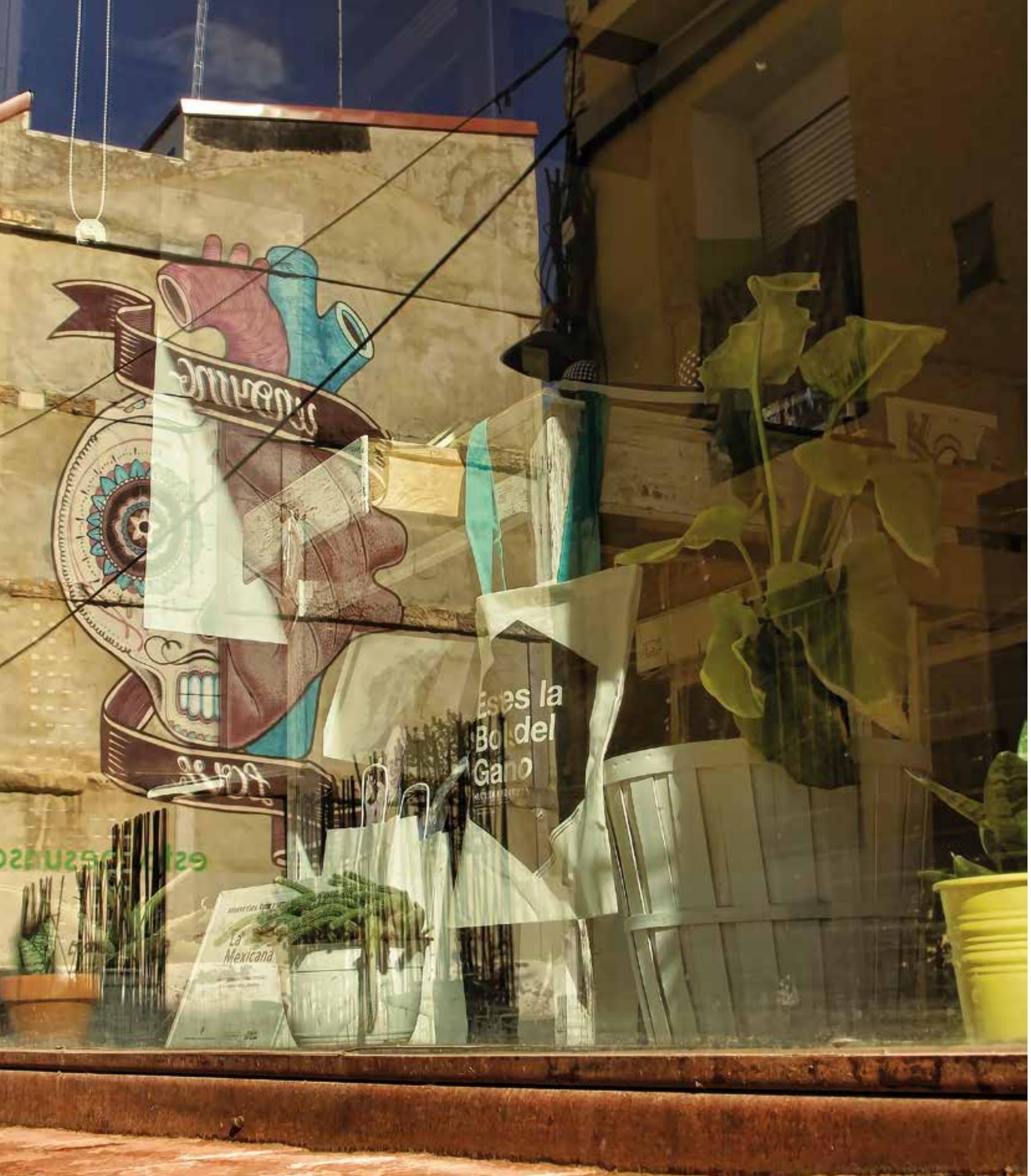

REFORMAS URBANAS EN ZARAGOZA

INNER URBAN RENEWAL IN ZARAGOZA

Ricardo S. Lampreave y Carmen Díez 
In the mid-19th century, European cities began to find themselves under pressure to grow. The significant increase of populations, advances made by the industrial revolution and the obsolescence of their medieval social fabric demanded corrective structural actions. Neither the expansion or extension of their walls, nor the proliferation of disorganised suburbs outside city walls had solved anything at all in the cities where such growth had taken place. In Spain, following the example of other European cities, Expansion and Inner Reform operations were also undertaken, as we well knowAs their names clearly show, some designed the urban landscape outwards with ambitions to expand and to grow territorially, while others corrected and adapted the interior, but both radically questioned the historic concept of the city. Compared to cities such as Bilbao, which due to their particular orographic conditions could only choose Expansion, the majority, including Zaragoza, chose with various degrees of commitment, to undertake operations of both types.

The difficulty of judging their complex political and economic vicissitudes determined the history of the 19th century. The changes that occurred during its course to replace the old system, which was already outdated, thanks both to Enlightenment's legacy and to liberal consolidation, caused a series of significant social conquests in Spain, mainly exemplified in cities. A new perspective on life, which challenged a society based on the privileges of power, and the consequent acceptance of the free market compared to any other type of economic control created thriving condtions for the new bourgeoisie. $A$ situation that, after the democratic revolution of 1868, in a predictable pendular movement, became clearly conservative

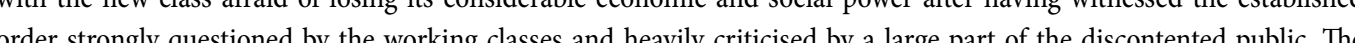
order strongly questioned by the working classes and hearly criticsed by a large part of the discontented public. The succession of conservative governments imposed restrictions of all kinds, ranging from those against the liberty of the press to those ncladed he clectoral system, opening up a sharp divide between the various social and political forces of Spain. The essential social peace required to ensure modernisation that emulated contemporary European advances was only achieved when the living condtions in cities were improved, thereby satisfying many social needs without reducing

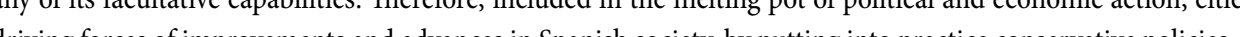
driving forces of improvements and advances in Spanish society, by putting into practice conservative policies.

Even if we study the peculiarities of each of the cities, we can see that in the end nothing substantially different happened in them. Only certain specific circumstances, always derived from their geography or history, differentiate them. In this context it is necessary to explain the particular urban history of Zaragoza during the last two centuries.

As the river Ebro obstructed everything but a modest suburb on its left side, the ecclesiastical confiscations processes took advantage of the destruction caused by the Napoleonic sieges of 1808 and 1809 to buildings of strong urban identity (the Abbey of Santa Engracia, the convents of San Francisco and Jerusalén, the Hospital Nuestra Señora de Gracia) in order to ensure that the city would grow southwards. There, where so many times the Council had championed the proposals of its officers, the venue proposed by Joaquín Asensio first extended the "el Coso" street up to the gate of Santa Engracia in front of the river Huerva, inspired by the Parisian rue Rivoli. After this, always moving southwards, the Expansions proposed by Casañal and Magdalena, Casañal and Burbano, Navarro, the urban development proposed the Expansions proposed by Casanal and Magdalena, Casanal and Burbano, Navarto, the urban development proposed

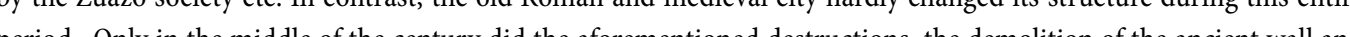
period. Only in the middle of the century did the aforementioned destructions, the demolition of the ancient wall and he successive Ecclesiasical Contscations or Mendzabal and Madoz slyghy herease hie ribn space in response to the (a) squares.

This was the opportunity for the Municipal Council Office, led by the architect José de Yarza y Miñana, to prepare the Geometric Map of the city in 1861 (fifteen years after the Royal Order that obliged councils to do so was enacted) which made a first set of significant alignment modifications possible. It is true that the debates that took place and the strong opposition to the proposed demolitions impeded the works. However, in exchange, it was the good fortune
El presente texto tiene por objeto presentar el trabajo desarrollado en el curso La ciudad como paisaje cultural. Construir sobre lo construido (código 69207, Área de Composición Urbanística) y los correspondientes trabajos de nuestros alumnos, que finalmente reseñamos. Preparamos el curso para complementar, desde las competencias de nuestra

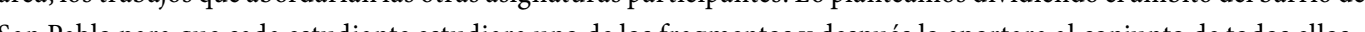
A mediados del siglo XIX, las ciudades europeas empezaron a verse acuciadas por la necesidad de crecer. El notable incremento de sus poblaciones, los avances propiciados por la revolución industrial y la obsolescencia de su propio tejido medieval exigian medidas estructurales correctoras. Ni la ampliación y extensión de sus murallas ni la proliferación de desordenados arrabales extramuros habian solucionado nada en la mayoría de las ciudades que así crecieron. En España, siguiendo el ejemplo de otras ciudades europeas, como es bien sabido, también se abordaron operaciones de Ensanche y de Reforma Interior. Provectando el tejido urbano hacia el exterior unas, con una ambición expansiva, de crecimiento territorial, y corrigiendo y adaptando el interior las otras, como expresamente indican sus denominaciones, ambas cuestionaron radicalmente la ciudad historica. Frente a ciudades como Bilbao, que por sus específicas condiciones orográficas sólo pudieron optar por el Ensanche, la mayoría, también Zaragoza, acometió con mayor o menor decisión sucesivas operaciones de ambos tipos. La dificultad de arbitrar sus complejas vicisitudes políticas y económicas determinó la historia del siglo XIX. Los cambios que se sucedieron en su transcurso para desbancar al antiguo sistema, ya caduco, gracias tanto al legado ilustrado como a la consolidacion Ilberal, propiciaron en nuestro país una serie de significativas conquistas sociales, plasmadas principalmente en las ciudades. Una nueva perspectiva vital, negadora de una sociedad sostenida por los privilegios del poder, y la consecuente aceptación del libre mercado frente a cualquier tipo de dirigismo económico moldearon pujantes presupuestos para la nueva

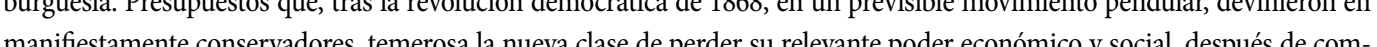
manticstantente conservadores, temerosa la nueva clase de perder su relevante poder econónico y social, después de comprobar el orden establecido fuertemente cuestionado por los sectores obreros y may criticado por gran parte de la descontenta opinión publica. La sucesion de gobiernos conservadores impuso restricciones de todo tipo, desde las impuestas a la libertad de prensa a las incorporadas al sistema electoral, facilitando una acusada division entre las diferentes fuerzas sociales y politicas del país. Sólo consiguieron la imprescindible paz social para asegurar una modernización emuladora de los contemporáneos avances europeos cuando mejoraron las condiciones de las ciuddes, satisfaciendo no pocas demandas sociales sin men-

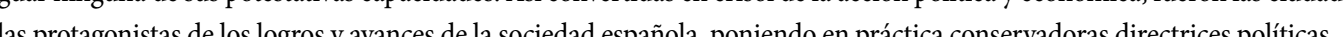
las protagonistas de los logros y avances de la sociedad española, poniendo en práctica conservadoras directrices políticas. Por más que aludamos a las particularidades de cada una de ellas, podemos comprobar que nada sustancialmente distinto acabó sucediendo en las ciudades. Sólo algunas circunstancias especificas, siempre derivadas de su geografía e historia, acaImpidiendo el río Ebro cuanto no fuera un modesto arrabal en su margen izquierda, los procesos desamortizadores aprovecharon los destrozos ocasionados por los sitios napolénicos de 1808 y 1809 en edificios de fuerte impronta urbana (el monasterio de Santa Engracia, los conventos de San Francisco y erusalén, el Hospital de Nuestra Señora de Gracia) para
facilitar que la ciudad fuera creciendo hacia el sur. Allí donde tantas veces el Municipio ha destacado por las propuestas de sus técnicos, el salón planteado por Joaquín Asensio prolongó primero el Coso hasta la puerta de Santa Engracia delante del sus tecnicos, el salón planteado por Joaquin Asensio prolongoo primero el Coso hasta la puerta de Santa Engracia delante del
rí Huerva, con la inspiración de la parisina rue Rivoli. Después llegarían, siempre hacia el sur, los Ensanches de Casañal y Magdalena y del mismo Casañaly y Burbano, el de Navarro, la urbanización propuesta por la sociedad de Zuazo, etc. Por el contrario, la vieja ciudad romana y medieval apenas modificó su estructura en todo este periodo. Sólo a mediados de siglo, las mencionadas destrucciones, la demolición de la antigua muralla de tapial y las sucesivas desamortizaciones de Menlas mencionadas destrucciones, la demolicion de la antigua muralla de tapial y las sucesivas desamortizaciones de Men-
dizábal y Madoz incrementaron ligeramente el espacio urbano, atendiendo las crecientes exigencias de vialidad e higiene y aprovechando el progresivo abandono del centro histórico para facilitar pequeñas operaciones puntuales de apertura, y aprovechando el progresivo abandono del cen

Fue la oportunidad de que la oficina municipal dirigida por el arquitecto José de Yarza y Miñana elaborara en 1861 el Plano Geométrico de la ciudad -quince años después de que se promulgara la Real Orden que obligaba a los ayuntamientos a hacerlo- la que permitió una primera serie importante de modificaciones de alineación. Ciertamente, los debates surgidos y la fuerte oposición a las demoliciones propuestas impidieron que se abordara. Pero, a cambio, pasó a ser una suerte de plan 


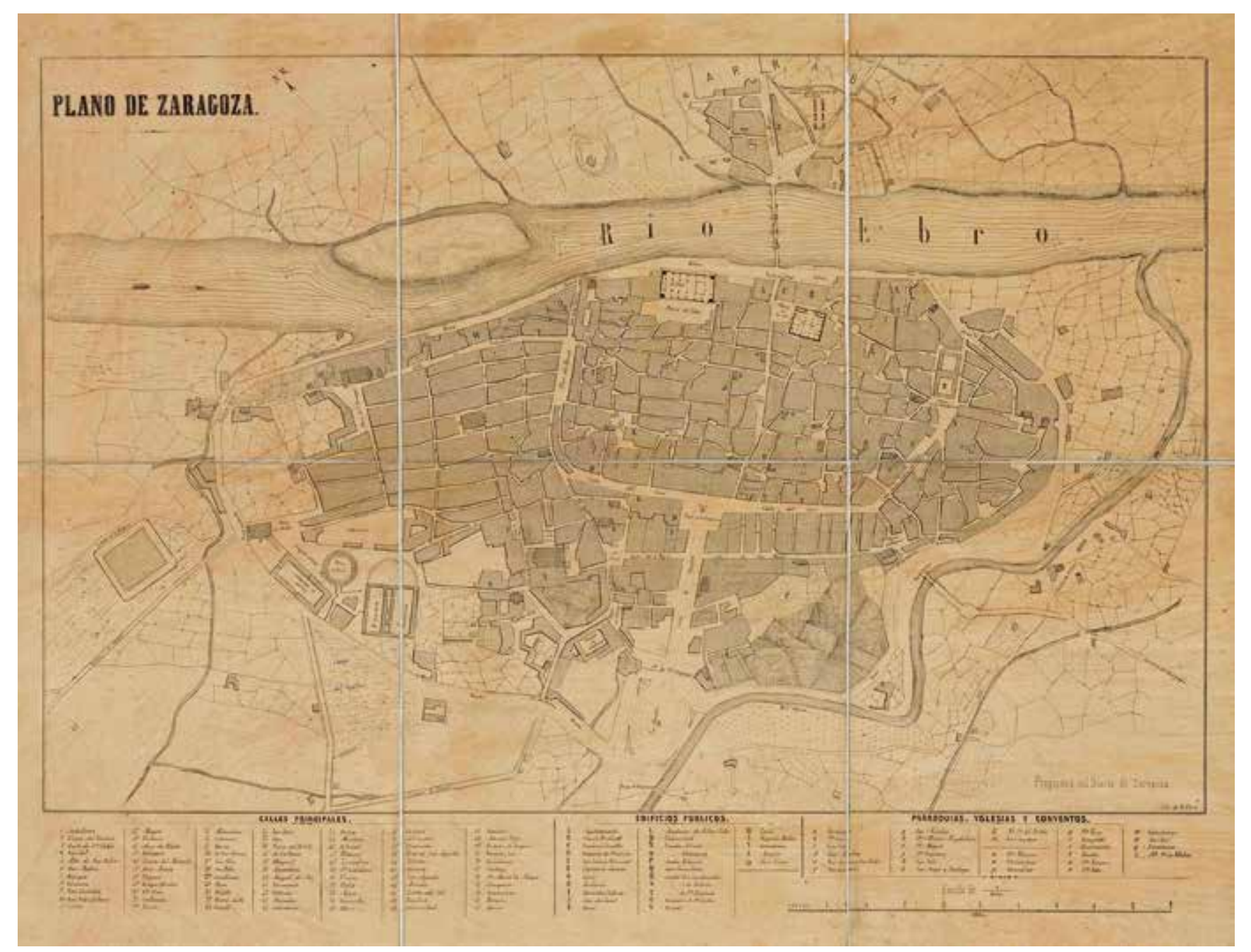

Zaragoza, Agustín Peiró y Sevil,
1850.

of the master plan that all of these Inner Reform works, which were all minor, were carried out in the city during the following decades. The fact that these works were not drafted by civil engineers and soldiers, as was the case in most cities that carried them out (only in certain cities was the Royal Order complied with), resulted in the survival of their design and solutions, without any detriment whatsoever to the accuracy and precision required to represent the shape of the city at the time. We should remember that the geometric maps were the first urban tool capable of projecting a general concept of a city's structure, transcending the traditional way of thinking and acting in the city through parts that were more or less unconnected. The San Pablo district therefore owes a great deal of the appearance that we know
today to Mr Yarza.

Despite the significant expansion that the city was experiencing, or perhaps to a large degree because of it, the Historic Centre of Zaragoza ( obviously also our district) reached the end of the century in a dilapidated state, with housing problems, including a lack of dwellings in acceptable conditions, which meant that they were expensive. Meanwhile, the Inner Reform Act of 1895, officially called the Inner Sanitary and Improvement of Cities Act, and enacted under the title "Act of 18th March 1895 for the inner sanitation, reform and expansions of cities with 30,000 or more souls", replaced the Geometric Map th until then had unofficially regulated the works carried out occasionally in the historic district for over thirty years, and became the new frame of reference. The objective of the Act was to improve the living conditions of many cities and also to impose greater administrative control on projects in larger cities, through a new expropriation act, for example.

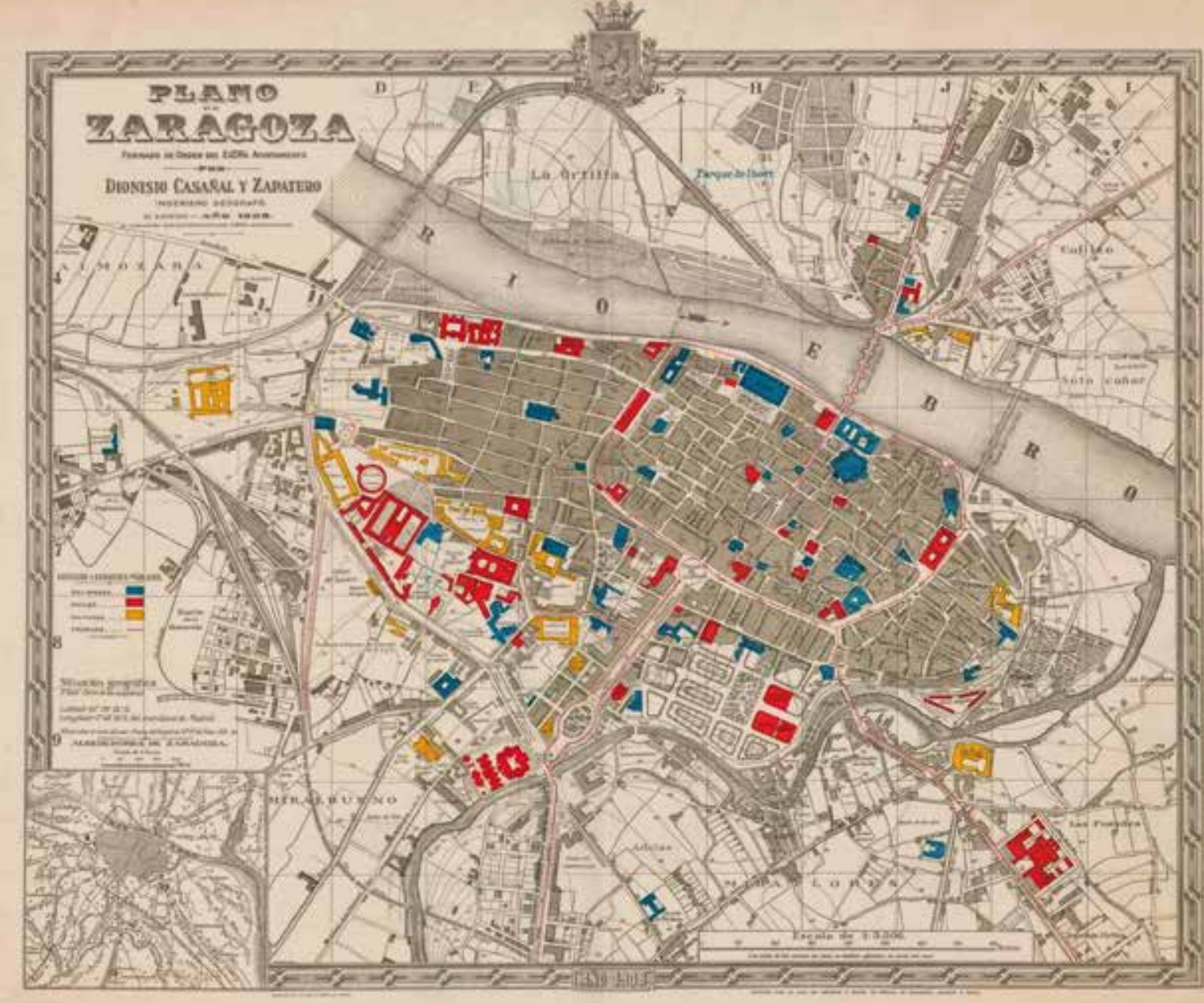

Zaragoza, Dionisio Casañ
yZapatero, 1908

director para todas aquellas operaciones de Reforma Interior que, siempre con menor alcance, se fueron acometiendo en la ciudad durante las siguientes décadas. Que no fueran ingenieros civiles y militares quienes lo redactaran, pues asi fue en la mayoría de las ciudades que lo elaboraron -sólo en contadas ciudades se cumplió la Real Orden-, redundó en la pervivencia de sus criterios y soluciones, sin menoscabo ninguno de la exactitud y precisión requeridas para representar entonces la forma de la ciudad. Recordemos que los Planos Geométricos fueron la primera herramienta urbanistica capaz de proyectar una idea general de su estructura, trascendiendo el modo tradicional de pensar e intervenir en la ciudad por fragmentos más o menos inconexos. Es pues a este Yarza a quien el barrio de San Pablo debe en gran medidal la fisonomía que hoy conocemos. Pese a la notable expansión que va teniendo la ciudad, o quizás en buena medida debido a ello, el casco histórico de Zaragoza -también obviamente nuestro barrio- llega extenuado al fin de siglo, con notables problemas de habitablidad, con una notoria escasez de viviendas en condiciones, que no las hace especialmente asequibles. Mientras, la Ley de Reforma Interior de 1895, denominada oficialmente como ley de saneamiento y mejora interior de las poblaciones, y que se promulgó con el título "Ley de 18 de Marzo de 1895 para el saneamiento, reforma y ensanche interior de las poblaciones de 30.000 ó más almass, vino a sustituir al Plano Geométrico que hasta entonces habia regido oficiosamente durante algo más de treinta años las operaciones puntuales acometidas en su casco historico, convirtiéndose en el nuevo marco de referencia. La ley tuvo como cometido mejorar las condiciones de muchos núcleos urbanísticos, y también interponer un mayor control administrativo sobre los proyectos de las mayores ciudades, a través, por ejemplo, de una nueva ley de expropiaciones. 

part of the Piarist School, the great opening up of the district took place with the opening of Portillo Street (late to be General Franco and then Conde de Aranda), proposed in the Geometric Map as early as 1861. This opening considerably improved the east-west traffic between el Coso and the road to Madrid and transformed the district José de Yarza Jose de Yarza Echenique, who at the time was also a municipal architect, who in 1913 proposed the plan that was

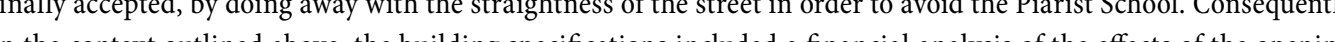
In the context outlined above, the building specifications included a financial analysis of the effects of the opening the Forced Expropriation Act of 1879. The long-term required for the complete opening of the street (in fast, sice 1917 the fol steth was

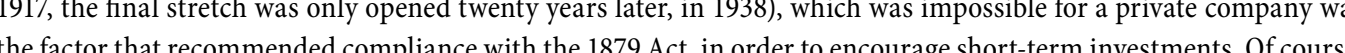
the factor hat recommended compliance withe realigned, the contrast caused by the new functions of a street that was now mecr ing streets were also extended and realigned, the contrast caused by he new functions of a street hat was now more in keeping with a modern city tha maximum height of 24 metres with respect to the rest of the divided district). The Gran Vias were so new and the and the of a new mass society, with the consequent change in the urban landscape and its city centres.

If, as Walter Benjamin said, a city is a book where you can read your own history, just as there was a moment when William Morris began to consider the double page, and not the individual page, as the graphic compositional problen to be resolved, cities also ceased to be thought of "by streets" and became more extensive areas. The most important point about this moment is that, as well as proposing the opening or expansion of a street including the rectificatio of its alignments, work was started on its structuring capacity regarding the adjacent streets in a relatively open environment. This new understanding meant that the old strip to be expropriated in tandem with the new alignmen started to form fairly regular-shaped blocks from a formal point of view, as shown by the Inner Reform Plan of 1939 by Regino Borobio and José Beltrán. It was this plan that for the first time would design the historic centre as a whole, by including partial and delayed inner reform projects. Its greatest contributions regarding the San Blas district were the reconfiguration of the points where the convents are located, reaching el Portillo, and the expansion of San Blas Street, so that the east-west connection was hierarchically organised through Portillo/General Franco Streets continuing along el Coso, with Predicadores Street following the line of the Roman decumanus maximus - nowadays Mayor Espoz, Mina and Manifestación Streets - to the northernmost point, and San Blas Street and its expansion on Cereros Street between Mercado and Maria Agustin Streets, between both main streets. The approval by the Central Board 1942 established the global vision of the historic centre and the need to consider its reconfiguration in a unique way. If Cerdá set out in his Theory of Urban Vitality how to deal with problems that require the greatest attention ("Science has already raised its powerful voice and from now on will do so for the reforms of large labyrinthine cities that we have inherited in recent centuries or for their enlargement when the excessive accumulation of citizens makes their expansio necessary, or for the foundation of new cities when special circumstances so demand... In all these situations it will be necessary to consult science, the friend and constant protector of humanity"), the specifications of the majority of Zaragoza projects that were carried out after that time confirmed his ideas. The Inner Reform project proposed by José de Yarz Echenique in 1914 explained exactly how much could be expected from the new city: "... it must provide: comfort, health and decoration, which in this case translates into what the law calls highways, hygiene and public ornamentation". Years later, in his Partial Inner Reform Plan by areas of 1937, Regino Borobio also defined his objectives as "improving the health of some sectors, easing traffic in the centre of the city and highlighting buildings of artistic and historic interest".

In short, what we mean is that to some degree, considering these problems both as strictly quantitative and as if we weighted the advances that occurred in each field, neither the problems of cities in evolving in step with everchanging times nor the plans proposed to solve them have changed. Living conditions, mobility and culfur wit considered as the objectives through which we continue to maintain, adapt and improve our cities. Of course, this has been and continues to be true of a district as influential in the history of Zaragoza as San Pablo.
En San Pablo, después de sucesivos intentos en 1893 y 1904, frustrados por pretender expropiar parte de las Escuelas Pías, la gran apertura que acometió el barrio fue la de la calle Portillo (futura General Franco y actual Conde de Aranda), planteada ya en el Plano Geometrico de 1861, mejorando considerablemente el trafico este-oeste entre el Coso y la carretera a Madrid y transformando el barrio, inevitable consecuencia de este tipo de reformas, con la elevación del precio de los

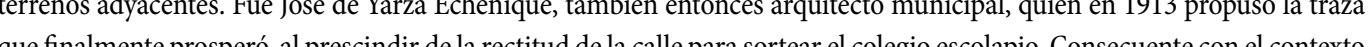
que finalmente prospero, al prescindir de la rectitud de la calle para sortear el colegí escolapio. Consecuente con el contexto a Forzos de 1879. Je la

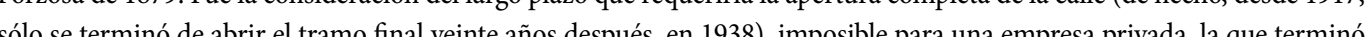
sólo se terminó de abrir el tramo final veinte alos después, en 1938), imposible para una empresa privada, la que terminó realineadas a la diferencia volumétrica que planteaban las ordenanzas -fijendo la altura máxima de $24 \mathrm{~m}$ respecto al resto del barrio seccic

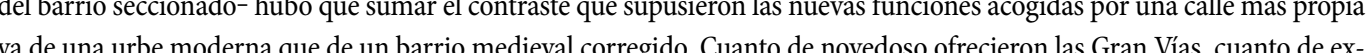
ya de con el consiguiente cambio en el paisaje urbano del centro de sus ciudades.

Si como decía Walter Benjamin la ciudad viene a ser un libro donde poder leer su historia, igual que hubo un momento en el que William Morris empezó a considerar la doble página, y no la aislada, como el problema compositivo gráfico a resolver, también la ciudad dejó de pensarse "por calles" para hacerse por zonas más extensas. Lo más relevante de este momento es que, además de proponerse la apertura o el ensanchamiento de una calle con la rectificación de sus alineaciones, comenzó a trabajarse con su capacidad estructurante sobre las adyacentes en un entorno más o menos amplio. De manera que, con esta nueva comprensión, la antigua franja a expropiar paralela a la nueva alineación pasó a configurar manzzanas más o menos regulares desde el punto de vista formal, tal como evidenció el Plan de Reforma Interior de 1939 de Regino Borobio y José Beltrán. Fue este el Plan que por primera vez vino a planificar el conjunto del casco antiguo, incorporando proyectos de reformas interiores parciales y demorados. Sus aportaciones más importantes en relación al barrio de San Blas fueron el ensanchamiento de la calle San Blas -de manera que la conexión este-oeste quedó jerárquicamente ordenada por la calle Portillo/General Franco continuando el Coso, la calle Predicadores siguiendo la traza del decumano máximo romano (hoy calles Mayor, Espoz y Mina y Manifestación), en el extremo norte, y la calle San Blas y su prolongación Cereros entre el Mercado y María Agustín, entre ambas mayores-, y la reconfiguración del extremo de los conventos, llegando al Portillo. Con la aprobación de la Junta Central en 1942 quedó consagrado el entendimiento global del casco historico y la necesidad de pensar su reestructuración de forma única.

Si Cerdá pautó en su Teoría de la Viabilidad Urbana cómo abordar los problemas que requerían mayor atención ("La Ciencia ha levantado ya su prepotente voz, y en adelante para las reformas de las grandes poblaciones laberinticas que en los pasados siglos nos han legado, o par su engrandecimiento cuando la excesiva acumulación de pobladores aconseje su ensanche, o para la fundación de algunas nuevas cuando especiales circunstancias lo aconsejenn... En todas ellas se deberá consultar a esa misma Ciencia amiga y protectora constante de la humanidad"), las Memorias de gran parte de los proyectos zaragozanos que desde entonces se fueron sucediendo vinieron a corroborarlo. El proyecto de Reforma Interior planteado por José de Yarza Echenique en 1914 clarificó cuanto cabía exigir a la nueva ciudad: "... debe cumplir: comodidad, salubridad y decoración que se traducen en este caso en lo que la ley llama vialidad, higiene y ornato público". Años después, en su Plan de Reforma Interior Parcial por zonas de 1937, también Regino Borobio fijó sus propósitos en "mejorrar la salubridad de algunos sectores, facilitar el tráfico en el centro de la población y realzar los edifficios de interés artístico o histórico"

Queremos decir, en definitiva, que en mayor o menor medida, tanto considerando estos problemas como estrictamente

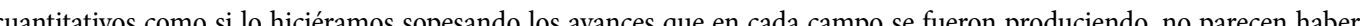
Q

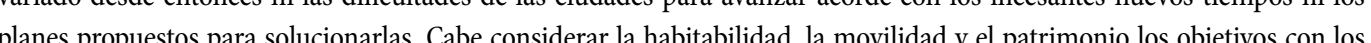
determinante en la historia de Zaragoza como es San Pablo. 
$98 \mid 99$ ANALILIS DE REFORMAS URBANAS |ANAIYSIS OF URBANREFORMS

01 CÉSAR AUGUSTO, UNA VÍA RECUPERADA | CÉSAR AUGUSTO, A RECOVERED ROAD Isabel Ezquerra Alćázar

El estudio realizado sobre la evolución de la histórica Vía Imperial de la ciudad de Zaragoza, esta vía ha logrado en los últimos años recuperar las principales cualidades que la acompañaron a lo largo de su histori

Vuelve a ser plaza, como lo era la antigua plaza de Lanuza, vacio articulador entre los primeros trazados de la ciudad durante todos los siglos en los que el mercado al aire libre se ubico en ese espacio de representatividad de la cuudad. Además es la Puerta de Toledo. Fl Mercado preside el espacio, de ccuerdo con el rol de equipamiento novedoso y funcional con el que fue creado. Aunque con una dudosfunción para la ciudad es, hoy en dia, uno de sus edificios con mayor valor arquitectónico e historicico. César Augusto asume también el papel de via arterial para la entre la Puerta del Carmen y el Coso, y para el público entre el Coso y el Puente de Santiago, con el tranvía como un medio limpio y respetuoso que conecta bos últimos crecimientos de esta ciudad y su cent

This study on the evolution of the historical Via Imperial of Zaragoza - currently Cisar Augusto Avenue - explains how this road has achieved, in these last yeers is a square again, as old Lanuza square was, in its role as a void that articulated the early gridding systems of the city throughout all those centuries where the entries ins located in that landmark space. Nowadays, it is also one of the main presides this space, as the new and functional equipment it woste. in spite of its dubious role in the city it is one of the buildings with a recognized architectural and historical value. César Augusto also assumes the role of an

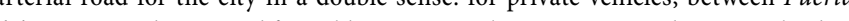
with the new $\operatorname{Cos}$, and for public transport, between Coso and Santiago bridge, the recent suburbs with its center.

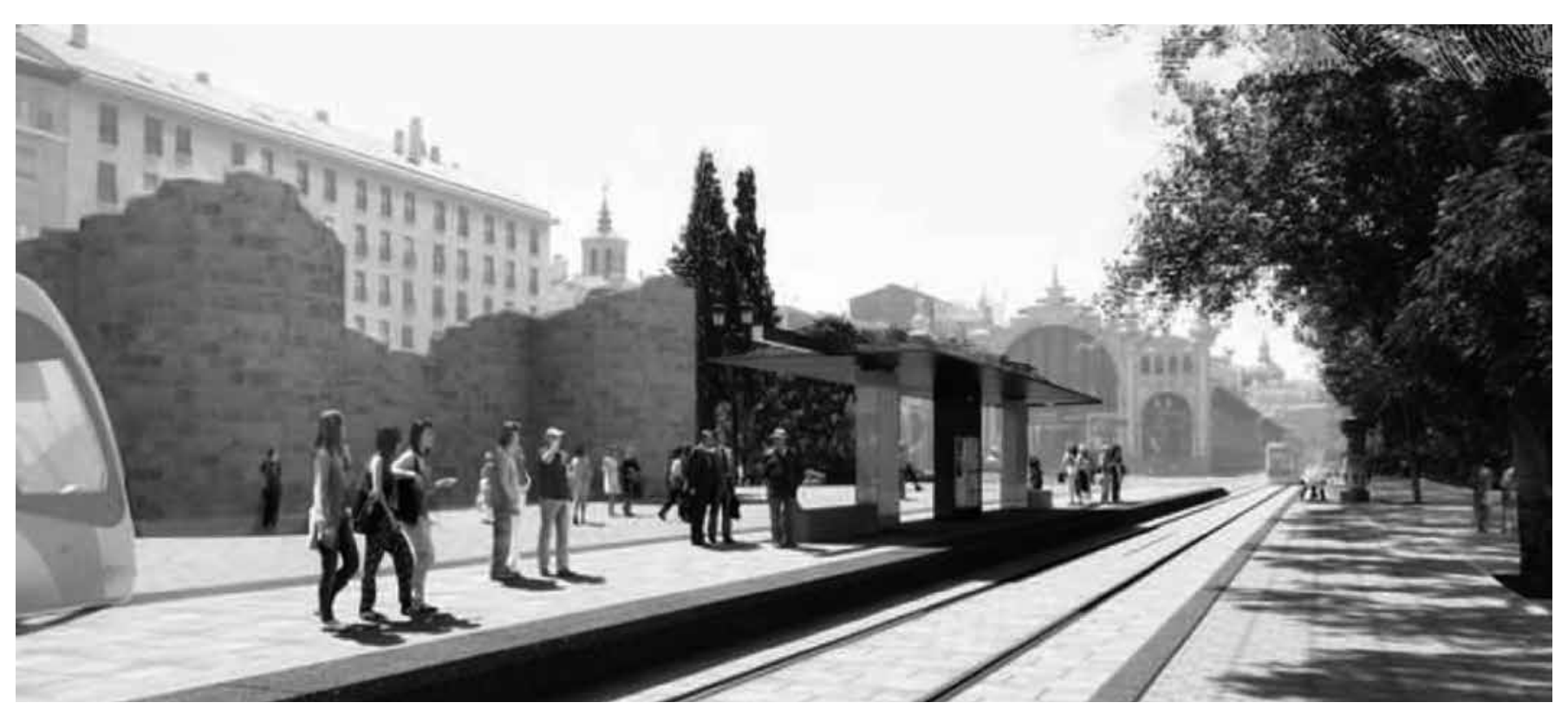

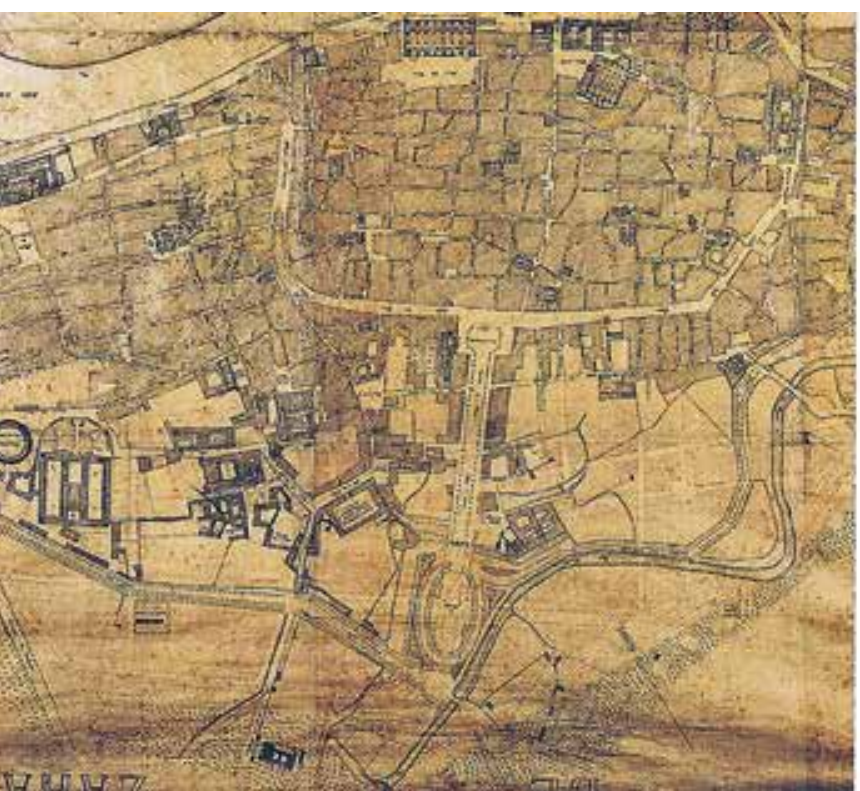

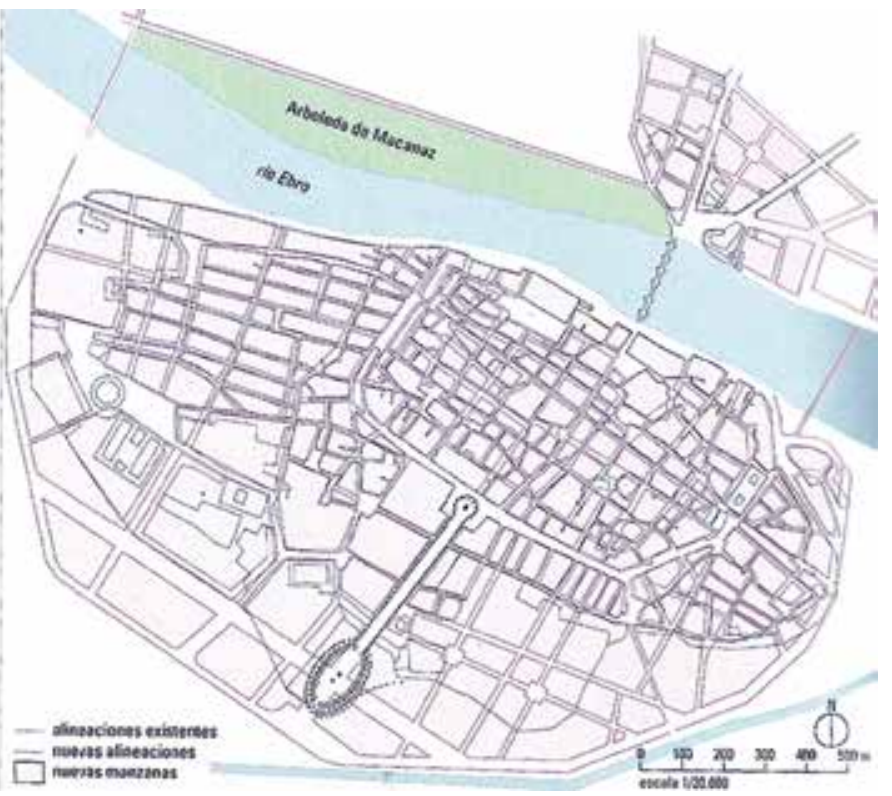

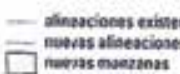

02 LA APERTURA DE LA CALLE DEL PORTILLO Y EL PLANO GEOMÉTRICO DE YARZA | THE OPENING OF PORTILLO STREET AND YARZA'S GEOMETRICAL PLAN Alicia María Gracia Aguilar

La apertura de la Calle del Portillo (1917) es una de las numerosas intervenciones que a lo largo del siglo XX se han desarrollado en el centro histórico de Zaragoz lado, el proyecto fue un plano integradoror, capazaz de representarar en é nel mismo toda las intervenciones que se proyectaban para la ciudad, y por otro lado, fue un plano
burgués, debido a la sucesión de decisiones que favorecian los intereses de b has pudiente frente a las evidentes necesiddes de hirinizción y reordenación que sufría el interior dela ciudda. Y ademass, fue un plano de falso ensanche que se orpo mis de Esta politica de ordenación urbana, en cierto modo predispuesta a la especulación

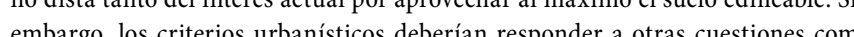
la responsabilidad de construir una ciudad habitable dinámica y adecuada a las necesidades de toda la poblacion sin olvidar que es imprescindible promover desarrollo tecnológico y económico para adaptarse a la sociedad cambiante qu

The opening of Portillo Street (1917) is one of the many interventions that have out the twentieth century in the Zaragozass historical centre and Yarza's Geometrical Plan was its indispensable instrument. On the one hand, hen the ect was able to integrate all the interventions that were planned for the city. the interests of the high-class aginst the obvious sanithy and phes that the city was demanding. Moreover, it was a false planning expansion that was concerned more with the inner consolidation than with a true development of the cily. This policy of urban planning, in some way predisposed to speculation, is hot far from the current interest in maximizing the buildable land. However, of planning an adequate living and dynamic city for its inhabitants, without forgetting that it is essential to promote technological and economic development to accommodate the changing society that inhabits it. 


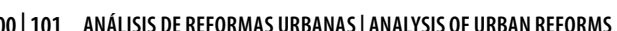

03 LA PROLONGACIÓN DEL PASEO DE LA INDEPENDENCIA Y LA CUESTIÓN DE LA «PROTECCIÓN CULTURAL》| THE EXTENSION OF PASEO DE LA INDEPENDENCA AND THE QUESTION OF «CULTURAL PROTECTION»

Beatriz Jara Beltrán

Desde que en 1812 se inaugurase el Paseo Imperial, que luego pasaría a llamarse Pilar, o incluso hasta la ribera del Fbro, ha sido unan cuestión recurrente que culm nará con la construcción de Puerta Cinegia en 2004. Detrás quedan dos siglos de
tendencias urbanísticas -en ocasiones heredaras, con cierto retraso, de las grandes

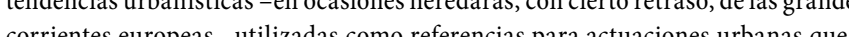
bien se posicionaban a favor de mantener la integridad de los centros antiguos de las ciudades con historia o bien en pro de la remodelación de estos centros.

En el caso de la ciuddad de Zaragoza la declaración como «Conjunto Histórico Attísticoy de su centro historico supuso un punto de inflexión. Desde ese momento se optó por apostar por la integridad del conjunto y desistir en la realización de proyecto. No corrieron la misma suerte conjuntos urbanos como el de Ferrol en $L$

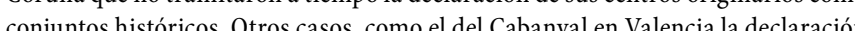
de «Bien de Interés Cultural» no fue suffiente para evitar la aprobación y desrrollo de un proyecto que amenaza los valores del barrio. Estos casos certifican déficit que aun hoy tiene la legislación, tanto urbanistica como patrimonial.
Since the Paseo Imperial -later renamed as Paseo Independencia - was opened In 1812, the debate about its extension up to Plaza del Pilar, or even to the Ebro River, has been a recurrent question that would end with the construction of lied behind: tendencies - Tometimes inherited, with some delay, from the major
lon European currents - used as the inspiration for a series of urban interventions that either favored preserving the integrity and historical values of the old town or its complete renovation

In the case of Zaragoza, the classification of its old town as a «Historical Artistic point. From that point onwards, the city center wa and the extentonseo dela Independencia was abandoned. Fis did not happen be dech roda areas, such as Ferrol in La Coruna, where the paperwork needed to like the $\mathrm{C}$ abs that was not enough to prevent the development of an urban plan that threatens the values of the neighborhood. These cases exemplify the important legal void, both urban and patrimonial, that still persists in the legislation nowadays.

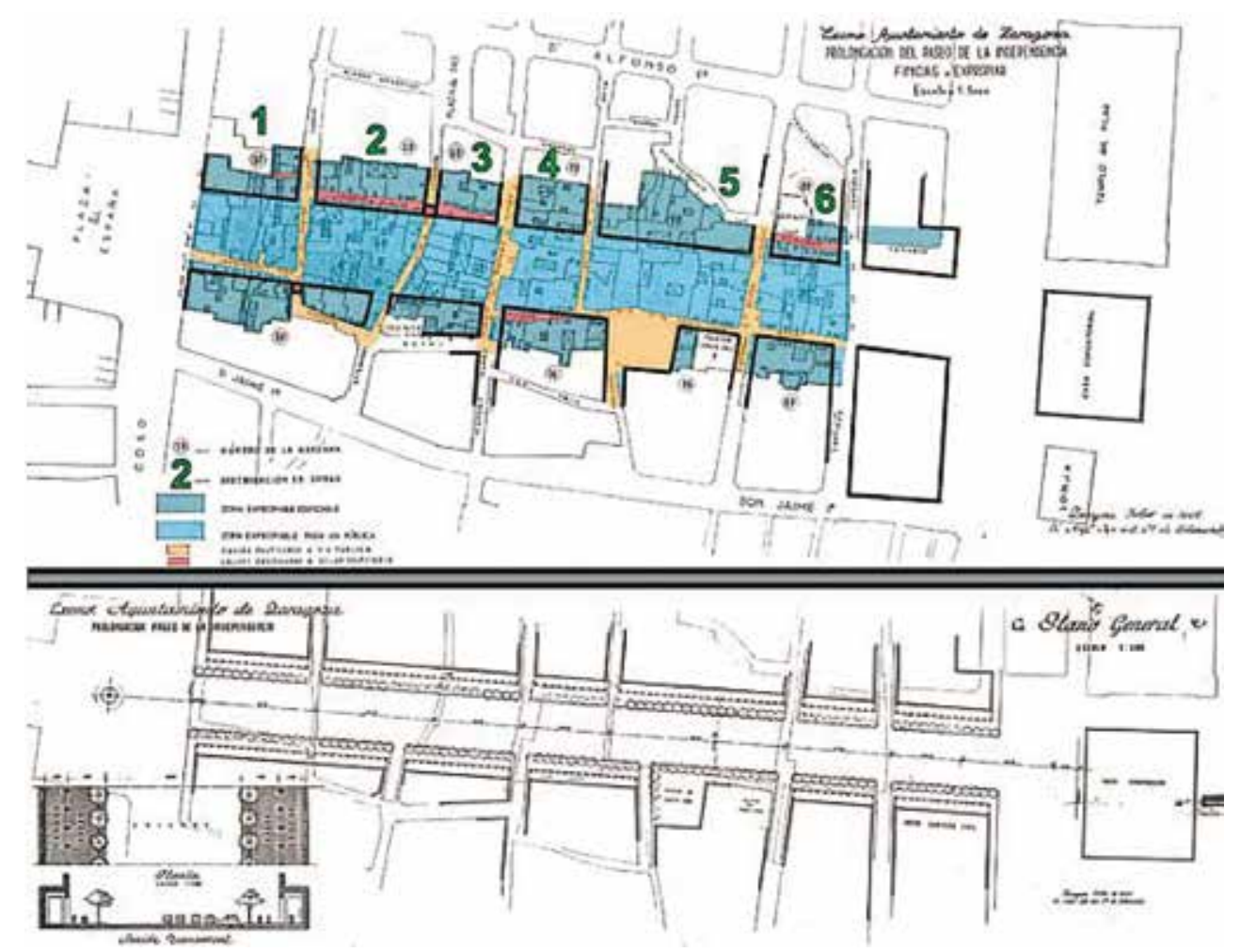

04 PLAZA DE NUESTRA SEÑORA DEL PILAR 0 LA PLAZA QUE QUISO SER AVENIDA | PLAZA NUESTRA SEÑORA DEL PILAR OR THE SQUARE THAT WANTED TO BECOME AN AVENUE

Cristina Jiménez lqquierd

A lo largo de los años varios proyectos urbanos fueron definiendo la morfologia de provecto germen de la configa la plaza tal y como hoy la conocemos. Sin duda el Pilar y de La Seo de Regino Borobio de 1937: «Proyecto Avenida de Nuestra Señora del Pilars. Oros proyectos anteriores intentaron dotar a la plaza de un aspecto «Provecto de alineción de la Plaza del pilare v posteriormente el proyecto de Jose de Yarza en 1914, «Unión de las plazas del Pilar y de La Seo», pero por diversas causas no se llevaron a cabo en su totalidad. El proyecto de Regino Borobio pretend configurar este espacio como el de una avenida, compitiendo con la ordenación

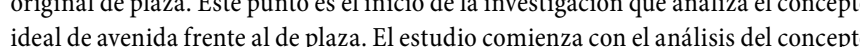
lineal de espacio que fuye y aranza través del ańlísis de los elementos que configuran el lugar hacia un concepto más cerrado.

Over the years there were several projects that shaped the morphology of the square of Nuestra Señora del Pilar untili it gained its current configuration. There is no doubt that its origin was the project proposed by the architect Regino Borobio Nuestra Señora del Pilary. Earlier projects tried to design a new, regular and uniform appearance for $E l$ Pilar. These were the design proposed by Ricardo Magdalena in 1897, «Proyecto de alineación dela Plaza del Pilar», and later, the one by José de Yarza in 1914, «Unión de las plazas del Pilar y de La Seo». However, for project was to configure this urban space as an anevenue, in contrast with its original organization as a square. This is the starting point for this research, which analyzes liner place and continus anlyzing those elements that orgaire the wrbe scene and turn it into a plaza.

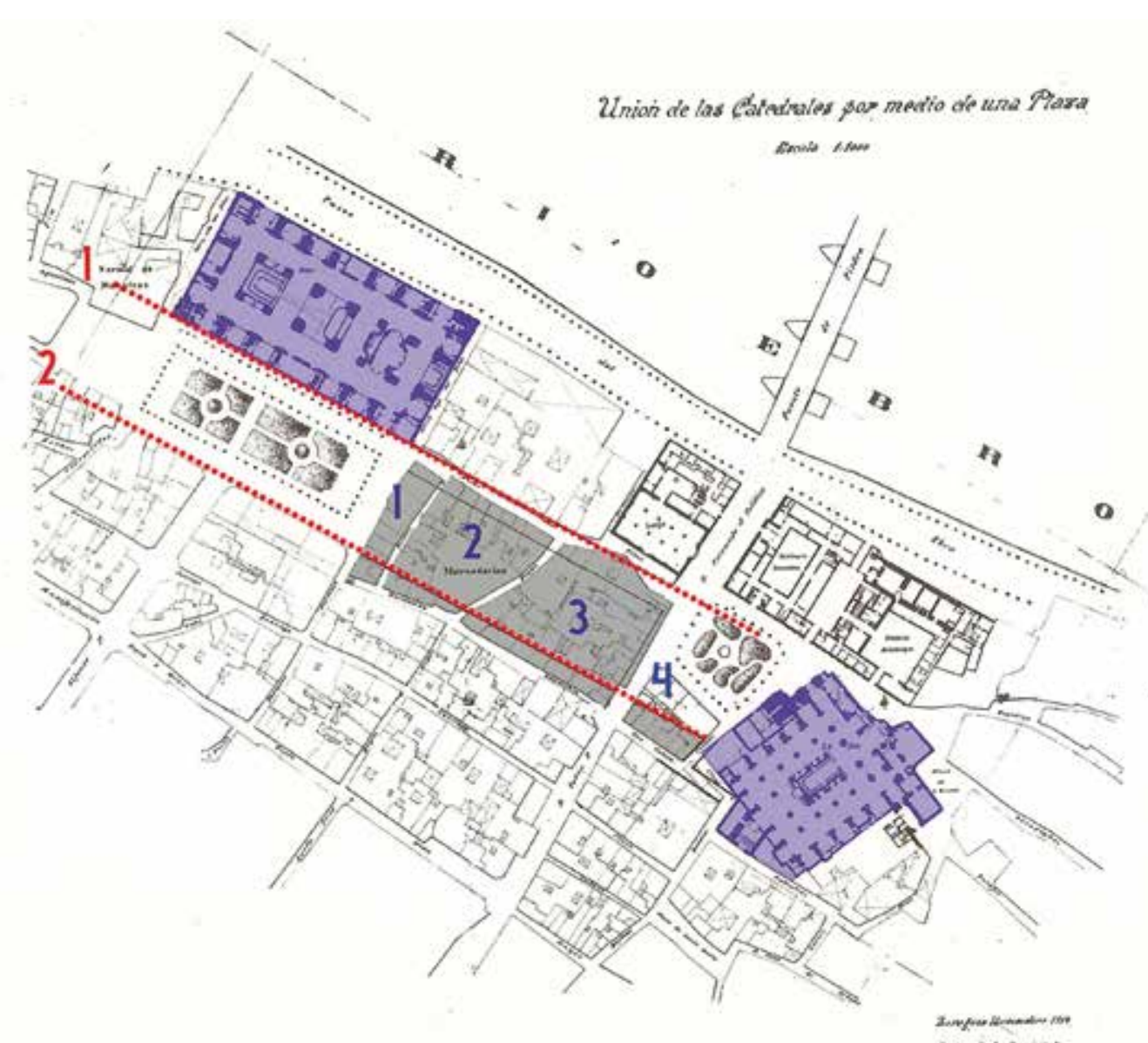




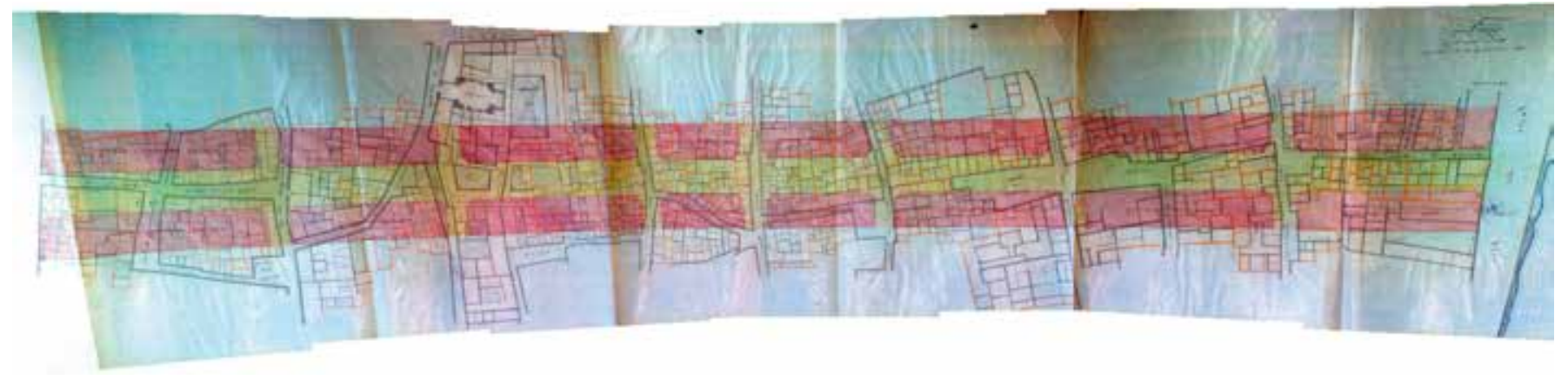

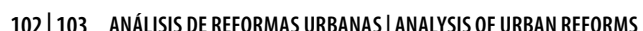

05 UNA CALLE QUE NO ES LO QUE PARECE. CALLE DE LA YEDRA 0 SAN VICENTE DE PAÚL | A STREET THAT IS NOT WHAT IT SEEMS TO BE. YEDRA STREET OR SAN VICENTE DE PAUL

José lópez Garrido

La calle San Vicente de Paúl es el resultado de un largo y tortuoso devenir de proyectos para la apertura y ampliación de la Calle de la Yedra, con el obj
el Coso con el Paseo del Ebro -actual Paseo de Echegaray y Caballero-.

San Vicente de Pauil street is the result of a long and complex series of projects Three consecutive projects -in 1888, 1905 and 1937 by architects Eusebio Lidon, Ricardo Magdalena and Miguel Ángel Navarro in collaboration with Regino Borobio-, were needed to finally open the street in 1940 with the shape that we know today, when its name changed to San Vicente de Paul. Such diflerent projects be, that lacks both interest and functionality and has become longitudinally a mere traffic artery, and, transversally, a barrier. Moreover, the imbalance between the amount of traffic and the scarcity of the space devoted to pedestrians results in a failure in terms of the use of the commercial areas located on the ground floor. stret, adds another weakess to the street that is abs an opporturly as they could be re-used. corísticas adolece de una falta do namiento, y que se ha convertido en una calle de paso para val un fracaso en lo

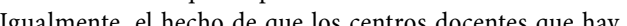
aimed at opening and extending Yedra street with the ultimate goal of connecting
El Coso with Poseo del Ebro - currently called Paseo de Echegaray $y$ Caballero.

\section{CALLE ALFONSO I, SU APERTURA | ALFONSO I STREET, ITS OPENING} Inmaculada Ferreira Gimeno

El urbanismo de una ciudad no es, en muchos casos, sino el reflejo de su historia En el siglo XIX, la expansión de las nuevas ideas heredadas fundamentalmente de Consecuentemente, la industrializazción trajio consigo la modernización de la so ciedad y su urbanismo. La apertura y trazado de amplias calles rectilineas, que clarifiquen la estructur.
banismo de este siglo. de vehículos protagonismo es signo de otra ch.
poder disponerse de los mismos.

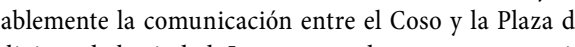
de las condiciones higienicas $y$ del trafico rodado $y$, adem de nueva burguesía de la ciudad. enerally, the planning of a city reflects its history. In the nineteen century, the the new ideas that sprang from the French Revolution prompted the 列eralization of production means. Consequently, industrialization brought about of new linear streets that clarify the existing urban structure is an archetypal procedure of urban planning in the Nineteenth Century.

The opening of Alfonso I Street began in 1861. The problem to solve was the high del Pilar the religious center of the city The openins of then 1 Coso and Plaza the improvement of the health standards and the traffic of the area, and even the creation of commercial areas. The city's regulations for new buildings and the use of a series of common elements in the design of their facades provided the street with f the new bourseoisie of the city-

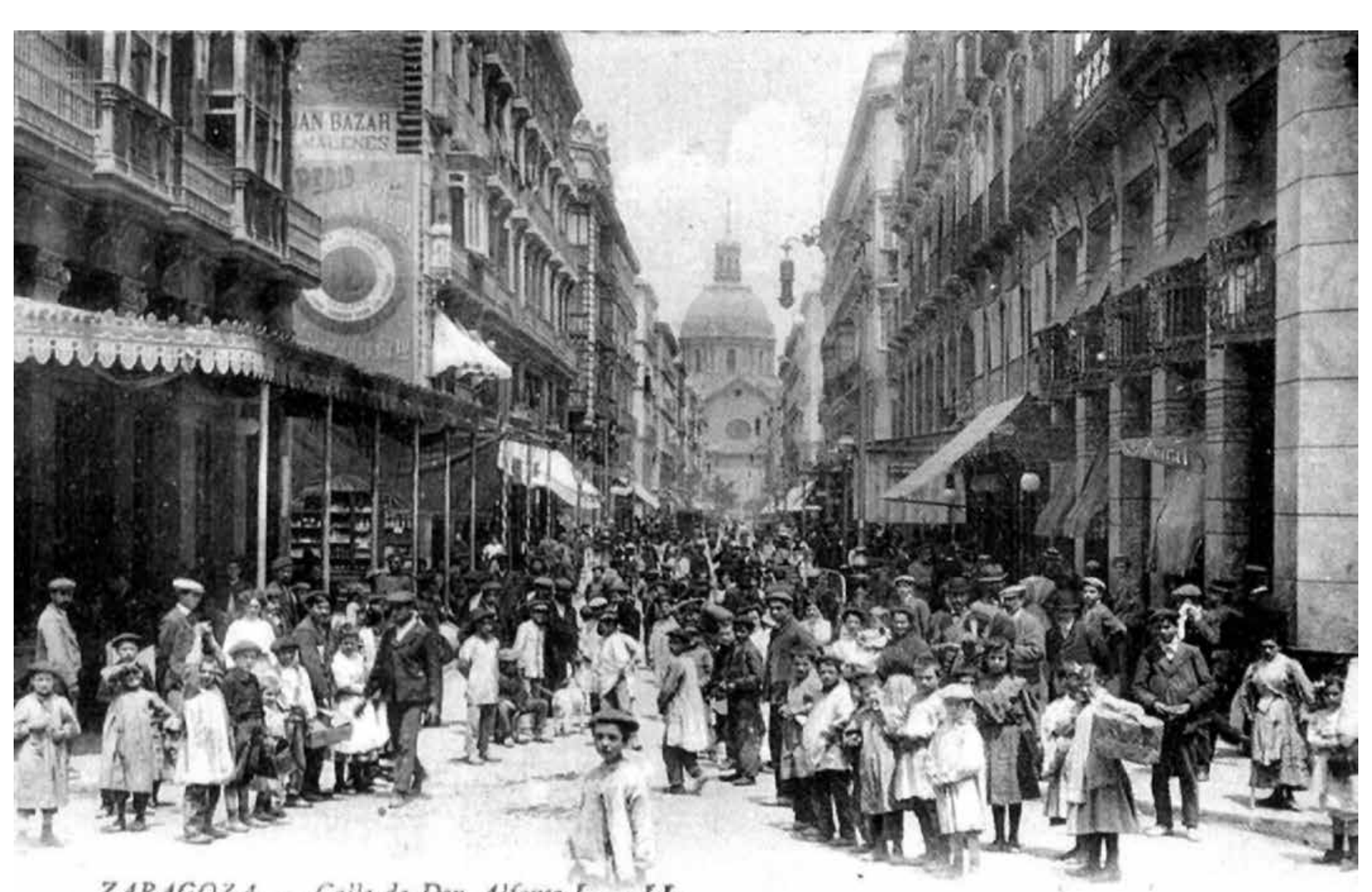

ZARAGOZA - Galle de Don Alfouso of - Vt. 


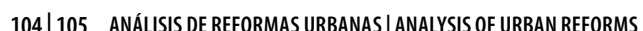

071969 CONCURSO DE IDEAS PARA LA REMODELACION URBANISTICA DEL CENTRO ANTIGUO DE ZARAGOZA. CUATRO MIRADAS A LA CIUDAD ANTIGUA 1969, COMPETITION FOR A PRELIMINARY DESIGN FOR THE URBAN RESTRUCTURING OF ZARAGOZA'S HISTORICAL CENTRE. FOUR GLANCES TO THE OLD CITY Elena Martínez Litargo

Al enfrentarse a un Centro Antiguo se debe reflexionar profundmente y enfrentarse a la dualidad del camino de la conservación o el de la remodelación. A esta dualidad se enfrentaron los participantes en el Concurso de Ideas para la Remodelación Urbanistica del Centro Antiguo de la Ciudad de Zaragozad del año 196

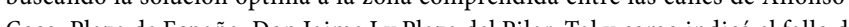
prado, las diecisiete popestas prolongación del Paseo de la Independencia, conservación y remodelación total o «casi» total.

Un estudio de las cuatro propuestas ganadoras muestra las tendencias de la época.

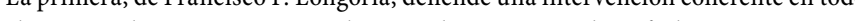
el conjunto historico. Mientras, la segunda propuesta, de Rafael Moneo y Manue entre lo antiguo y lo nuevo. Por otro lado, la tercera propuesta de Juan Enrique de Balbín Behrmann y Juan López Ján propone la creación de una arteria principla subterránea -reminiscencia de las New Town inglesas-, con respeto absoluto por la trama antigua del Casco Historicico. Y por ültimo, Regino Borobio Navarro, plan-

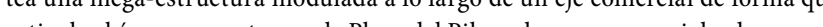

Intervening in an old town means to think and face the duality between in between Alfonso I, Cosso, Plaza España, Don Iaime I and Plaza España. As stated by the jury, the seventeen proposals could be grouped into three categories: the oxtension of the Paseo de la Independencia, the conservation of the old city centre A the total or «almost totaly restructuring of the old town

A carefully analysis of the four winning proposals shows the urban planning trends of the moment. In the first one, Francisco F. Longoria defended a consistent intervention in the whole historical centre. Meanwhile, the second proposal, by as link between the new city and the old town On the a ther bulding hat worked de Balbin Behr mand Jun road -reminiscent of the English New Towns - that scrupulously respected the trace of the old town. Finally, Regino Borobio Navarro proposed a modular megastructure sitting on a commercial axis that articulated the agora -in this case, the

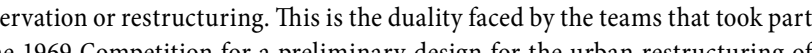
In the 1969 Competition for a preliminary design for the urban restructuring of

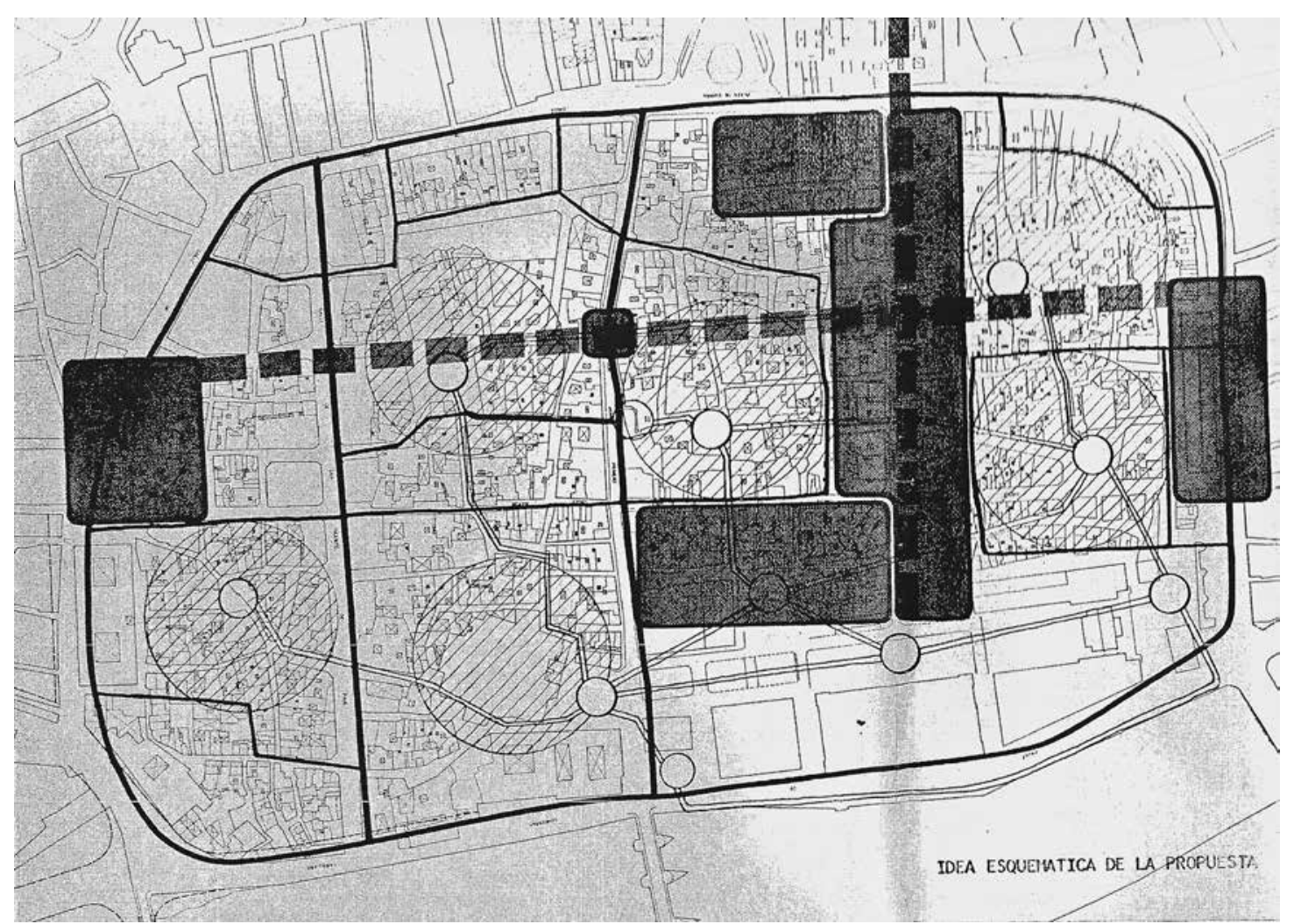

08 CESAR AUGUSTO: LA RUPTURA DE UN TEIDO EXISTENTE| CESAR AUGUSTO: A RUPTURE IN AN EXISTING WEAVE Sandra Pilar Liarte Romero

A lo largo de la historia abundan actuaciones que transforman la ciudad mediante Alo constraccinde calles principales e influyentes. La Avenid a César Augusto se trata de una de ellas, un nuevo corte en la ciudad existente que se realizó durante e transcurso de cuatro décadas.

Es en la redacción del «Plan de Reforma Interior» donde se observa por primera vez el trazado de esta avenida. No tuvo materialización directa, pero sí una clara influencia en los planes desarrollados posteriormente. Su transformación fisica se
lleva a cabo mediante el «Plan Parcial Especial para el Sector de San Ildefonsou «Plan Especial Vía Imperials.. El tráfico y su solución fue su objetivo principa rompió el tejido urbano existente y se distanció de la naturalidad de aquellas propuestas como la Avenida Nevsky. Una calle para el coche, un mort a la rue como diría Le Corbusier.

Pero, irealmente ha cumplido dicha funcion? La avenida César Augusto desemboca en un punto muerto para ese tráfico, un colapso debido al estrechamiento que produce el Mercado Central. Incluso se ha vuetto a disponer el tranvia, tal y como les are offen conveniently tagsed as the villhins responsible for the ills of cities and the disappointments and futilities of city plannings. But the destructive effect of aut o mobiles are much less a cause than a symptom of our incompetence at city building

Throughout History, there have been many projects that transformed the city by building main, influential streets. The César Augusto Avenue is one of them, a cut on the existing city made in the course of four decades. The «Plan de Reforma Interior was the document where the design of this avenue was revealed for the first time. It had no direct materialization, but it had a clear influence on the following plans. Its morphology was carried out at the ePlan Parcial Especial para el Sector de Sa was its main goal: it broke the existing urban fabric and distanced itself from the naturalness of other proposals such as Nevsky Avenue. As Le Corbusier would say it was a street for the car, a mort a la rue.

However, has it really fulfilled this role? The César Augusto Avenue ends in stalemate for that traffic, a collapse due to the narrowing of the Central Market. The tram was even rebuilt as it was before the reform. As Jacobs says. AAluomobiles

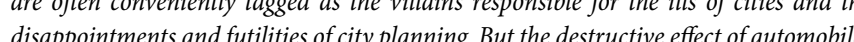
disappointments and futilities of ccity planning. But the destructive effect of au
are much less a causs than a symptom of our incompetence at city buildingo.

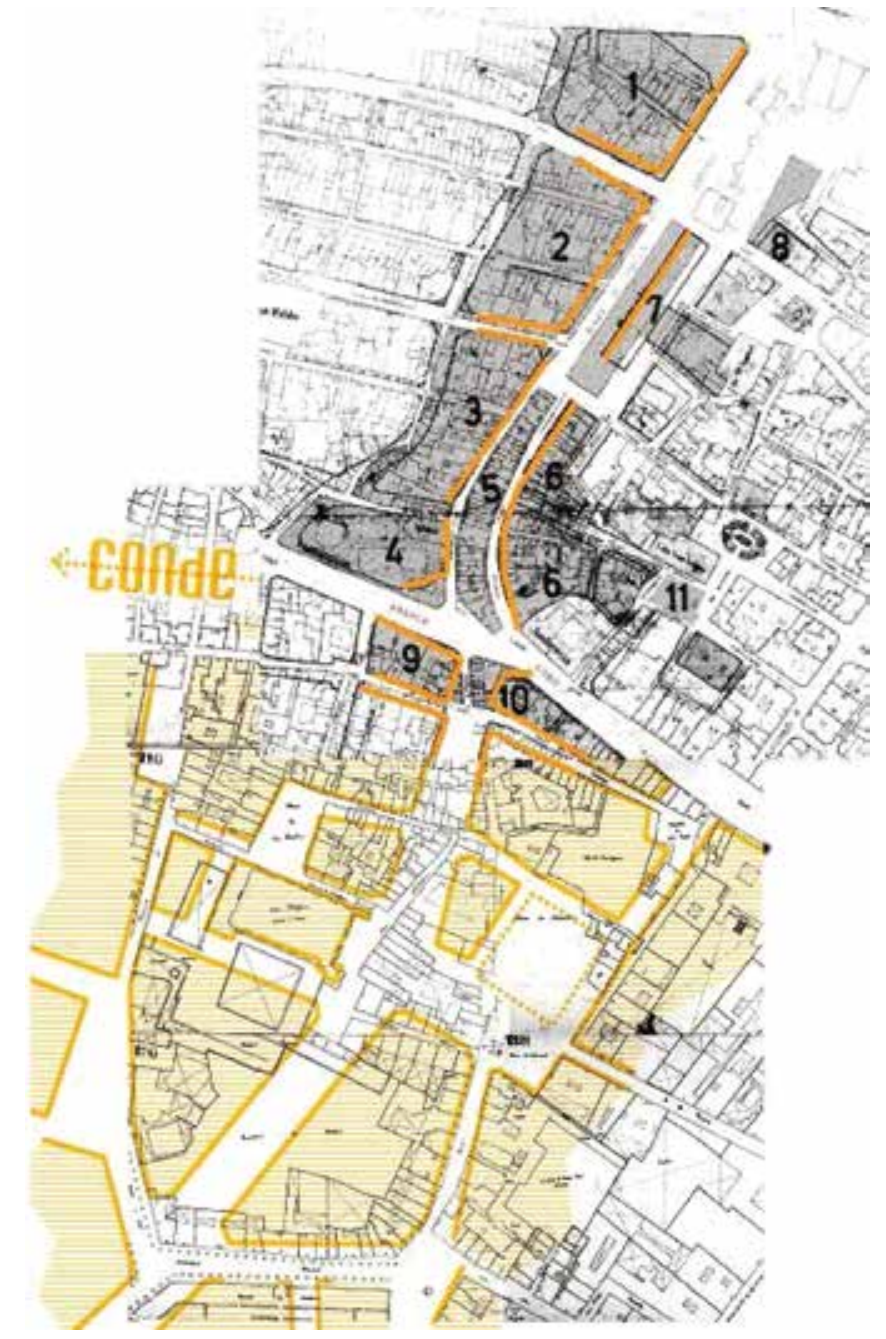




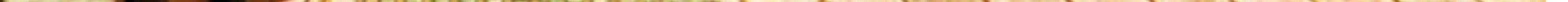

REHABILITAR UN LOCAL PARA REVITALIZAR UN BARRIO: APRENDIZAJE BASADO EN UN CASO REAL

REFURBISHING PREMISES TO HELP REVITALISE A NEIGHBORHOOD: REAL CASE-BASED LEARNING

Begoña Genua y Belinda López-Mesa 
The reasons why current architecture decides to reuse existing buildings are diverse. Buildings with heritage value have traditionally been kept. Recently, the decision to reuse also depends on other values inherent in the existing construction, some of which are studied in the examples below.

In the original design for the Can Framis Museum in Barcelona, which won the competition, Jordi Badia proposed demolishing the existing building. Located in the Poble Nou district, Barcelona's production hub, it was the fir factory built in the area. Pressure from residents made the architect reconsider the importance of the building in collective memory; although it was of scant architectural interest, its symbolic value made it worth keeping, since it was the first of many factories that had made Modernism possible in the city.

Another impetus for recycling buildings comes from their type and construction value. This is the case of the Water Tower in Soest, Holland, whose use was changed between 2002 and 2004 by the architectural firm Zecc Architecte transformed after much consideration of housing types into a nine-storey house with a circular plan.

Tate Modern, by the Swiss architects Herzog \& de Meuron, which opened in London in 2000, represents another example of industrial recycling. The old Bankside Power Plant, originally designed by Sir Giles Gilbert Scott, built in two phases between 1947 and 1963, became obsolete in 1981. The Swiss architects' project was situated in Southwark, a degraded but strategically placed area in the centre of London with good public transport links. The construction of Tate Modern significantly boosted the economic and cultural development of the area. It is considered an example of how to develop degraded areas in cities and transform them into new dynamic focal points for growth and economic development.

Recycling buildings can also be motivated by the simple fact that buildings exist and recycling allows their spaces and grey energy to be reused. Recycling consciousness is part of a new productive and cultural model based on the balance between social, environmental and economic factors. Architecture is not oblivious to this trend. Reusing buildings has environmental advantages in comparison with recycling or reusing materials. Recycling construction materials requires transport and processing to obtain raw materials. Both involve the use of energy. Reusing construction materials eliminates processing, although it does throw up other problems: availability of materials, suitability for the project, disassembly and transport. However, reusing empty buildings does not require transport; the materials are right where they are needed. Reusing buildings is a sustainable construction practice because it extends the building materials service life and, therefore, the environmental impact of the annualised grey energy is lower. This is the case the refurisher of an old sawmill by the fim AH Arquitectos to transform it into its own office. The origin structure and entope were kept, and enterior insulation and galvanised steel sheet were installed. This solution makes the most of the thermal inertia of the ongignal materials at a low price. Inside the bullding, contemporaty .

To conclude, reusing buildings can offer several advantages. These include: upgrading the built heritage; the symbolic value of buildings; the structural or typological interest; the artistic potential of traditional construction; the strategic location; the development of degraded areas in a city; and the use of grey energ $y$.

In the practical sessions of the course Materials and techniques: producing designs and refurbishments of the University Master's Degree in Architecture, which represents 50\% of the total mark, students in the academic year D

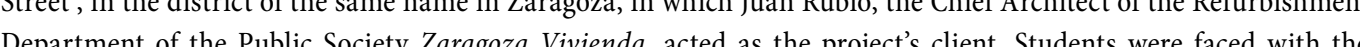
Department of the Pablic Society Zaragoza Vivenda, acted as the project's client. Stadents were faced with the challenge of intervening in a building with a broad range of pathologies, in a vulnerable district in the city of Zaragoza, S Pas

During this first year of the Master's Degree in Architecture, the Public Society Zaragoza Vivienda, a usual collaborator with the University of Zaragoza and the owner of properties throughout the city needing rehabilitation, provided us
Los motivos por los que la arquitectura actual decide reutilizar la edificación existente son diversos. Los edificios con reconocido valor patrimonial se han mantenido tradicionalmente. Recientemente, la decisión de reutilizar radica través de ejemplos.

Jordi Badia proponía en el proyecto original del museo Can Framis de Barcelona, con el que ganó el concurso, derribar el edificio original. El edificio se situaba en el Barrio del Poble Nou, motor productivo de la ciudad de Barcelona, y constituía la primera fábrica que había existido en la zona. La presión vecinal hizo recapacitar al arquitecto sobre los valores de memoria del edificio existente, que a pesar de ser un recinto industrial sin ningún interés arquitectónico, tenía un importante valor simbólico que merecio la pena conservar por ser la primera fábrica de entre muchas que hicieron posible el Modernismo en la ciudad de Barcelona.

El valor tipológico y constructivo de los edificios es otro motor que puede impulsar el reciclaje de la edificación. Es el

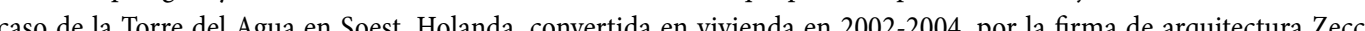
caso de la lore de cague en Soest, Hos 政

El Tate Modern, de los arquitectos suizos Herzog \& de Meuron, inaugurado en el año 2000 en Londres, representa también un ejemplo de reciclaje industrial de la antigua central de energía de Bankside, originalmente diseñada por Sir Giles Gilbert Scott, construida en dos fases entre 1947 y 1963, y que había quedado obsoleta en 1981. El proyecto de los arquitectos suizos se situaba en Southwark una zona degradada de la ciudad, pero con una situación privilegiada en el centro de Londres y una buena accesibilidad mediante transporte pablco. La constraction de Tate Modern ha supuesto un impulso al desarrollo económico y cultural del área en la que se sitúa. Se considera un ejemplo como forma de desarrollar zonas degradadas de la ciudad y convertirlas en nuevos focos dinámicos de crecimiento y de desarrollo económico. Asimismo, el reciclaje de la edificación puede estar motivado simplemente porque el edificio existe y permite el aprove-
chamiento de sus espacios y de su energía gris. La conciencia de la reutilización es parte de un nuevo modelo productivo y cultural basado en el equilibrio entre los factores sociales, ambientales y económicos. La Arquitectura no es ajena a a ste y cultural basado en el equilibrio entrel los factores sociales, ambientales y económicos. La Arquitectura no es ajena a este movimiento. La reutilización de edificios en comparación con el reciclaje o reutilización de materiales presenta ventajas
sostenibles. El reciclaje de un material constructivo requiere de un proceso de tratamiento para obtener la materia prima sostenibles. El reciclaje de un material constructivo requiere de un proceso de tratamiento para obtener la materia prima
así como de desplazamientos. Ambos procesos requieren un gasto de energía. La reutilización de materiales constructiasí como de desplazamientos. Ambos procesos requieren un gasto de energia. La reutilización de materiales constructi-
vos evita la energía del proceso de transformación, pero se enfrenta a otros problemas: disponibilidad de los materiales, vos evita la energia del proceso de transformacion, pero se enfrenta a otros problemas: disponibilidad de los materiales, adecuación al proyecto, desmontaje y transporte. Sin embargo, la reutilización de edificios en desuso no requiere desplazamientos. Los materiales se encuentran en el lugar para sacarles su mejor partido. Reutilizar edificios es una práctica
constructiva sostenible porque prolonga la vida útil de los materiales originales, con lo que la incidencia ambiental de constructiva sostenible porque prolonga la vida útil de los materiales originales, con lo que la incidencia ambiental de
su enerǵia gris anualizada es menor. Es el caso de la rehabilitación integral de una antigua serrería por la firma AH Arsu energia gris anualizada es menor. Es el caso de la rehabilitación integral de una antigua serreria por la firma $\mathrm{AH} \mathrm{Ar}-$
quitectos para transformarla en su propia oficina. Conservando su estructura y cerramiento perimetral actuales, se aísla quitectos para transformarla en su propia oficina. Conservando su estructura y cerramiento perimetral actuales, se aísla
por el exterior y se reviste con chapa de acero galvanizado, aprovechando la inercia termica de los materiales originales por el exterior y se reviste con chapa de acero galvanizado, aprovechando la inercia termica de los materiales originales y resolviendo la obra con una gran economia de medios. En el interior, el lenguaje de la modernidad se enfrenta a la inicialmente mostrándonos un rostro ingrato, pero tener un alto potencial plástico oculto

Por tanto podemos decir que la reutilización de edificios en desuso puede ofrecer ventajas diversas, incluyendo la puesta en valor del patrimonio inmueble, de la carga simbólica de un edificio, del interés tipológico o constructivo, del potencial artístico de la construccín tradicional de la localización estratégice el desarrollo de ronas degradadas de la ciudad y el aprovechamiento de la energía gris.

En las sesiones prácticas de la asignatura Técnica y Materia: generación del Proyecto y Rehabilitación del Máster Universitario en Arquitectura -que representan un 50\% de la nota- en el curso 2013/14 se ha propuesto a los alumnos llevar a cabo una operación de rehabilitación y metamorfosis de los espacios de un antiguo almacén situado en el n ${ }^{\circ}$ 59 de la calle San Pablo del barrio del mismo nombre de Zaragoza, en la que Juan Rubio, arquitecto jefe del Área de Rehabilitación de la Sociedad Municipal Zaragoza Vivienda, ha actuado como cliente del proyecto. Los alumnos se enfrentan al reto de intervenir en un edificio que presenta un amplio cuadro de patologías, en un barrio vulnerable de 


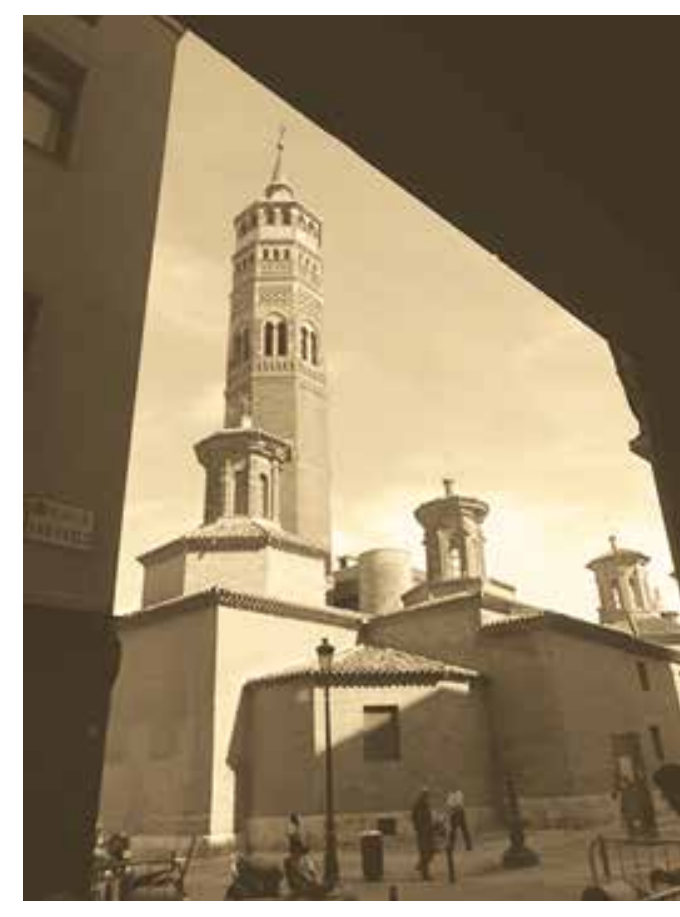

Visión desde la entrada | View from the entrance

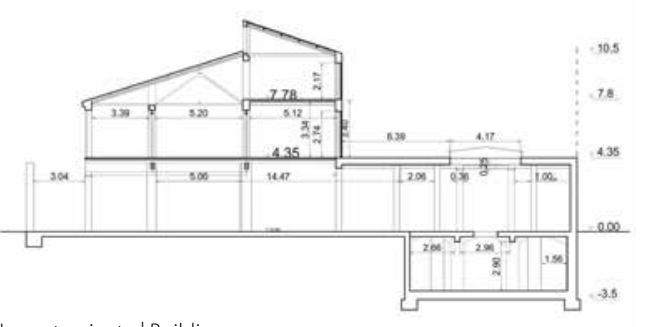

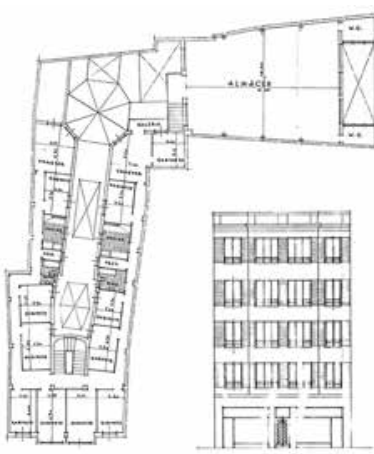
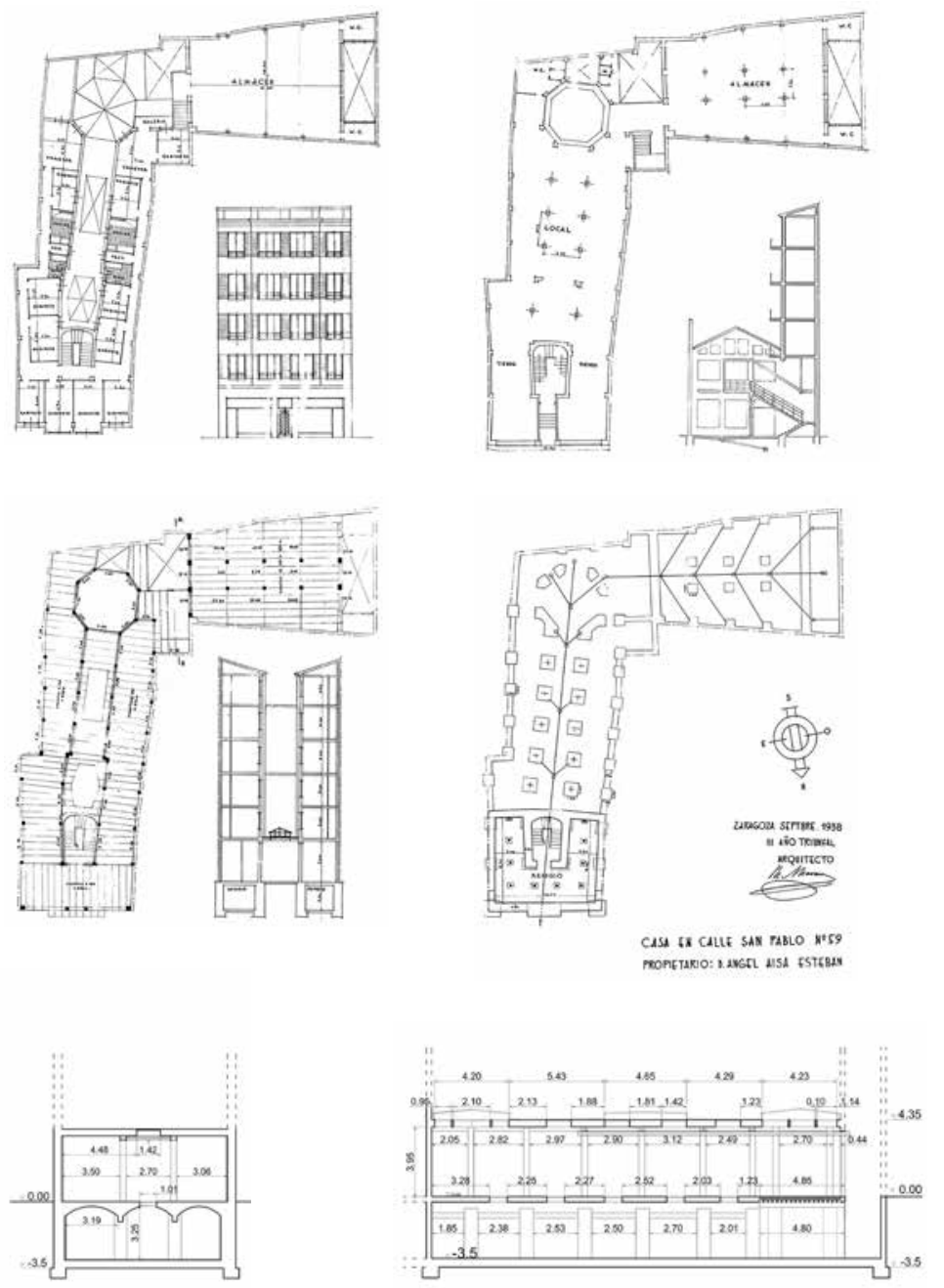

with an ideal location, accessible to students and with good safety conditions. The society even allowed us to use their showroom to present and explain the results of our work to those interested in improving activity in the district and its heritage.

To collaborate with other modules in the Master's Degree, we selected the refurbishment of the shop and warehouse of the company Montajes Eléctricos Coca, located in the heart of the San Pablo district, among other reasons because the Integrated Urban and Landscape Projects course was working on this urban environment. Their in-depth analysis of the district provided us with a good basis for the choice of appropriate and compatible uses in the refurbishment of the building

The students' topic comprised a site of almost $1000 \mathrm{~m}^{2}$ consisting of the basement and the ground floor of a residential building together with a large warehouse with a ground floor, first floor and attic. These uses were already in the original design by the architect Miguel Ángel Navarro, drafted in 1942, in the post-war period. The students consulted the original documentation, which explains the reason for the singular solution of the basement, with towering columns that actually form the foundations of the building but moved one floor below, since in the design the basement consisted exclusively in the bomb shelter under the stair core. The site has two entrances from San Pablo street, right in front of the square, and several light wells.
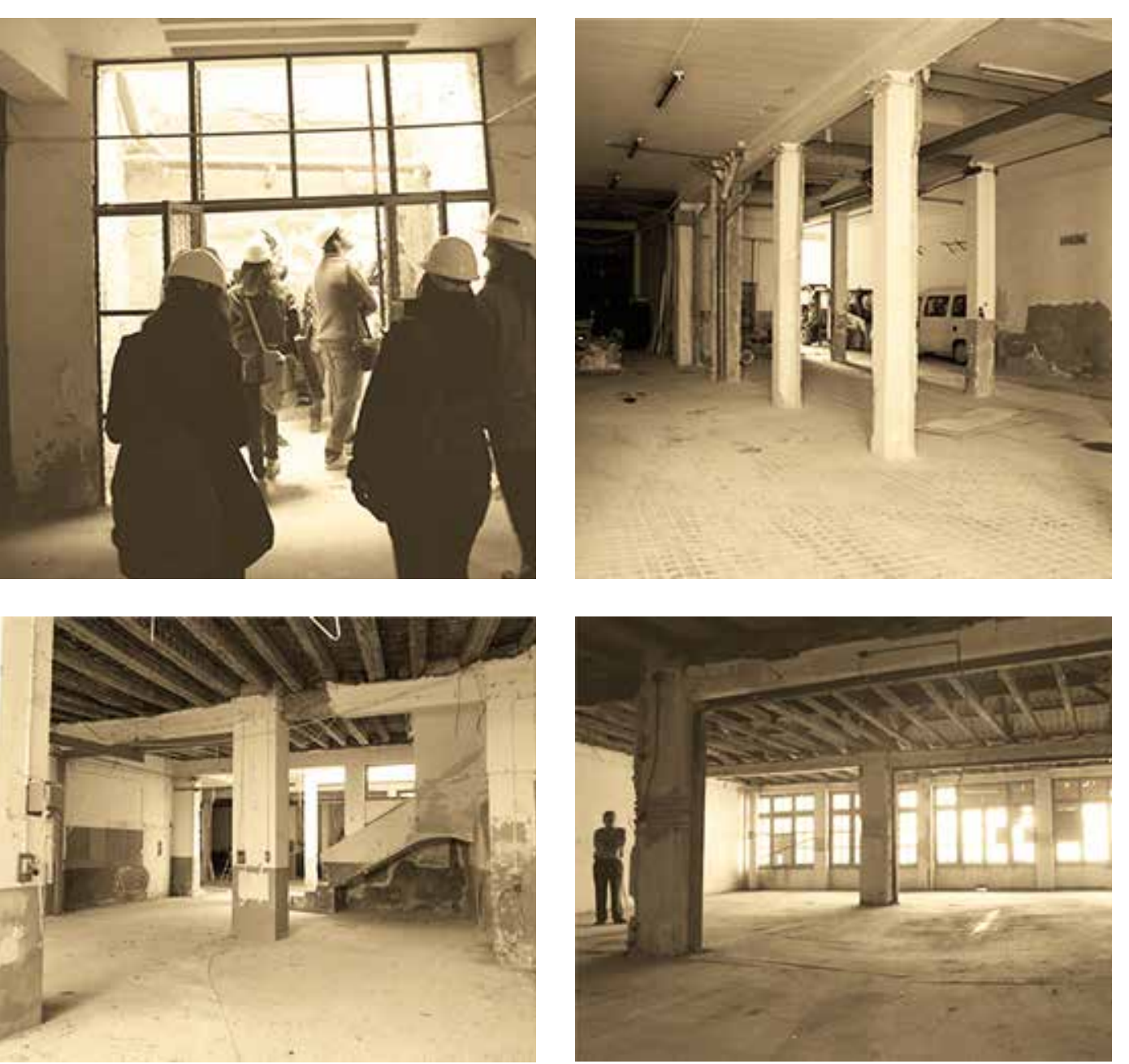

Imágenes del local photographs of the facilities

la ciudad de Zaragoza, con espacios con soluciones constructivas tradicionales con un alto potencial formal, la posibilidad de vistas a la iglesia de San Pablo y con un programa abierto que debe dinamizar el barrio.

Durante este primer año del Máster Universitario en Arquitectura, la Sociedad Municipal Zaragoza Vivienda SLU, habitual colaboradora de la Universidad de Zaragoza y poseedora de inmuebles repartidos por toda la ciudad que están esperando ser rehabilitados, nos ha proporcionado un emplazamiento idóneo, accesible para los alumnos y con buenas condiciones de seguridad. Incluso nos ha facilitado su sala de exposiciones para mostrar y explicar el resultado de los trabajos a las personas interesadas en dinamizar la actividad del barrio y su patrimonio.

Buscando la colaboración con las demás asignaturas del Máster, se eligió la rehabilitación del local y la nave de la We tajes Electricos Coca situada en el corazón del barrio de San Pablo, entre otras razones porque en la asignatura Proyectos urbanos $y$ paisajisticos integrados se estaba trabajando en ese entorno urbano. El profundo análisis del barrio que han llevado a cabo nos ha permitido tener un buen soporte para la elección de los usos adecuados y compatibles en la rehabilitación del edificio.

El tema al que se han enfrentado es un local de prácticamente $1000 \mathrm{~m}^{2}$ formado por el sótano y la planta baja de un edificio de viviendas unido a un gran almacén de planta baja+pl+altillo. Esta dotación estaba ya en el proyecto ori- 


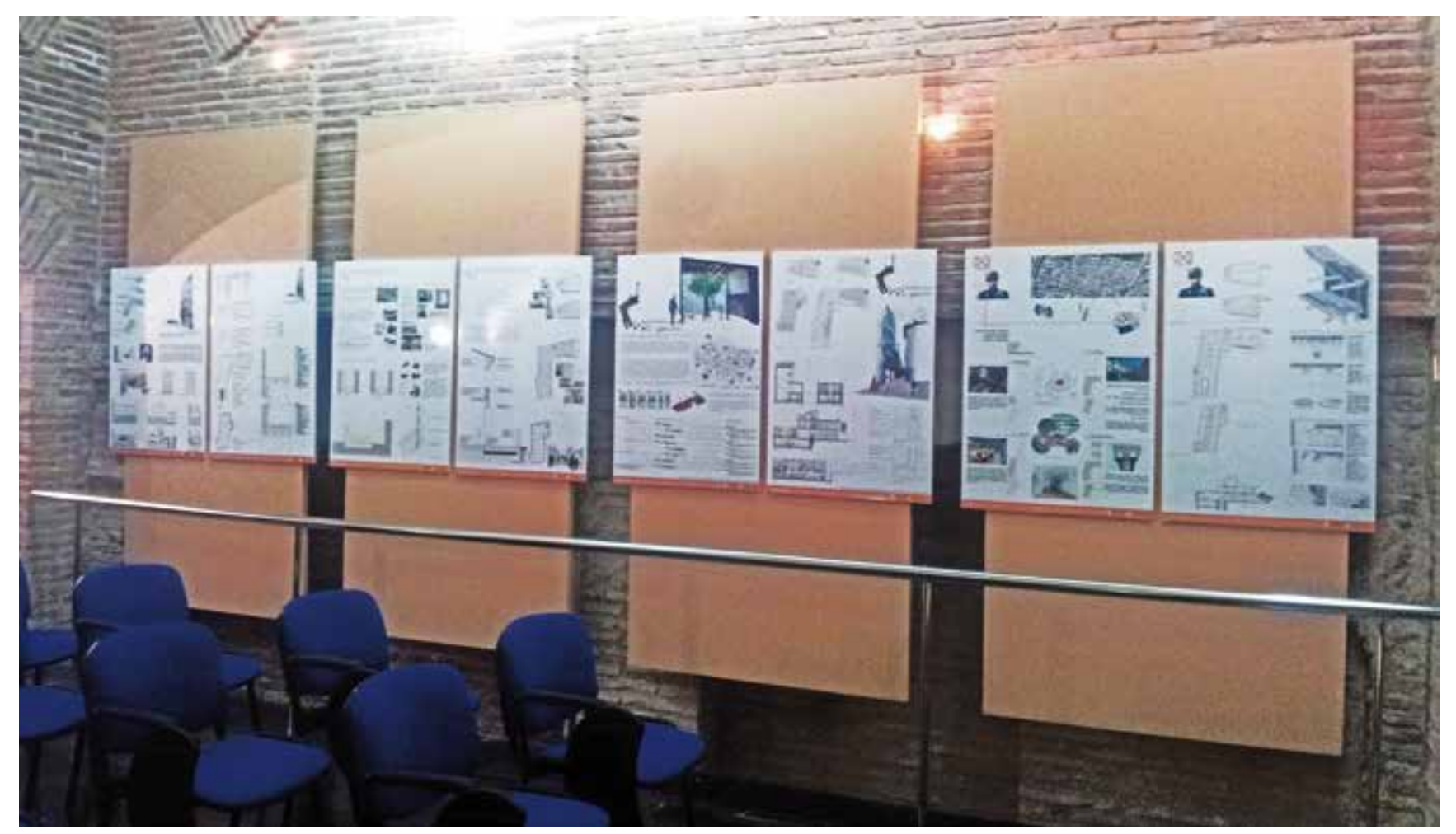

The experience of this first academic year has indeed proved that practical work on an existing building provides possibilities that theoretical case analysis or exercises using hypothetical scenarios cannot improve upon. We believe that with this practical work based on using a real activity, the objectives we were seeking have been met:

-Ensuring students perceive the refurbishment project as an inclusive process.

Providing the possibility of acquiring knowledge from situations that supply students with real information and material that they have to learn "to perceive" with all their potential and problems.

- Helping students understand that techniques and materials not only culminate in the project but also make it possible and boost it.

- Providing students with the possibility of presenting and defending their work in a setting that differs from the university and in front of potential clients, in an almost professional sphere.

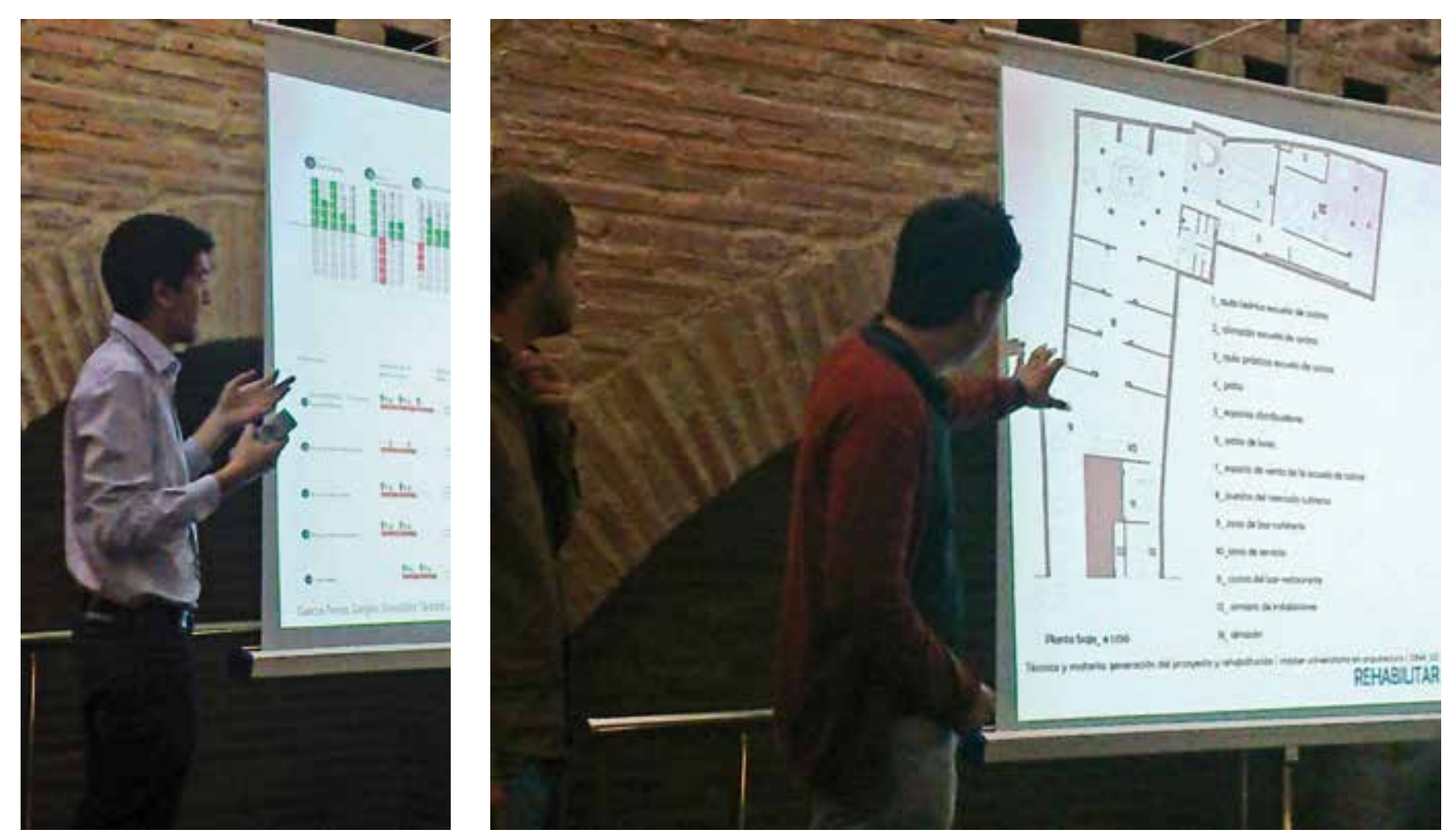

ginal del arquitecto Miguel Ángel Navarro, redactado en 1942, en plena postguerra. Los alumnos han consultado la

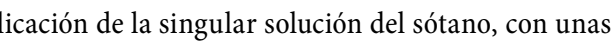
imponentes columnas que no son sino la cimentacion del edificio trasladada wa planta más abajo, ya que en proyecto el sótano se reducía al refugio antiaéreo situado bajo al núcleo de escaleras. El local tiene dos accesos desde la calle San Pablo, justo enfrente de la plaza, y varios patios de luces. La experiencia de este primer curso ha servido para verificar que realizar las prácticas sobre un edificio existente propor-

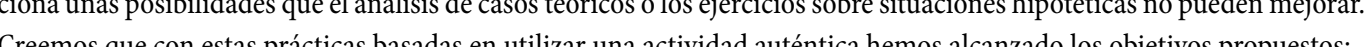
Conseguir que el alumno perciba el proyecto de rehabilitación como un proceso integrador.

Proporcionarle la posibilidad de adquirir conocimientos sobre la realidad, que es la que suministra la información, dándole un material de trabajo que los alumnos han aprendido a "ver", con su potencial y sus problemas.

- Contribuir a que el alumno comprenda que las técnicas y la materia no sólo encuentran su culminación en el proyecto sino que lo posibilitan y lo estimulan.

- Proporcionar al alumno la posibilidad de exponer y defender su trabajo en un ámbito distinto al de la Universidad y ante potenciales clientes, en una experiencia cercana a la práctica profesional. 
Isabel Ezquerra Alćazar, Diego García Yagüe, Alejandro Lezcano Maestre

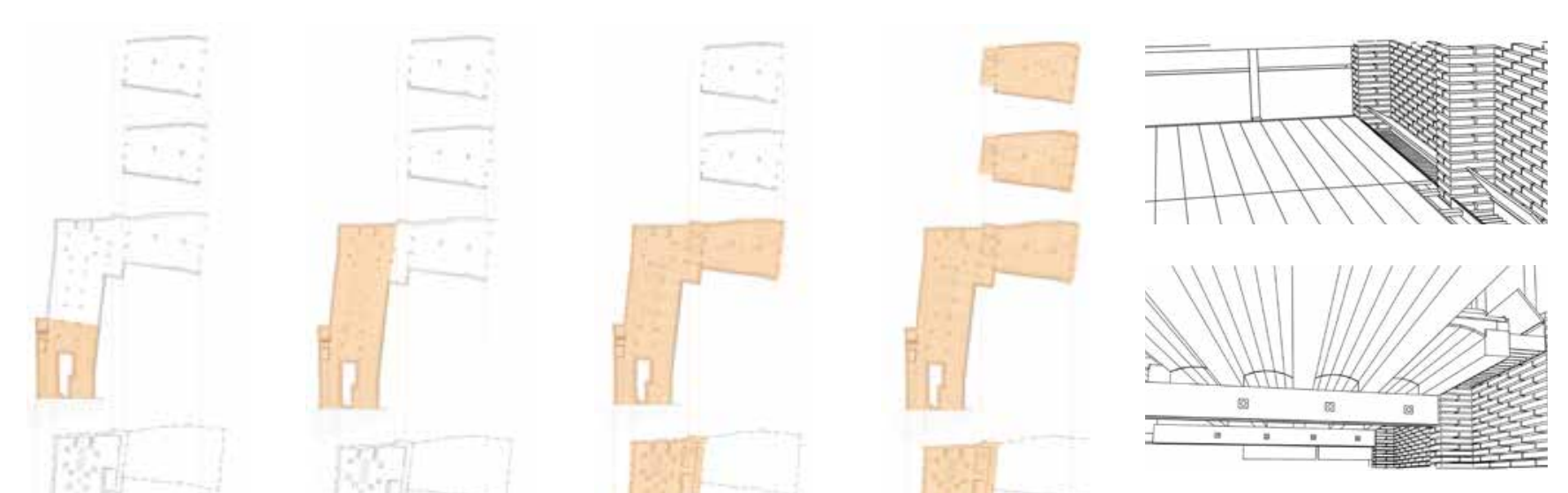

Detalle rehabilitación forjado mixto
Refurbishment detail. Composite structur
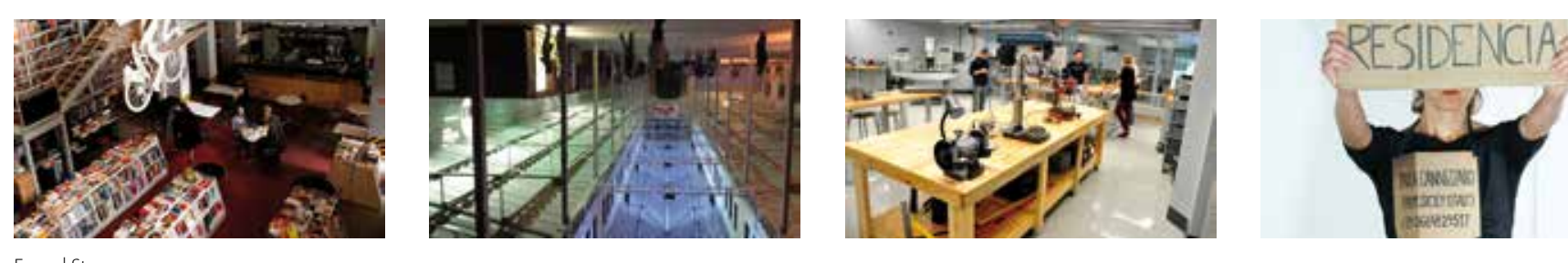

Es una intervención profundamente consciente de la dificultad de actuar en los momentos de crisis que vivimos. Propone actuar por fases, de manera que cada actividad vaya generando nuevas necesidades y oportunidades, que culminen en
la rehabilitación y puesta en funcionamiento de todo el local. El objetivo final es la rehabilitación y puesta en funcionamiento de todo el local. El objetivo final es
lograr un centro especializado en trabajos relacionados con las artes gráficas y el lograr un centro especializado en trabajos relacionados es:

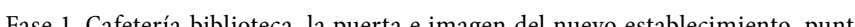
de encuentro entre interesados y con el barrio. Es punto de partida para, con un inversión limitada, generar los ingresos que activen las siguientes fases.

Fase 2. Fab-lab. Taller de experimentación en la producción de ele para necesidades básicas como artísticas.

Fase 3. Co-working. El taller se desplaza al sótano y el espacio se convierte en un lugar de trabajo en común construido in-situ, con espacios para desarrollo de im gen, estaciones de autoedicion y postproducción. Para hacer proyecciones y diff列 generar una circtlacon
de la plaza.

Fase 4. Una vez alcanzado el punto máximo de demanda y actividad, una pequeña

As this intervention is deeply aware of the difficulties we face in this current time of crisis, the proposal unfolds in stages. Each activity generates new needs and opportunities, culminating in the refurbishment and operation of the whole

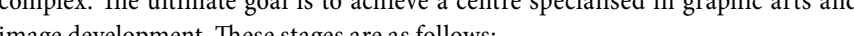

Stage 1. Cafeteria-Library. The door and image of the new establishment, the point for generating revenues with a limited investment, which, in turn, will activate the following phases.

Stage 2. Fab-lab. Experimental workshop for producing elements that can be used to transform the building. Open to the district for both basic and artistic needs. Stage 3. Co-working The workshop moves to the basement and the space becomes a built-in-situ shared workplace, with spaces for image development, desktop publishing and post-production stations. The inner courtyard inside the block bertith er of the square.

Stage 4. Once peak demand and activity are reached, a small temporary residence residencia temporal para los profesionales y artistas que estén trabajando en las
02 ESPACIO CULINARIO EN SAN PABLO | CULINARY SPACE IN SAN PABLO

Alejandro Alda García, Daniel Esabén Boldova, Paula Gordo Gregorio, avier Sancho Melís
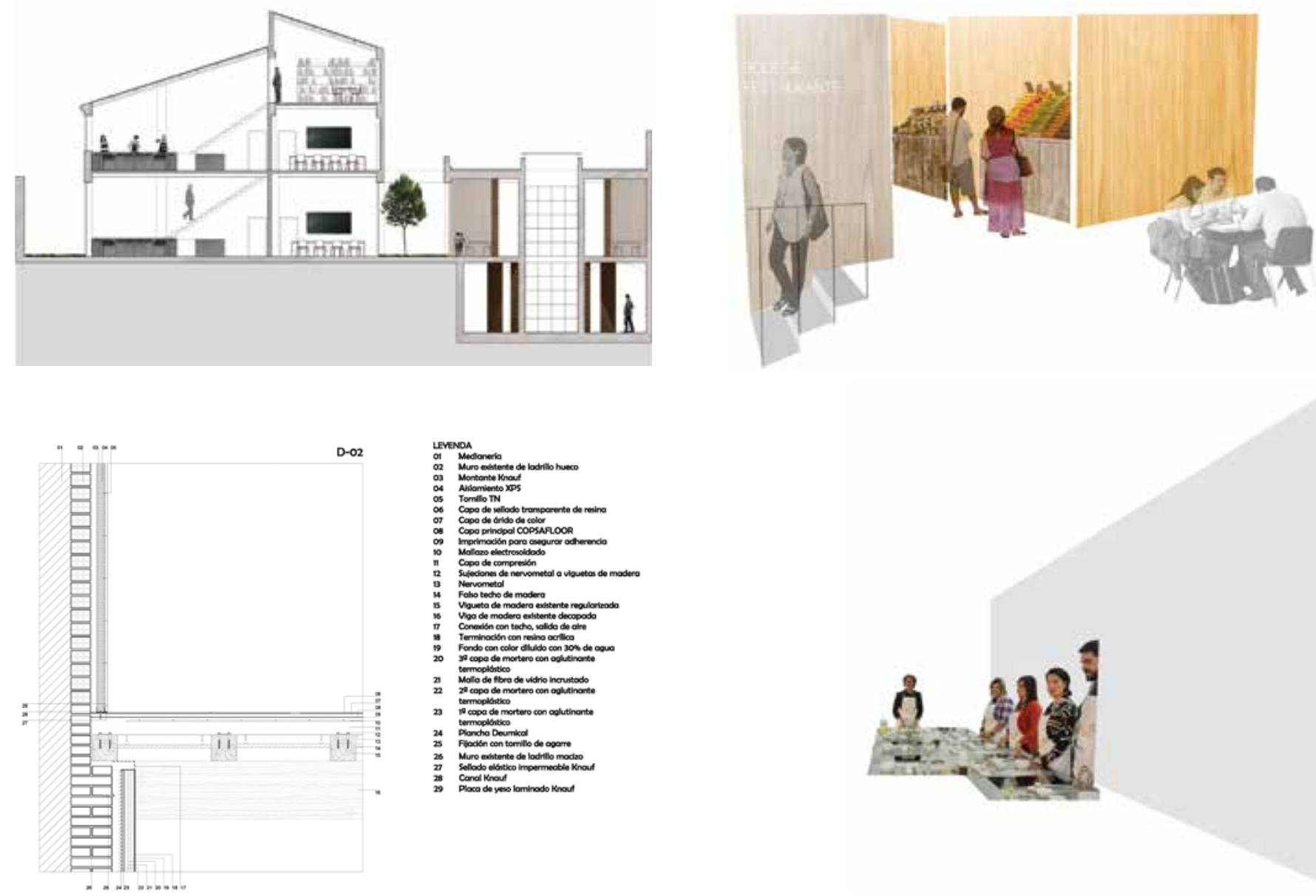

Es un espacio educativo abierto a toda la ciudad. Incluye cafetería, zona de degusalumnos de la escuela a precios económicos. En el sótano, una bodega-restaurante que se aprovecha de la singularidad del espacio, completa el programa. La escuela gastronómica se articula en dos piezas: la que da a la calle contiene los espacio destmados a dietre a

Los elementos de comunicación vertical no interffieren en el patio interior, que que

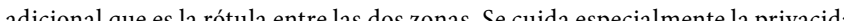
de los vecinos para que la nueva actividad no interfiera en la convivencia.
This is an educational space open to the entire city. It includes a coffee shop, tasting stalls selling freshly prepared food and food offered by the school's students at affordable prices. In the basement, a wine cellar restaurant takes advantage of divided into two parts: the one facing the street contains the eating spaces, whilst 列 their administrative counterparts are located in the attic.

The core communication areas do not interfere with the inner courtyard, which of light joining the two areas together. Special care has been taken to ensure the privacy of residents so that the new activity will not interfere in their lives. 
04 REHABLLITACIONES CON GANCHO | EFFECTIVE REFURBISHMENT

Sergio García Pérez, An G González Taratiele, Alicia Gracia Aguilar, Sandra Pilar L Liarte Romero
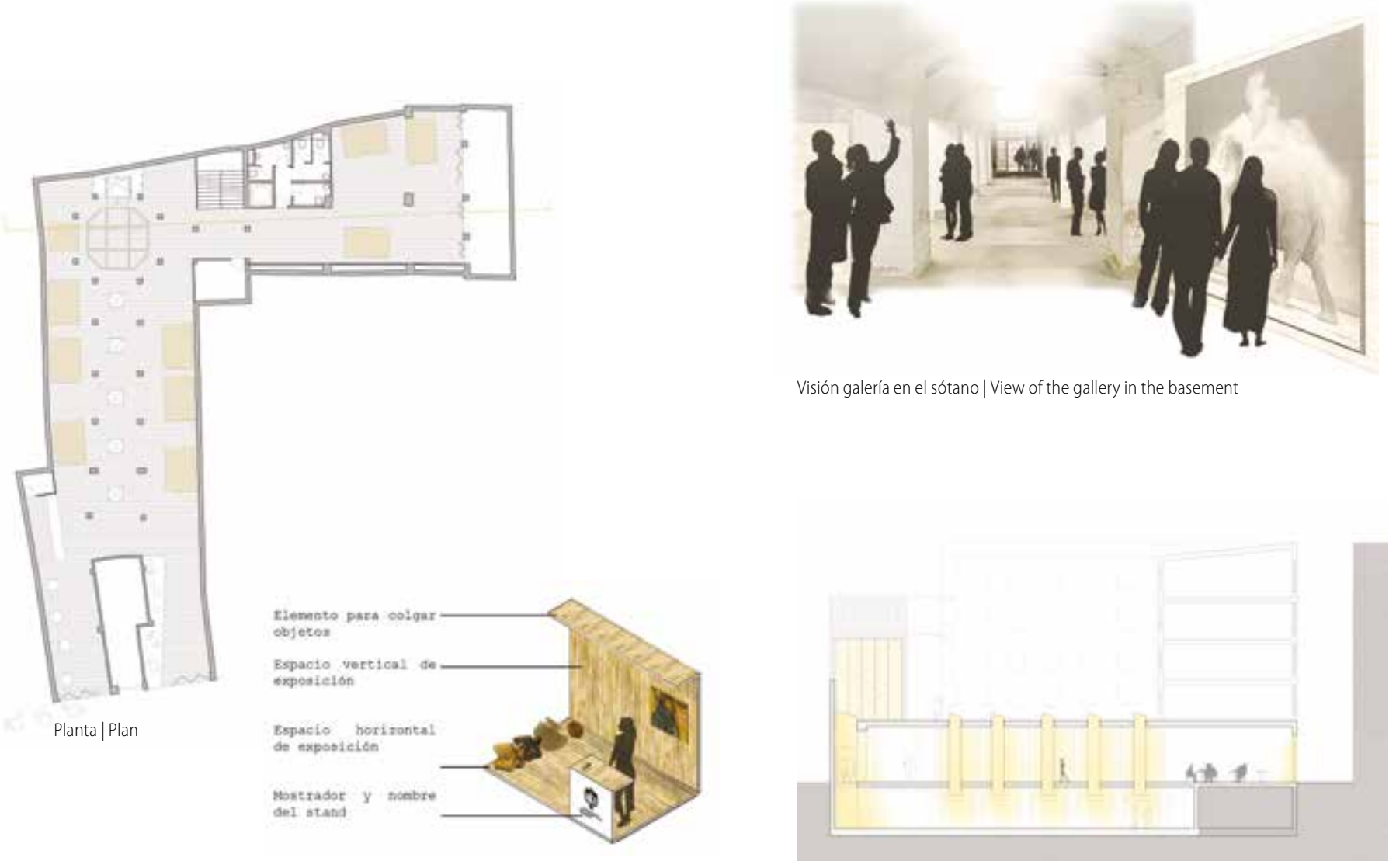

Sección|Section

The proposal is to create a cooperative art workshop to exchange experiences, display each participants screations and organise a co-vending system. It talso seeks incentives to bring psers by int the new premises.

The formal proposal recovers the original industrial value of the old workshop container of light ephemeral structures, such as pieces of furniture that can adapt to each user's needs. This is the entrepreneur's kit: a minimum, developable and assemble-it-yourself wooden module that can be rented, customised and grouped An exhibition space with optimal conditions of filtered natural light is located in

1 San Pablo is also known as El Gancho, which means "the hook"

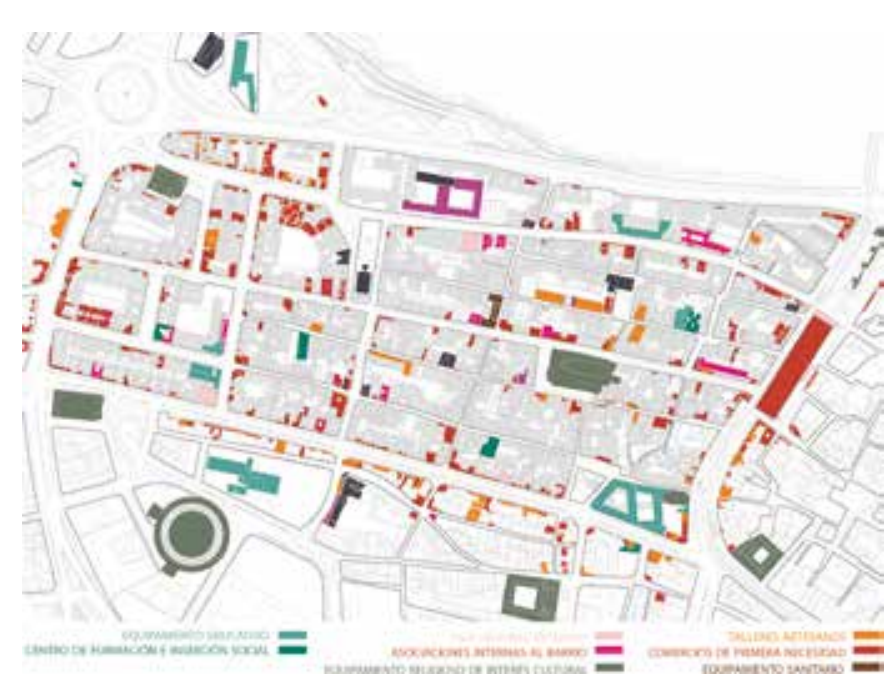

Estudio de actividad del Barrio | Study of the activity of the district

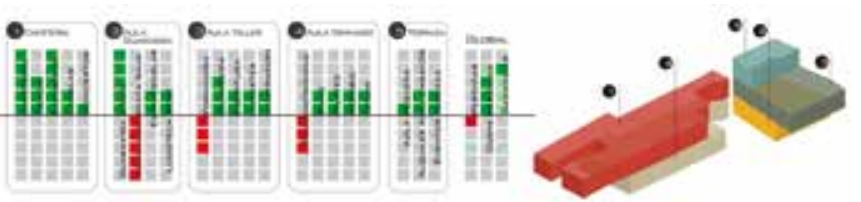

\author{
Estudio de la rentabilidad | Study of the profitability
}

El proyecto busca la cohesión social del barrio mediante la oferta de actividades que fomenten la convivencia y la educación. Tras un análisis de las dotaciones, se vidad y al niño en general se orgnizan otras complementarias con la intención de involucrar a todo el barrio.

Es un espacio complejo y flexible, con cafetería, librería infantil aulas y talleres para la formación de adultos en temas relacionados con niños, espacios para pro yecciones representaciones de espectaculos infantilies.... En el sotano, un gimnasio para los alumnos, pero abierto al público en función de los horarios.

Se busca que la rentabilidad de algunas actividades ayude al sostenimiento de otras ficio final sea social.
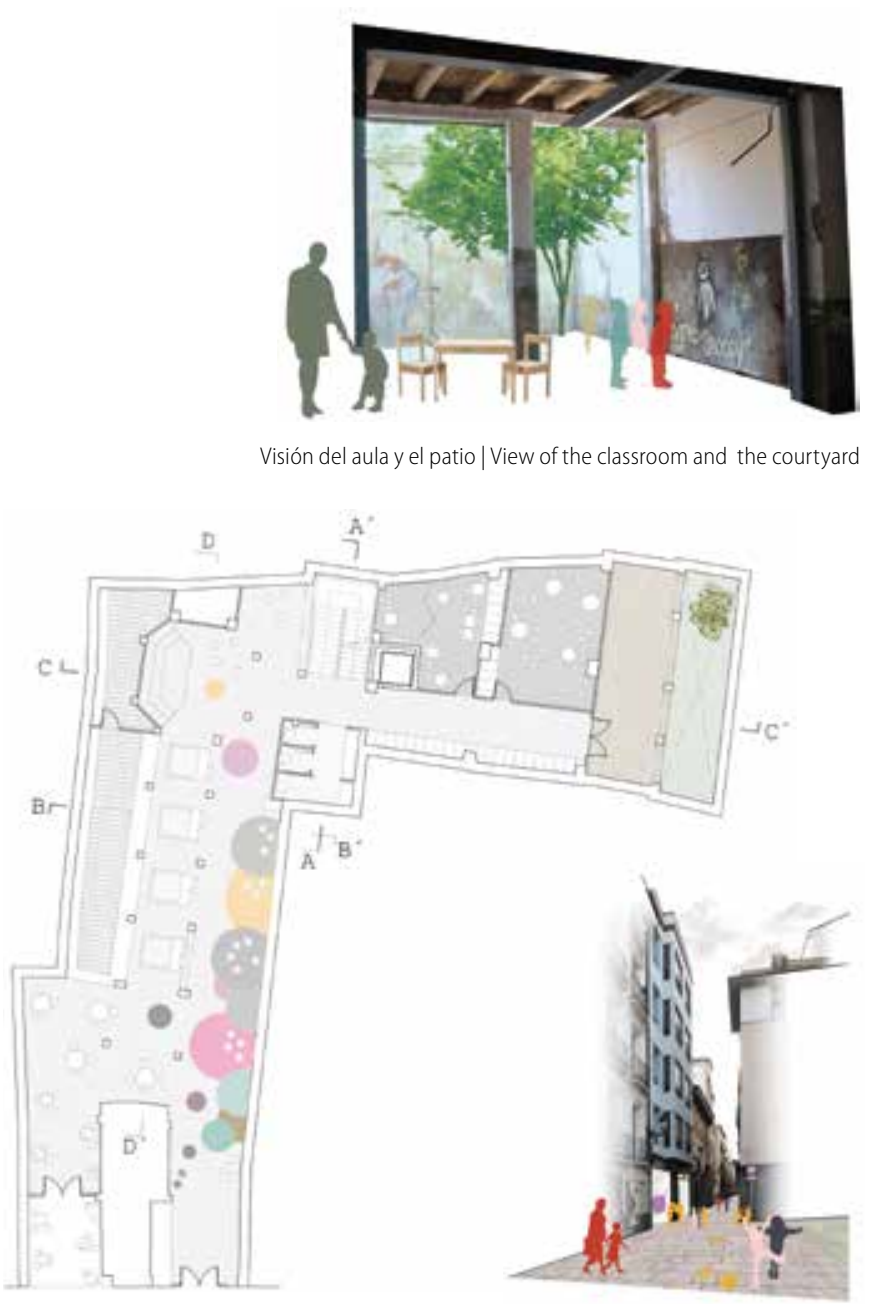

Planta | Plan

The aim of the project is the social cohesion of the district by offering activities that promote coexistence and education. An analysis of the services in the area children in general with the intention of involving the entire district.

It is a complex and flexible space with a cafeteria, children's library, classrooms and workshops for training adults in issues related to children, spaces for screenings, performances of children's shows, and so on. In the basement, there is a gym for students, although it is sometimes open to the public.

The idea is for the profits from some of the activities to help run others that are not as lucrative. The balanced management of all of them ensures that the ultimate 


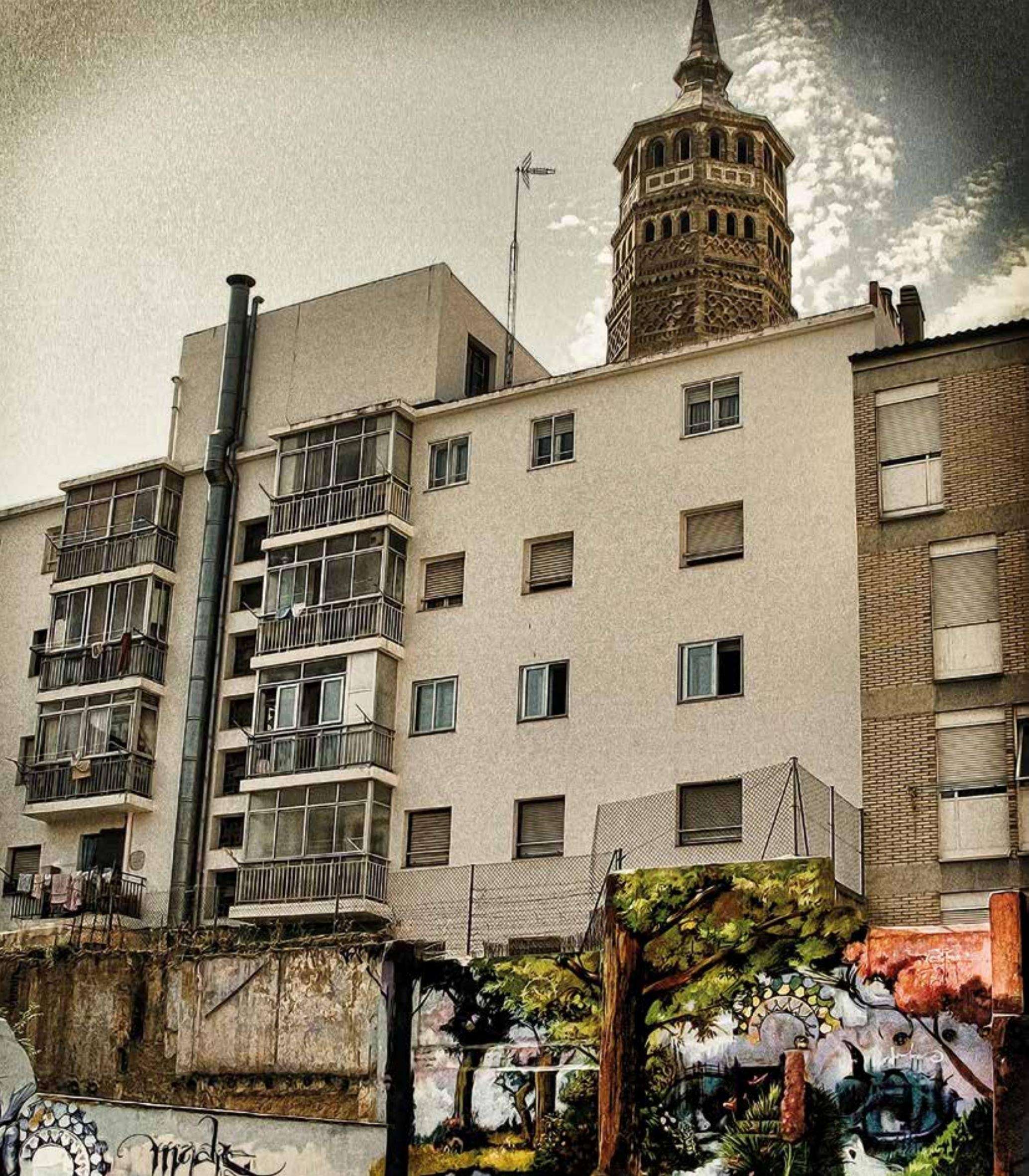

TALLER SAN PABLO-ZGZ.

UNA EXPERIENCIA ACADÉMICA DE REGENERACIÓN URBANA

SAN PABLO (ZARAGOZA) WORKSHOP.

AN ACADEMIC EXPERIENCE IN URBAN REGENERATION

Francisco Berruete, Pablo de la Cal y Miriam García

PROYECTOS DE URBANIZACIÓN

DEVELOPMENT PROJECTS

Enrique Cano y Juan Antonio Ros 

FRANCISCO BERRUETE
PABLO DE LA CAL

Tallersan Pablo-ggz. Una experiencia académica
de regeneración urbana San Pablo (Zaragoza) worksho

San Pablo (Zaragoza) workshop.
An academic cexperience is urban
regenention

\section{El barrio de San Pablo en el plano
de calificación del suelo del} de calificación de
PGOU vigente. San Pablo districti in the Zaragoza
Master Plan. Classification and land usemap.

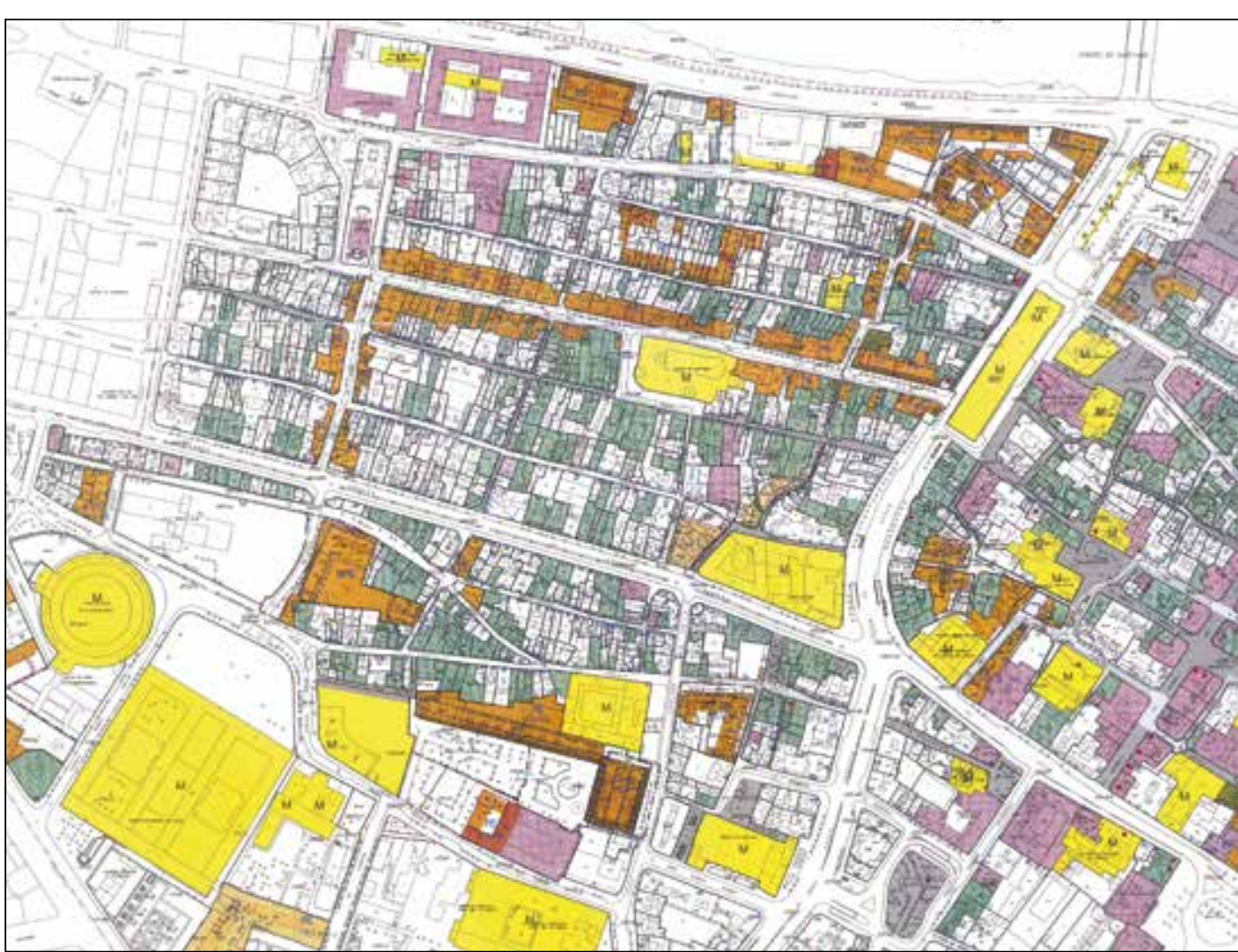

In recent decades, urban regeneration processes have gradually received more acknowledgement as an urban

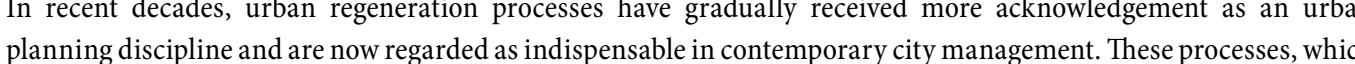
planning discipline and are now regarded as indispensable in contemporary city management. These processes, which started in historic centres as a first investment in the renovation of traditional issues, are now strategies that are
also implemented in districts built in the mid twentieth century whose social and spatial features are desperately in also implemented in districts built in the mid twentieth century whose social and spatial features are desperately in
need of regeneration. As a result, the complexity of urban regeneration processes has increased; added to the analysis need of regeneration. As a result, the complexity of urban regeneration processes has increased; added to the analysis
of the morphology, infrastructures and habitability of the dwelling are other equally important concerns in the of the morphology, infrastructures and habitability of the dwelling are other equally important concerns in the contemporary city experience. These include improving environmental, scenic an

In this context of reformulating the practice of urban regeneration, the main challenge for Schools of Architecture is how to address it from the perspective of disciplines such as urban development, which tools and methodological bases we should convey to students to help them integrate in multidisciplinary design and urban management team and how can spatial planning allow city agents to form part of a shared resilient and supportive project.

Whilst it is true that deadlines for academic exercises compress the time needed to collate data and to sort available information, academic experiences also represent an experimental and creative potential that makes them excellent opportunities for collaborating with the agents in charge of urban regeneration processes. This is the case of our experience during the 2013-2014 academic year in the subject "Integrated urban and landscape projects", as part of the Master's Degree in Architecture at the School of Engineering and Architecture of the University of Zaragozal

Four teachers in charge of the subject, Javier Monclús, Pablo de la Cal, Francisco Berruete and Miriam García and 16 students took part in

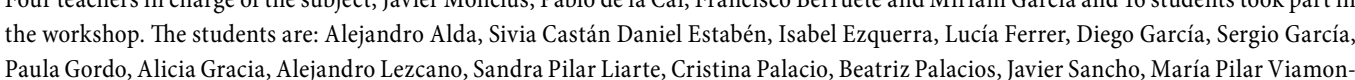
te and Pilar Villuendas.
Los procesos de regeneración urbana han adquirido en las últimas décadas y de una manera progresiva mayor reconocimiento desde la disciplina urbanística, configurándose como un proceso imprescindible en la gestión de la ciudad contemporánea. Comenzaron en los cascos históricos, como primera apuesta por la renovación de los tejidos rradicionales, pero en nuestros días estas estrategias se aplican también en bartios corstricos a nu des de siglo $\mathrm{XX}$ que requieren intensos procesos de regeneración espacial y social. Cor

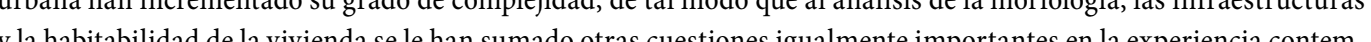

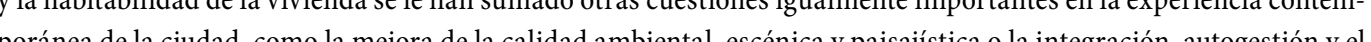

En este contexto de reformulación de la práctica de la regeneración urbana, uno de los retos actuales de las Escuelas de Arquitectura es cómo abordarla desde disciplinas como el urbanismo, qué herramientas y fundamentos metodológicos 列 planificación espacial posibilita la integración de los agentes de la ciudad en un proyecto resiliente, compartido y solidario. Si bien es cierto que el plazo de un ejercicio académico comprime el tiempo para la obtención de información y para la necesaria decantación de la información disponible, no es menos cierto que las experienciss académicas posen un la necesaria decantación de la información disponible, no es menos cierto que las experiencias académicas poseen un responsables de procesos de regeneración urberte en excelentes oportunidades para la colaboracion con los agentes asignatura Proyectos urbanos y paisaíisticos integrados, del Máster en Arquitectura en la Escuela de Ingeniería y Arquitectura de la Universidad de Zaragozal ${ }^{1}$ donde se ha desarrollado un Taller de regeneración urbana en el barrio de quitectura de la Universidad de Zaragozal donde se ha desarrollado un Taller de regeneración urbana en el barrio de San Pablo en Zaragoza. Este barrio posee un elevado indice de vulnerabilidad urbana, reseñado a nivel nacional en los primeros trabajos que afrontan esta materia desde el Ministerio de Fomento ${ }^{2}$. Más que en ningun otro de la ciudad, en el barrio de San Pablo se concentra una intensa actividad asociativa y reivindicativa que pone sobre la mesa no solo
problemas, sino también alternativas y oportunidades para mejorar la calidad de vida en el mismo. Por último, aunproblemas, sino también alternativas y oportunidades para mejorar la calidad de vida en el mismo. Por último, aun-
que no menos importante, es también un barrio en el que se vienen desarrollando propuestas de regeneración urbana que no menos importante, es tambien un barrio en el que se vienen desarrollando propuestas de regeneración urbana programa de renovación de este Plan, para el periodo 2005-2012, la Oficina del Plan Integral afronta en la actualidad la programa de renovación de este Plan, para el periodo 2005-2012, la Oficina del Plan Integral afronta en la actualidad la
revisión del Plan para el periodo 2013-2020. Todas estas cuestiones hacen de San Pablo un laboratorio vivo de técnicas y tendencias contemporáneas de regeneración urbana en el que un taller académico puede resultar muy válido si se asienta sobre una colaboración estrecha con los agentes gestores.

En un ejercicio de cuatro meses, los alumnos organizados en equipos de trabajo pero integrados en el equipo Taller como si de un equipo redactor profesional se tratase, deben "aterrizar" lo más rápidamente posible en la problemática como si de un equipo redactor profesional se tratase, deben "aterrizar" lo más rápidamente posible en la problemática
concreta del barrio. Este reto se afrontó desde una triple dimensión: teórica-documental, de experiencia transmitida y de experiencia directa. La dimensión teórica-documental corrió de la mano de los profesores responsables de la asig-
natura, que persiguieron mostrar una visión retrospectiva y crítica de la renovación urbana dentro y fuera de nuestro natura, que persiguieron mostrar una vision retrospectiva y critica de la renovación urbana dentro y fuera de nuestro
país. Los alumnos realizan, a título personal, reflexiones sobre textos imprescindibles de intervención en la ciudad consolidada (Sutcliffe, Campos Venuti, Jacobs, Gehl, etc.) y extraen enseñanzas útiles para el caso del centro histórico de Zaragoza y el barrio de San Pablo. El análisis de planes como el Plan Integral del Casco Histórico de Zaragoza o de documentos de prospectiva urbana como "Zaragoza 2016. La cultura transforma el centro" resultan también imprescindibles para tener un panorama amplio del marco teórico de partida.

Estas sesiones teóricas se combinaron con otras, impartidas por los protagonistas de la gestión en el barrio, que sirvieron para obtener informaciones cruzadas, stuadas en planos que de otra manera "tomar el pulso" de la percepción del funcionamiento del mismo. Los arquitectos Fernando e Ignacio Aguerri, redac-

IEl Taller ha estado integrado por cuatro profesores responsables de la asignatura, Javier Monclús, Pablo de la Cal, Francisco Berruete y Mirriam Garciá, y por 16 alumnos: Alejandro Alda, Sivia Castán Daniel Estaben, Isabel Ezquerra, Lucia Ferrer, Diego Garcia, Sergio
Garcia, Paula Gordo, Alicia Gracia, Alejandro Lezcano, Sandra Pilar Liarte, Cristina Palacio, Beatriz Palacios, Javier Sancho, María Pilar Viamonte, Pilar Villuendas.

2 Atlas de la Vulnerabilidad Urbana en España. Ministerio de Fomento, Gobierno de España. Edición, Enero de 2012 


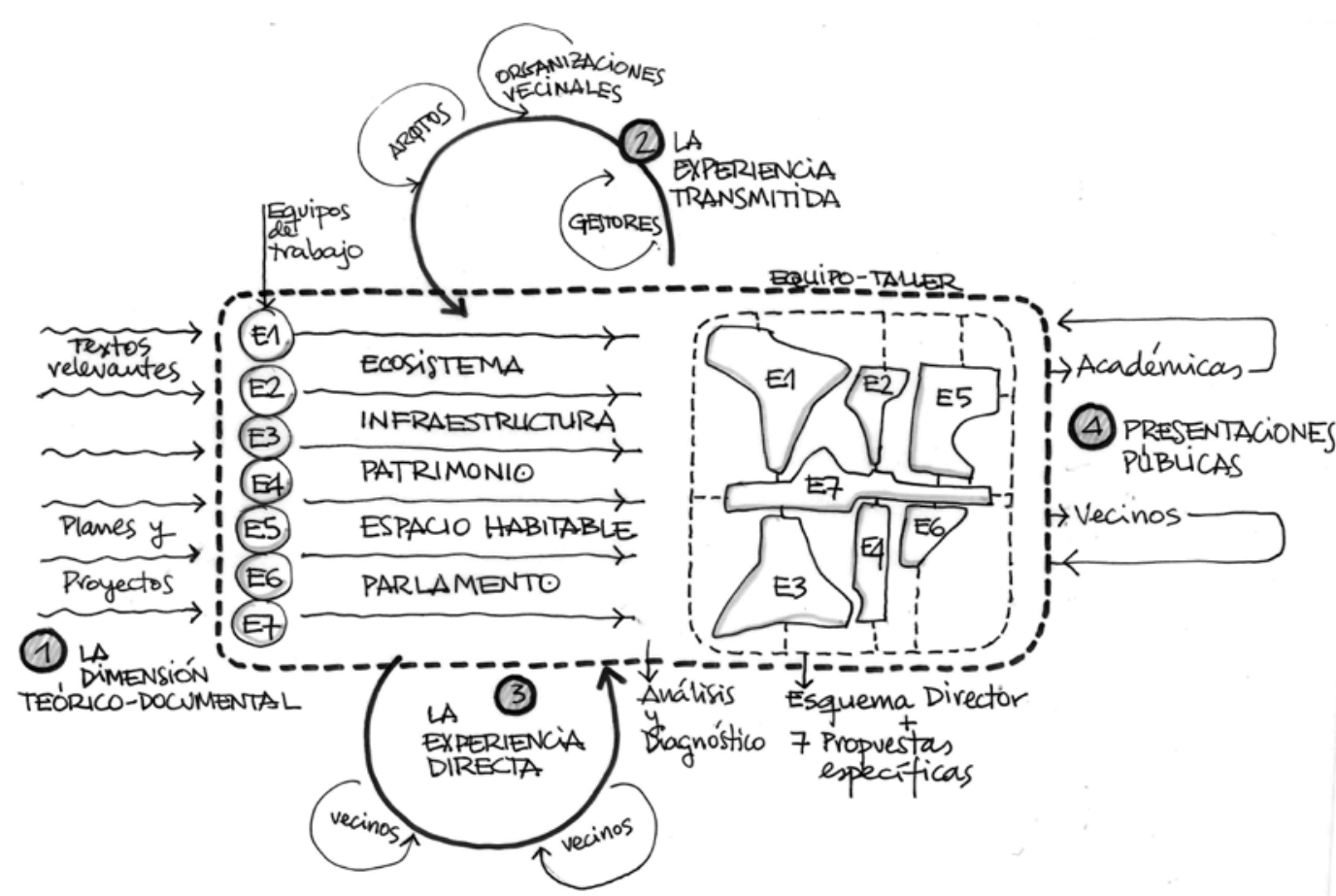

Esquema metodológico del Taller de regeneración urbana San Pablo-Zaragoza Methodologitad chememerlhe San Fablo urban regeneration workshop, Zaragoza.

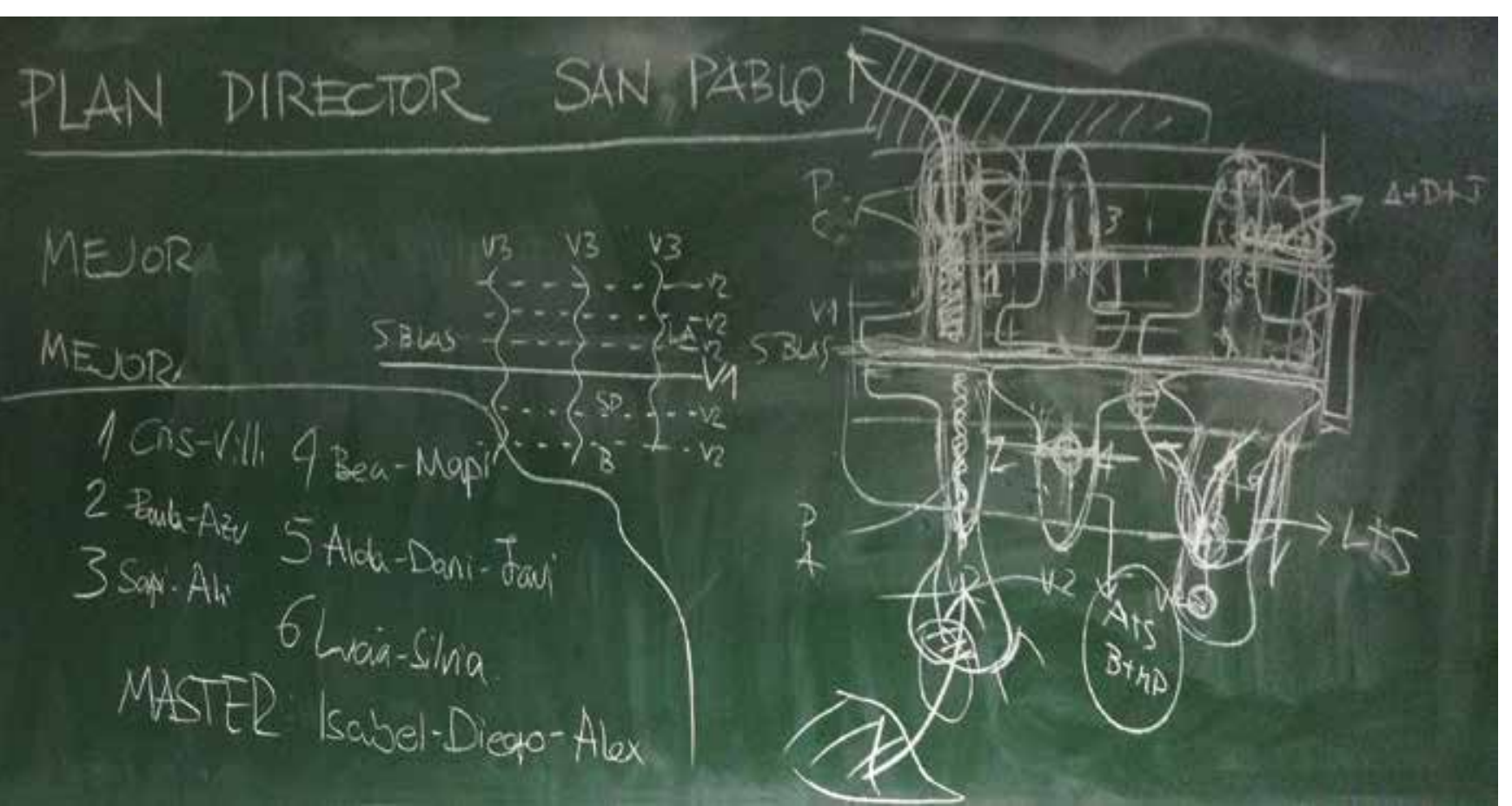

Zzarra del Taller. Selección de emplazamientos para los proyectos especificos

sketch on the board. Sites selection for the specific projects. where we conducted an urban regeneration workshop on the district of San Pablo. This district has a high rate of urban vulnerability as described, at national level, in the first document addressing this topic produced by the Ministry of
Development? More than any other district in the city, San Pablo has witnessed intense associative and protest activity. This activism not only highlights problems, but also croposes alternatives and opportunities to improve the quality of life This activism not only highlights problems, but also proposes alternatives and opportunities to improve the quality of life
in the area. Last, but not least, San Pablo is also a district where urban regeneration proposals have been implemented in the area. Last, but not least, San Pablo is also a district where urban regeneration proposals have been implemented
since 1997, following the directives of the Comprehensive Plan for the Historic Centre of Zaragoza, PICH 1997-2004. since 1997 , following the directives of the Comprehensive Plan for the Historic Centre of Zaragoza, PICH 1997-2004.
After completing this plan's renovation programme for the 2005-2012 period, the Comprehensive Plan Office is today After completing this plans renovation programme for the 2005-2012 period, the Comprehensive Plan Office is today
facing the task of revising the Plan for the 2013-2020 period. All these issues have transformed San Pablo into a living facing the task of revising the Plan for the 2013-2020 period. All these issues have transformed San Pablo into a living
laboratory for experimenting with contemporary techniques and trends in urban regeneration; therefore, in this case, introducing a workshop turned out to be very relevant if based on close collaboration with the managing agents.

During a four-month exercise, the students were organised into work teams that were integrated in the main workshop team at the same time as if they were a professional drafting team. Meanwhile they received an overview of the district's specific problems. This challenge was addressed from a triple dimension: theoretical-documentary, transmitted experience and direct experience. The theoretical-documentary dimension was provided by the course tutors and traced urban regeneration processes in a critical retrospective both in Spain and outside our country. The students individually studied indispensable texts relating to interventions in the consolidated city (Sutcliffe, Campos Venuti, Jacobs and Gehl, among ohters) and extracted useful lessons regarding the historic centre of Zaragoza and

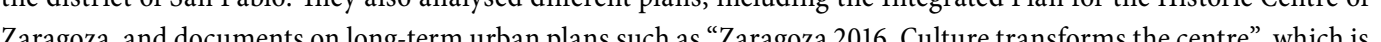

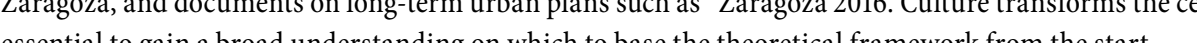

tores del Plan Especial de la manzana de Las Armas, nos hicieron partícipes de su particular experiencia en el barrio, de las voluntades, las oportunidades y las dificultades a las que tuvieron que enfrentarse, de la gestión de la manzana, de su habitabilidad y de su aceptación ciudadana. La sensibilidad del movimiento vecinal organizado fue aportada por Pedro Santisteve, abogado y miembro de la plataforma que impulsa el proyecto para la reutilización del edificio, hoy cerrado, del antiguo instituto Luis Buñuel, junto con el arquitecto municipal José Javier Gallardo. Ana Sanromán, directora de la Oficina del Plan Integral del Casco Histórico, nos transmitió la realidad social del barrio y los planteamientos actuales en el marco de la acción pública, y el arquitecto Juan Rubio, de la sociedad Zaragoza Vivienda, al análisis de las luces y sombras de la gestión en Zaragoza y en otras ciudades españolas.

Por último, la dimensión de la experiencia directa de análisis y diagnóstico del barrio corrió, como no podía ser de otra manera, de la mano de los alumnos que, organizados en siete equipos, realizaron un análisis integrado del barrio con el objetivo de generar un diagnóstico evaluativo que atendiera, al menos, a cinco líneas transversales que intentaban abarcar la complejidad a la que antes nos hemos referido:

- San Pablo como Ecosistema. El análisis del sistema de espacios abiertos (públicos o privados), y de manera especial el papel del río Ebro en los espacios verdes que configuran una matriz de valor ambiental y social interconectada a través patios interiores, plazas, jardines, cubiertas y medianeras.

- San Pablo como Infraestructura. Importante cuestión por la condición de barrio circunvalado por grandes avenidas, con una implantación reciente de la Línea 1 del tranvía, ante el reto de una progresiva peatonalización, que debe atender a la vez a cuestiones de vitalidad urbana, accesibilidad, tematización y funcionalidad.

- San Pablo como Patrimonio, que afronta el anali isis de los distintos elementos (tangibles e intangibles) de valor identitario y cultural y su relación con la trama humana y urbana de la ciudad. 


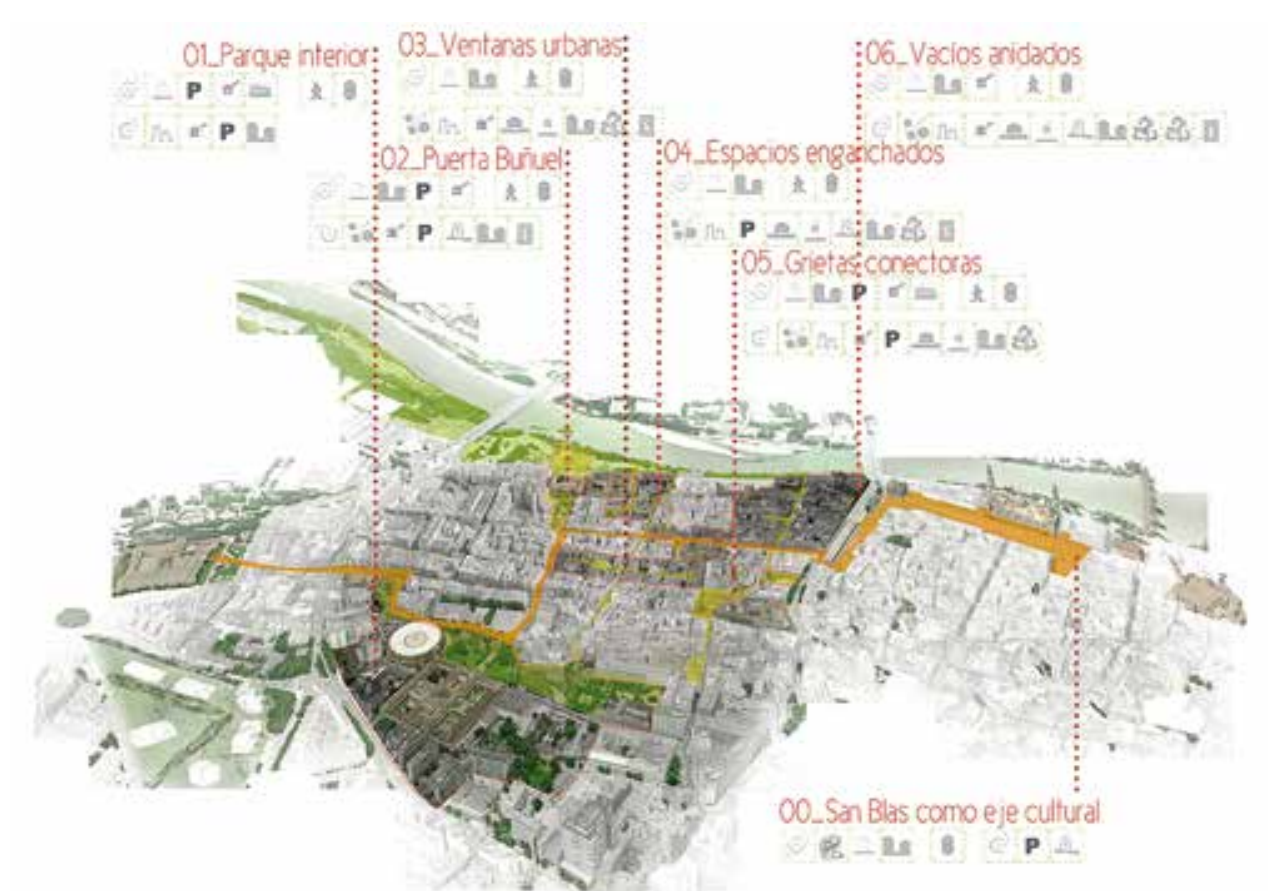

Equema director: Integrar, Cohesionar, Recualificar San Pabblo

Master plan:" "San Pablo Integration, Cohesion and Reuualification" These theoretical sessions were combined with others given by those involved in the district's management. They were
very useful for exchanging information on different plans that otherwise would have been impossible to extract and test first hand. The architects Fernando and Innacio Aguerri, the designers of the Special Plan for Las Armact bock invited us to share their particular experience in the district the aims. opportunities and difficulties they had to face as well as issues relating to the mangement of the block its habitability and residents' approval Pedro Santisteve lawyer and member of the programme behind the project for the reuse of the former Luis Buñuel. School together with the municipal architect José Javier Gallardo, promoted awareness about the district's movement. Ana Sanromán, the director of the Office of the Integrated Plan for the Historic Centre, described for us the social reality of the district and currector of the Office of the Integrated Plan fos as part of public action. The architect Juan Rubio, from the public society Zaragoza Vivienda a key figure for the workshop and provided us with insights from over 30 years in the field of urban regeneration an his analysis of the dark and bright sides of urban management in Zaragoza and in other Spanish cities.

Finally, the students analysed and diagnosed the district for the direct experience dimension. They were organised into seven teams to perform an integrated analysis of the district with the objective of producing a diagnostic evaluation of at least five transverse lines to try to encompass the complexity we have referred to above:

- San Pablo as an Ecosystem. The analysis of the open spaces system (public or private), and especially the role of the Ebro river in the green spaces that make up a matrix of environmental and social value through interconnected courtyards, squares, gardens, roofs and walls.

- San Pablo as an Infrastructure. This is an important issue concerning the condition of the district encircled by wide avenues, with the recent implementation of tram line 1 , the challenge of a gradual pedestrianisation, which deals with issues of urban vitality, accessibility, functionality and theming.

- San Pablo as Heritage. This addresses the analysis of several tangible and intangible elements of identity and cultural value and the relationship with the human and urban fabric of the city. San Pablo como Espacio habitable, que afronta el análisis del tejido residencial, la morfología y el estado de la edifi-
cación y de la población residente, la accesibilidad y habitabilidad del espacio residencial, los espacios de vulnerabilidad, junto con otras actividades que cualifican el espacio urbano, como el comercio o los equipamientos.

- Y, por último, San Pablo como Parlamento, que profundiza en la identificación de los agentes ( 0 actantes) sociales, de los espacios de relación y de los elementos, experiencias y prácticas de apropiación del lugar, de los "espacios fríos y espacios calientes", espacios amables y espacios de conflicto.

Los alumnos, con su "invasión" pacífica del barrio, recabaron datos, testimonios y experiencias que les permitieron construir un diagnóstico personal y renovado. Para conseguir realizar la información y el diagnóstico de forma ágil, constrif un dagnostico personal y renado. Para consegur realizar la información y el diagnostico de for a agl,

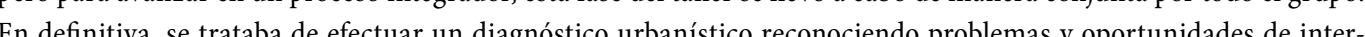

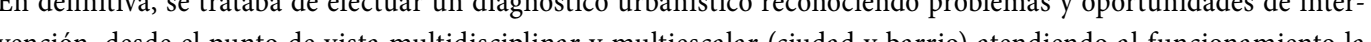
cella sus potencialidades de cambio.

El diálogo, el pacto y la negociación forman parte del aprendizaje del arquitecto, y por ello las líneas estratégicas en as que deberia basarse la intervención fueron consensuadas en el marco del conjunto del Taller, si bien un equipo adquirió la responsabilidad de integrar toda la documentación que tiene el carácter de plan marco o esquema director. Desde el Taller se planteaba superar la escala del proyecto urbano, y afrontar la necesaria dimensión y alcance del conjunto de intervenciones necesrias No olvidemos que San Pablo es un bario junto de intervenciones necesarias. No olvidemos que San Pablo es un barrio complejo, suma de distintas realidades
urbanas, pero de espacios públicos escuetos y de manzanas alargadas cuya parcelario medieval ha experimentado un urbanas, pero de espacios publicos escuetos y de manzanas alargadas cuya parcelario medieval ha experimentado un
proceso de densificación y crecimiento en altura muy considerable, especialmente en sus bordes, hacia las avenidas perimetrales. Esto ha convertido cada manzana en una isla y el barrio en un archipiélago que a pesar de su emplazamiento central en Zaragoza, junto al casco romano, no posee la suficiente accesibilidad y "gancho" como para garantizar la to central en Zaragoza, junto al casco ronanod económica y social deseada. En nuestros dís todos estos problemas se han visto amplificados de la mano de la recesión económica, la desigualdad y la obsolescencia de parte de su tejido e infraestructuras.

En este contexto, el margen para la intervención urbanística desde una dimensión convencional de transformación de las condiciones físicas resulta muy limitado. Por eso, nos pareció necesario profundizar conjuntamente desde la perspectiva de la regeneración urbana y social. Esta cuestión debía ser central en las propuestas urbanas y arquitectónicas, de los alumnos que debían formular estrategias de intervención y perfilar los instrumentos adecuados para su efectiva gestión urbanística. Para ello, cada equipo seleccionó un ámbito de investigación y de diseño desde el que poder trabajar sobre alguno de los problemas urbanos previamente identificados en el esquema director. A su vez, el avance de cada una de los proyectos específicos servía para la reflexión colectiva y para re-pensar los contenidos del esquema director. Este método iterativo de trabajo, pensar, planificar y diseñar desde la escala de ciudad hasta la de la
vivienda pocas veces es posible en este tipo de procesos en la práctica profesional pero, como pudo comprobarse, no vivienda, pocas veces es posible en este tipo de procesos en la práctica profesional pero, como pudo comprobarse, no es sólo útil, sino necesaria para evitar situaciones indeseables de falta de flexibilidad y coherencia en nuestro planes. Por otro lado la estructura de calles paralelas del barrio de San Pablo débilmente trabadas por un sistema de calles o callejones transversales ofrecía la oportunidad de convertir precisamente estos enlaces transversales en el argumento de articulación espacial de los distintos proyectos. Así al Oeste del barrio se desarrolla un eje urbano de rango ciudad en el que se apoya el equipo "Puerta Luis Buñuel" al objeto de profundizar en el potencial de la rehabilitación y regeneración del edificio del antiguo instituto y su conexión con el parque del Ebro. Otro equipo, denominado "Parque interior", con el mismo objetivo de romper las murallas físicas y sociales del barrio, enlaza la calle Mayoral con el sistema de espacios libres del edificio Pignatelli, sede del Gobierno de Aragón. En el sector central, "Ventanas urbanas" y "Espacios enganchados" la condición de eje central de la calle Cerezo sirve a sendos equipos para profundizar en las posibilidades de permeabilidad, recualificación y mejora de las condiciones interiores del tejido residencial, en una estrategia de atención a lo pequeño, a lo doméstico. En el sector Este, "Espacios anidados" aborda las potencialidades que presenta el infrautilizado edificio del Mercado Central y la regeneración del interesante sistema de espacios públicos y privados que enlazan el mercado con la ribera del Ebro. Y "Grietas conectoras" investiga las aperturas o nuevas puertas al barrio, las posibilidades arquitectónicas de los solares estratégicamente dispuestos junto a las grandes avenidas, 
-San Pablo as a Living Space. This addresses the residential fabric analysis; the morphology and the state of the other activities that qualify the urban space, such as trade or equipment.

-And finally, San Pablo as a Parliament. This delves into the identification of social agents, relationship spaces and the elements, experiences and practices of appropriation of the place, "cool spaces and hot spaces", friendly spaces and spaces of conflict.

By peacefully "invading" the district, students collected data, testimonies and experiences that allowed them to build an updated and personal diagnosis. To diligently obtain the information and make a diagnosis, but to advance an integrative process, the whole group was involved in this phase of the workshop. In short, the aim was to make an urban diagnosis by recognising problems and opportunities for intervention from a multidisciplinary and multi-scale (city and district) point of view, focusing on the workings of the city, understood as a living and interrelated system of human and non-human factors, its processes and its potential for change.

Dialogue, agreement and negotiation are all part of learning how to be an architect, and therefore the strategic lines was responsible for integrating all framework plan or master plan documentation.

The workshop proposed to exceed the scale of the urban project and address the dimension necessary and the scope of the set of interventions required. San Pablo is a complex district, a sum of different urban realities, but small public spaces and elongated blocks whose medieval structure has undergone a considerable process of densification and growth in height, especially at its edges to the perimeter avenues. This has transformed each block into an islan and the district into an archipelago which, despite its central location in Zaragoza, next to the Roman town, is not accessible or attractive enough to ensure the desired economic and social diversity. Today, all these problems have been amplified by the economic recession, inequality and the obsolescence of its urban fabric and infrastructure.

In this context, the margin for urban intervention based on a conventional dimension of transforming physical conditions the reger intervention and specify the appropriate instruments for effective urban management. Consequently each team selected asphere of reser. as the same time, the progress of each of the specific projects helped the group to reflect on the mor he master pla the pos but necessary to avoid undesirable situations wh

On the other hand, San Pablo's structure of parallel streets, weakly interlocked by a secondary system of narrow streets cutting across them, afforded the opportunity of transforming these transverse links into the spatial argumen of several projects. As a result, in the west of the district, an urban corridor across the city, in which the "Puerta Luis Buñuel" team relies on, is developed with the objective of furthering the rehabilitation and regeneration potential of the old school building and its connection with Ebro linear park. The "Parque interior" team, with the same objective of breaking down a district's physical and social barriers, links Mayoral Street with the open spaces near the Pignatell building (Government of Aragón headquarters). In the central sector, "Ventanas urbanas" and "Espacios enganchados" teams, the condition of Cerezo Street allows both teams to further explore the permeability, requalification and improvement of the inner conditions of the residential fabric, with a strategy that focuses on small domestic aspects. In the East sector, "Espacios anidados" team addresses the potential of the underused Central Market building, and the regeneration of the interesting system of public and private spaces linking the market with the Ebro riverbank. And "Grietas conectoras" team investigates openings and new gates to the district and the architectural possibilitis f empty plots strategically located next to major avenues (such as Conde Aranda or César Augusto).

These six interventions are linked by the proposal of transforming San Blas Street into a new commercial and cultural pedestrian hub, and by the job developed by the team managing the master plan, with a triple motto: "San Pablo integration, cohesion and requalification
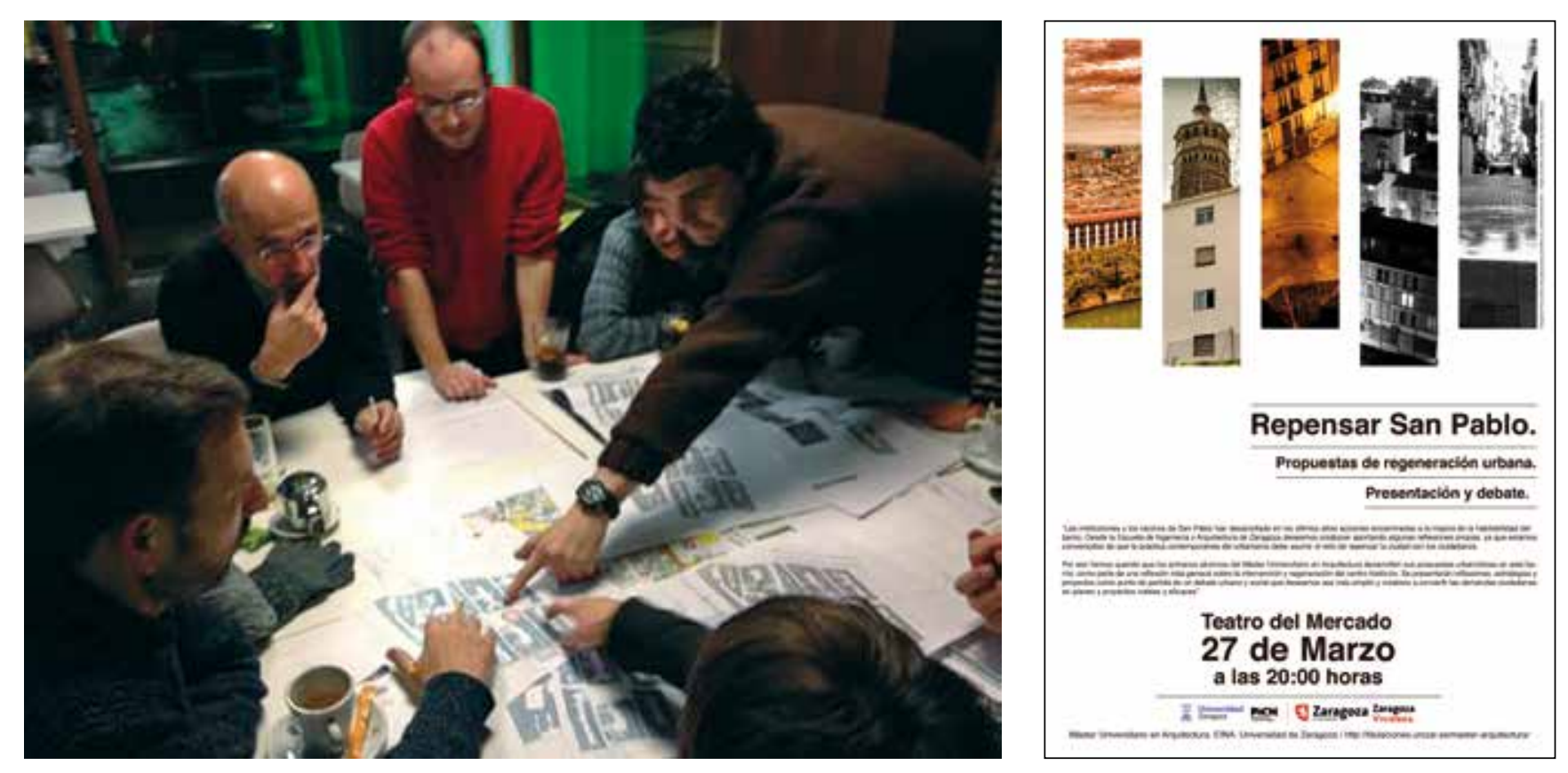

Worksession in a bar in San Pablo.

Cartel de la sesión de presentación "Repensar San Pablo".
Informative poster of the "Rethinking San Pablo" session.

como Conde Aranda o Cesar Augusto. Estas seis intervenciones quedan articuladas por la propuesta de convertir en equipo encargado del esquema director, con el triple lema "Integrar, Cohesionar, Recualificar San Pablo"

Queremos referirnos a este plan marco o esquema director porque somos conscientes de que la dimensión de la habitabilidad de la ciudad no implica solo al urbanismo no puede dar la espalda a otras políticas como la ambiental la sociocultural o la económica, aunque tampoco debe sustituirlas. Sin embargo, sí puede servir de soporte cualificado del conjunto de estrategias que referidas a un escenario futuro permita una gestión dinámica, sransparente e integrada del barrio A partir de ahí es cuando cobran sentido las propuestas realizadas y consensuadas por los al umnos para un conjunto de ámbitos específicos, siempre integrados en un planteamiento general, y retroalimentados de las críticas del taller. Esa metodología era el fundamento del Taller. el cómo más que el qué en sí mismo.

Si desarrollar esta metodología y llegar a definir el marco y las propuestas era uno de los objetivos del taller el otro, tan importante era darlo a conocer y someterlo a una reflexión colectiva fuera de las aulas. Los alumnos del Taller tuvieron la oportunidad de presentar los resultados de los trabajos ante arquitectos de reconocido prestigio, como Rafael Moneo ${ }^{3}$ y representantes del Ayuntamiento de Zaragoza, como José Manuel Alonso, Concejal Delegado de la Oficina del Plan Integral de Casco Historico de Zaragoza. Moneo elogí la calidad de las propuestas y la coordinación y competencia profesional del grupo, pero quiso abrir el debate planteando por un lado la excesiva confianza que depositada en anos dibujos tan tem de solo por el "ch de dif 316 de enero de 2014 : tras la presentación de los trabajos del Taller San Pablo, Rafael Moneo impartío una conferenciai en la Escuela de In-
genieríay A Arquitectura de la Universidad de Zaragoza sobre la propuesta que habiá realizado conjuntamente con Manuul de Solá Morales en 1969 para el Concurso de remodelación del Casco Histórico de Zaragoza. hitp://urbanismouz.blogspot.com.es/2014/02/aprendiendocon-rafael-moneo.html 
We refer to this framework plan or master plan because we know that the city's habitability dimension does not just involve urban development, which cannot turn away from other policies such as environmental, sociocultural or economic ones, although it should not replace them. However, it can serve as a qualified backer for the set of strategies for a future stage and it enables dynamic, transparent and integrated district management. This gives meaning to the propos st de approach and amence

If developing this methodology and defining the framework and proposals was one of the workshop's objectives, the other extremely important one was to share it by submitting it to collective reflection outside the classrooms. Studen had the chance of presenting their results to prestigious architects, including Rafael Moneo 3 , and to Zaragoza's city hall representatives, such as José Manuel Alonso, the councillor for the Comprehensive Plan for the Historic Cent of Zaragoza. Although Moneo praised the quality of the proposals, and the group's coordination and profession competence, he wanted to stat a debate by, on the one hand, highlighting excessive confidence in finished drawi - which can make us think that the regeneration of the problems will be solved just because they have been defined in that way - and, on the other hand, he would have preferred a greater variety of alternatives in the set of projects presented as a "complete and integrated exercise". That is the reason why he questioned whether the uniformity was due to students yielding to teachers, and opened the floor for discussion: do we lose our creativity when we try to analyse complexity? The experience of his work and his career as a researcher make us think that behind this "warning" lies its social requalification.

The students' generosity and commitment did not finish there. Some weeks later they showed their proposals to residents and to some district associations. This second presentation was the perfect counterpoint to the first on thus completing the last workshop lesson: Moneo asked for more creativity and architecture, while residents asked for more participation and decision-making in local actions. Above all in urban regeneration projects, creativity must be strongly linked to the population's needs and demands. We have to accept that in an academic workshop such as be strongly linked to the population's needs and demands. We have to accept that in an academic workshop such as
this, we cannot embrace the complexity of the actions that have to be implemented to requalify a part of the city that this, we cannot embrace the complexity of the actions that have to be implemented to requalify a part of the city that
has lost its functionality and has serious habitability issues. However, we have proved that it is possible to establish a framework and a "master route" that enable teamwork and urban regeneration processes. Outlining a system of architectural, urban and social measures is more important than producing a concrete solution. a uniformidad advertida no se debería más bien a un sometimiento de los alumnos a los planteamientos del profesoado, y dejó abierta la puerta a la reflexión jacaso cuando pretendemos analizar la complejidad perdemos creatividad La exp yesconde otra lección

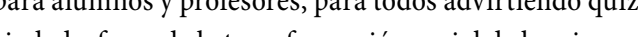

Pero la generosidad y compromiso de los alumnos con el barrio no terminó ahí y semanas más tarde expusieron sus propuestas ante los vecinos y varias asociaciones del barrio4. Esta segunda presentación resultó ser un contrapunto perfecto de la primera, cerrando la última lección del Taller: si Moneo pedia más creatividad y arquitectura, los vecinos reclaman mas participación y decisión en las actuaciones del barrio. De manera especial en las actuaciones de regeneración urbana, la exigencia de una creatividad propia le nestra disciplina arquitectónica debe estar firmemene enraizada con las necesidades y voluntades de la población. Es necesario reconocer la imposibilidad de abarcar la complejidad de acciones que han de activarse para aspirar a la recualificación de una parte de la ciudad que ha perdido su funcionalidad y que posee serias dificultades de habitabilidad desde un taller académico como el que hemos presentado. Pero hemos comprobado que sí es posible establecer el "marco" y trazar una "hoja de ruta" que permita el trabajo en equipos y procesos de regeneración urbana, donde quizá no resulte tan importante la formalización de una solución concreta, sino la articulación integrada de un sistema de medidas de enfoque arquitectónico, urbanístico, y social. 

athough currently the focus is also on interventions that reinstate and boost urban areas that have become obsolete degraded or derelict. These districts, hie tradtional historic centres of European cities, require regeneration schemes through urban redevelopment; in other words, renewals that allow them to regain that central role they played in the nitial layout of the city. This is only possible with a precise and accurate analysis that identifies not only each distric's problems, but also the social, cultural and tourist potential that would again enable it to play a substantial role residents' lives. The planning and urban development skills employed in these cases must detect he shortcomings

Urban redevelopment processes often need technical solutions for two basic aspects: the renewal of the district's infrastructure and social renewal. Successful cases systematically solve connectivity issues with the rest of the urban layout, improving and optimising pedestrian and vehicular flows. These isolated interventions create cultura commercial and social activity; in other words they tend to improve the exchanges between people and their quality. Understanding urban redevelopment from this twofold technical and urban viewpoint makes it possible to develop infrastructure solutions that help undo obsolete or marginal situations.

The San Pablo district in Zaragoza was used as an educational experiment. After a process of analysis of the problems and proposals, basic guidelines were established that would allow students to develop ideas into a specific viable solution.

These basic guidelines were split into two large groups: urban design and associated accessibility, on the one hand, and facilities that shape the city's infrastructure, on the other. An analysis of location and intervention requirements was included.

Work related to urban design

The students analysed the potential for organising and streamlining urban flows to increase access to the district by pay attention to traffic-calmed areas for pedestrians and vehicles, loading and unloading bays, accesses for emergenty vehicles and parking places.

The students estimated the possibilities of consolidating, improving and opening new quality public spaces - green building-free or mixed types - that would foster walking social and cultural exchange and make streets and sques look more attractive.

Complying with restrictive accessibility regulations for people with disabilities was mandatory at all times.

Finally, the group decided to promote the district's identity using quality urban elements. The power of customised, singular, unique, considered and buildable design became apparent in the component each group created for the distrit. panels, etc, some of which have been successfully realised.

\section{Urban infrastructure solutions}

Students analysed the techniques, limitations and peculiarities of the urban development of a consolidated city centre focusing on the main utilities and services (water supply, sewer system, public lighting, gas supply, electricity and telecommunications.

They explored the possibilities of implementing a new network of district heating to increase energy efficiency.

Using these guidelines as a basis, every group worked on one of the road axes that had been identified. In each case they addressed the particular conditions of each street, but contributed solutions compatible with an overall integrated solution for the problems detected in the San Pablo distric.
Hacer ciudad es un proceso complejo y largo en el tiempo, fuertemente ligado a las dinámicas sociales y económicas, no sólo ocales, sino ya globales en un mundo altamente interconectado. En épocas recientes la ampliación de la ciudad se ha desarro-

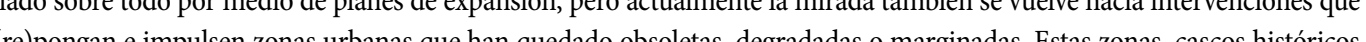
de la ciudan e in cen

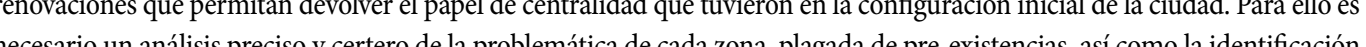
de sus posibles potencilidades (sociles culturales su centralidal), que permitan su re-inclusión comp pute sil de

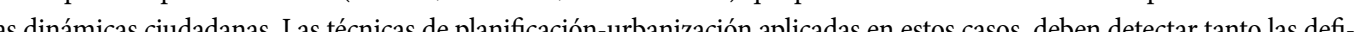
ciencins en sus dotaciones (espacio público equipamientos y estado de los difics) como en el str do de binfestros u Los presos de reba Los procesos de reurbanización a menudo requieren soluciones técnicas que respondan y den soluciones a dos aspectos básicos: La renovacionn infraestructural del barrio, y la renovación social. Los casos de exito resuelven sistemáticamente la conectividad con el resto de la trama urbana, mejorando y optimizando flujos, tanto de personas como de vehículos y a través de actuaciones puntuales crean actividad, de tipo cultural, comercial y social. Es decir que tiendan a mejorar los intercambios entre personas y su calidad. Entendiendo el proyecto de reurbanización desde esta doble óptica técnica-urbana, es posible desarrollar soluciones infraestructurales que coadyuvan a revertir situaciones de obsolescencia o marginalidad. El barrio de San Pablo en Zaragoza se ha usado como didáctica experimental. Tras un proceso de análisis de las problemáticas y síntesis propositiva, se pasó a fijar las directrices de actuación básicas que permitiesen al alumno pasar de las ideas a la ejecución de una solución concreta y viable. Estas directrices básicas se han dividido en dos grandes grupos. Por un lado aquellas que hacen referencia al diseño ciudad, con el análisis de su ubicación y necesidades de intervención.

\section{Trabajos relacionados con el Diseño Urbano}

Se analizó el potencial de la ordenación y racionalización de los flujos urbanos, orientados a aumentar la permeabildad del barrio a través de la mejora y renovación de los puntos de conexión con la red urbana existente de la ciudad. En estos casos es importante atender a la coexistencia calmada de tráficos, cargas y descargas, accesos de vehículos de emergencia y aparcamientos.

Se estimaron las posibilidades de consolidación, mejora y nueva abertura de espacios públicos de calidad, de tipo libre, verde y mixto, que favoreciesen el paseo, el intercambio socio-cultural y que embelleciesen las calles y plazas.

En todo momento fue obligatorio atender a la restrictiva normativa de accesibilidad para ciudadanos con discapacidades. Finalmente, se quiso potenciar la identidad del barrio por medio de elementos urbanos de calidad. El poder del diseño particularizado, singular, único, reflexionado y construible se puso de manifiesto a través de la pieza que cada grupo creó para el barrio, como alcorques, bancos, luminarias, paneles interpretativos, etcétera, algunos de los cuales se han llevado exitosamente a producción real.

\section{Resolución de las Infraestructuras Urbanas}

Se analizaron las técnicas, limitaciones y peculiaridades de la obra de urbanización de un casco consolidado, en lo relativo a los servicios principales de abastecimiento de asua, saneamiento, alumbrado público, suministro de gas, electricidad y telecomunicaciones.

Se exploraron las posibilidades de implantar una nueva red de calefacción centralizada para la mejora de la eficiencia energética de la red.

Con estas directrices como base, cada uno de los grupos ha desarrollado uno de los ejes viarios identificados, introduciendo en cada caso las condiciones particulares a cada una de las calles, pero aportando soluciones compatibles con una resolución global e integrada de las problemáticas detectadas en el Barrio de San Pablo. 
Proyectos de urbanizacion
Development projects

Croquis de panel interpretativi
Isabel Ezquerra Diego Garcia Isabel Ezquera, Dieg,
Alejandro lezcano. Sketch of interpretive panel. Isabel Ezquerra, Diego Garter.

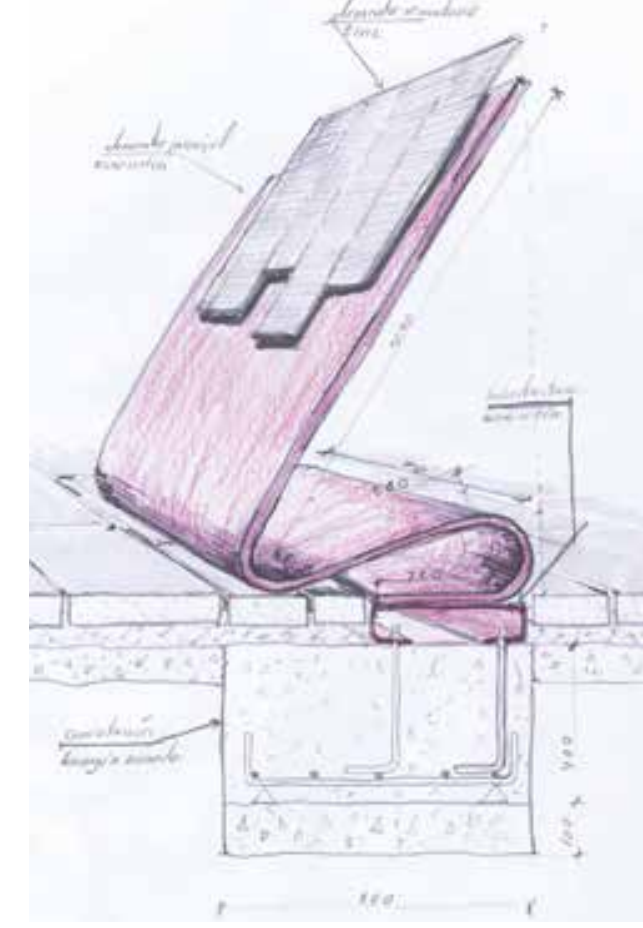

The groups worked to professional guidelines ensuring that their projects were viable and met design, operation an strict construction quality standards.

Consequently, they produced professionally structured mini projects with a substantiating report and a description of design decisions for a top-quality outcome with minimal uncertainty. We emphasised the need to attach as many documents as necessary to implement the technical solutions correctly.

All the designs therefore include enough drawings with varying levels of detail; in some cases the quality is even the al specification were useful for learning the importance of standard of a detailed construction document. The tect
tailoring the technical conditions of works accurately.

Finally, the priced bill of quantities produced using a tried and tested method marked the end of the final document. This publication puts forward the solutions the students have proposed. These are not limited to a mere graphic proposal or list of interventions and guidelines. Instead, the students' complex multidimensional work first analysed the urban and social problems they encountered. They then managed to outline the proposal to a level of detail that would make direct implementation possible. The documents they submitted had to comply with standards found in professional and legal practice. Using urban planning and management tools and skills, the solutions are compatible with the most advanced practices in urban development and take into account sustainability, and construction, energy and economic efficiency.

By controlling and designing technical solutions for infrastructures and making reasoned and judicious choices of materials and construction techniques for the street in question, the students learned how to execute projects to high standard of quality which they will be able to carry forward into their future careers in all aspects of urban developments: urban design, techniques and materials, solutions for facilities, urban and administrative management, compliance with regulations, submission of documentation and implementation.
Pene interprelativo jeccurado Jan Antonio Ros, sabel Ez20 Lezcano. Interpretive panel once installed.
Juan Antonio Ros, Isabel Ezquerra, Diego García and Alejejn

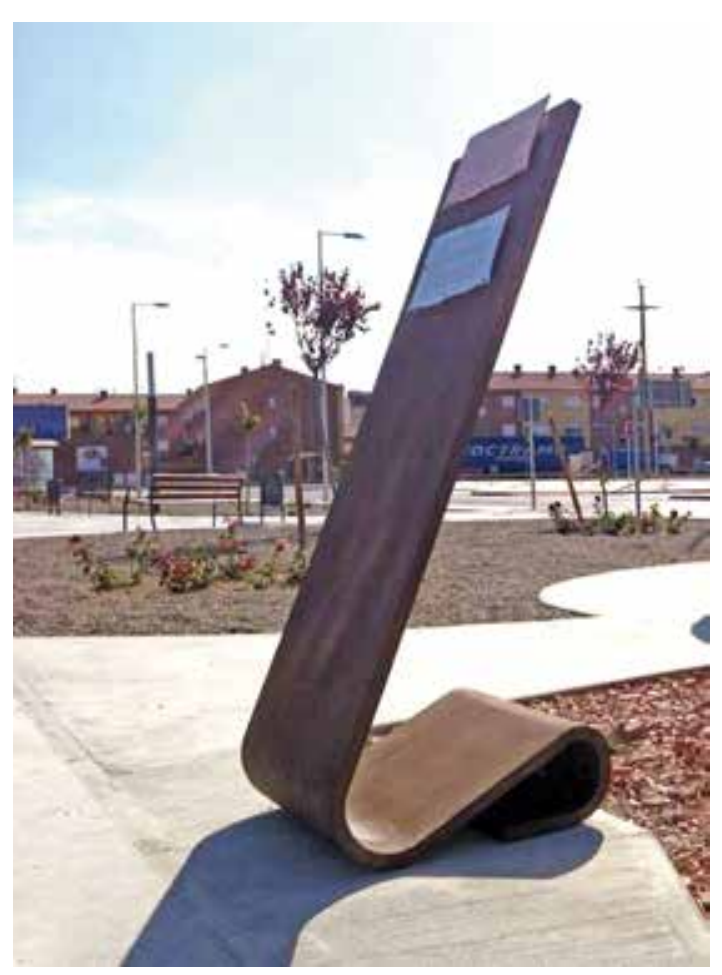

Los grupos han trabajo con criterios profesionales. Los alumnos han tenido que completar sus proyectos en condiciones de calidad de diseño, viabilidad, funcionalidad y rigor constructivo.

Por consiguiente, se desarrollaron semi-proyectos profesionalmente estructurados con la Memoria justificativa y descriptiva de las decisiones proyectuales dirigidas al resultado de máxima calidad y mínima incertidumbre. Se ha insistido en la necesidad de establecer cuantos anejos sean necesarios para la correcta ejecución de las soluciones técnicas adoptadas. Todos los proyectos contienen suficientes planos con diferentes grados de detalle, alcanzando en algunos casos el uctivo. El pliego de lo proyectos sirvió para conocer el papel que juega la correcta y particularizada prescripción de las condiciones técnicas de las obras.

Finalmente, las mediciones y el presupuesto, realizados siguiendo técnicas contrastadas y fiables permitieron cerrar el documento final.

En definitiva, se presentan en la presente publicación las soluciones planteadas por los alumnos, que no se han limitado a una mera propuesta gráfica o enumeración de un conjunto de actuaciones y directrices, sino que han desarrollado un trabajo complejo y multidimensional, en que partiendo de un análisis de las problemáticas urbanas y sociales, han sido capaces de desarrollar la propuesta hasta alcanzar un grado de detalle que permite su implementación directa, a través de su ejecución. Se ha exigido que los documentos generados, sean presentados bajo los criterios establecidos por la práctica profesional y legal. A través de las herramientas y técnicas de la gestión y planeamiento urbano, las soluciones son compatibles con las tecrnicas más avanzadas en urbanizacion, atendiendo tanto a su sostenibilidad y eficiencia constructiva y energética como económica.

A través del control y diseño de las soluciones técnicas de las infraestructuras y de una razonada y juiciosa elección de los materiales y técnicas constructivas que componen el vial, los alumnos podrán en su devenir profesional, acometer proyectos y ejecución de urbanizaciones de calidad, tanto desde el punto de vista del diseño urbano, de la funcionalidad técnica y material, de la resolución de las instalaciones, de la gestión urbanística y administrativa, de la normativa exigible, de la documentación presentada y de su ejecución. 


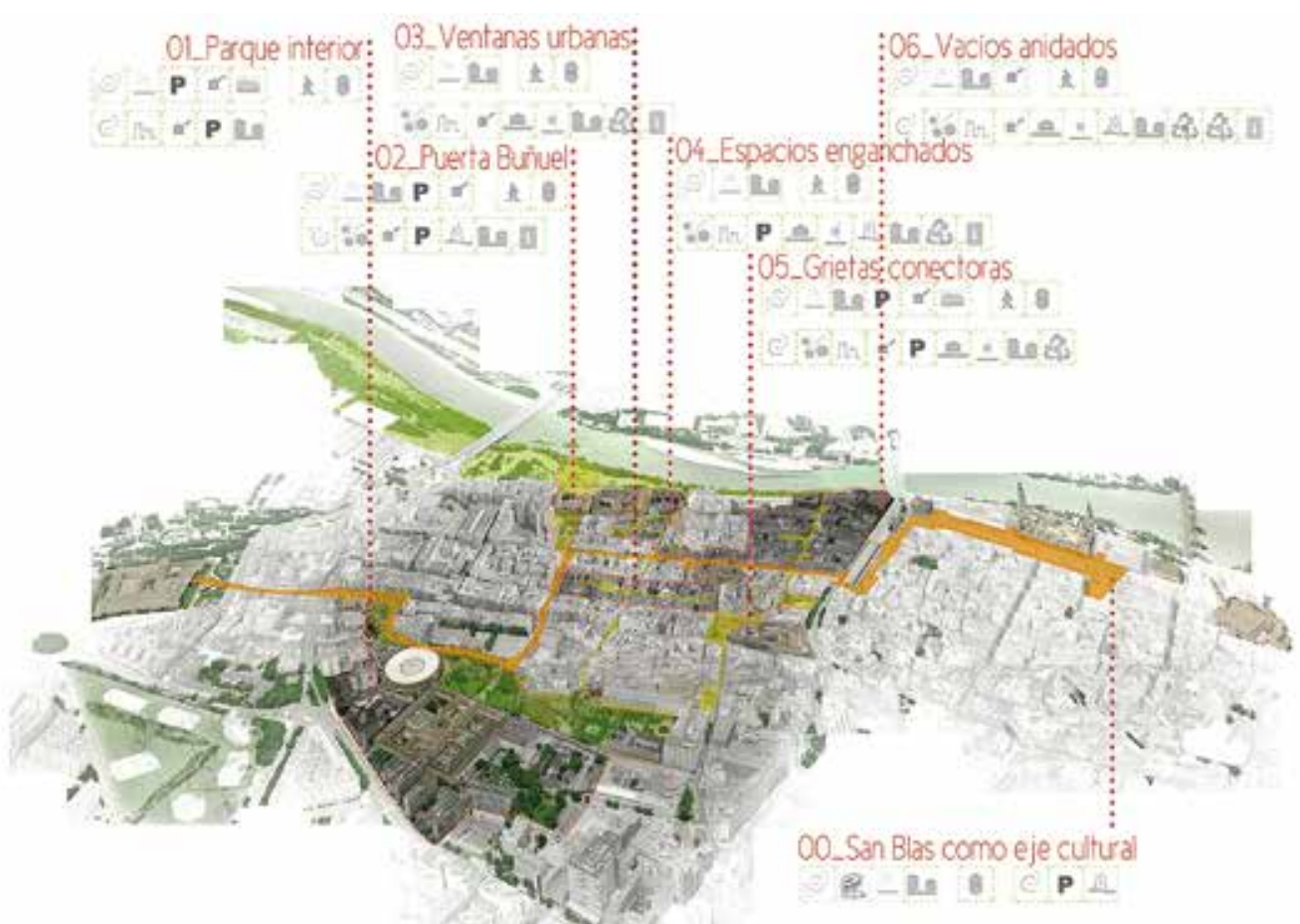

Integrar, Cohesionar, Recualificar San Pablo Integrate, Cohesionate, Requalify San Pablo

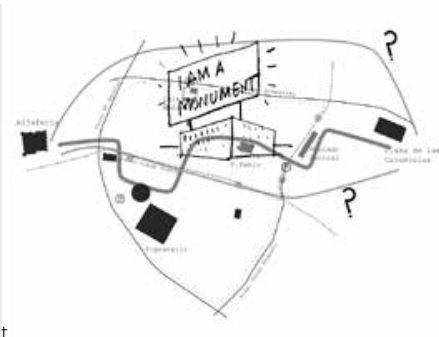

Concepto | Concept

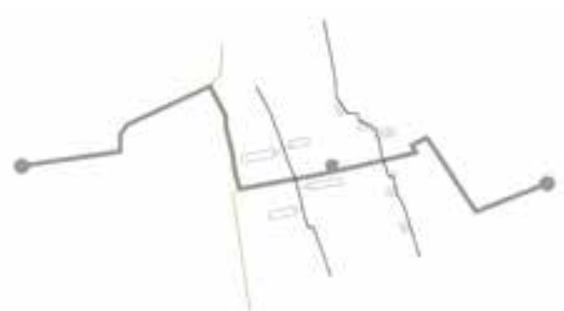

Concepto | Concept

Intervenir en la ciudad consolidada es cada vez más necesario en cuanto la ciudad

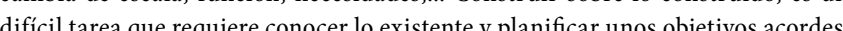
sus habitantes y necesidades.

Actualmente el barrio de San Pablo es uno de los sectores más degraddados de la ciudad. Sus antiguas callejuelas se suceden unas a otras sin que exista una com nicación directa con el exterior. Las infraestructuras requieren una intervención urgente tendente a su renovación y ampliacion. Los edificios han sufrido un pro-

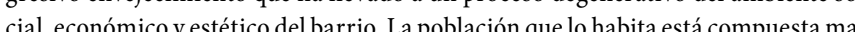
yoritariamente por ancianos $y$ por los sectores menos pudientes. La marginación hace de ese problema social el de más difíil solución. on the city's inhabitants and their needs. the

The San Pablo district is currently one of the most run-down parts of Zaragoza. Its old, narrow, labyrinthine streets offer no direct access to the outside. The district's infrastructures need urgent intervention if they are to be renewed and extended. The buildings have aged badly over the years, which has led to a gradual

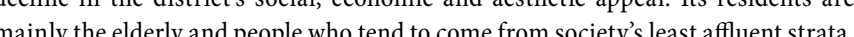
Warginlisation makes this a whocial problem that is soficiety's least taffluent strata.

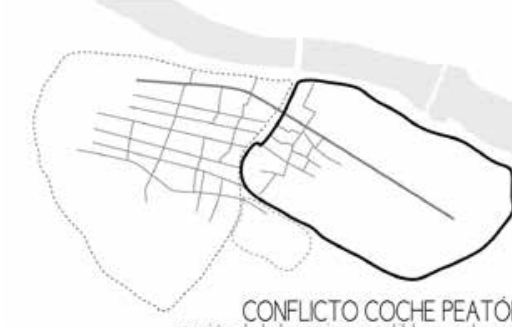

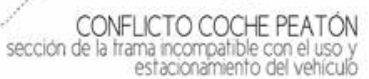
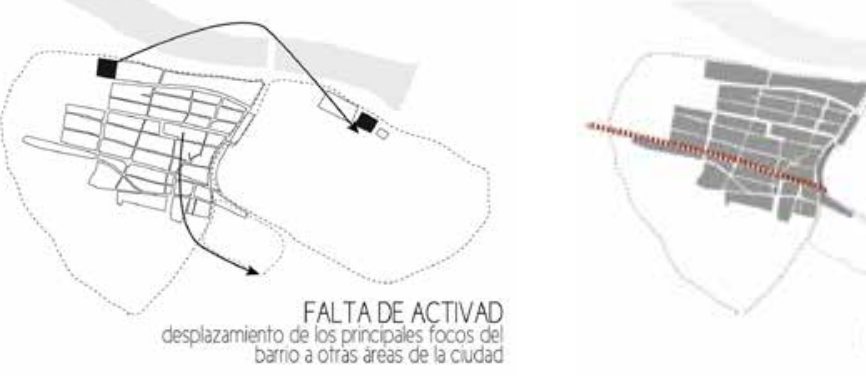

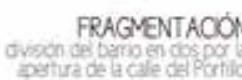
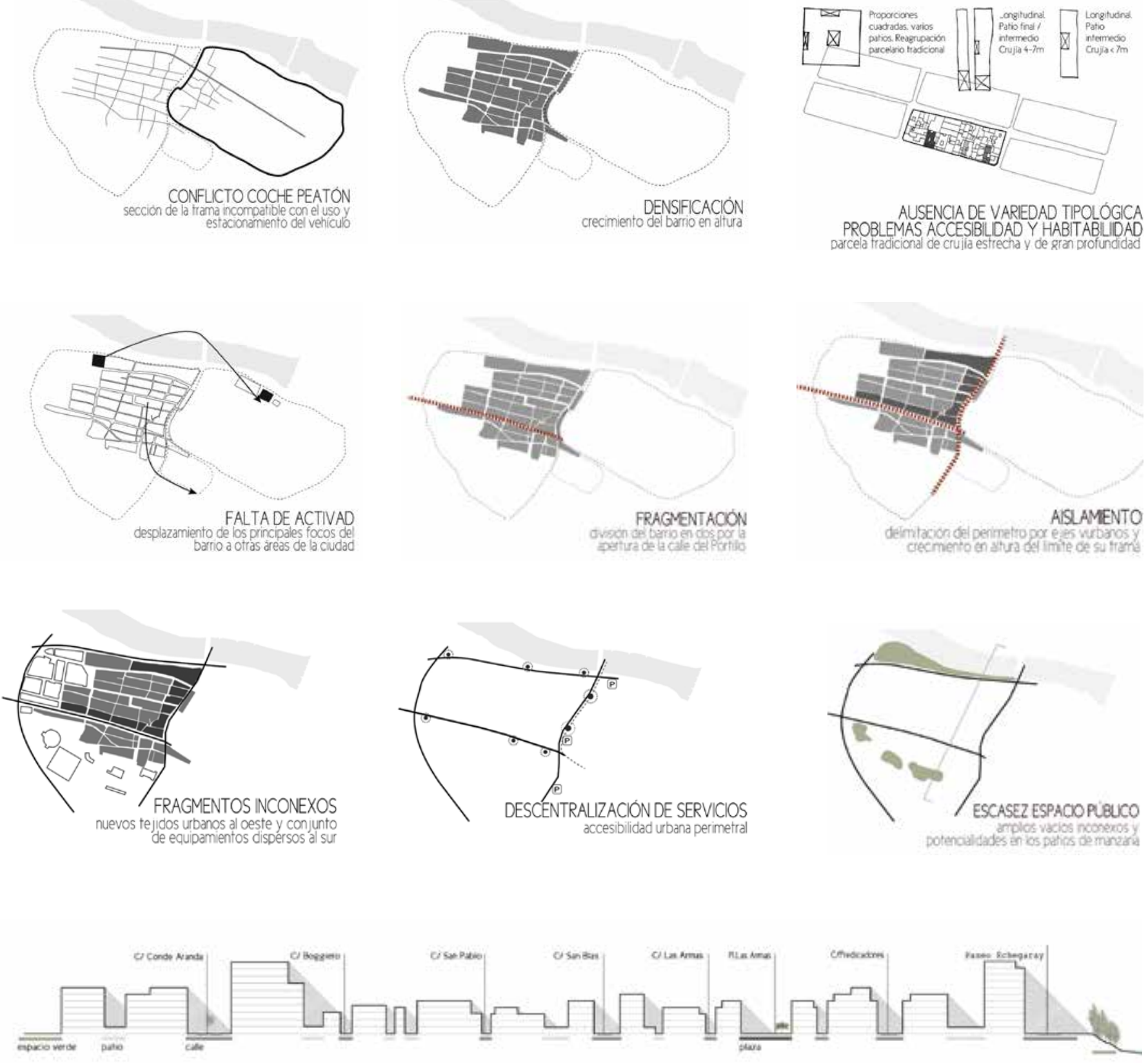

$$
\text { ① }
$$

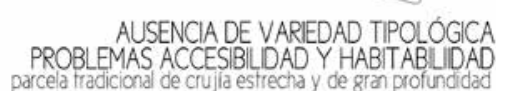

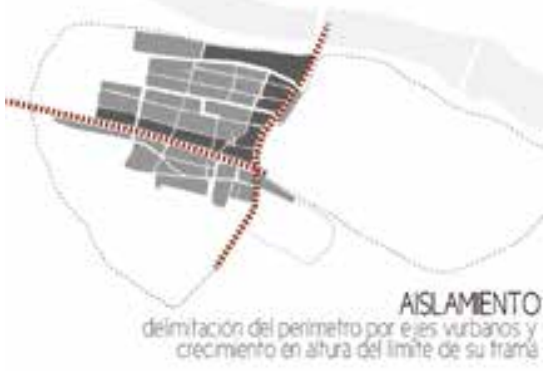

agnóstico | Diagnostic

Tras un análisis que pone de manifiesto las condiciones de marginalidad $\mathrm{y}$ ais lamiento, una edificación perimetral de mayor altura que acentua este enclaus tramiento en si mismo, espacios abiertos escasosos y de poco interés, transpportes perimetrales, infraestructuras deficentes, an tejido residencial que ocupa las planintervenir de dentro de la ciudad, se potencie su atractivo turístico, se permeabilice y se generen

Affer an analysis that highlighted the marginalisation and social isolation, a perimeter building at a greater height that accentuated the sense of confinement, a lack of open
spaces of any interest, peripheral transport services, deficient infrastructures, a residential fabric that occupies the ground floors of buildings preventing activities in the contact point with the street etc., the decision was taken to intervene in its attractiveness from a tourism perspective and re-establishing and generating activities that invite new residents and people in general to return to the area 


\section{INTEGRAR | INTEGRATE}

Abrir el barrio a la ciudad / Creación de puertas potenciando el patrimonio del barrio/ Destacar su valor pathmolial medante un eje este-oeste a través de la calle

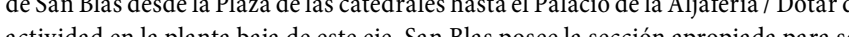

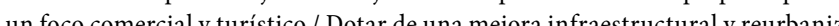
gran parte del barrio / Dotar de aparcamientos perimetrales de uso rotativo que permitan la accesibilidad a visitantes y residentes / Aprobar la linea 2 del tranvi por Conde Aranda potenciando la accesibilidad de la ciudad en sentido este-ees

Open up the district to the city / Create gateways that reinforce and highlight the district's heritage / Highlight its history and culture through an east-west axs taken through San Blas Street from Catedrales Square to the Aljaferia Palace

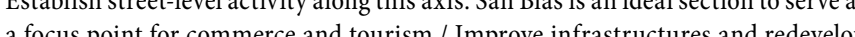
a focus point for commerce and tourism / Improve infrastructures and redevelop accessibility for residents and visitors alike / Approve the construction of tram line 2 along Conde Aranda Street, improving urban transport accessibility to the city along an east-west axis.

COHESIONAR | UNITE

Permeabilizar la trama de San Pablo generando tres ejes norte-sur que, traspa-

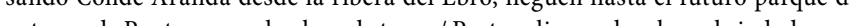
el tráfico que se mantiene con un acceso restringido. Destaca la peatonalización des Conde Aranda con la planificación del tranvía y la consiguiente unión entre las dos partes del Ebro.

Clear the San Pablo section by creating three north-south axes which would run from the bank of the river Ebro, cross Conde Aranda Street and continue to the future park in the Pontoneros area and the bullring / Pedestrianise and ensure people-friendly district where people have priority over traffici, by restricting the access. The pedestrintisngor Conde

\section{RECUALFICAR | REQUALIFICATE}

Dotar de equipamientos locales específicos, no olvidando edificios ya existentes a potenciar, como el $\mathrm{N}$ (un el ámbito residencial que asegure una diversidad social y económica / Dotar habitabilidad y accesibilidad a las viviendas existentes mediante la intervención en patios de manzana / Permeabilizar el barrio, posibilidad de utilizar los patios in-

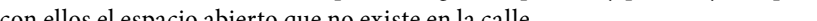

Provide specific local services, not forgetting existing buildings to be renovated, such as the Central Market/ Ensure greater residential typological diversity order to ensure greater social and economic diversity / Improve the habitability / Clear the district, allowing interior block courtyards to be used and creating publicly and privately managed spaces in order to recover open spaces which do not exist in the street.
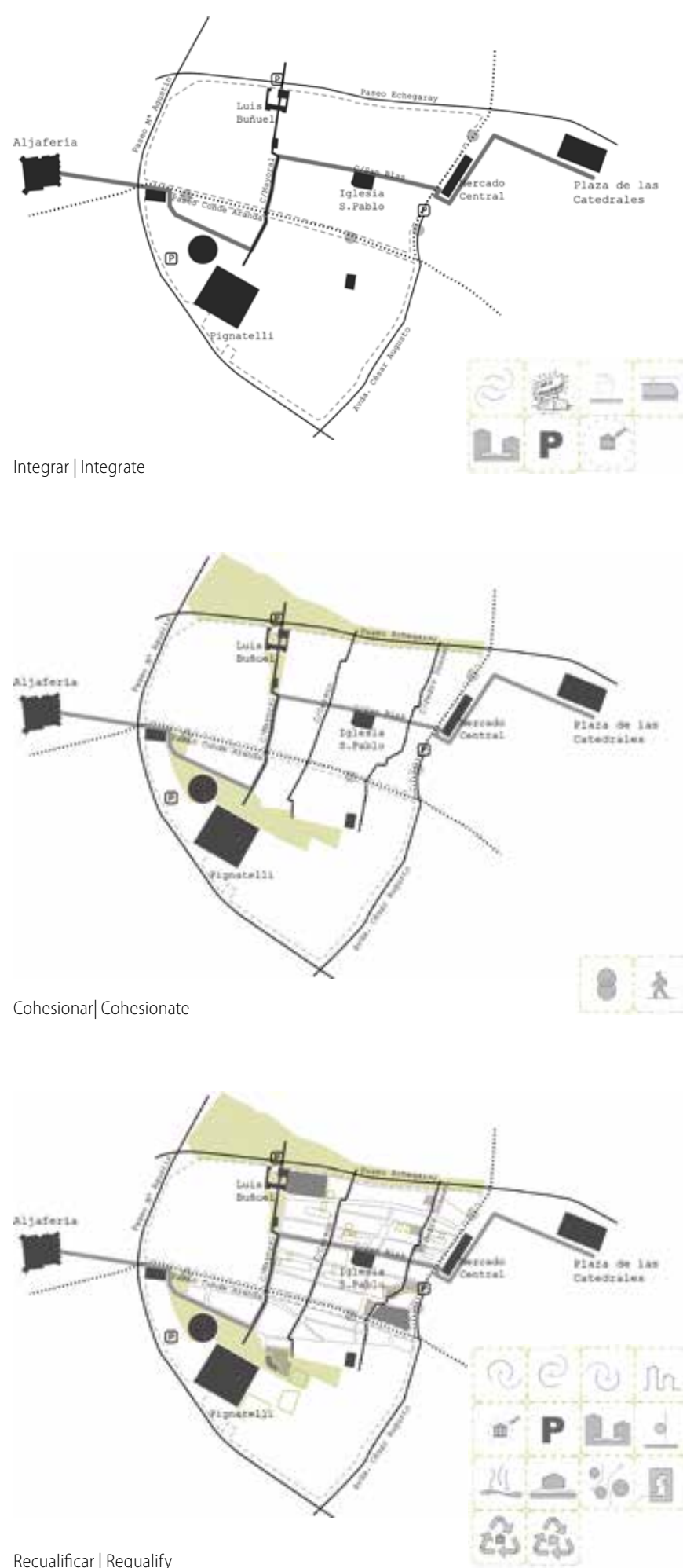
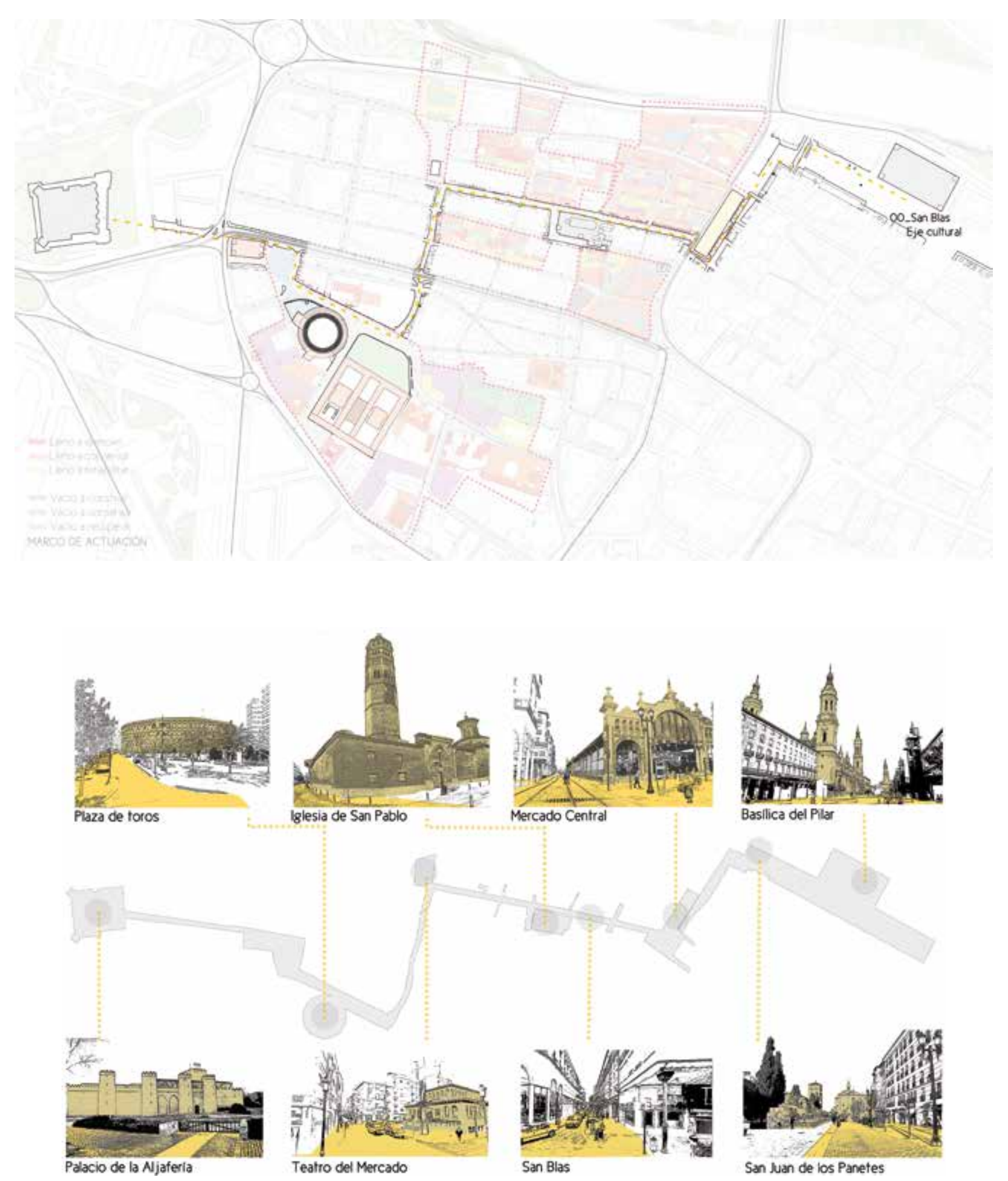


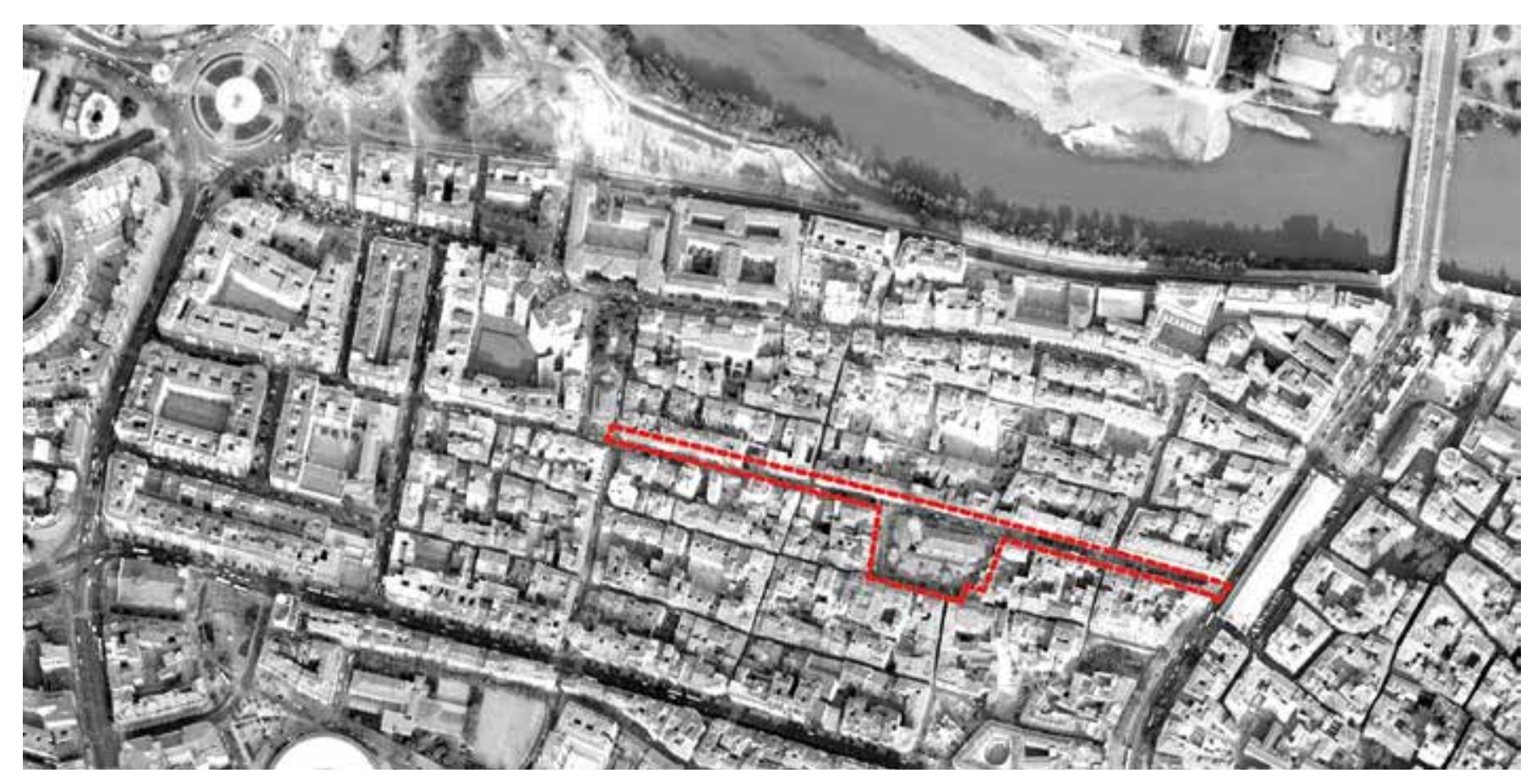

Se escoge la calle de San Blas por su centralidad dentro del barrio y su sección generosa de todas las del barrio, igualando la anchura de calles comerciales de referencia en la ciudad como la calle Alfonso. Su transcurso, que conecta los puntos de interés principales dentro de San Pablo es, también, un criterio para tomar decisiones de proyecto.

Se busca así, cambiar el carácter residencial del barrio al menos en esta vía, crear un foco de atraccion y una complejtad. se centra este objetivo en un trabajo de

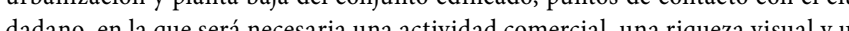
dinamismo que atraiga a más "movimiento" $y$ más personas.

Se propone generar un espacio peatonal fluido sin obstáculos espaciales o perceptivos que limite el uso del vehículo reduciéndolo ónicamente a carga y descarca acceso a garajes privados. Para ello, se repavimentará la calle con adoquines de hormigón, sin diferenciar en altura y material en ningún ámbito de la sección de

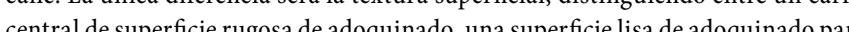
los extremos de la calle y una superficie lisa de hormigón " "insitu" para resolver en encuentro del pavimento con la superficie edificada si romper ningun adoquii. In superficie del carril central, de una anchura minima de $3,5 \mathrm{~m}$. (medida mínima para permitit el tránsito del camión de bomberos), está compuesto de pavimento tán de deshoplo

Las superfficies de los extremos tendrán la función de distribuir al peatón hacia lo minación y los elementos de jardinería. Todos estos elementos tendrán la función además de la propia, de delimitar el espacio de esta superficie con el del carril central.
San Blas Street has been chosen for its central location within the district and its which thanks to the reform works carried out in the mid-20th century, is the widest in the district, as wide as Zaragoza's main shopping streets, such as Alfonso Street. Its route, which connects the main points of

The plan is therefore to change the district's residential nature, at least along this whin an mban planning and steet level development framework, points of is visully rich and dynamic in order to attract greater "movement" and more people.

The idea is to which limits the use of vehicles to that of loading and unloading and for access to private garages. It will therefore be necessary to repave the street with concrete of the strees. What he need to alter the height or material used in any section (1)

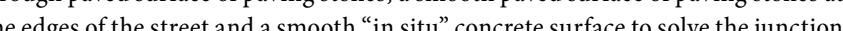
between the paving and the built area, obviating the need to break any paving unit.
The surface of the central lane, which will have mininum width of 3.5 metres (the minimum width to allow a fire engine to pass), will consist in high-strength paving

The surfaces of the edges of the street will direct pedestrians to the various shops along the way, as well as being the location for the various urban fixtures and area of this surface from the central lane. street, creating an attractive yet complex point of focus. This aim is to be developed
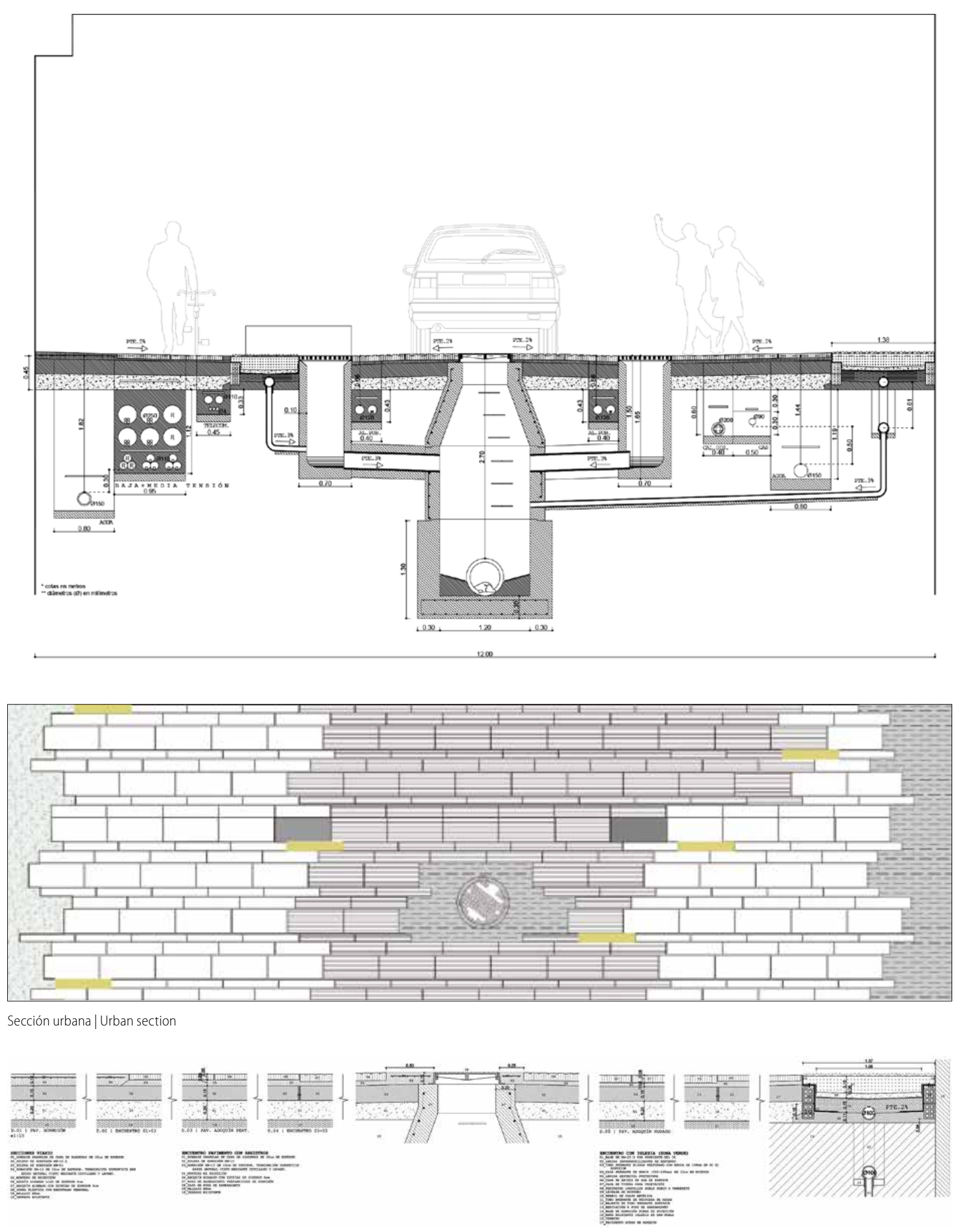

Detalles sección urbana l Urban section details 


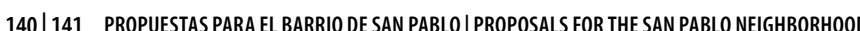

01 UN PARQUE INTERIOR | AN INTERIOR PARK

$$
\text { Paula Gordo Gregorio y Azucena Guerrer }
$$

Bajo la filosofia de otorgar un parque interior para San Pablo, se propone la implantación de un proyecto a escala ciudad que consiga una permeabililidad en la tram

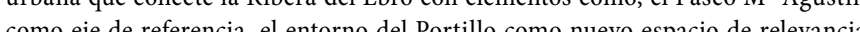
para la ciudad, o la Aliafería, elemento de gran interés patrimonial.

El hecho de crear un espacio tan permeable y capaz de relacionar ámbitos tan diincidir en que de esta propuesta surgen los tres grandes ejes que propiciarán la rehabilitacion del conjunto del barrio de San Pablo.

With the aim of providing an interior park for the district of $\mathrm{San}$ Pable, we propose green line park along the river Ebro with different landmarks in the city. This park must connect with the Boulevard $M^{2}$ Agustin, a referent axis in the city with a large This space with plenty of permeability, would be able to relate such different areas.

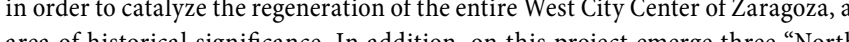
South axes" which will encourage the rehabilitation of the district of $S_{n}$ Pablo-
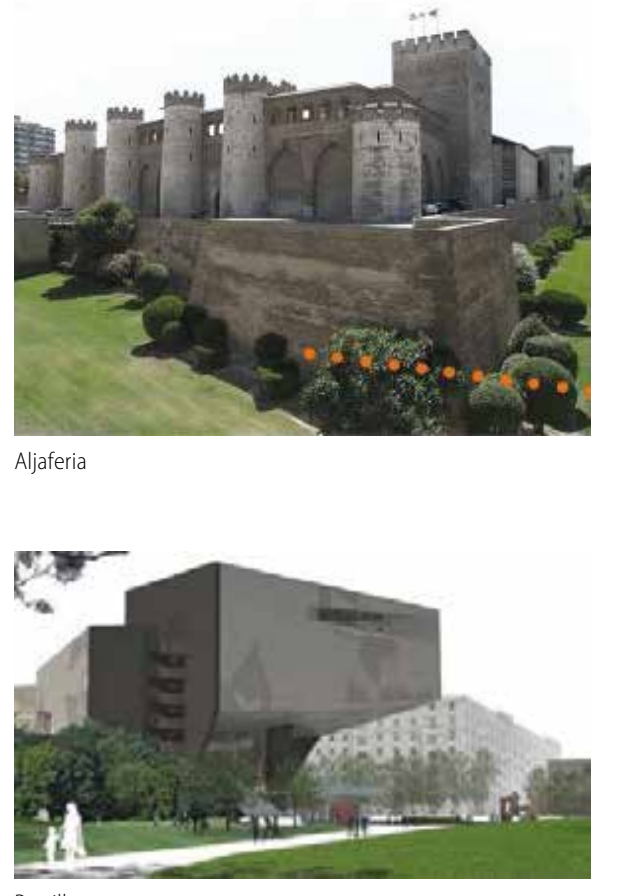

EVOLUCIOON HISTORICA | URBAN-HISTORICAL DEVELOPMENT
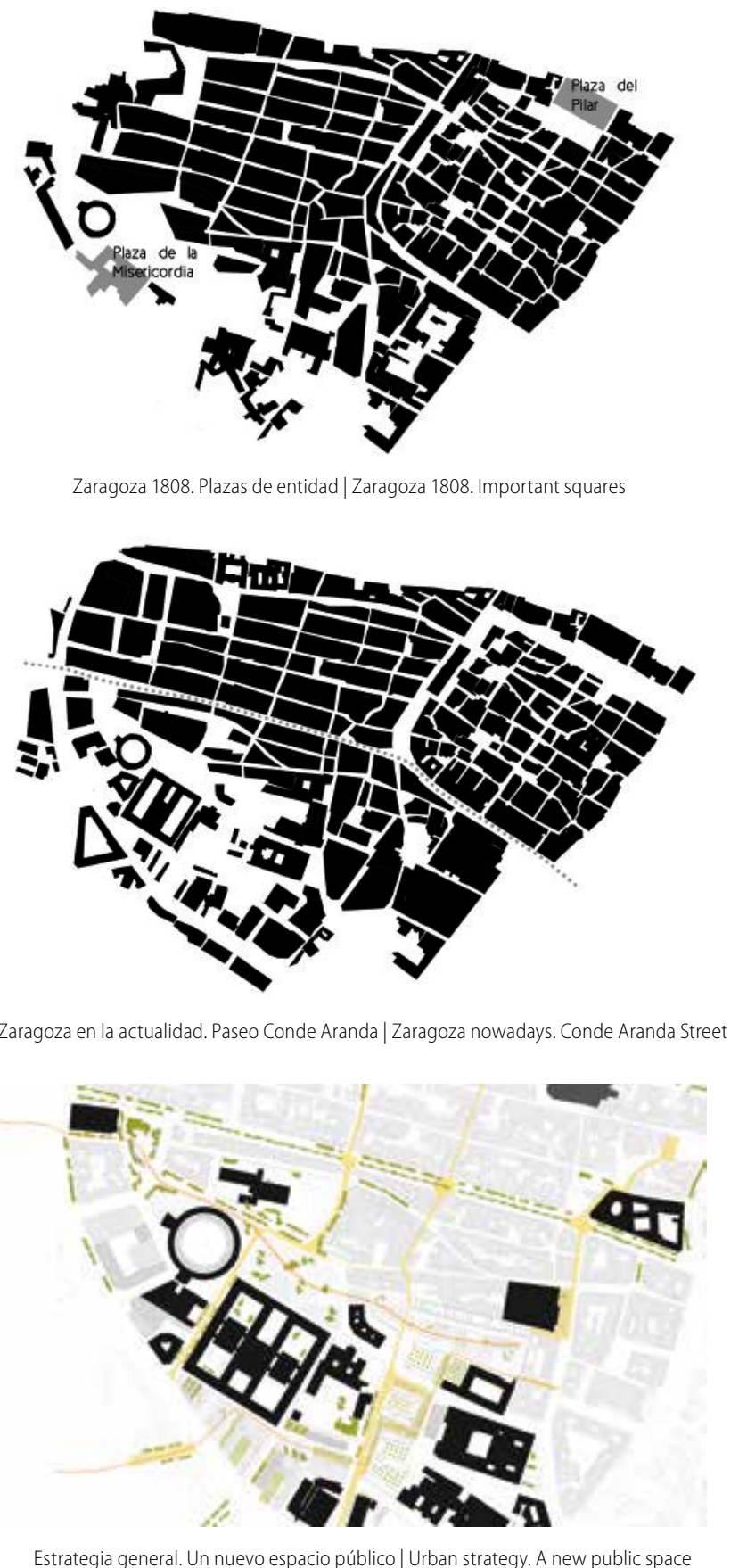

ESPACIOS VERDES | GREEN OPEN SPACES

Este enclave se caracteriza por tener la capacidad de conectar grandes

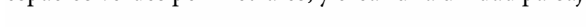

This
cape.

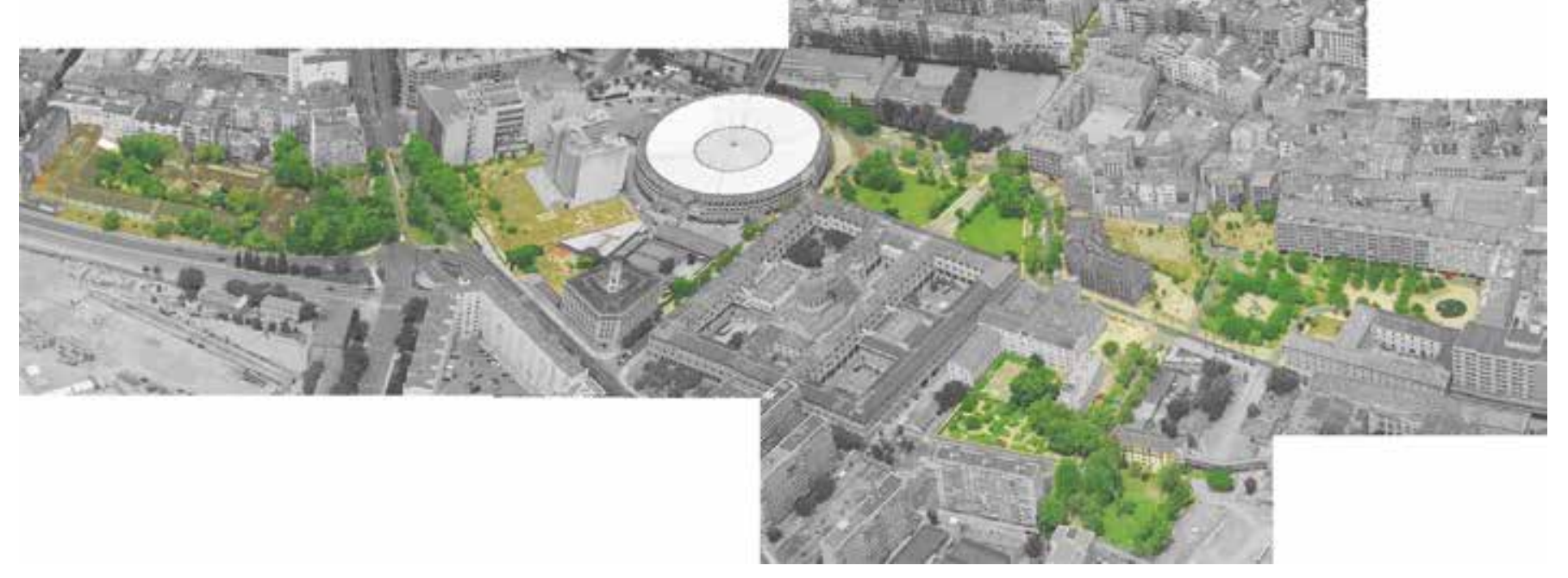

PLANO DE PROPUESTA. SECTOR PIGNATELI | MASTERPLAN. PIGNATELI DISCTRIC

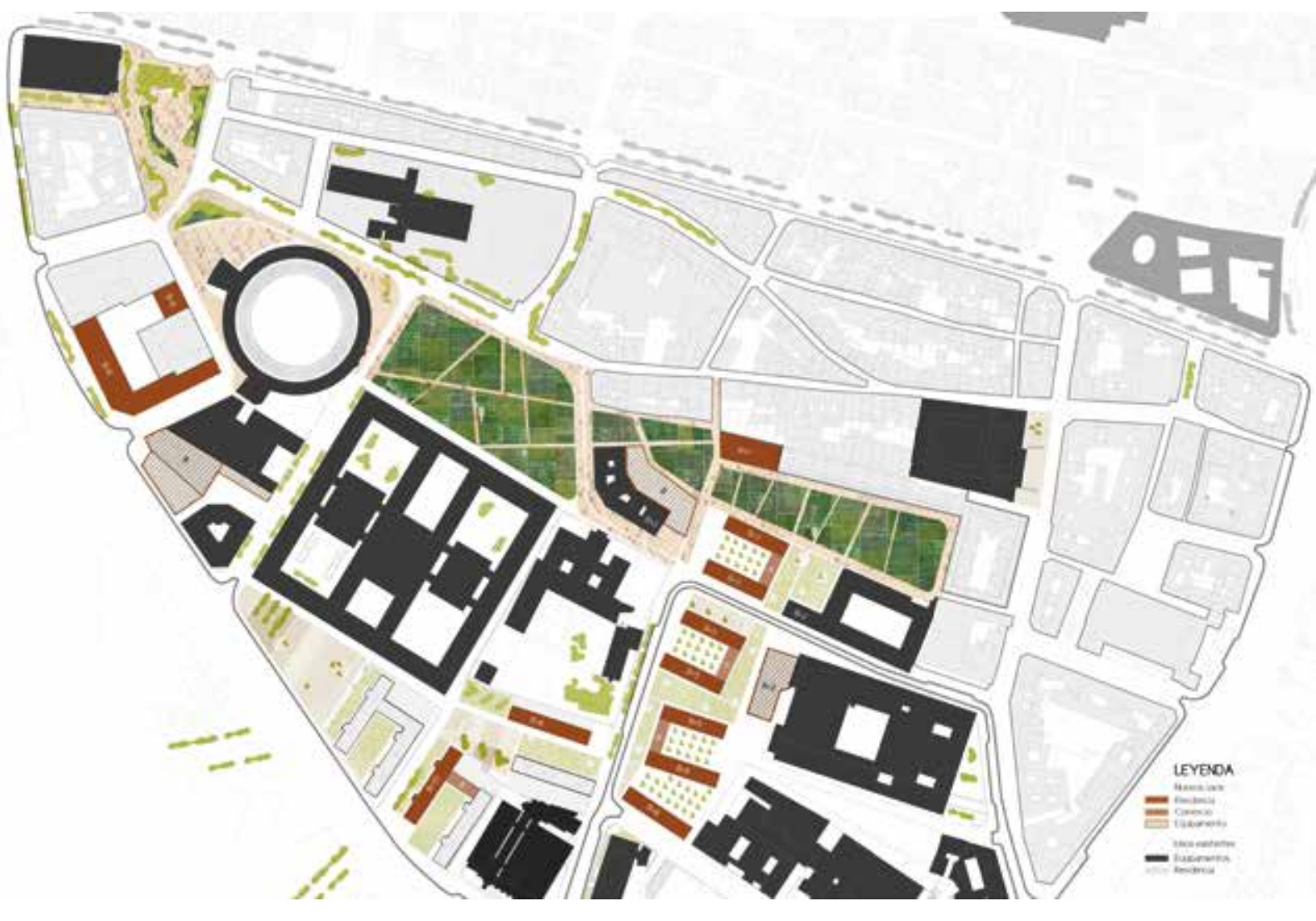


La intervención se lleva a cabo mediante la creación de un parque configución de un tejido se completa con los usos del denominado Territorio Erasmus, que actúa de rótula entre el nuevo tejido residencial y el parque interior.

The project is set up with a new park that gives public space to this area of the city and setting up a residential grid which seens the space-gap existing between civic buildings. This grid would be completed by another project which introduce an Erasmus Distric

INTRODUCIR UN PAISAJE | INTRODUCE A LANDSCAPE

La primera estrategia de actuación sobre el barrio debe ser la de estructurart todos los espacios publicos desiligados que caracterizan a ess espacio longitudinal, articulando una secuencia de parques y plazis que generen espatos de rew La introduccín del tráfico restringido alrededor de todo el entorno tosespcios y faroecesu utilización como de ciudadano por esLa implatación de espacios con estas características en pleno cent to de la ciudad resultaría beneficioso para el conjunto de la ciudad incluso como incentivo turístico.

Este espacio actuará como pulmón vegetal y mecanismo de unión de las distintas puertas. De el surgiran los distintos ejes que tien

A su vez, en su interior apacterá el denominado "Territorio Era cill y los especios públicos Se introduce por tanto un uso que artic esta transicion y trata de recuperar len cierto modo a geometría de antiguo "Cuartel de Pontoneros", situado en este mismo ámbito

The first action strategy for the district should be to structure all the is the opportunity to carry out work in the wide longitudinal space by developing a series of parks and squares that offer meeting and gathering spaces for the entire city.

The introduction of traffic restrictions all around El Pignatelli allows for greater circulation of citizens through these spaces and promotes

列 would serve as a green lung and would connect the various gates. Extending out from the space would be the different axes aimed at rehabilitating the district of San Pablo.

In addition, situated in its interior will be the "Erasmus Territory" a space that will serve as a link between the area for residential use to facilitate this transition and to ty to recore to suced in orde geometry of the old barracks, the "Cuartel de Pontoneros", which is located in the same area.

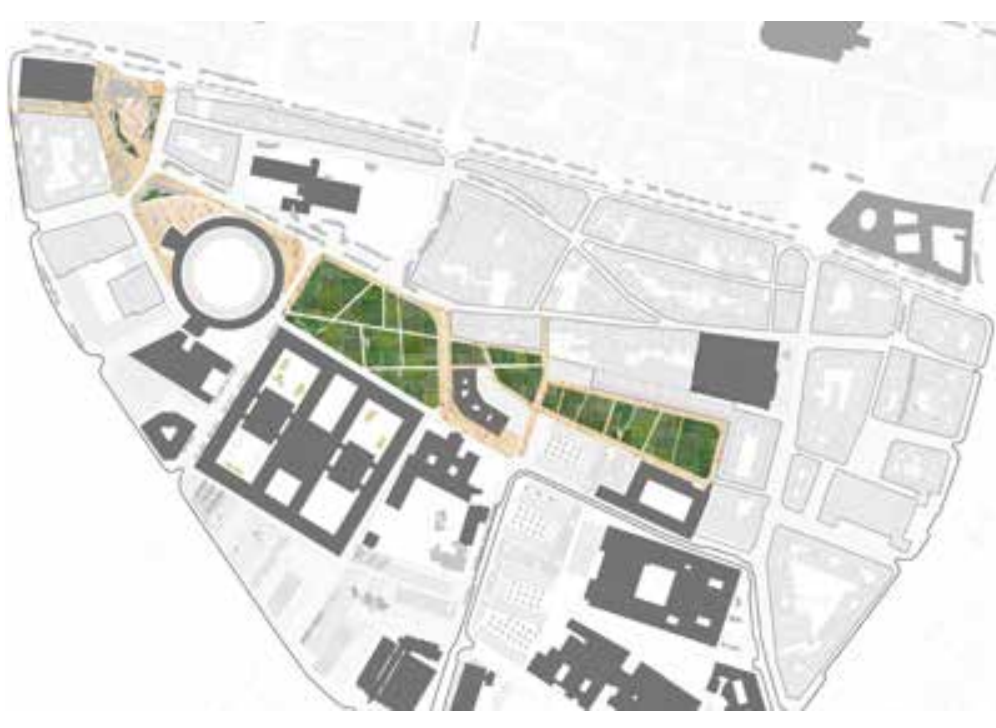

巾
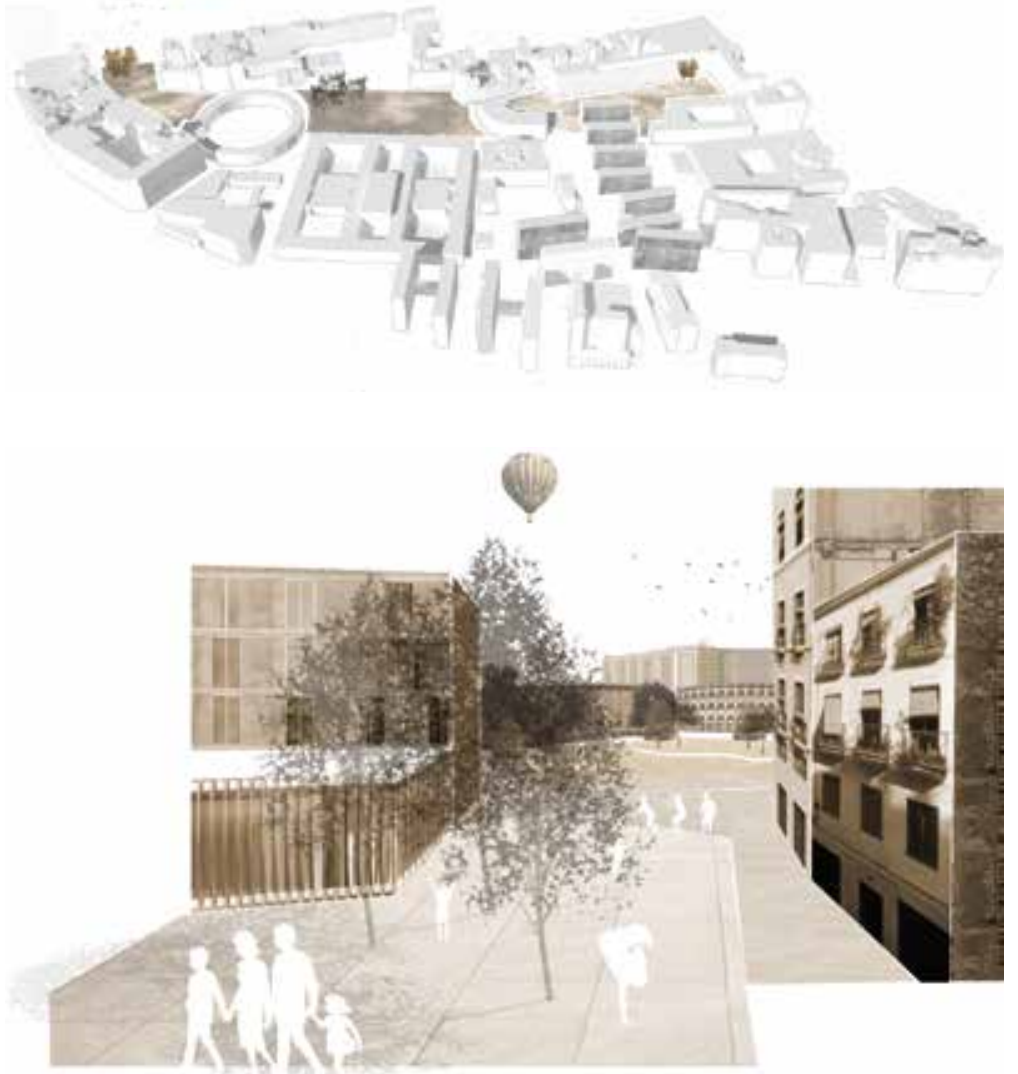
tenga como objetivo completa
actualmente desestructurado.

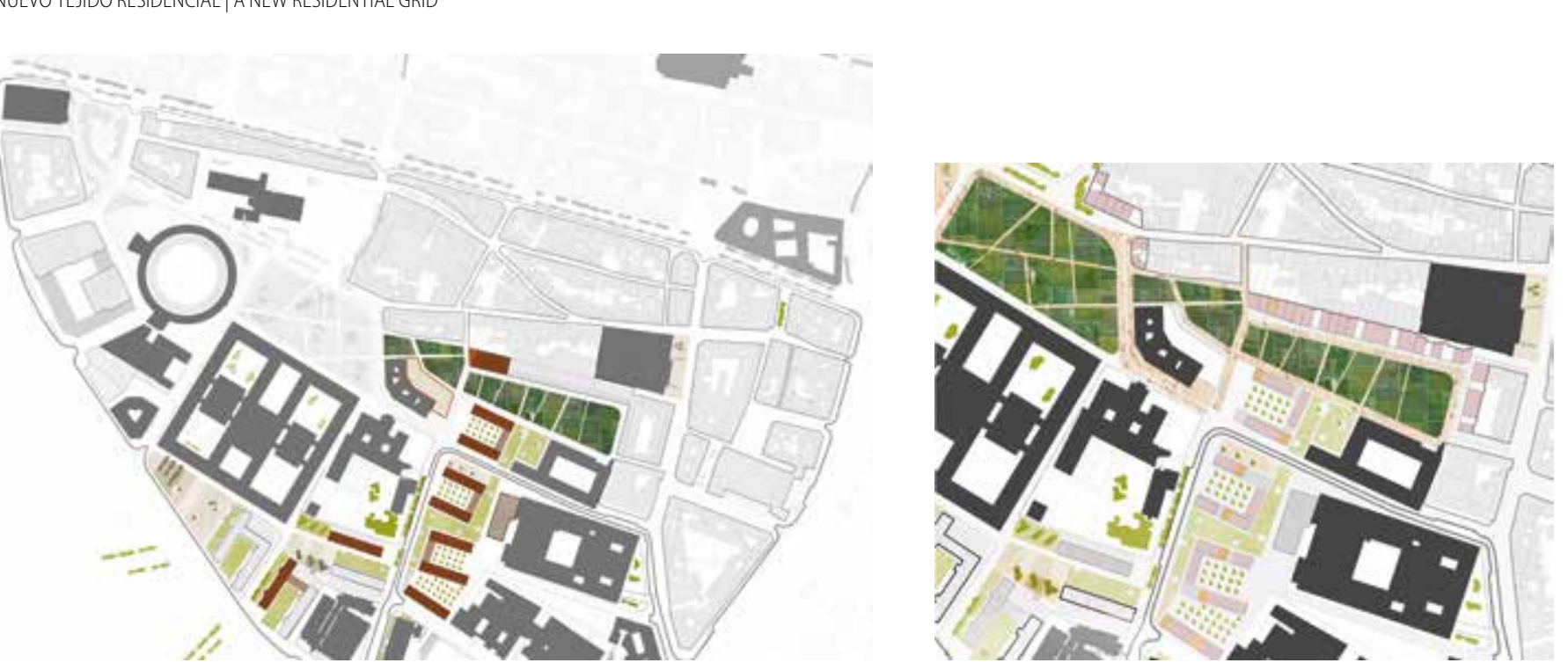

REHABITAR | REPOPULATE

Una vez proyectado el espacio catalizador y revitalizador de todo el conjunto es el momento de llevar a cabo una intervención que

Puesto que nos encontramos en un enclave donde la densidad de us o del suelo dotacional es desmesurada, se propone la recalificación de parte de este suelo en uso residecial, y la configuración de un tejido necte el Paseo $\mathrm{M}^{2}$ Agustín con la nueva red de espacios públicos al Norte. Como coronación de este nuevo tejido, aparece la residenci estudiantil con bloques de menor escala que relaciona tipológica funcionalmente los dos únicos edificios vivos del antiguo cuartel. Por último se construye el solar que cose la plaza Jose María Forque

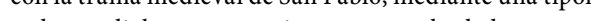

Once the catalyst and revitalising space of the entire complex has been designed, an action will then be carried out to complete the urban layout of the currently unstructured areas of the complex. Since the density of non-residential land is disproportionate in this be between the facilities and connects the Paseo $\mathrm{M}^{\mathrm{a}}$ A gustín with the new network of public spaces to the North. The culmination of the new layout will be the student halls of residence, with smaller-sized blocks, that will typologically and functionally connect the only Lastly, a space will be constructed that will connect Jose Maria
Forgué Square with the medieval part of San Pablo, by means of a terraced typology that intencts with the surrounding achisecturce
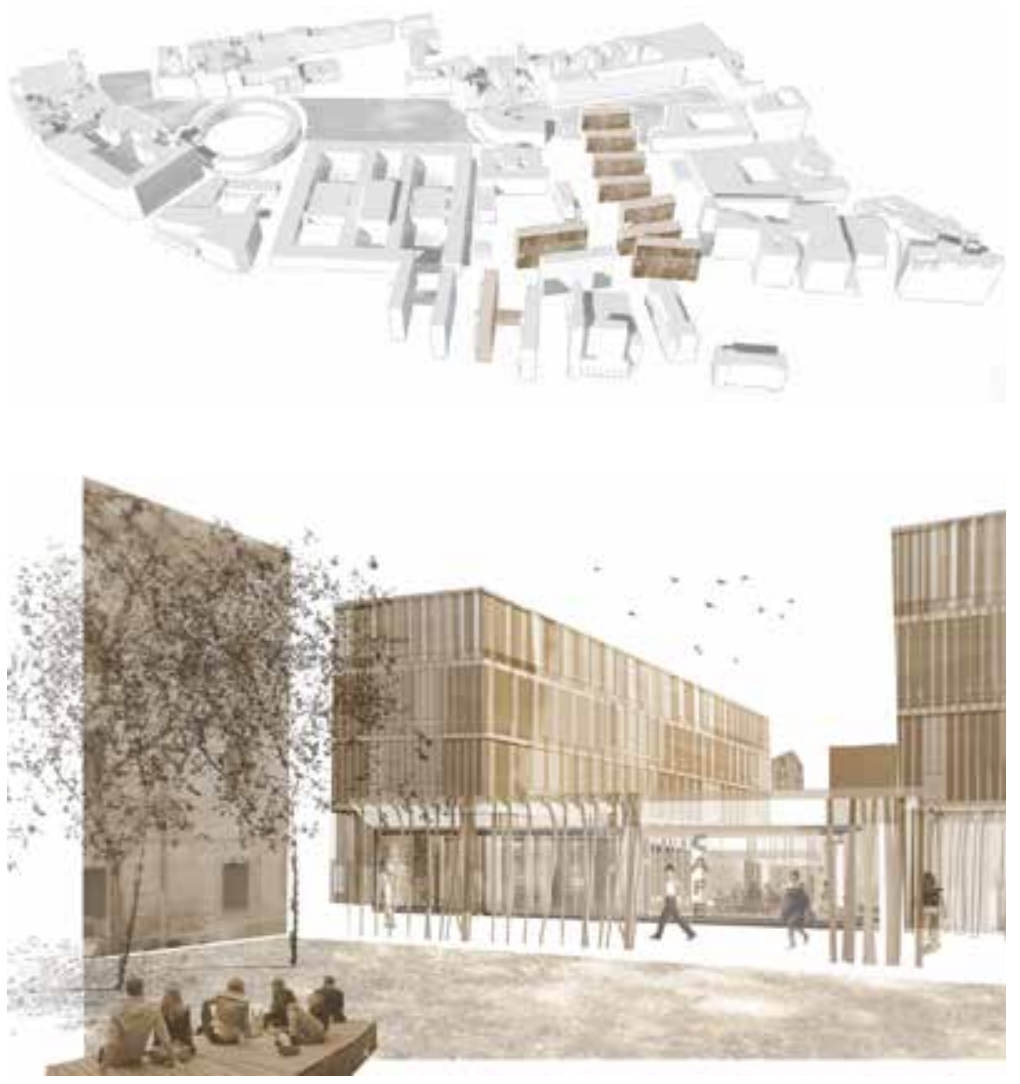
Proyecto de urbanización sobre uno de los ámbitos de intervención en el Sector

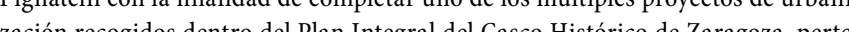
neciente al Área de Reforma Interior del barrio de San Pablo.

Se pretende reurbanizar las calles Ramon Pignatelli, Madre Rafols, Vicente Gómez Salvo y Mayoral, junto con los jardines Pignatelli, con el objetivo de transformar estos
viales en nuevos ejes peatonates centrafico de vehículos en uso restringido únicemente a residentes. Además se pretende llevar a cabo la apertura de unos nuevos jardines como zona verde de uso publico que actualmente se encuentra vallada

Urban development project on one of the areas belonging to one of the different .

It is intended to redevelop the streets Ramon Pignatelli, Madre Rafols, Vicente Gomez Salvo and Mayoral, including Pignatelli gardens, with the aim of transforming these roads in new pedestrian axes with restricted vehicular traffic. It also intends to carry out the opening of a new garden for public use which currently is fenced, despite the neral plan provides that it is a green public are.

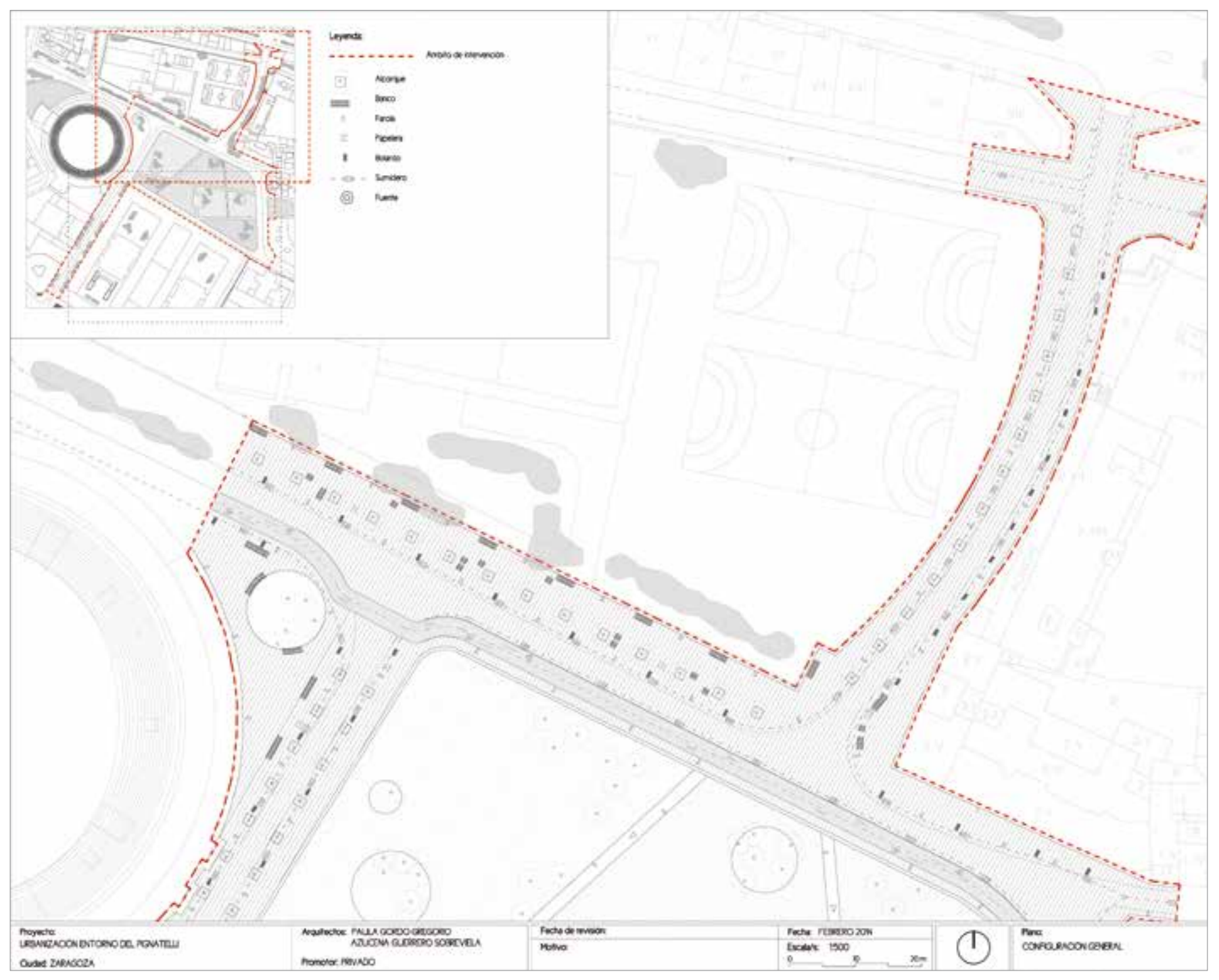

Plano de Configuración General| Masterplar
ALCANCE DEL PROYECTO | SCOPE OF THE PROJECT

Llevar a cabo una renovación de todo el ámbito con la voluntad de crear una nuevi

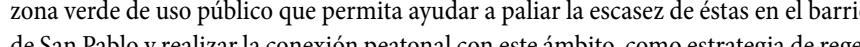
neración urbana La finalidad de esta intervención es además unir el proyecto de re habilitación del barrio de San Pablo con el proyecto de un nuevo parque en el Portillo.

To undertake the renovation of the entire area with the aim of creating a new green district and to create a pedestrian connection with this area, as an urban regeneration strategy The purpose of this action is also to join the San Pablo district rehabilitation project with the project for a new park in El Portillo.

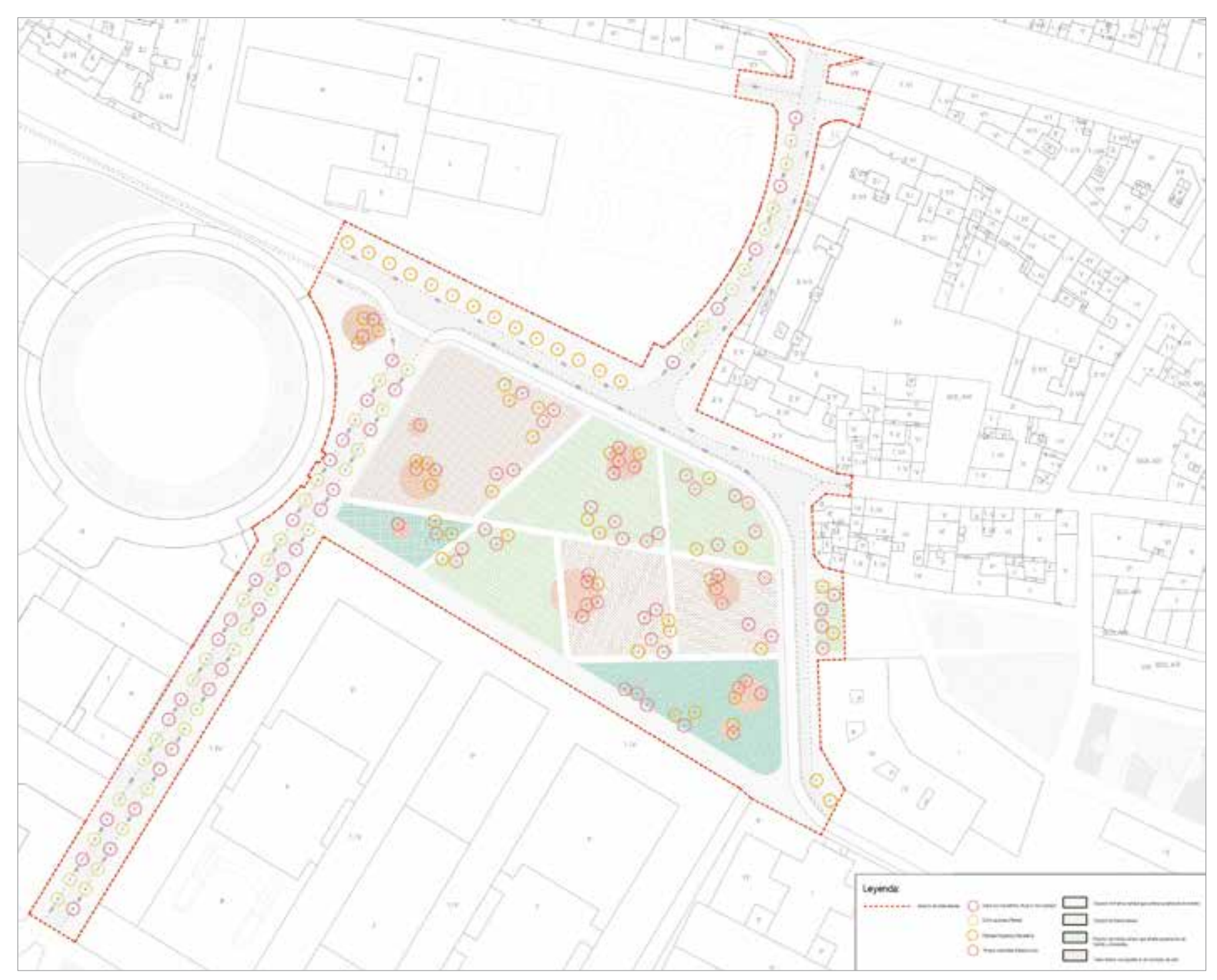

ALCANCE DE LA EJECUCIÓN | SCOPE OF EXECUTION

Demolición del pavimento existente en su totalidad incluyendo la reordenación del contorno de los jardines del Pignatelli y su reurbanizací́ clusa la demolición

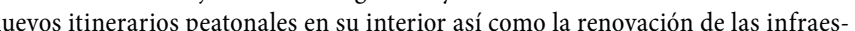
tructuras.

Complete demolition of the existing paving, and traffic restructuring for possible pedestrianisation. Also included is the demolition and redevelopment of the area hways in its interior and the renewal of its infrastructure. 


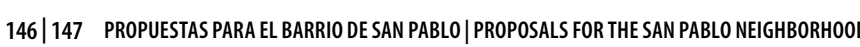

02 PUERTA LUIS BUÑUEL | LUIS BUÑUEL GATE

Ma Pilar Villuendas, Cristina Palacios

La propuesta general consiste en convertir la calle de San Blas en el principal atraviesss San Pablo.

La Puerta Luis Bañuel se encarga de desarrollar la zona norte de la primera trategia consiste en crear un nuevo eje peatonal a través de la calle Mayoral entendiendo esta como una secuencia de equipamientos. Este eje atraviesa

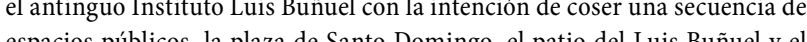
parque de ribera para

El principal objetivo de este nuevo eje es crear una nueva puerta al barrio a que permite crear un paso subterráneo que se abre al parque de Ribera. Por otra parte, el trrafico rodado que es resuelto mediante la creación de un aparrodado.

The general proposal consists in making that San Blas street becomes in the main commercial axis of the neighbourhood and act in the three transverse

We have to develop the North area of the first transverse street, which is located where it is the old tuis Buntuel high school. The strategy consists in a guideline of equipments. This axis is going to cross the old Luis Buñuel High School with the aim of sewing a public spaces sequence, Sto Domingo square, Luis Buñuel's Playground and bank park.

The main objective of this new axis is become a new door for the neighbourhood, taking the new different flows of the area. In the one hand, pedestrian circulation goes through this axis and dint the Buntuel playground to create a traffic is assumed by a underground parking and that allows to release the inside street from traffic.

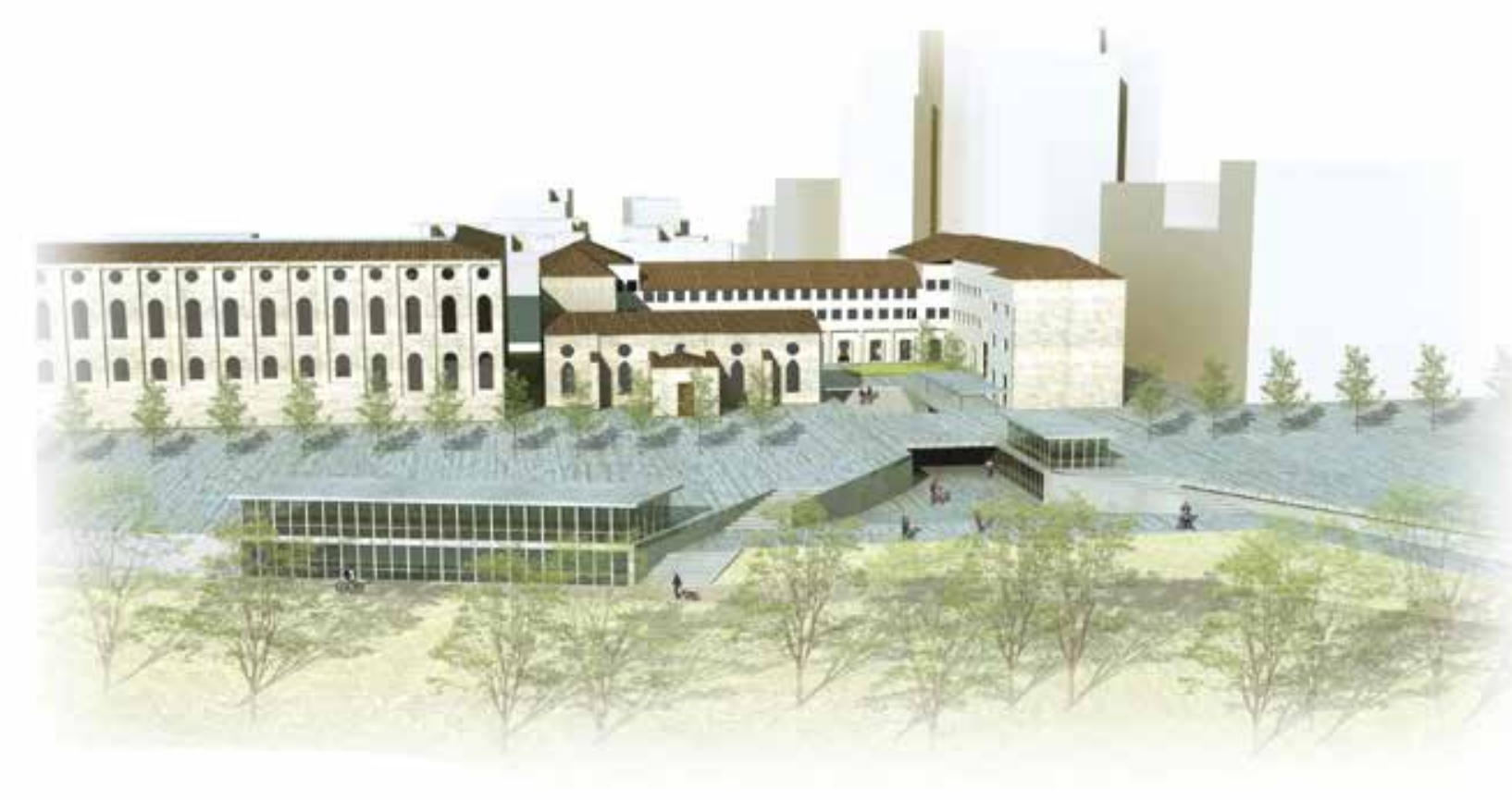

Vista de la nueva puerta Buñuel desde la ribera del Ebro | View of the new Buñuel gate from the banks of the river Ebro

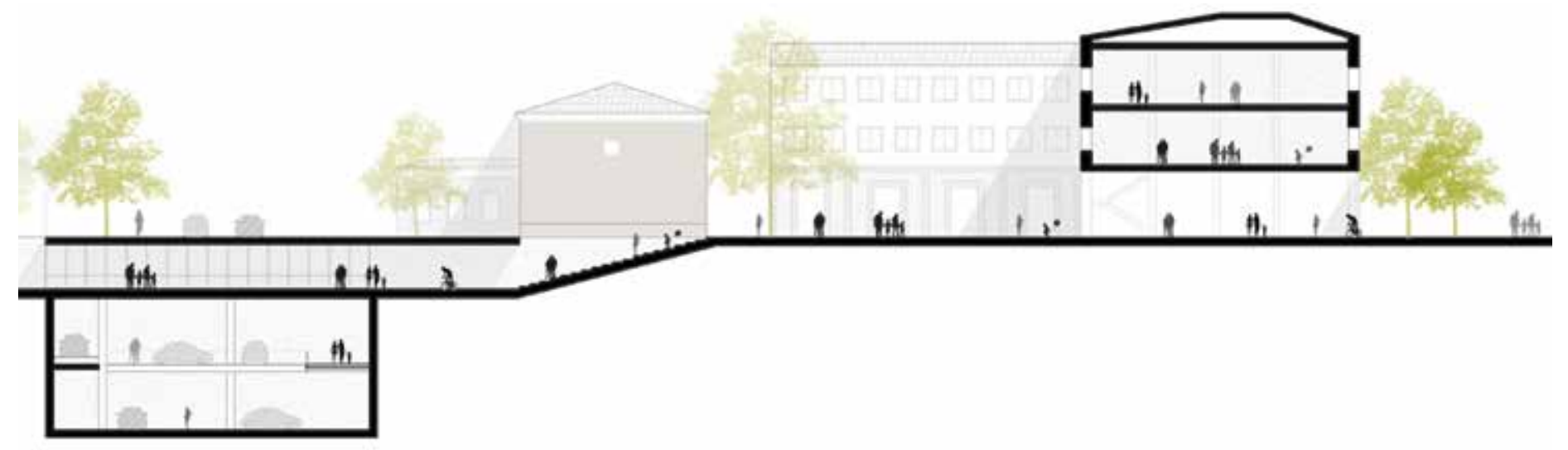




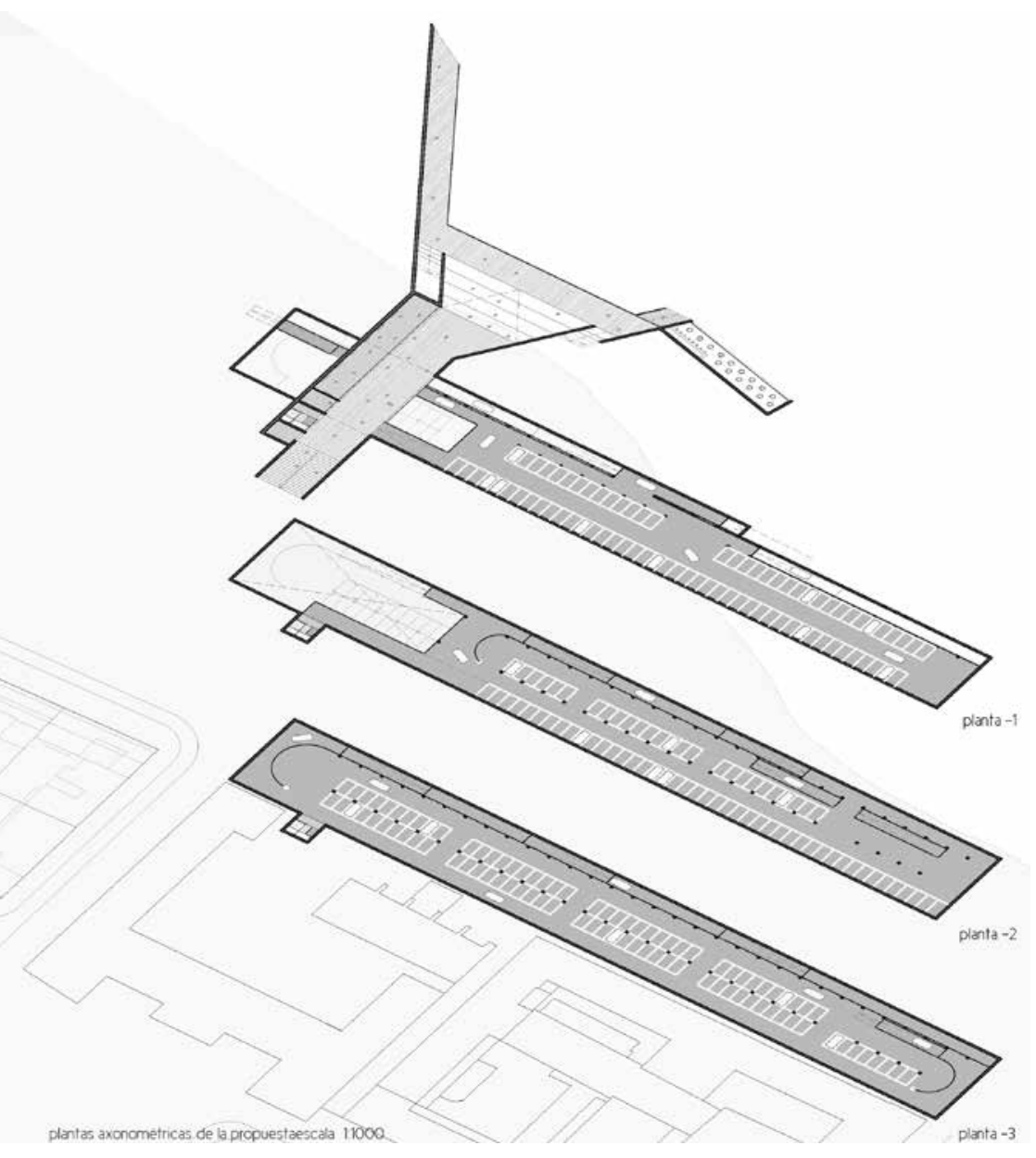

COMPARATVA DATOS ESTADO ACTUALLNTERVEVCON

Relicion de equipamientos

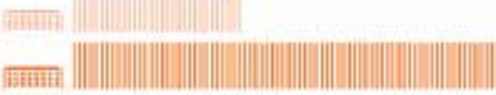

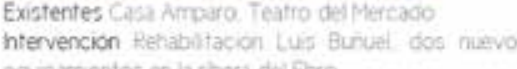

Relecion de esarcamientos

Prover

Q Privade

a
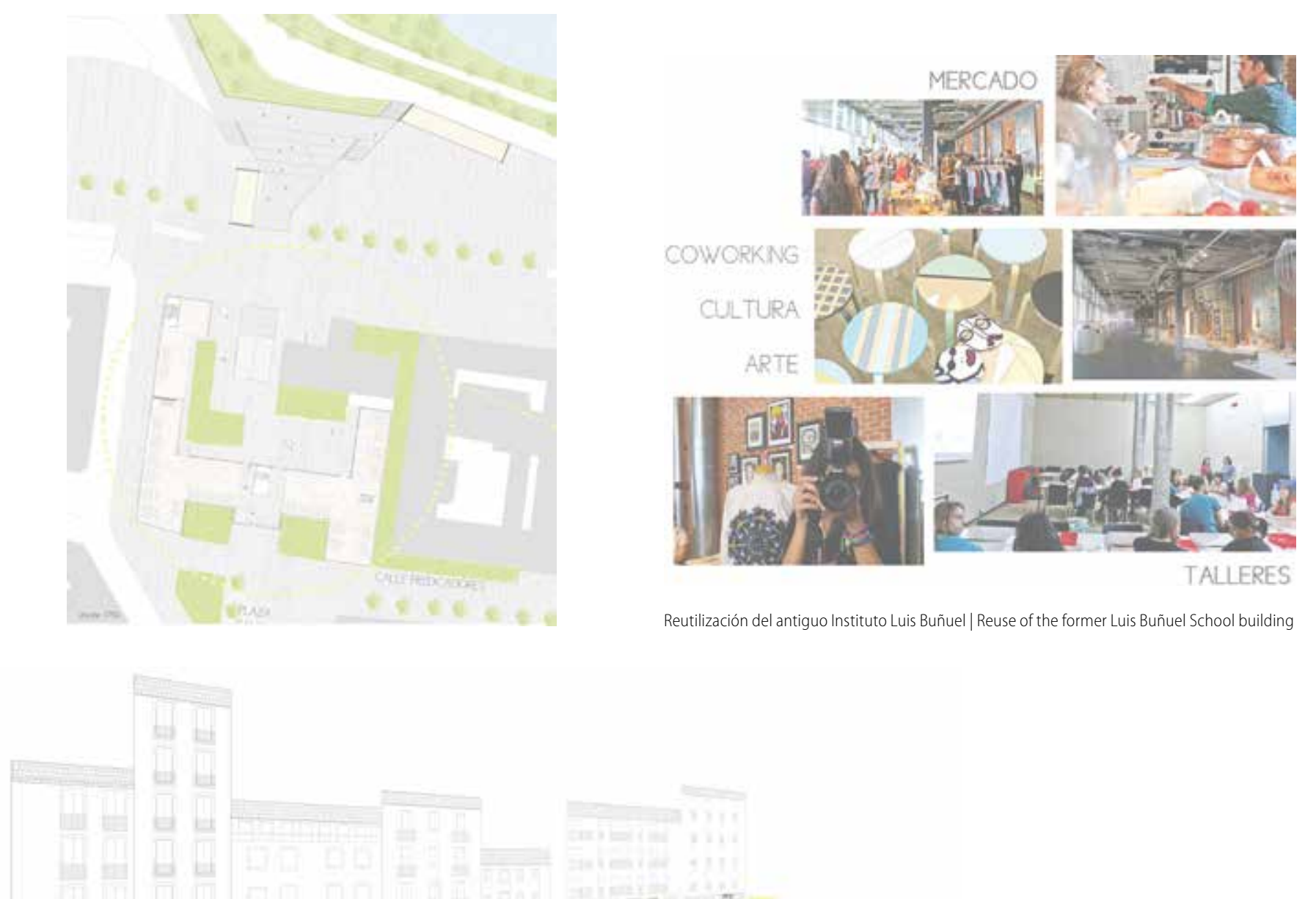

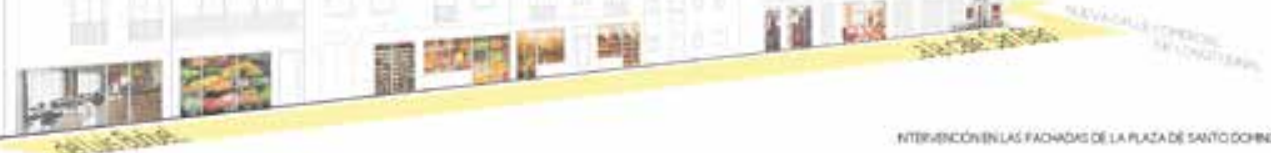

Aparcamiento previsto baji Paseo Echegaray y Caballero | Parking planned under Paseo Echegaray y Caballero

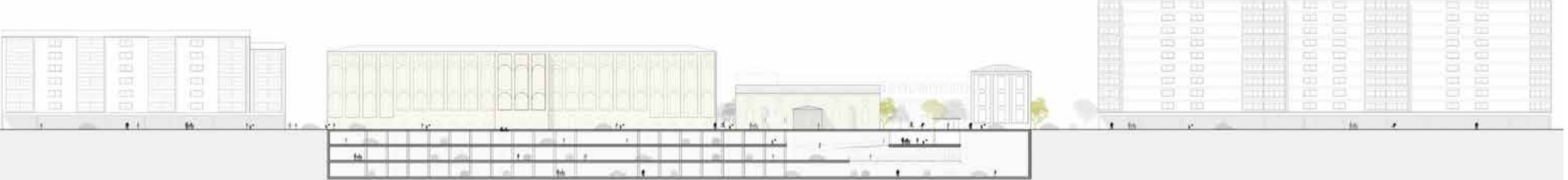


150| 151 PROPUESTAS PARA E E BARRIODE SAN PABLO| PROPOSALL F FR THE SAN PABLO NEIGHBORHOOD

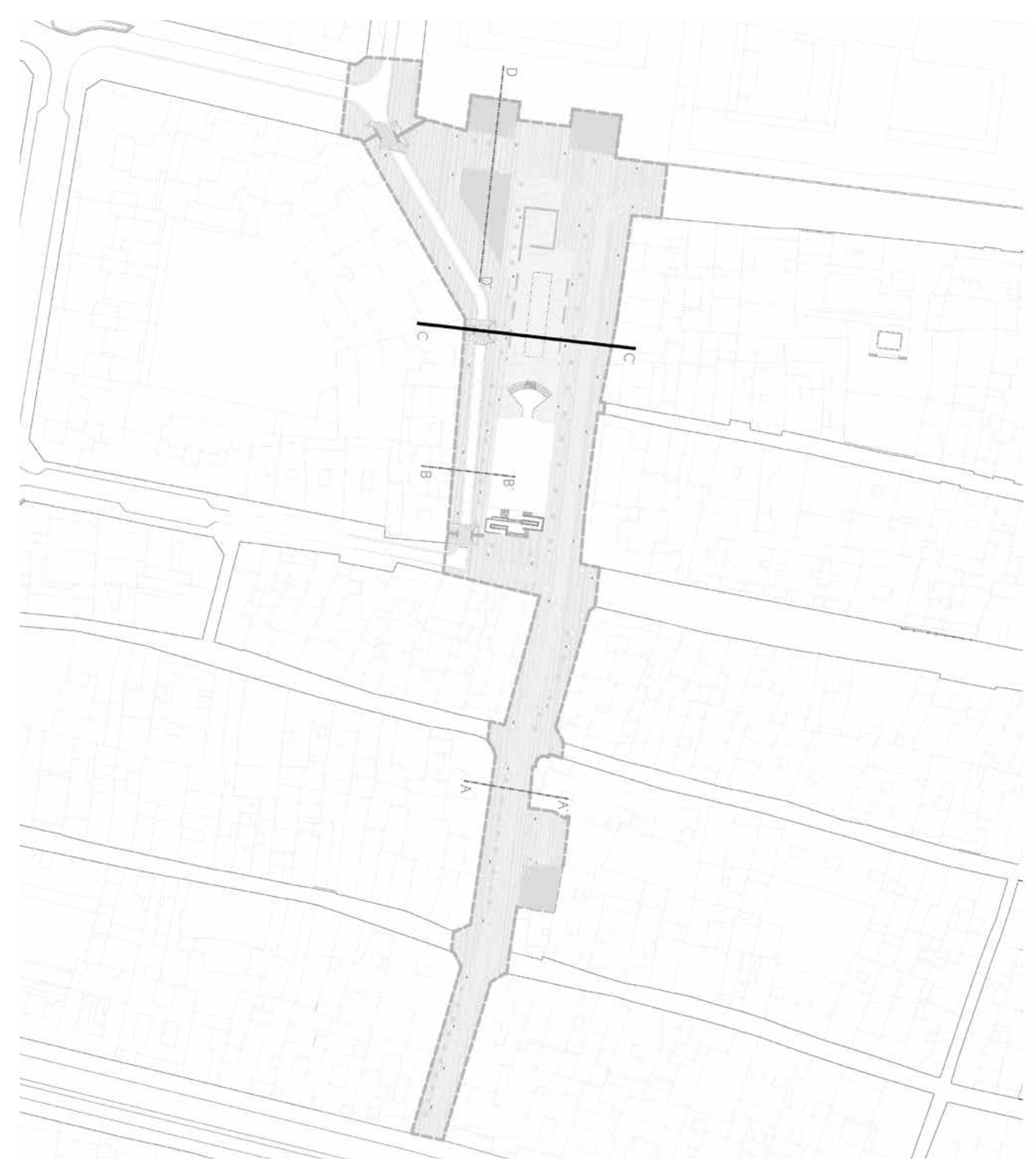

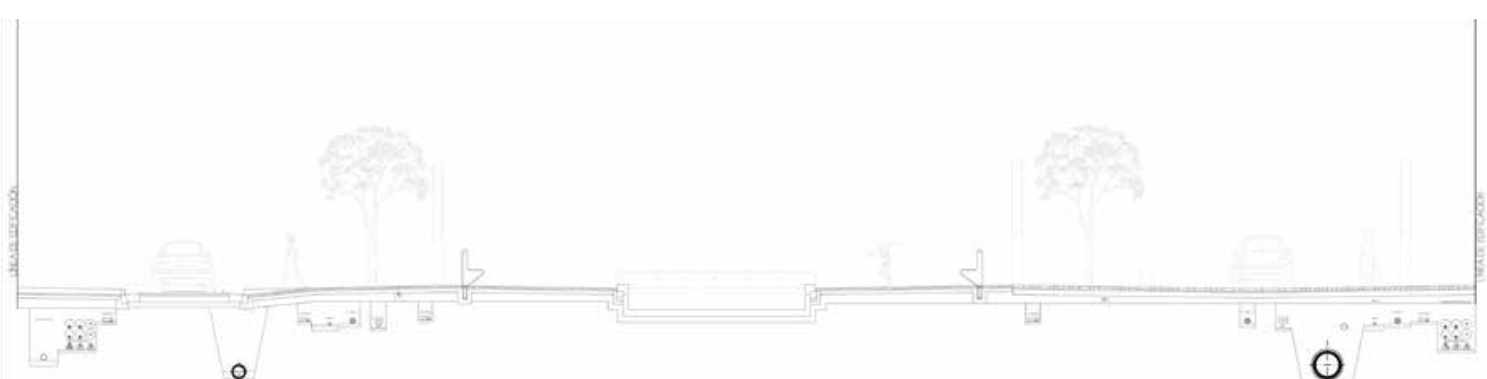

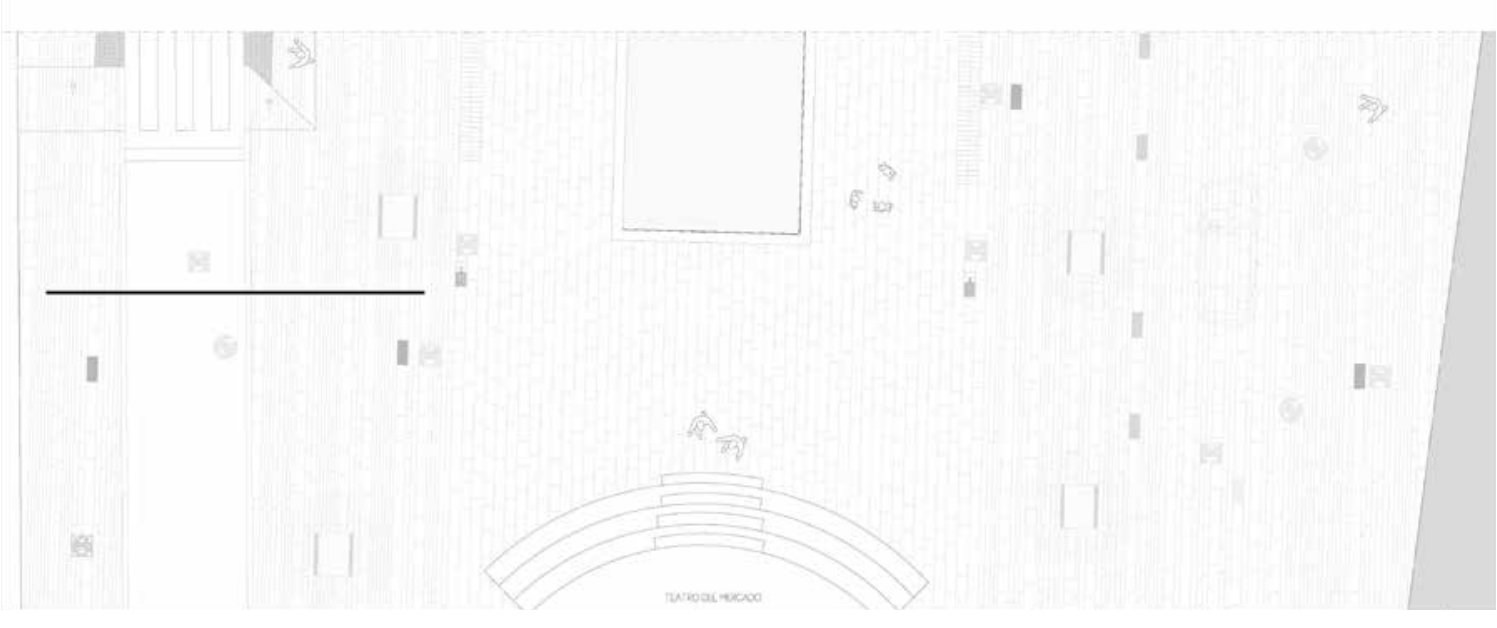

Sección representativiva de urbanización. Plazza de Santo Domingo | Representativive Section of the urban development processs. Santo Domingo Square

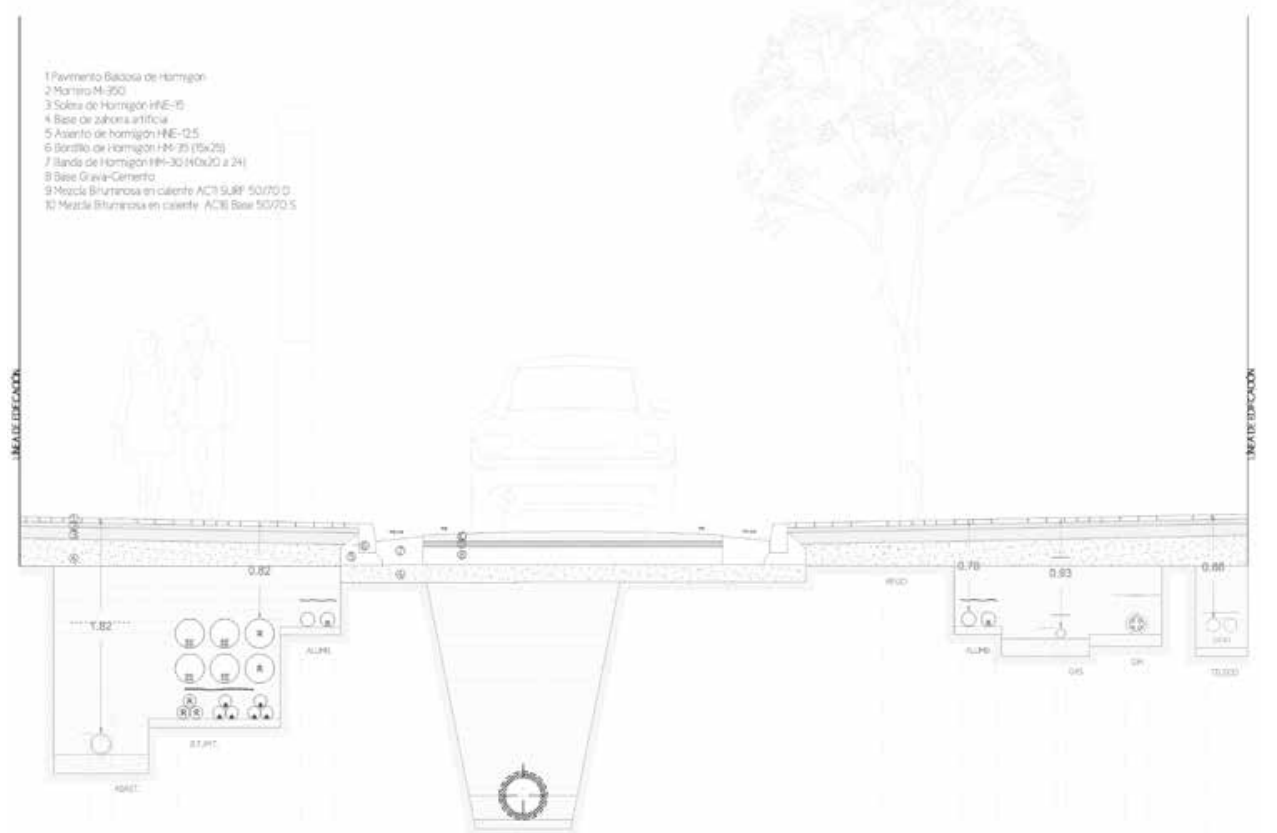

Detalle de urbanización sección transversal calle Plaza de Santo Domingo| | Urban development detail. Cross-sectional section Santo Domingo Square Street 


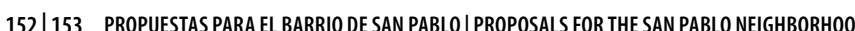

\section{O3 VENTANAS URBANAS | URBAN WINDOWS}

Beatriz Palacios Muñoz, Ma Pilar Viamonte Fernández

La propuesta parte de la intención general de fijar la población tradicional fomenten su activación: consolidando usos residenciales la diversidad social, facilitando la recuperación del comercio tradicional y preservando arquitecturas, tipologias y modos de construir en coexistencia con actuaciones contemporanneas con poder regenerativo prestando especial base a tres argumentos: fomentar la creación de un espacio públiceos a en base a tres argumentos: fonentar la creaclo do $\mathrm{y}$ e espacio libre e incertar elementos regeneradores puntuales que funcionen como catalizadores. amplios patios interiores de manzana de desahogo. Tras una labor de eliminación de construcciones de escasa entidad presentes en el patio y tomando como modelo la intervención de Lacaton y Vassal en La Chesnaie se idea un sistema de amplacion de las $v$ hindas hacia el we lor de la manzana genemejoran las condiciones climáticas y estéticas de su piel y permiten solucionar la accesibilidad "entrando por el balcón". Además, se generan elementos de centralización de servicios.

The proposal springs from the general intention to stabilize the traditional population of the San Pablo neighborhood, as well as the aim to attract new resident groups that could foster its activation. This would be achieved by consolidating residential uses, keeping social diversity, supporting the
recovery of traditional commercial businesses, and preserving architectures, recovery of traditional commercial businesses, and preserving architectures,
typologies and traditional construction methods -all those coexisting with contemporary interventions endowed with regenerative abilities, and whe
a special focus on the architectural scale of urban issues. The work has been developed around three different ideas: fostering the creation of an active public space, improving inhabitability by ameliorating accessibility and free space, and ins The project tries to emphasize the compactness of the existing structure, as opposed to the ampitude of the free courtyards of the city blocks. After

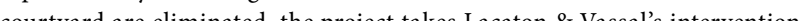
a strategy to extend the dwellings towards the inner block area. Hhus, a new system of plattorms provides extra terrace space, improves the aesthetic and climatic conditions of the balcony" Also, service-centralization elements are generated in the process.
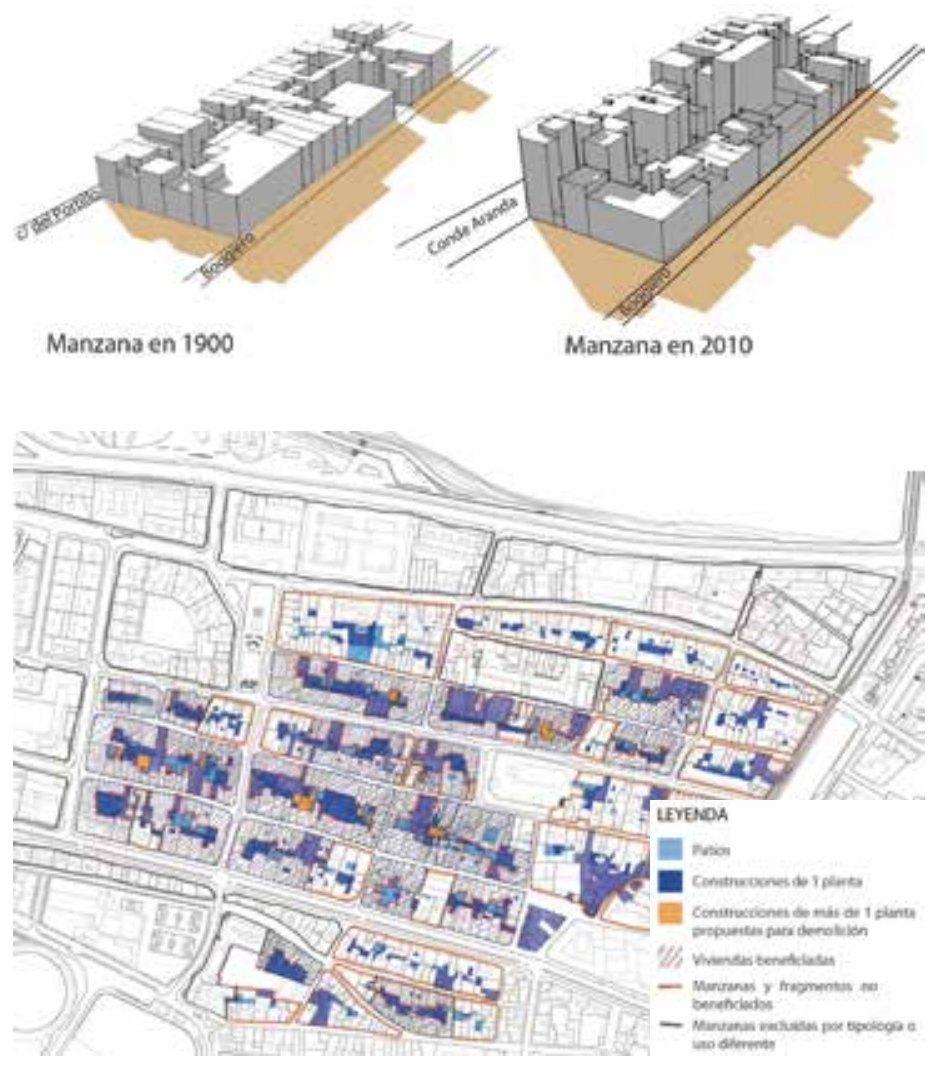

Situación y desarrollo de las manzanas I Block state and develoopment
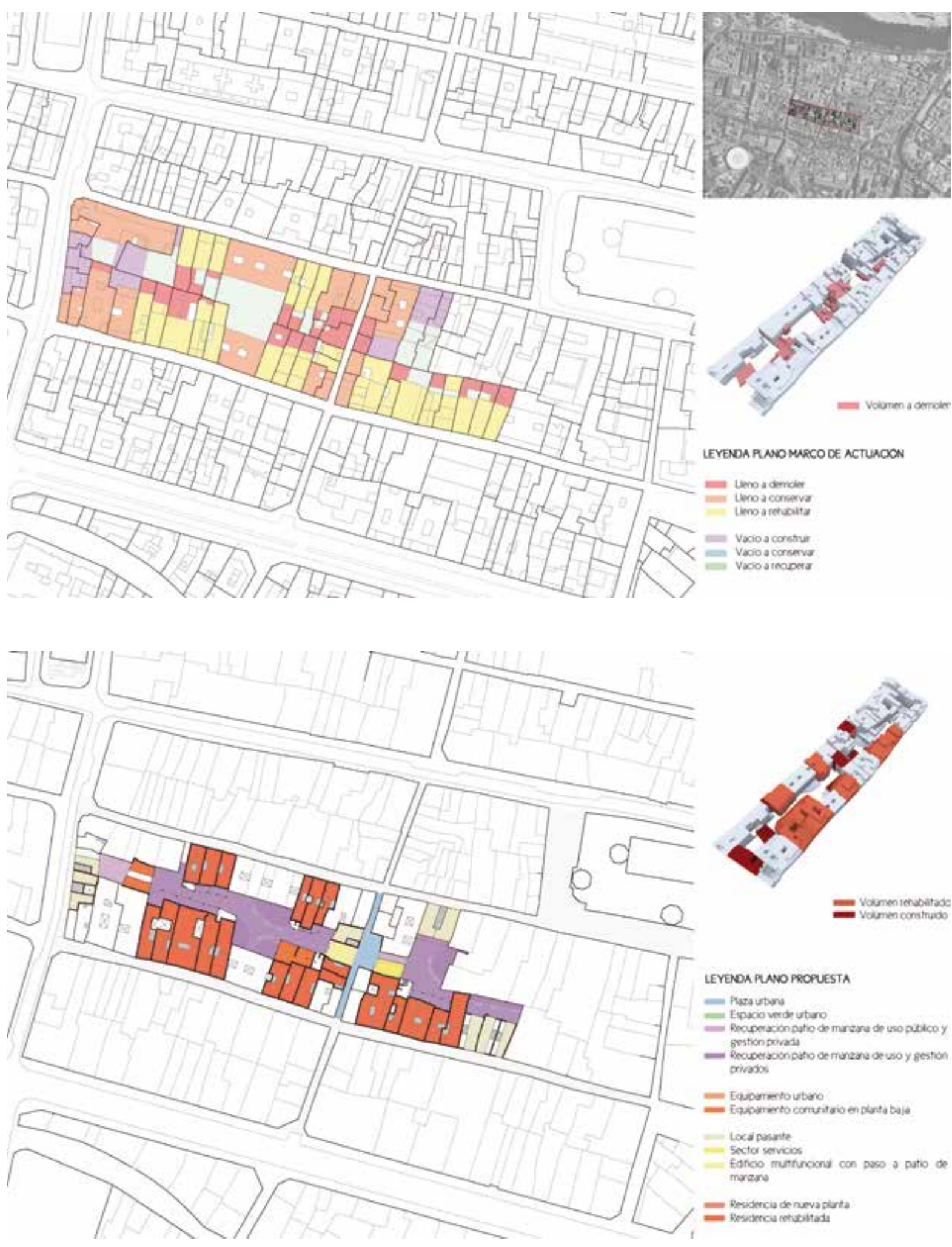

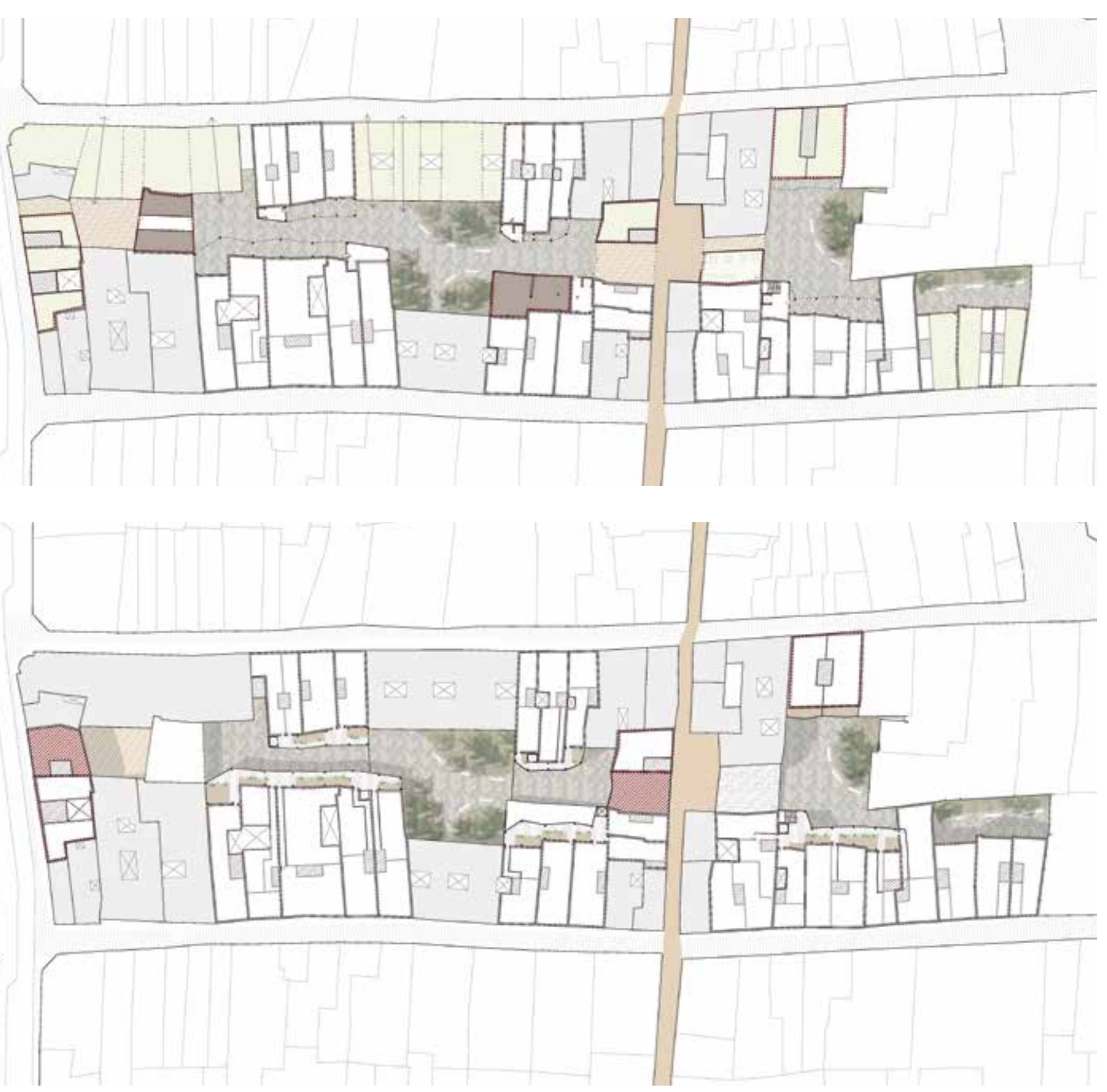

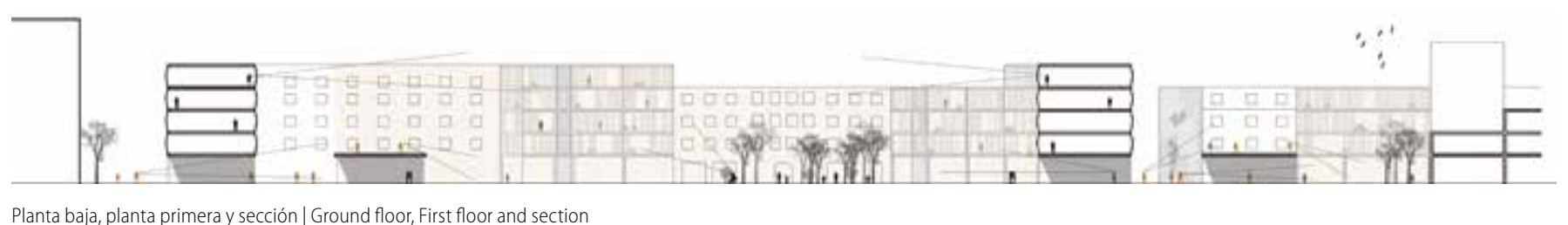

- Mueva construcción
Cale Mariano Cerezos

- Respericion plio de marean de uso y gestion privados

Espacio verde comunitaia

Equpamiento comunitrio en planta baja

- Editicio multifiuncional con paso a patio de marzana

Residencia rehabilitada

Edifcios del ambito exentos de intervencion
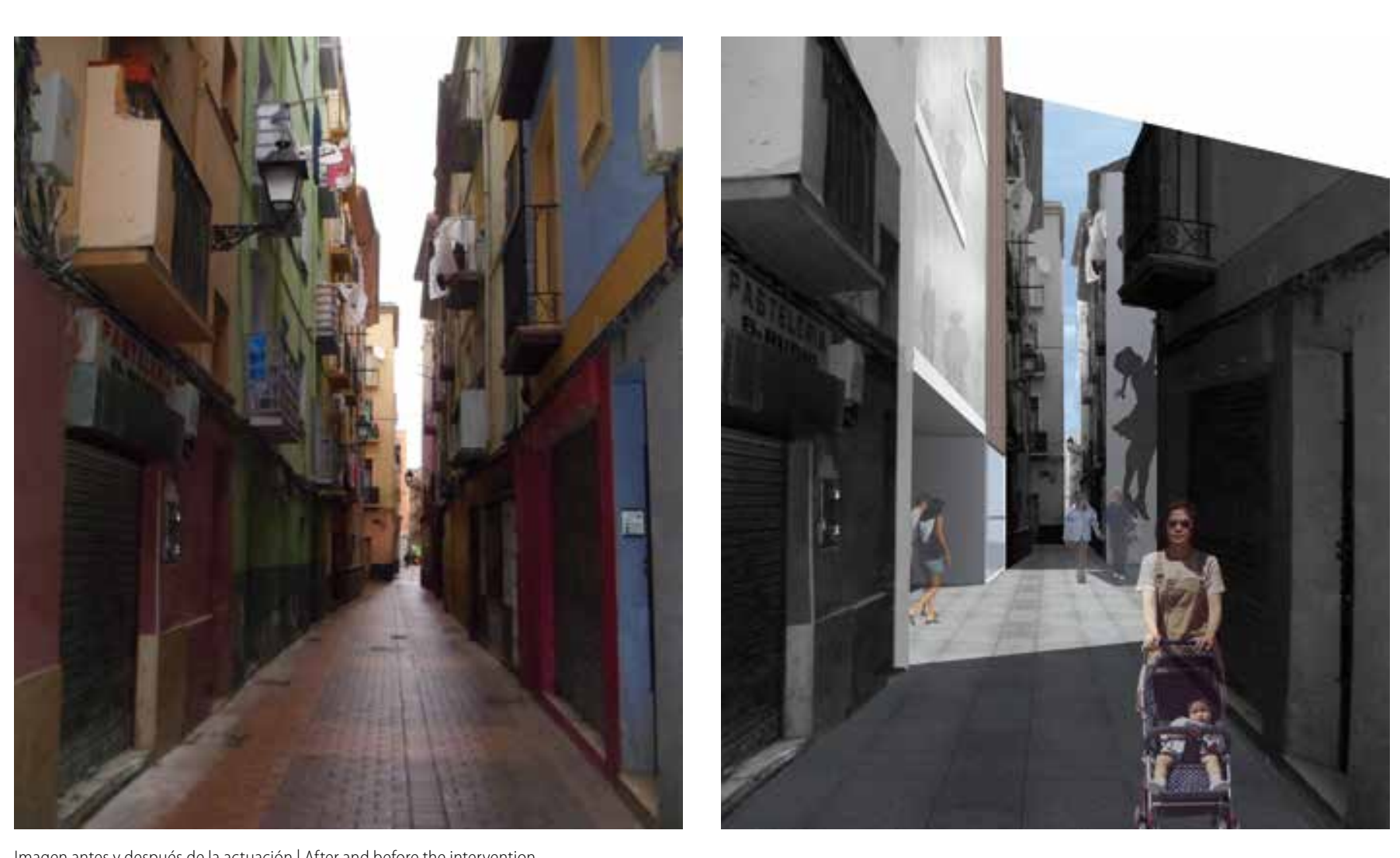

DATO DE LA OPERACIÓN IIMPACT OF THE OPERATION

vivienda rehabilitada $52,3 \%$

vivienda construida $5.6 \%$

equip. construido $35 \%$

sin interverii

$38.6 \%$

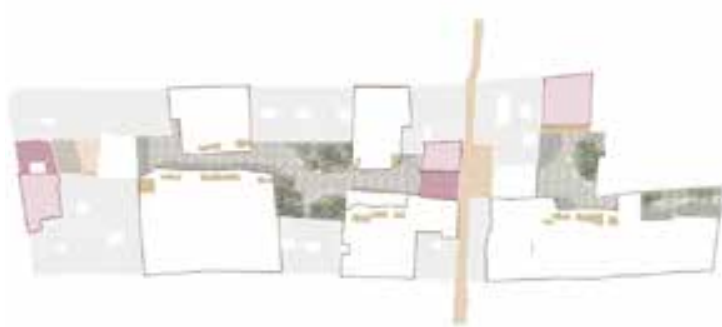




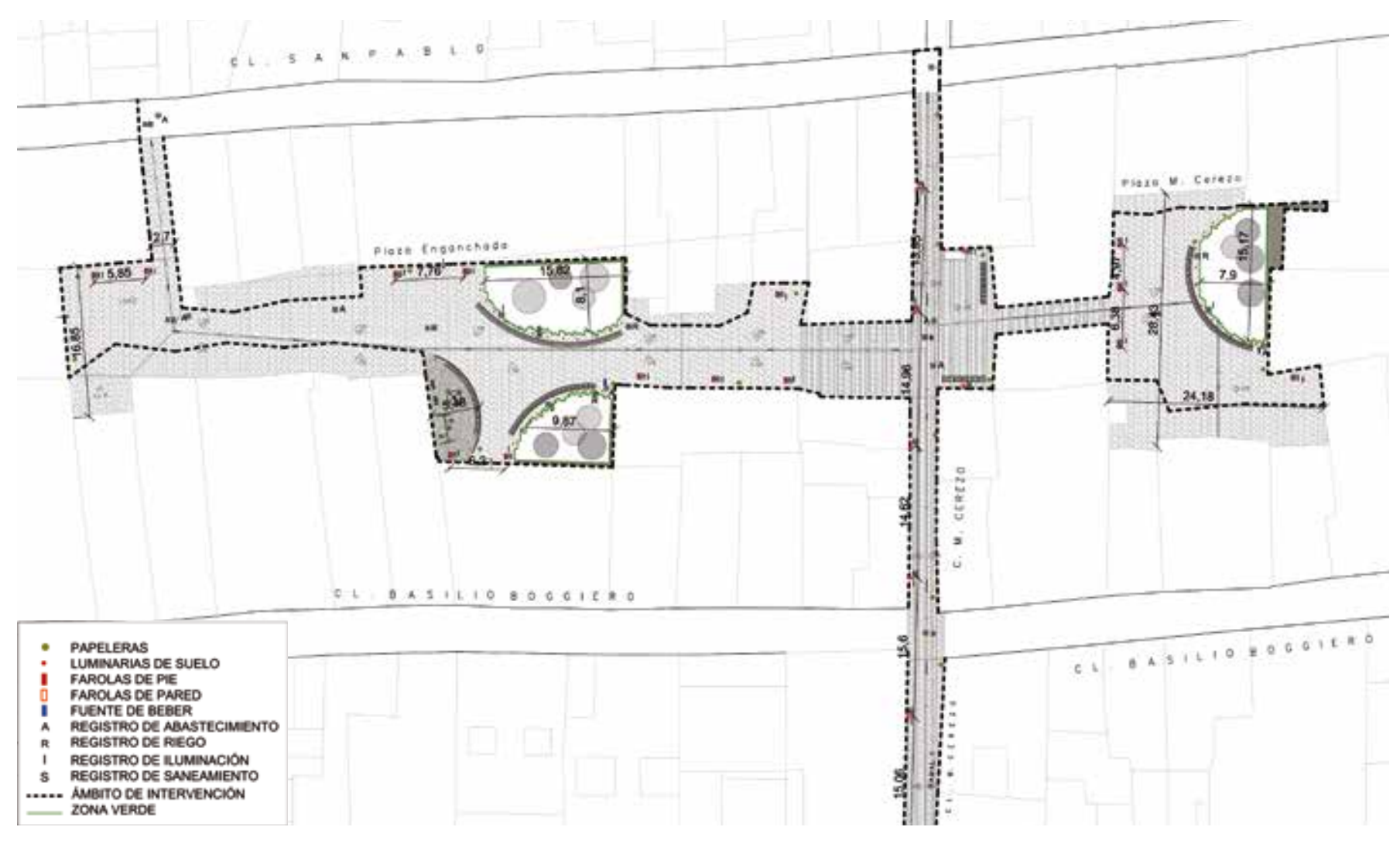

Plano de Implantación | Urban design plan

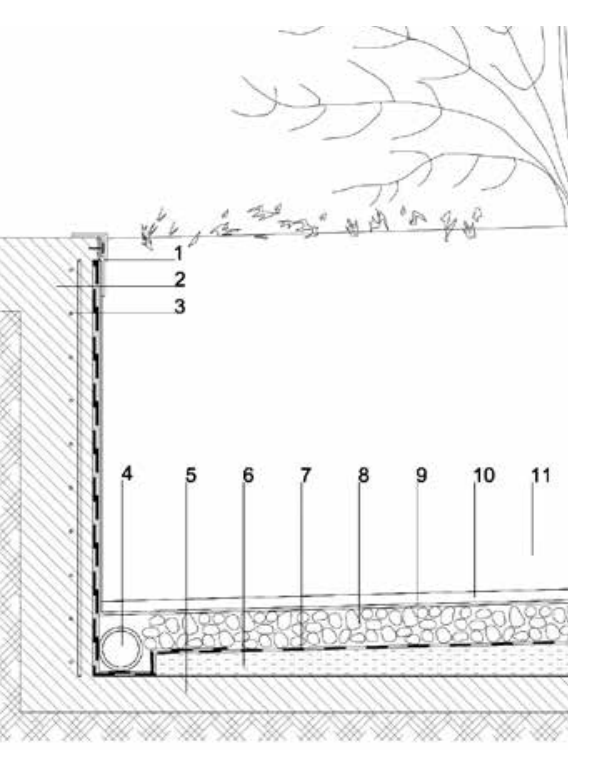

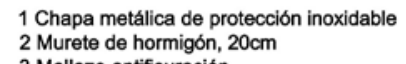

3 Mallazo antifisuración
4 Tubo de deranie 4 Tubo de drenaji
5 Solera de horrigon, $10 \mathrm{~cm}$

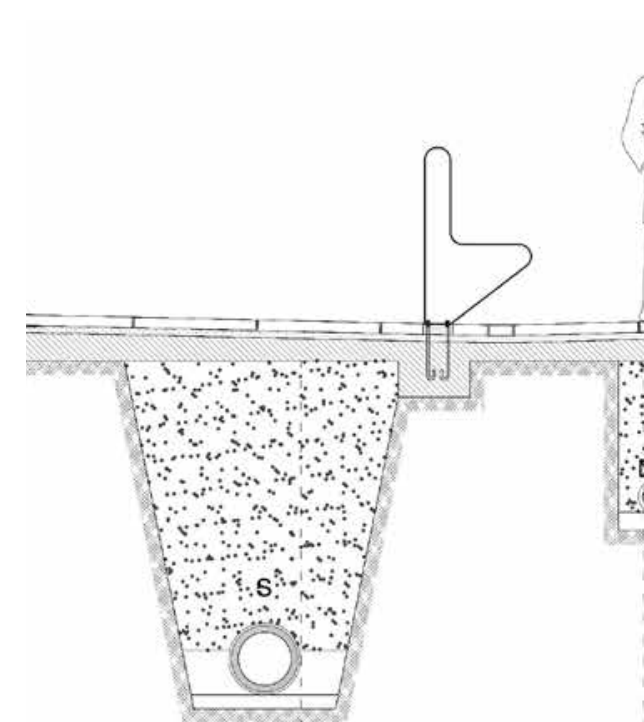

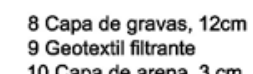

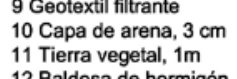

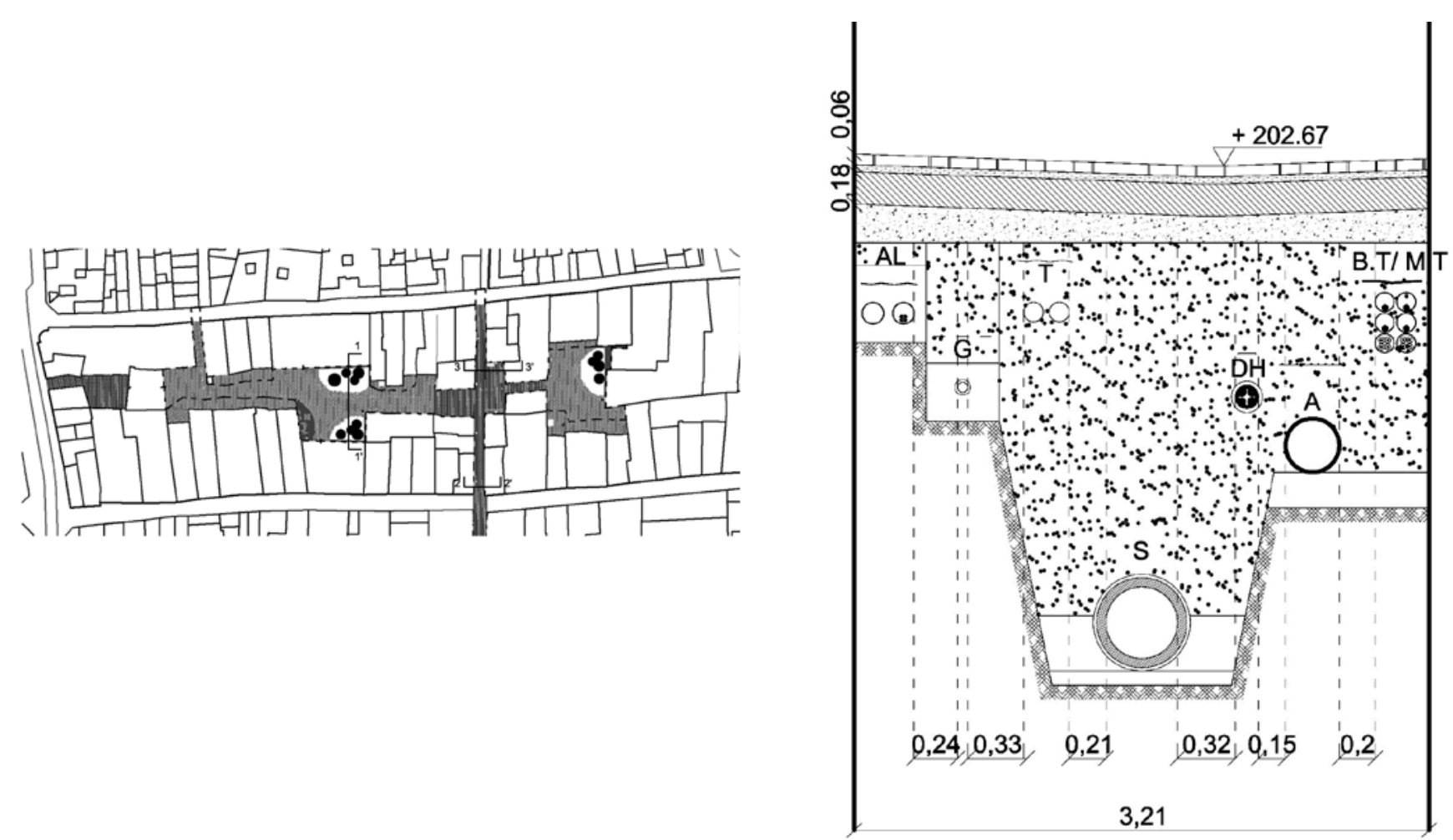

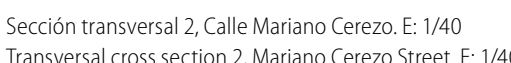

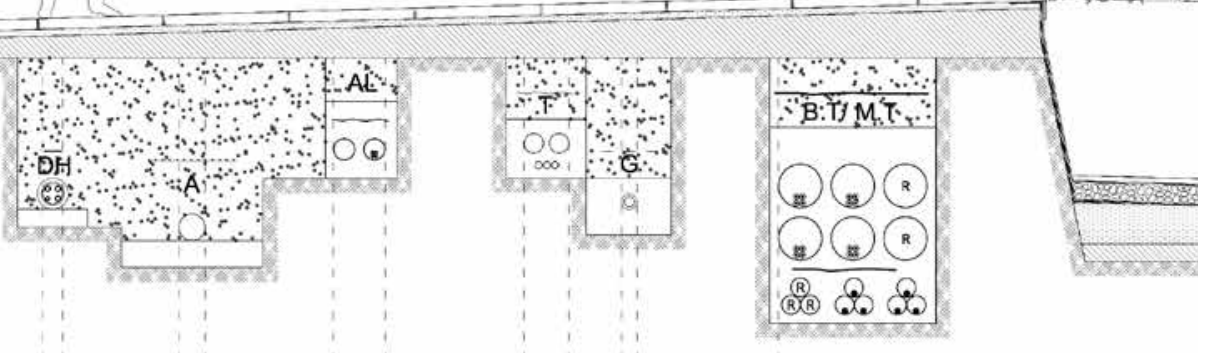




\section{ESPACIOS ENGANCHADOS |'HOOKED' SPACES}

Sergio García Pérez, Alicia Gracia Aguilar, Sandra Pilar Liarte Romero

Nos gusta pensar que el mayor activo del barrio de San Pablo es el poder de su dana y más vida en sus calles.

¿Qué entendemos por enganchar un espacio? Enganchar es una estrategia de actidesde el diseño del soporte fisico e inicia sinergias con lo social y y lo económicico: - Habitabilidad: búsqueda de una mayor complejidad social y una mejora de la competitividad del tejido residencial mediante actuaciones tanto de renovación
como de rehabilitación en criterios de flexibilidad y generación de diversidad. - Generación de nuevos espacios de relación: acordes a la realidad social e identtaria del barrio. Espacios por lo tanto soporte de una sociedad capaz de autogestionarlos $\mathrm{y}$ controlarlos, $\mathrm{y}$ que deben valorarlos como un activo más del actante

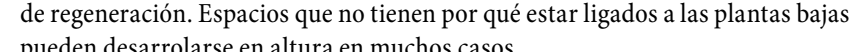

- accivación de la actiada conómica mediante la liberación de las plantas ba valorando el espacio umbral que se genera entre calle y fachada. Estos criterios generarán variedad y actividad diversa en las calles.

- Jerarquía, secuencialidad y permeabilidad del espacio público con el fin de dotar de una mayor legibilidad y calidad al conjunto del mismo en relación no sólo consigo mismo sino con el resto de la ciudad.
We like to think that the main asset of the San Pablo neighborhood is the selfpclaimed identity of its inhabitants as El Gancho ('The Hook'), which translates

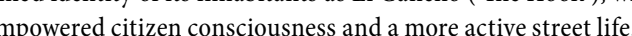

What do we understand as 'hooking' an urban space? Hooking is a strategy to activate processes of urban regeneration on a multi-disciplinary basis that starts by designing
the physical stratum and engenders synergies on the social and economic levels: -Inhabitability. The search for a greater social complexity and an improven the resident al tissue by means of both renewal and refurbishing interventions that foster flexibility and generate diversity.

-Generation of new social spaces: Spaces in accordance with the social and identity realities of the neighborhood. Therefore, these will be spaces that support a society capable of self-managing and controlling them, which should regard them the grous foor and and devop ertically in

Re-activation of the economic activity by freeing ground and even upper floors, value of the threshold space that appears between the facade and the street. These strategies will generate diversity and varied activities on the streets.

Hierarchy, sequentiality, and permeability of public space with the aim of
endowing the whole with greater legibility and overall guality not only in terms of itself, but also in its interaction with the rest of the city.
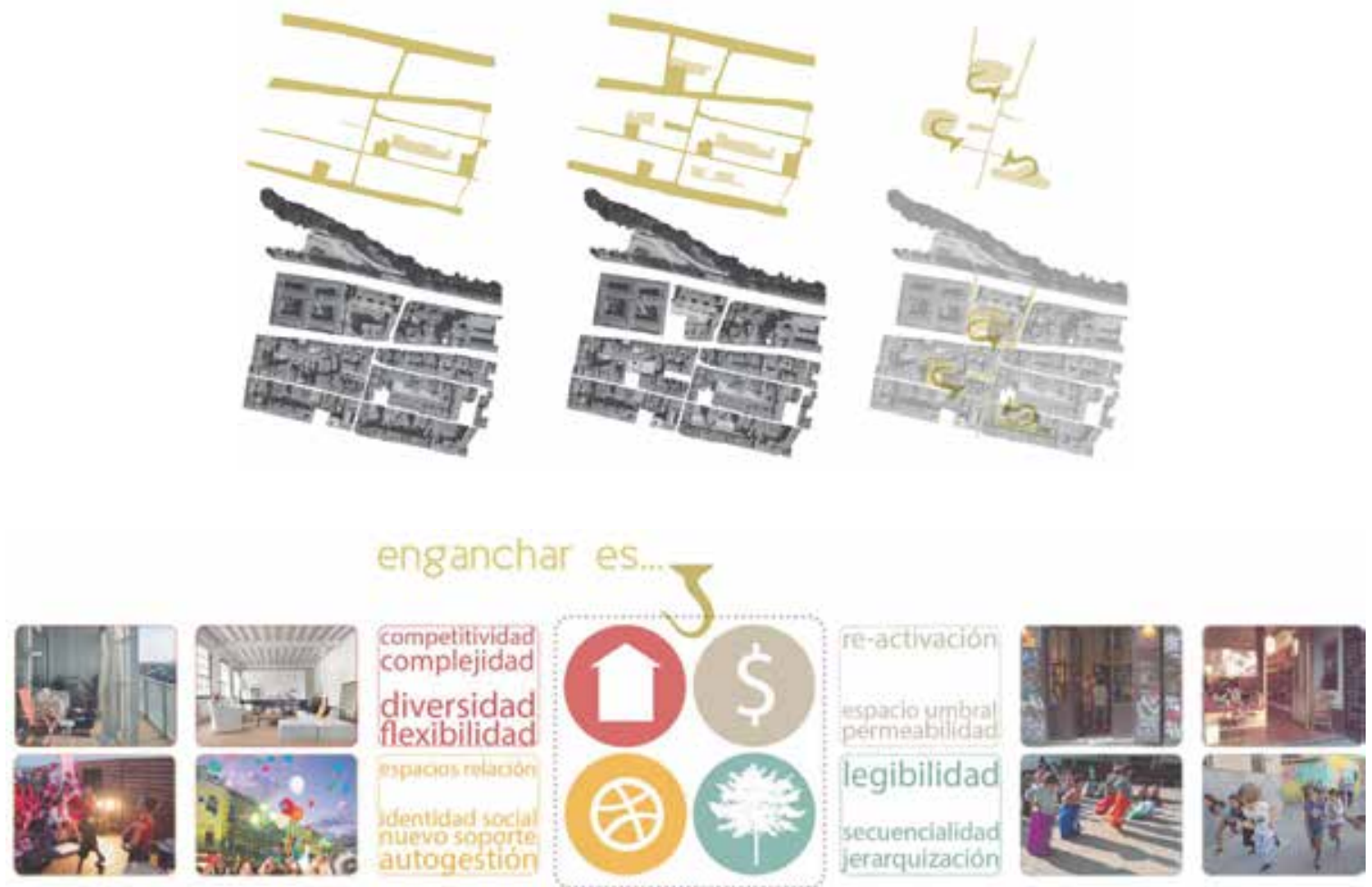
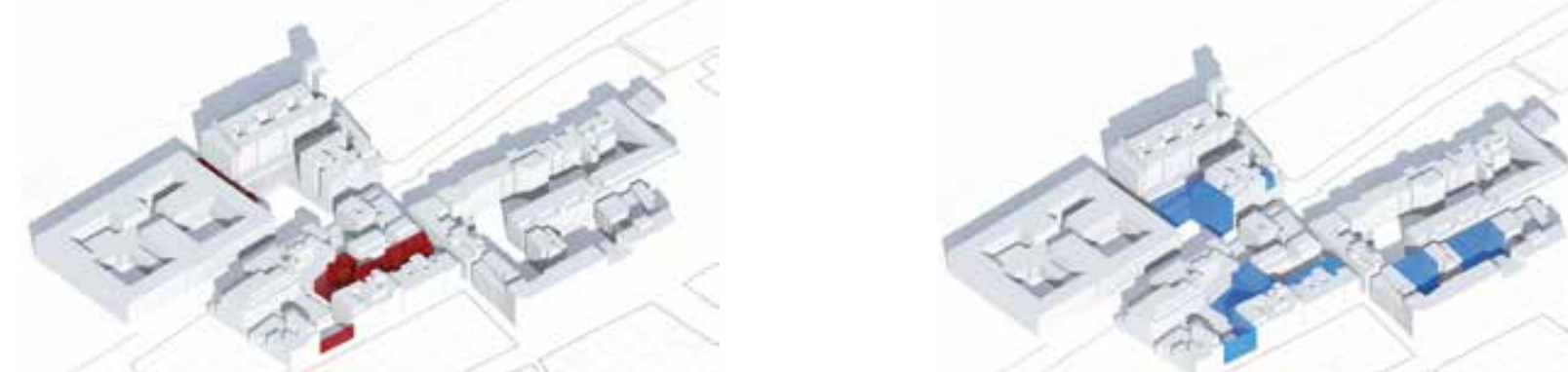

Situación actual (rojo-demolicíón) | Current state (in red: demolitions

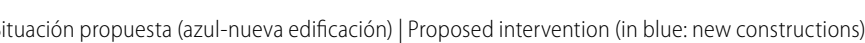
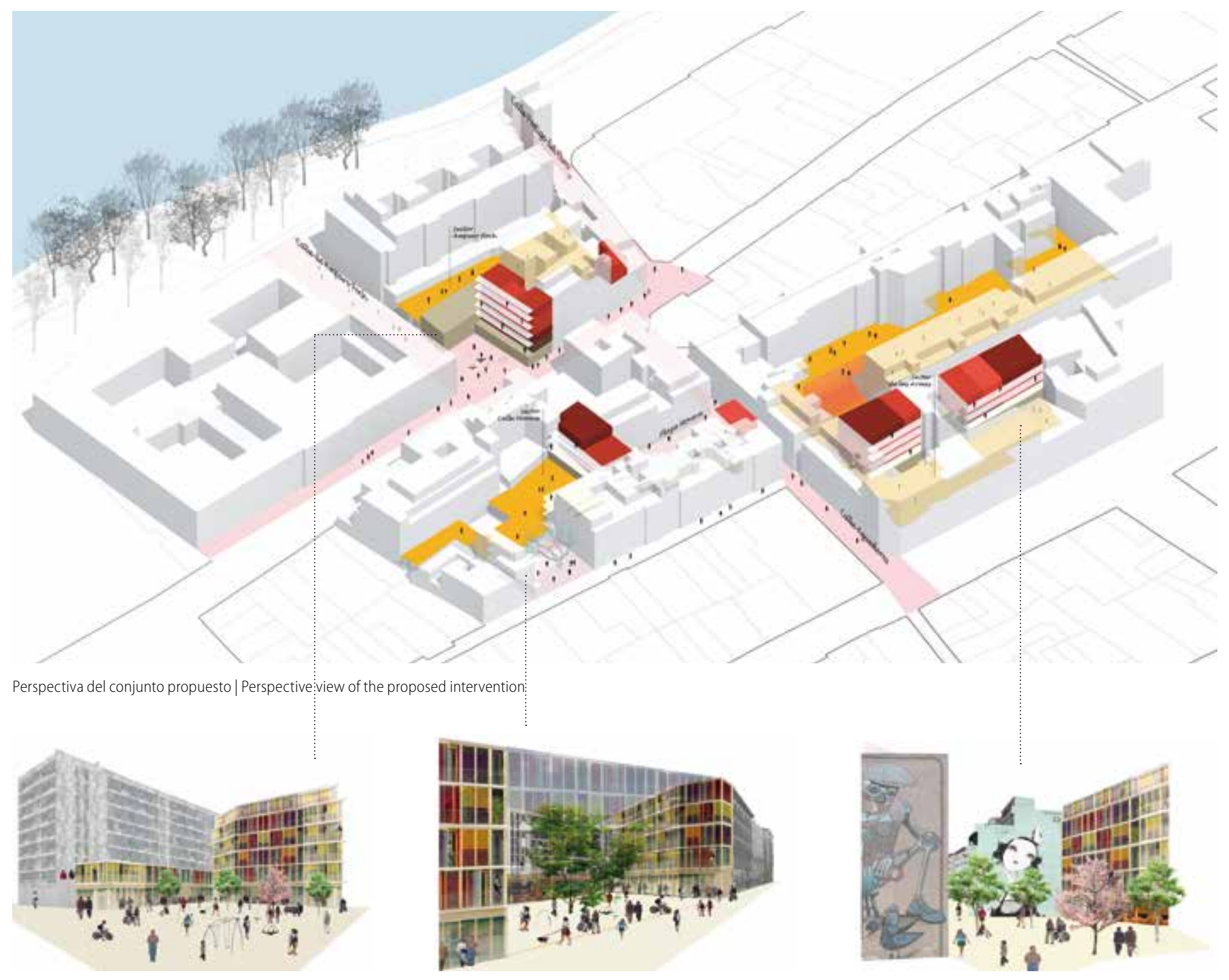
Aprovechando los solares existentes se establece una estrategia de consolidación de y se consigue nuevas conexiones y y aperturas, con el fin de disolver la purmalla exis tente hacia la ribera del Ebro. Se genera nuevo espacio público, además de aprove mayor legibilidad del espacio y del eje en su conjunto.

Opening doors, re-discovering interior spaces

Using the existing plots, the project designs a strategy to consolidate them as a way to generate activity and attract attention, while also increasing their permeability with new connections and openings that dissolve the existing barrier towards the Ebro River bank. A new public space is generated, adding to the revaluation of the

CALLE MORERA | MORERA STREET

Redescubrir la manzana

La manzana sobre la que actuar presenta un alto nivel de congestión y falta de va. vo. Además, el parcelario orignal encuentra aquí una ir regularidad que seŕa aproactual de las construcciones anexas al interior, con el fin de por una parte mejora la habitabilidad y por otra garantizar una nueva accesibilidad generando una nueva galería continua por la fachada interna.

Rediscovering the block

The housing block subject to the intervention presents a high level of congestion and a be used as an opportunity to free public space At the same time the existing building will be freed from the annexes that have been built in the inner areas, in an attemp to improve inhabitability, on the one hand, and to guarantee a better accessibility by generating a new, continuous gallery that runs through the inner facade, on the other:

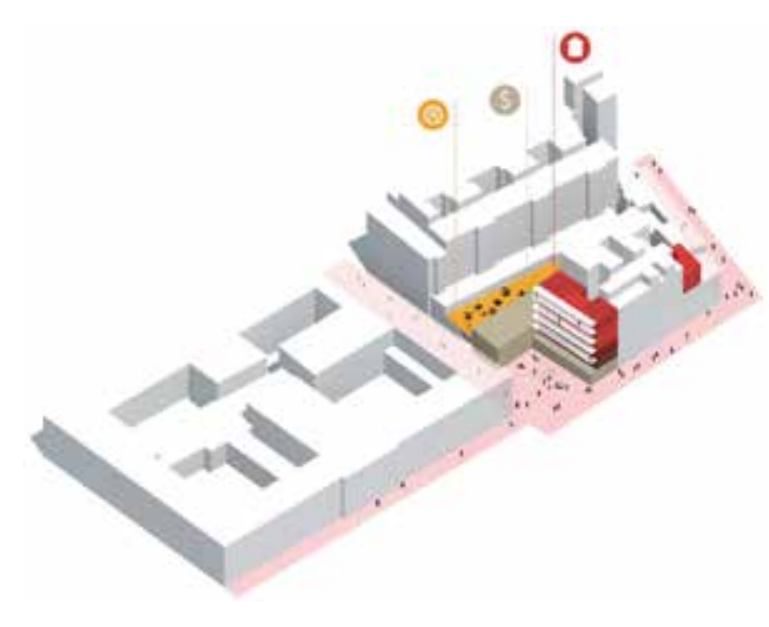

(구 $\mathbf{0}$

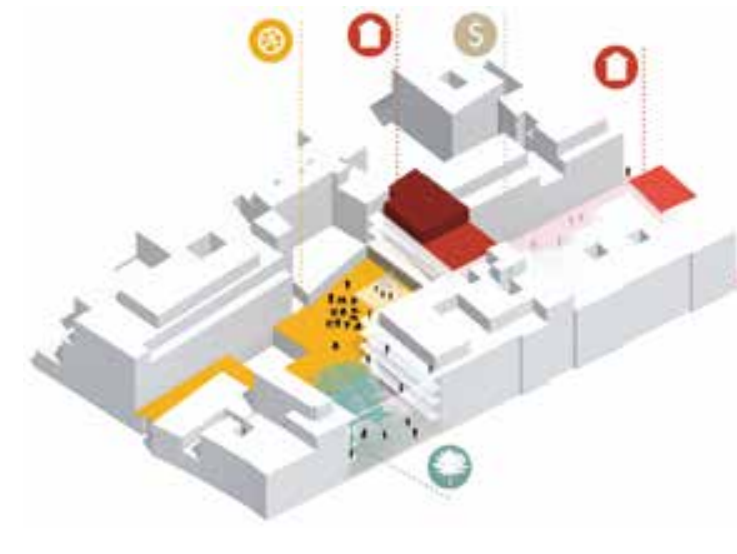

CALLE LAS ARMAS | LAS ARMAS STREE

Consolidar el vacío

El estado actual de solares bajo la actividad temporal de EstoNoEsUnSolar no cons tituve un estrategia definitva de renovación urbana la propuesta plantea el cierce de la manzana y la liberación del espacio interior de manzana, buscando la mayor permeabilidad posible en la planta baja. Una vivienda configurada con la mayor

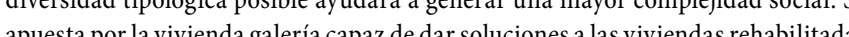

\section{Consolidating the void} The state of the building lots currently subject to the temporary activities of
EstoNoEsunnsolar does not constitute a definitive strategy of urban renewal. The project proposes closing the block and freeing the inner courtyard, searching conf complexity. We choose gallery-accessed housing as a typology able to provide solutions to the adjacent refurbished dwellings by improving their accessibility.

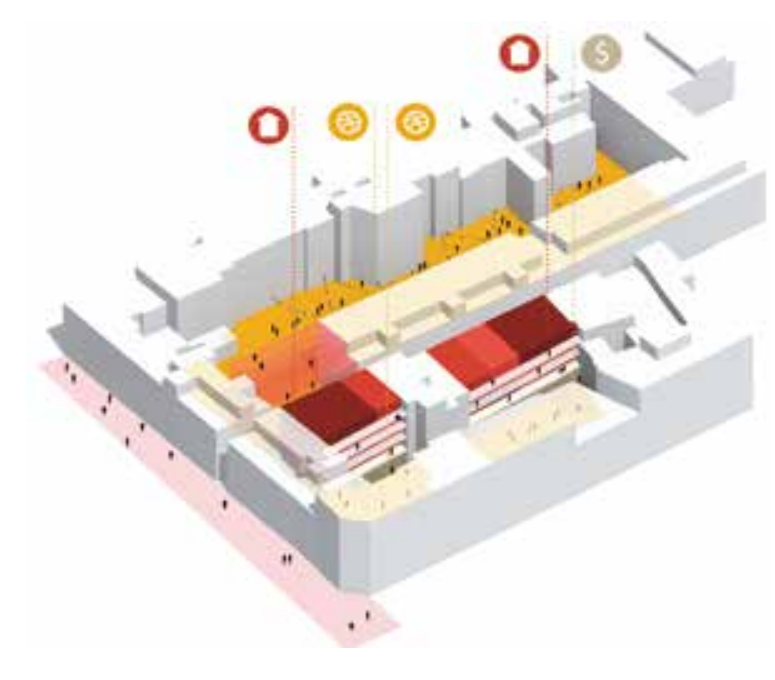

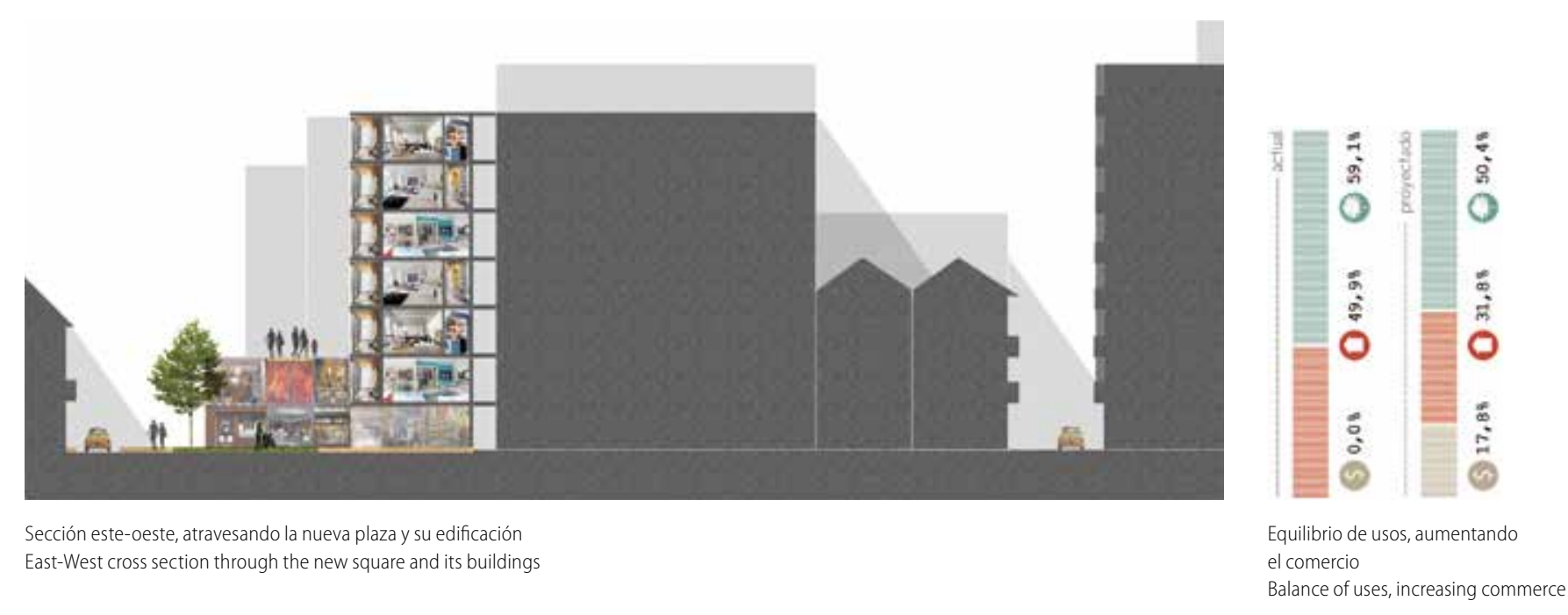
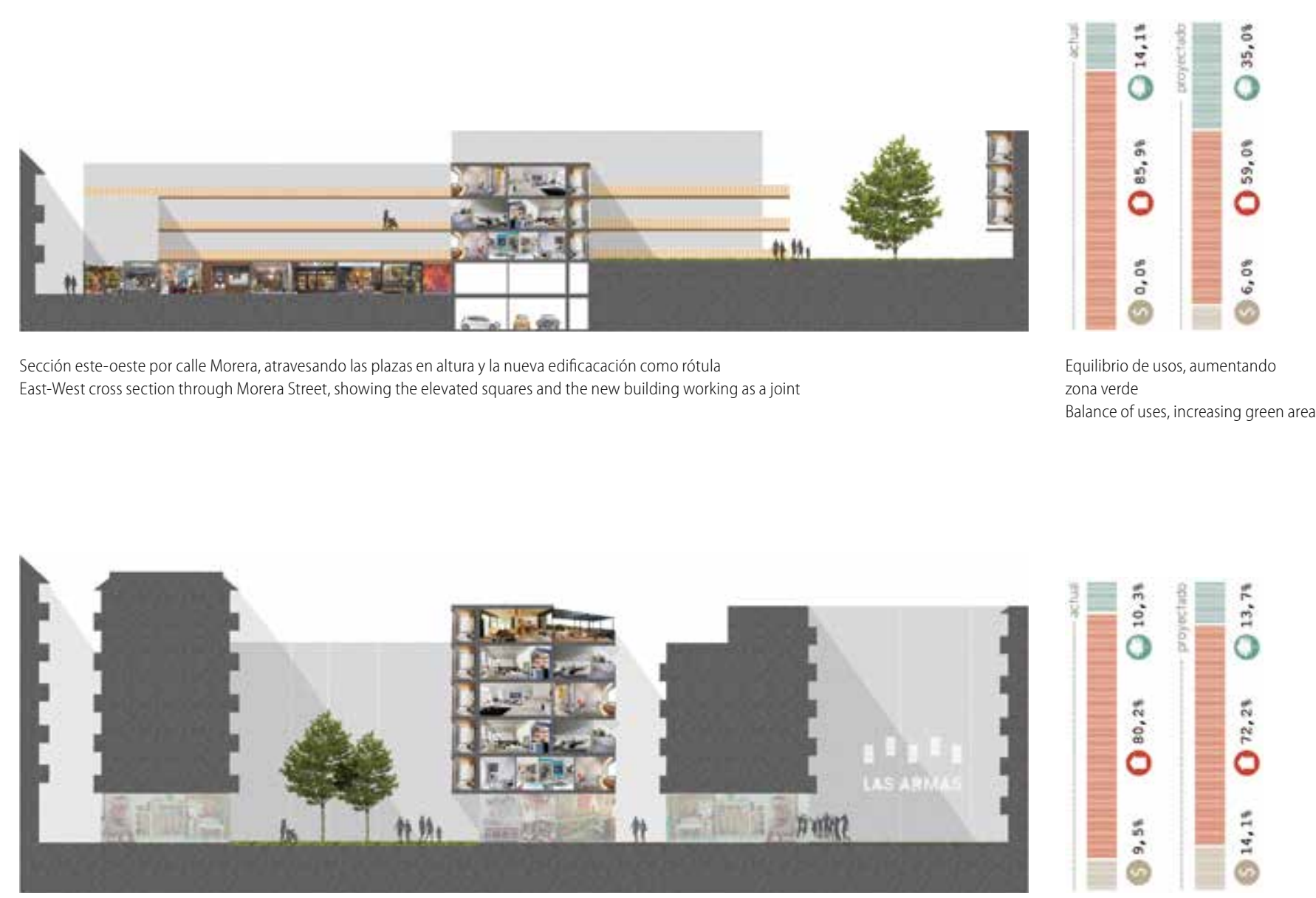

Sección norte-sur, mosstrando la permeabilidadd del interior de la manzzana
North-South crosss section, showing the permeability of the block's inner space

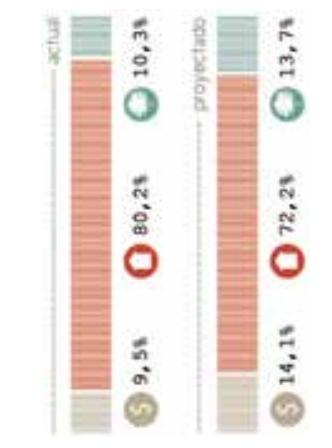

Equilibrio de usos, creación de viviend
Balahce of uses, creating housing 


\section{Criterios de proyecto}

Se busca la mejora de la conectividad y legibilildad, fisica, social y medioambiental. En primer lugar para ello se ha elegido comúnmente un pavimento propio discretización y discontinuidad, son capaces de adaptarse a cada una de las situa ciones particulares.

Un segundo objetivo es la no especialización de la calle. Para ello, se considera que este pavimento discontinuo debe generarse como un tapiz neutro definido pero
especifico consiguiendo así un lugar donde la no definición de actividades concretas opción a una mayor adaptabilidad del espacio. El espacio yel diseño del mismo se llen

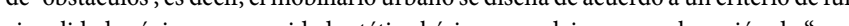
piación" de cada usurio pueda establecer el uso del mismo que considere opotuno

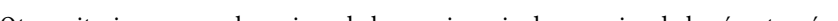
un diseño que frente a la delimitación de los mismos, sea capaz de delimitar las velocidades que cada usuario deba tener.

Por último se mejora la conectividad de zonas verdes, estudiando la posibilidad de cada una de las calles en pormenorizado. Se es consciente de que una nueva gestión de los recursos hídricos y de riego debe ser exigible. Se opta así por una solución
más seficiente desde el diseño de la sección del vial y la elección de la plantación más eficiente desde el diseño de la sección del vial y la elección de la plantacio
mejorando el ciclo del agua siempre de acuerdo a las lógicas del propio lugar.

The goal is to improve physical, social, and environmental connectivity and legibility. The first step las been choosing a speciific, conmon parement for the

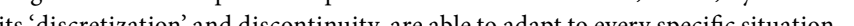

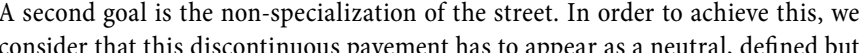
not specific tapestry, thus generating a place where the non-definition of specific activities endows the space with a greater adaptability. Space and its physical design are filled with obstacles; that is: urban furniture is designed following maximum-functionalty/ basic aesthetic capacty citteria, in order to let each ase

Another criterion focuses on the improvement of the cohabitation of different users bility to delimit by dising a design which, instead of delimiting those, has the

Finally, the project improves the connectivity of green areas, studying the hydrological and irriation resources would be required. Thus, we choose a solution that is more efficient by using the design of the street's cross section, and by choosing the planted vegetation, which will improve the water cycle, always

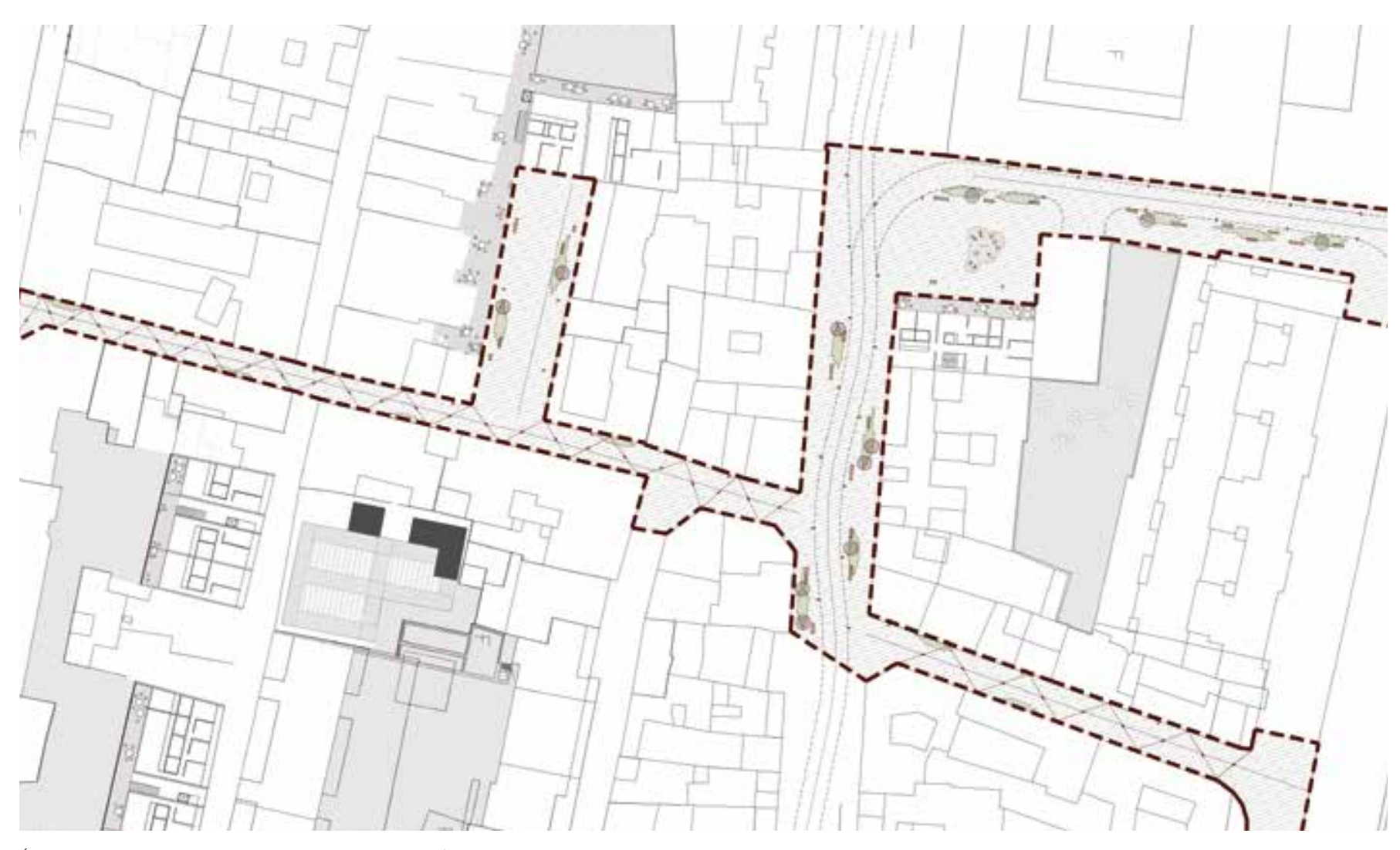

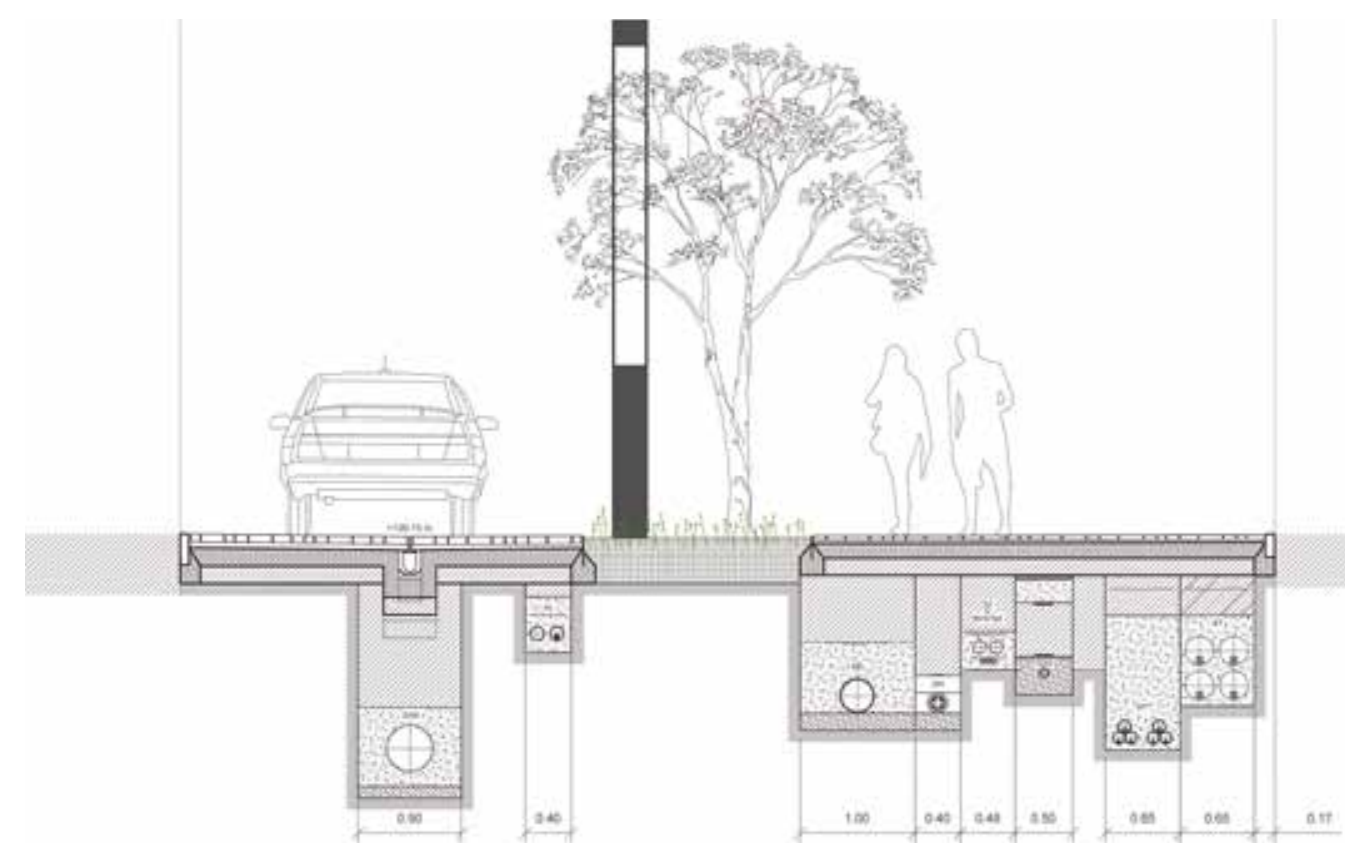

Sección transversal de la nueva calle | Transversal cross section of the new street

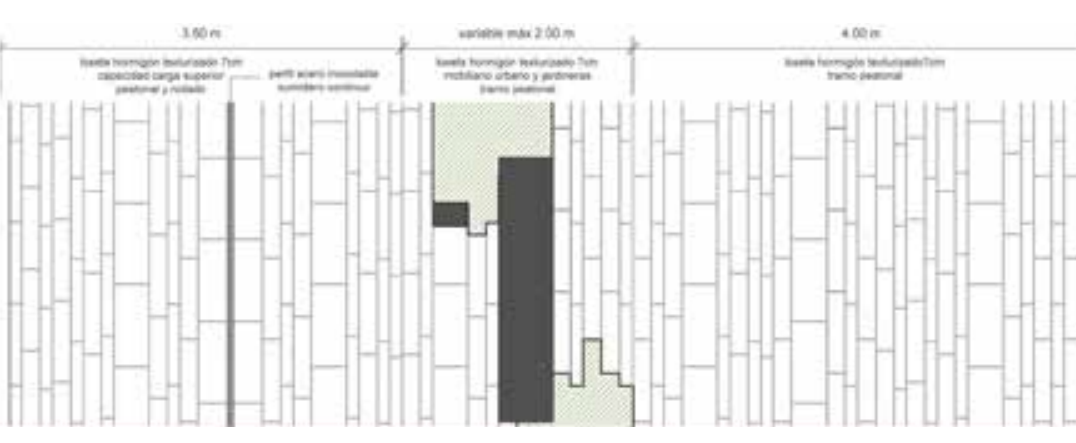

Detalle pavimentación y diseño de la nueva calle | Detail of the pavement and design of the new street
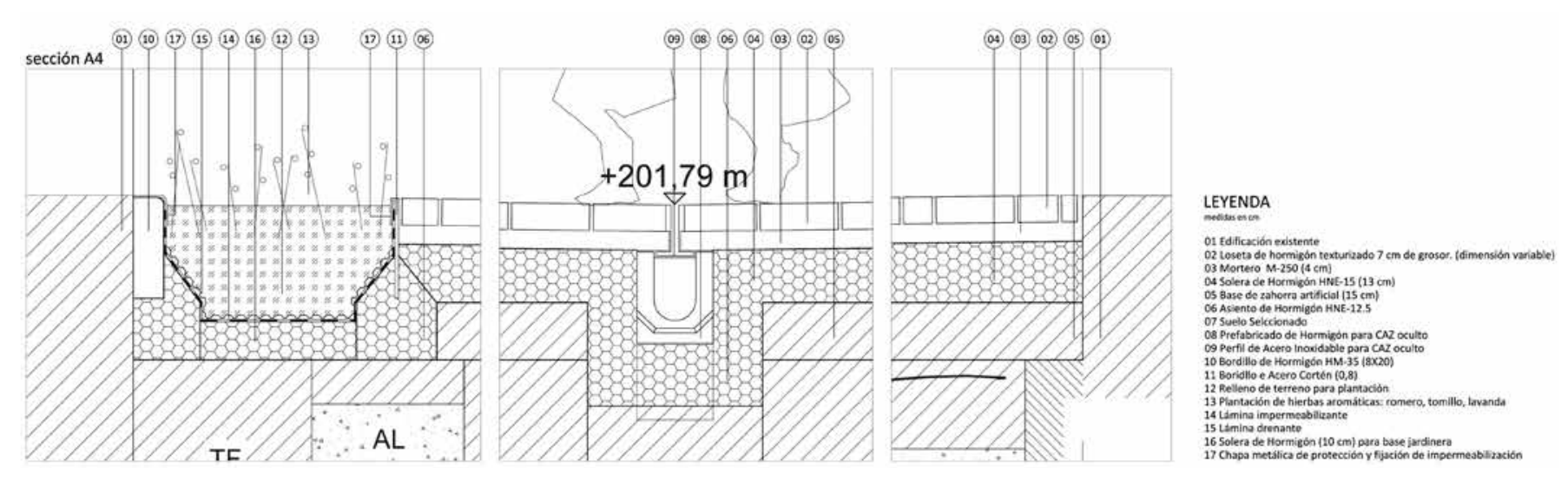


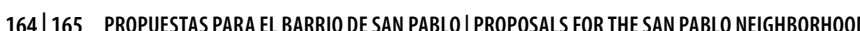

05 GRIETAS CONECTORAS | CONNECTING CRACKS

Silvia Castán Castrillo, Lucía Ferrer Gómer

La propuesta para el sector Cesaraugusto-Conde Aranda trata de consolidar una nueva manzana en el borde del barrio de San Pablo, trabajando sobre las dos avenidas siendispersas e inconexas entre ellas y solares edificables. Asi, la intervención tratará $c$ introducirse en ellas, mejorando lo existente $y$ construyendo la manzana para dact actual que solucionelos problemes existentes de habitabilidad falta de espacio panziso creación de una entrada sureste al barrio atractiva para el resto de la ciudad. OBJETIVOS

Thesionar: norte y sur del barrio salvando el límite de Conde Arand - Abrir: nueva puerta que funcione como acceso Este al barrio. Dotar: habitabilidad, espacios públicos, actividad en planta baja, equipamientos

ESTRATEGIAS

. Ayuda a la creación de espacio públice, tra de evitar los recorridos ango
de voladizos pronunciados.

Creación de grietas en los edificioos. Ayuda a fraccionar la visión de las planta

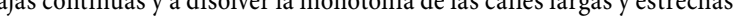
- Apertura de patios. Favorece la ventilación e iluminación de las viviendas existen-

- Acceso mediante corredores. A partir de una solución unitaria conseguimos ho-

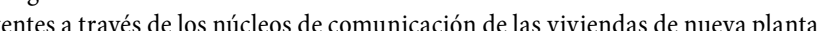

This proposal for the sector César Augusto-Conde Aranda area tries to consolidate new block on the limit of the San Pablo neighborhood, working on the two avenues that we understand as the neighborhoods natural expansion ways. In it, we find scattered, disconnected constructions, and emply binding lots. Thus, the goal of the and building the block in oder to ndow the whole with consistency The project will be conceived as the creation of a contemporary block that solves the existing problems regarding inhabitability, the lack of public space, and the creation of an attractive Southwest entrance to the neighborhood from the rest of the city.

Unite: North and South of the neighborhood, breaking thelimit of Open: a new door that works as the East entrance to the neighborhood. Provide: inhabitability, public spaces, activity on the ground floor, global facilities

STRATEGIES

The strategies we will use to accomplish these goals are:

- Compression-expansion of space: Promoting the creation of public space trying

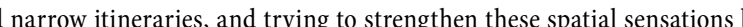
using deep cantilevers.
- Creating cracks on the buildings. It helps split the usual vision of a continuous flloor, and eliminates the monotony of narrow, long streets. ds. It helps the air circulation of the existing dwellings, and makes it possible to place the new buildings around them.

- Access through corridors. By using a single solution we manage to homogenize munication cores of the new buildings
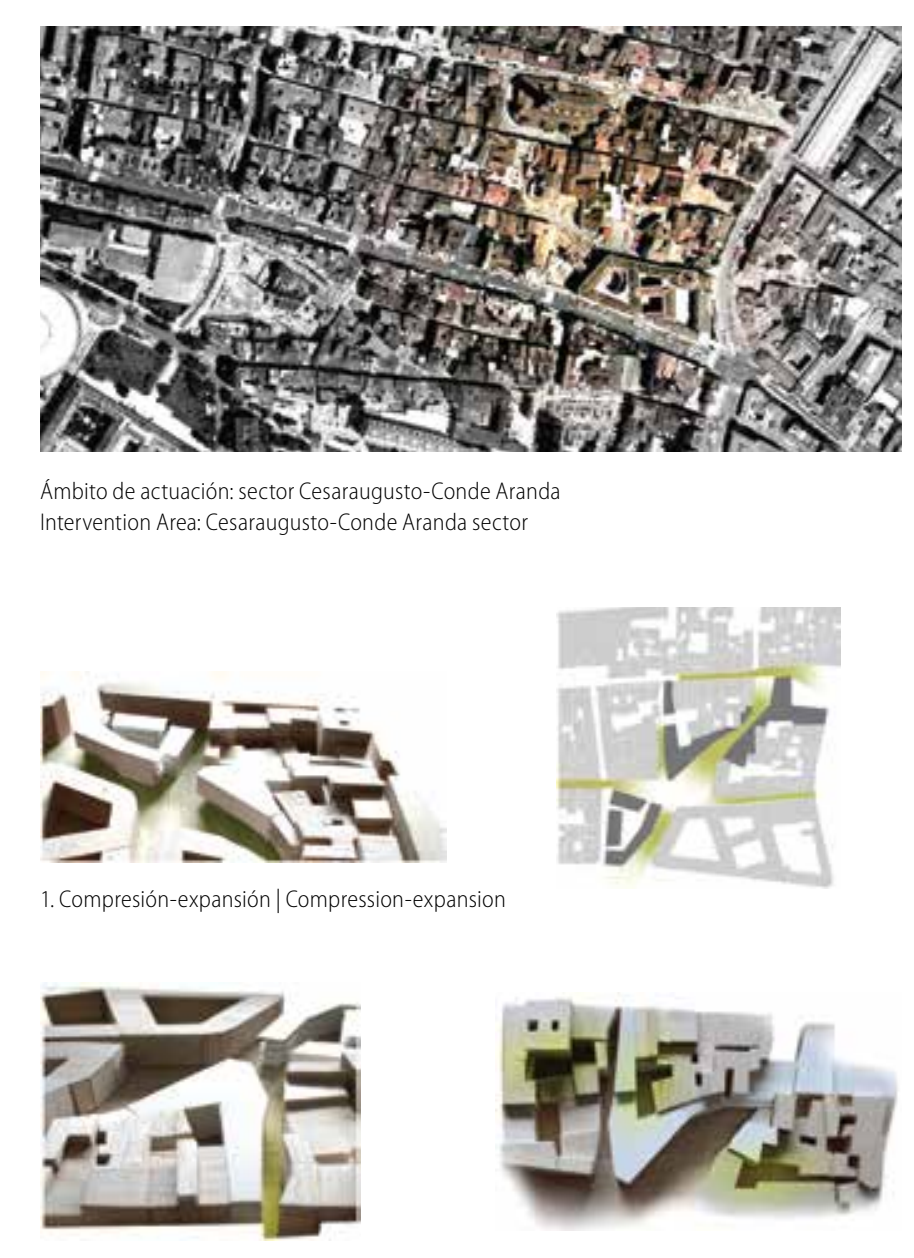

2. Grietas en los edifficios | Cracks in the building 3.Apertura de patios | Courtyard opening

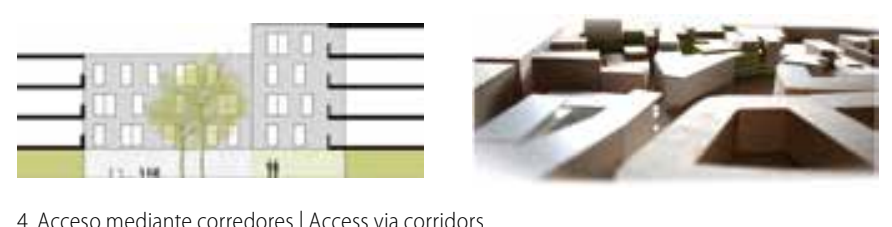

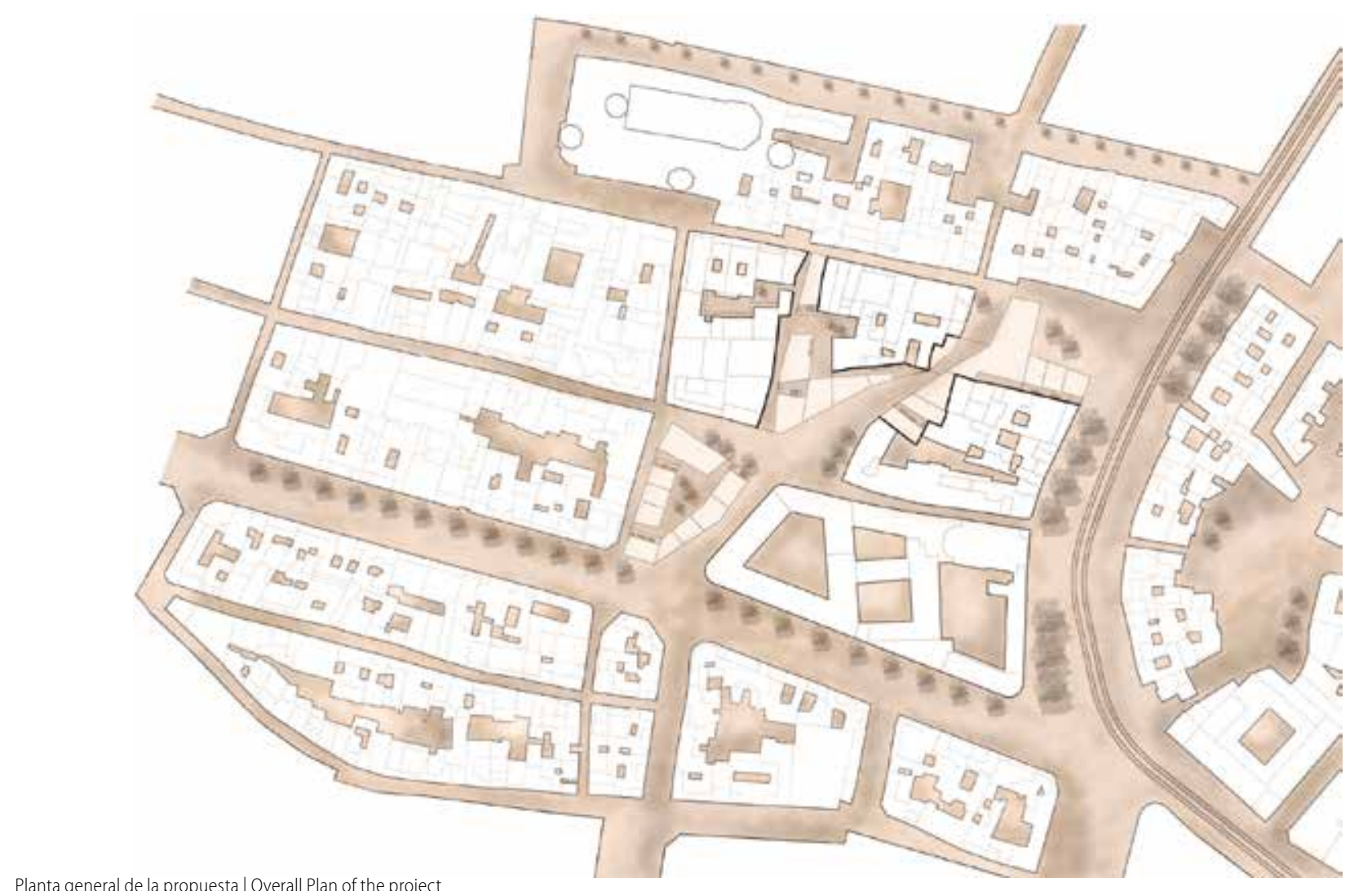

Proceso formativo de la manzana | Generative process of the block

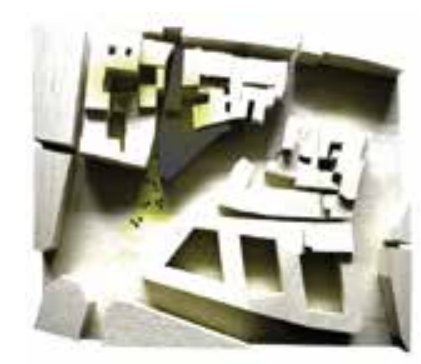

FASE 1|PHASE 1

Mejora de lo existente

acceso a los patios. Aperturua de éstos pas que respiren las viviendas existentes y dotación de accesibilidad
del las nuevas viviendas.

Improvement of existing elements access to the courtyards . Opening of the

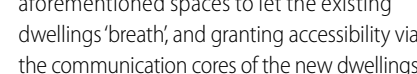

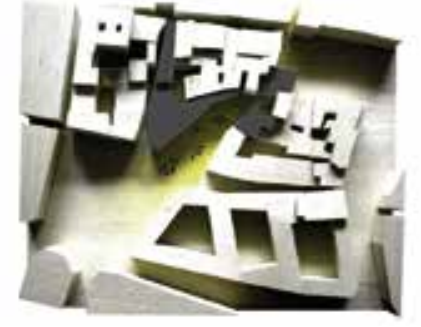

FASE 2 | PHASE 2 El corazón de la manzana través de un passiey y nuevos ed edificios aue completan ellugar para la generación de un espacio público amplio a q que vierten tod The core of the city block a passageway and new buildings that completet the whole, creating a nev, ample
public space that al the dwellings overlook,
in the way of a traditional corralla

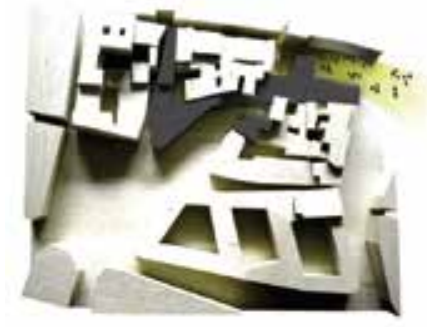

FASE 3 | PHASE 3

Puerta calle de San Pablo Generacion de una plaza equipada con
viviendas, usos terciarios, espacio público yaparcamientos. Visión atractiva desde el
exterior del bario que incita a introducirse por sus calles.

Gate of San Pablo Street

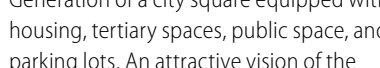
neighborthood from the outside that incites

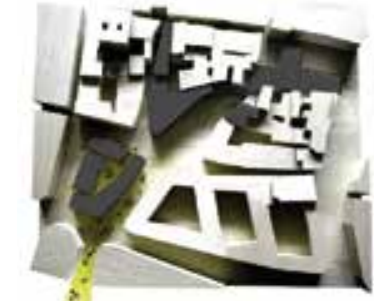

:ASE 4 | PHASE 4

Conexión sur del barrio través de una pieza permeable, de uso mix y volcada a su propio patio de manzana. South connection of the neighborhood inserting a permeable, mixed-use piece thy Soekts onto its owneable, mixed courtyard. 

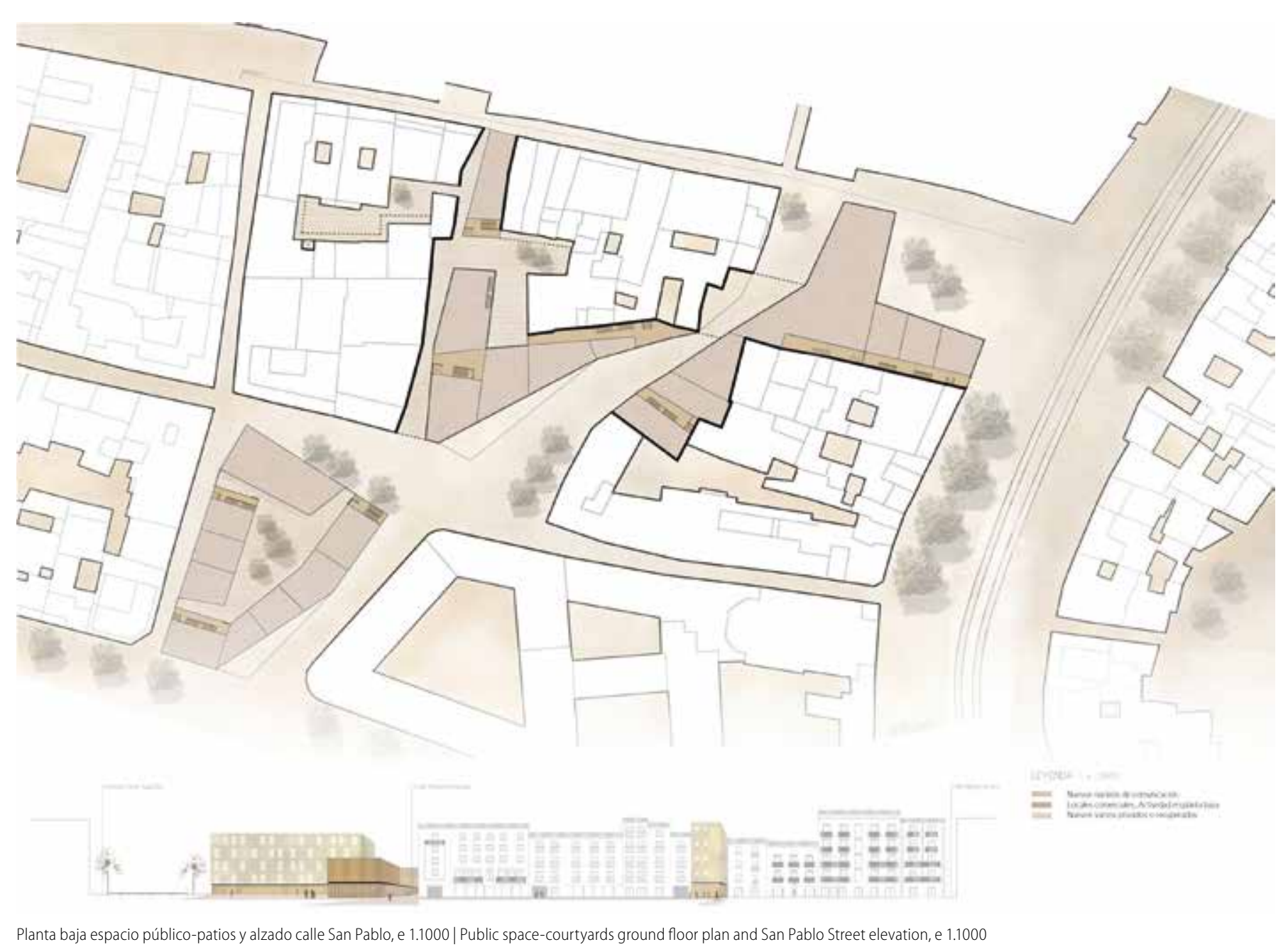

Planta baja espacio público-patios y alzado calle San Pablo, e 1.1000 | Public space-courtyards ground floor plan and San Pablo Street levation, e 1.1000

En respuesta a la necesidad de regeneración de la actividad del barrio, la propuesta se materializa en una planta baja de locales comerciales pasantes,
dominados y la vida interior de los edifícios. Este hecho permite al mismo tiempo la vi

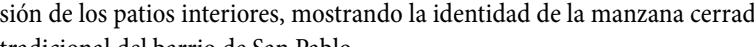

Dicha planta baja, se desvincula de las plantas alzadas ayudando a la ampliación del espacio público y creando un recorrido lleno de actividad.

As a response to the need to regenerate the neighborhood's activity, the proposal offers a ground lloor consisting of transparent, facade-to-facad the inner life of the buildings to aloo allows them to se the colly blocks that constitute the identity of the San Pablo neighborhood.

The ground floors are disassociated from the upper floors, providing an

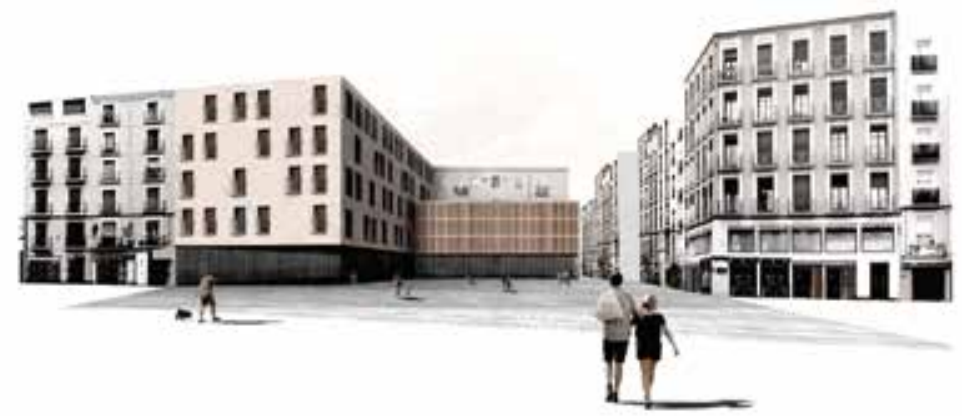

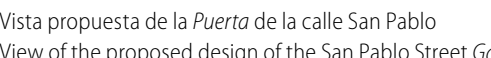

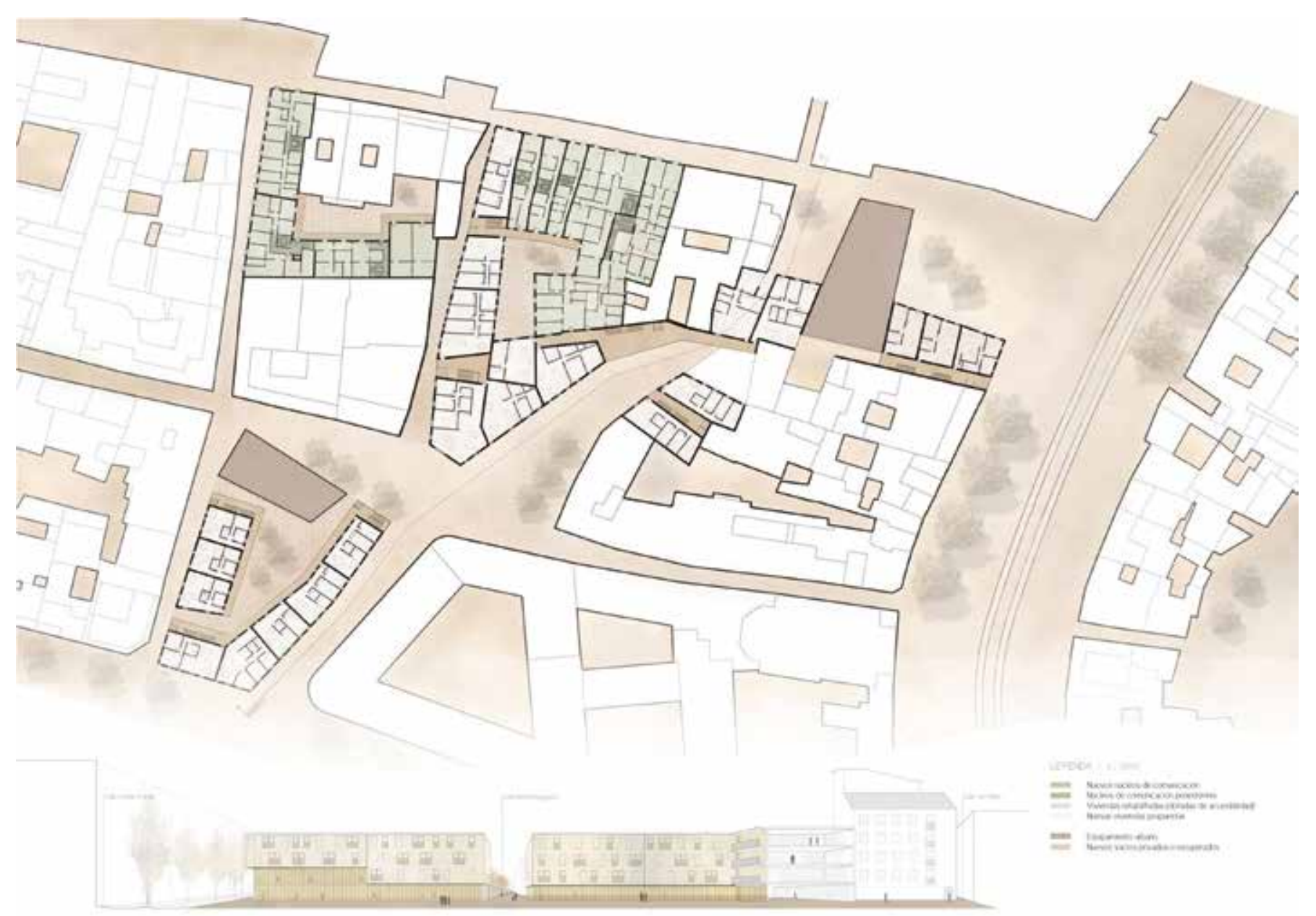

Planta tipo viviendas-equipamientos y sección transversal, 1 1.1000| Housing units-service areas typical floor plan and cross section, 1.1000

La formación de los nuevos volímenes construidos busca seguir un esquema de adición de pequeñas piezas residenciales que concuerda con el
resto de la morfología urbana del barrio, permitiendo cohesionar la edificación dispersa presente en el lugar.

Los nuevos edificios se posicionan de modo que mejoran notablemente la accesibililidad a la edificicacion preexistente, dotando de ascensor a unas 60 la convivencia directa de lo nuevo con lo ya existente.

The creation of the new residential volumes aims at following a strategy of addition of small housing units that fits with the urban morphology of the net the are nowadas

列 elevators. In addition two block courtyards that show the direct cohbhitstion of preexisting and new constructions are recovered.

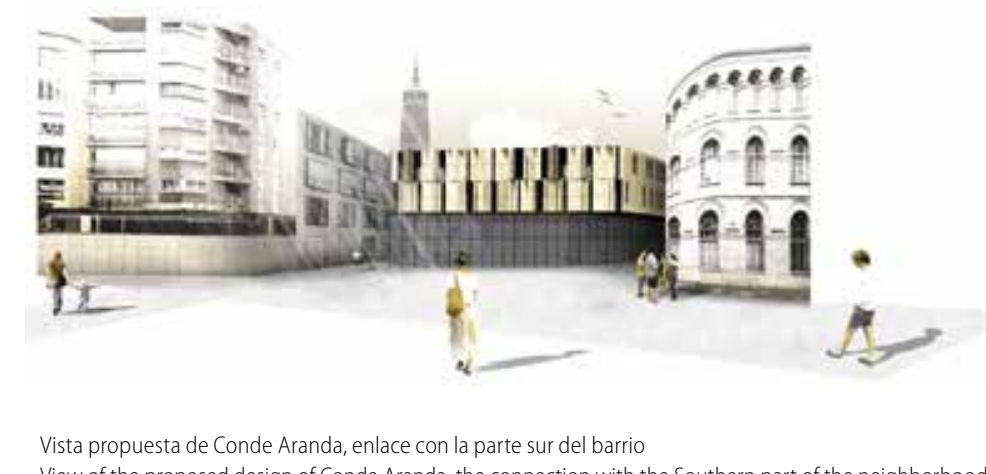


En este apartado de una forma más "técnica" se pretende materializar las ideas

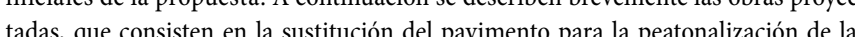
calles de ámbito, la modificación del trazado de las redes de saneamiento y abasteci. miento existentes conforme a la edificación proyectada y la equipación de mobiliario urbano y zonas verdes.

El proyecto de urbanización del sector César Augusto-Conde Aranda representa una oportunidad urbanistitca para resolver los problemas de permeabilidad, acceso

Se plantea así la peatonalización de las calles interiores al barrio incluidas en e ambito con la intención de potenciar los mecanismos de compresión y expansión

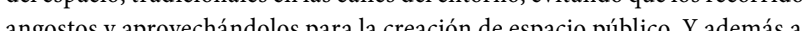
el barrio a la ciudad con la situación de espacios urbanos estratégicos que sirvan de "Puertas del Barrio".

The aim of this section is to materialize the original ideas of the proposal in a more "lechnical' way. Below, there is a brief description of the projected works, which the streets of the area the modifiction of the outline of the water supply and sanitation networks according to the projected constructions, and the insertion of urban furniture and green areas.

The re-urbanization of the Cesar Augusto-Conde Aranda area represents an urban opportunity to solve the problems of permeability, accessibility, and scarcity of public space of the San Pablo neighborhood.

Thus, the project proposes the pedestrianization of the inner streets of the neighborlood included in the intervention area, with the purpose of strengthening

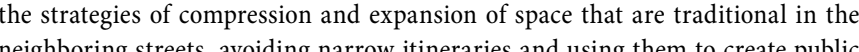
neighboring streets, avoiding narrow itineraries and using them to create public
space. In addition, it aims at bringing the neighborhood closer to the city by creating strategic urban spaces that work as "Neighborhood Gates".

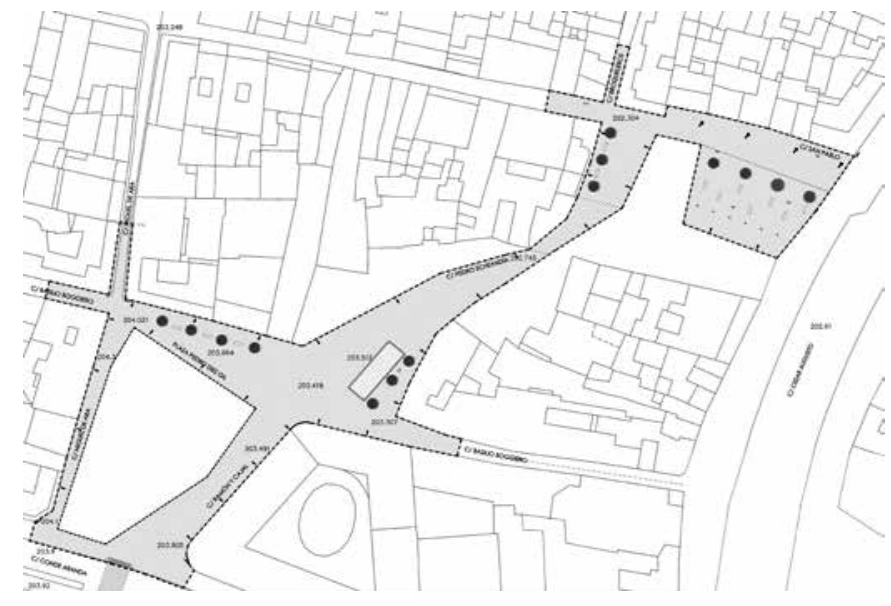

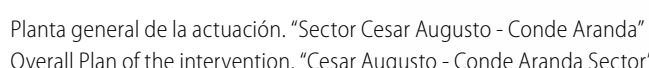

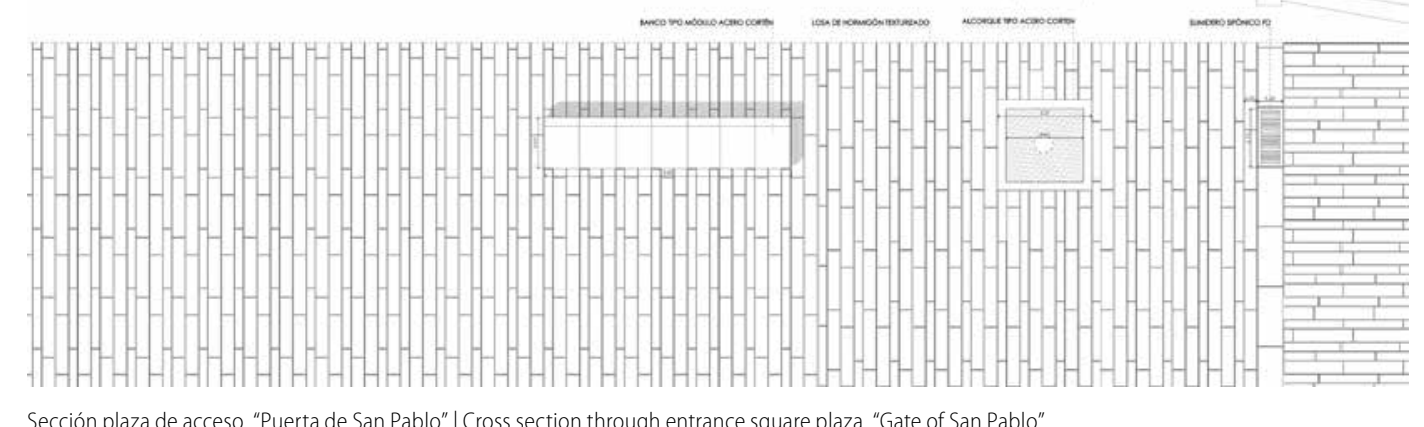

INFRAESTRUCTURAS URBANAS | URBAN INFRASTRUCTURES
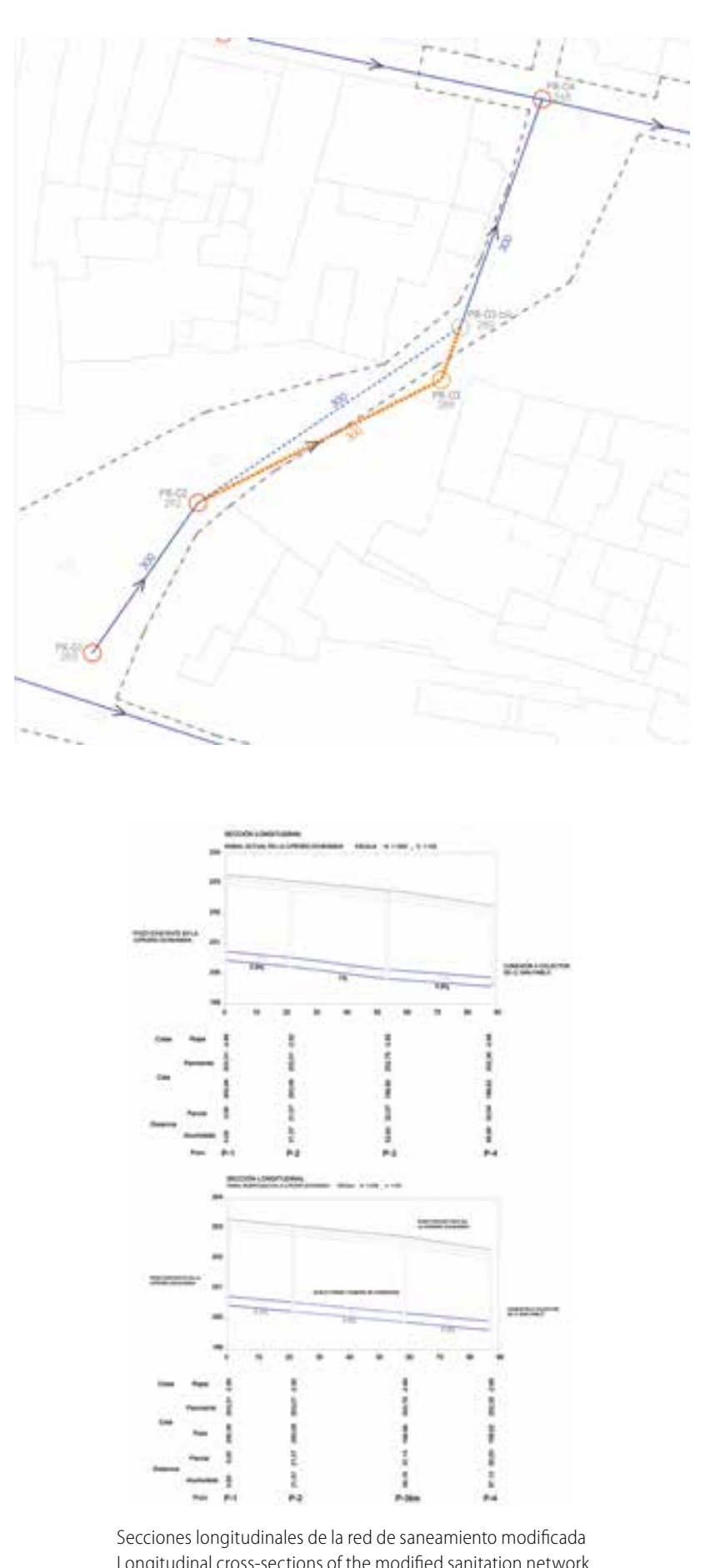

DISEÑO DE MOBILIARIO URBANO | URBAN FURNITURE DESIGN

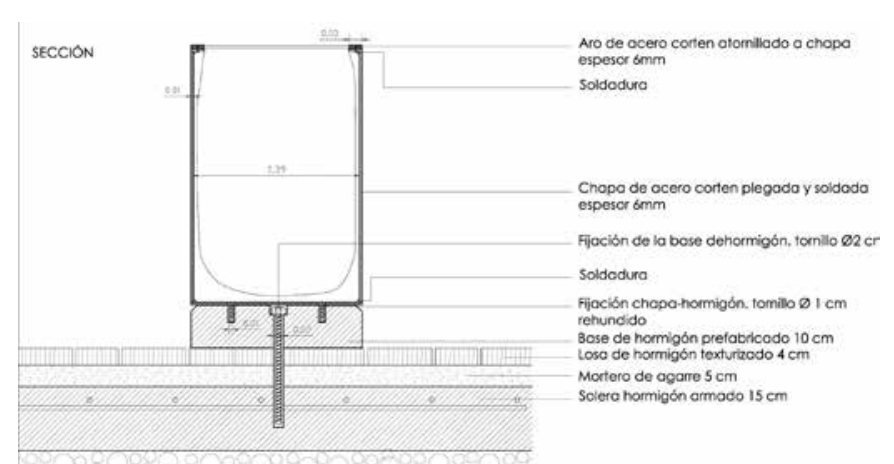

Pieza de mobiliario 1. Papelera | Furniture piece 1 L itter can

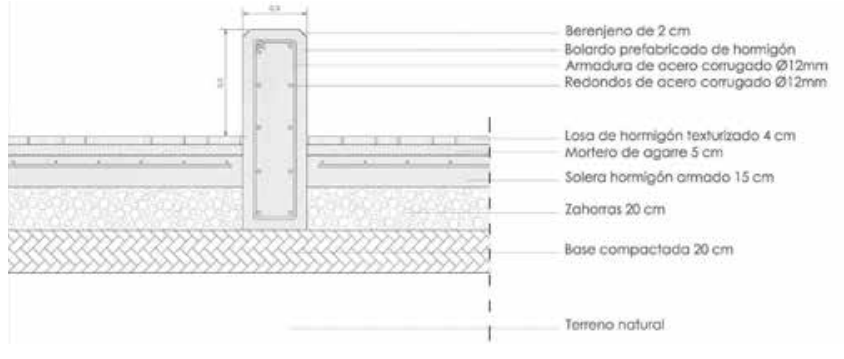

Pieza de mobiliario 2. Bolardo | Funniture piece 2. Bollard

INFRAESTRUCTURAS URBANAS | URBAN INFRASTRUCTURES

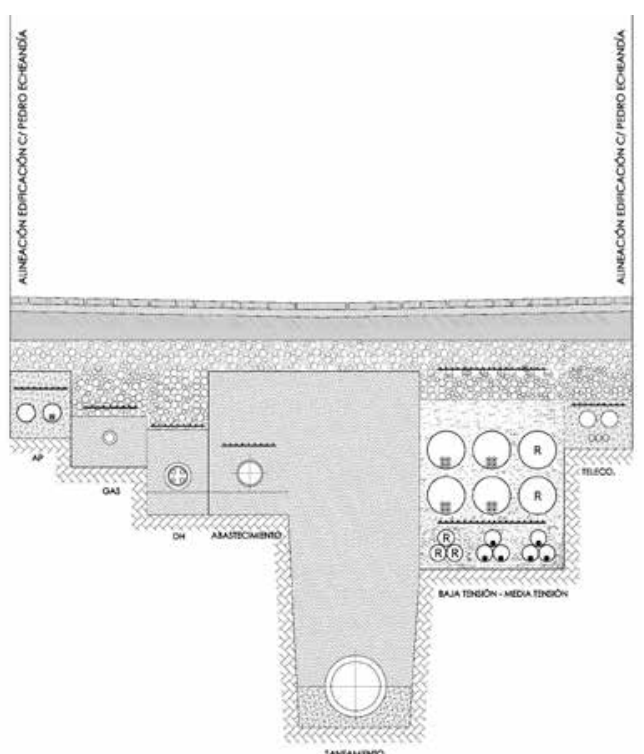




\section{ESPACIOS ANIDADOS | TRODDEN SPACES}

Alejandro Alda García, Daniel Estabén Boldova, Fco Javier Sancho Melús

Es incuestionable que el diseño urbano tiene consecuencias didanos, siendo el vacio el elemento estructurador de la ciuda. Por ello, el trabajo se fundamenta en la sucesion de vacios com espacios publicos y privados desde los que el ciudadano se

Se propone pues, a lo largo de la calle mosén Pedro Dosset, la articulación de una serie de pequenanas plazas publicas, como una agrupadas que proporcionan intimidad en distintos grados función del entorno proyectado en cada caso. Se piensa en las plazas tal y comolas pensaba C.Sitte, para la constitución de una secuencia en base a la concatenación de espacios.

La concatenación de plazas, a través de umbrales y pasos que se contraen y que filtran las perspectivas para después abrirse pau lathamente, busca expandir hialmentela vis

a nas, la compositorn de esta concatenación articula dos el interior de las manzanas. Aparecen aquí los espacios "in-between" de Aldo van Eyck, que articulan dos espacios continuos y diferentes al mismo tiempo.

Urban design has direct consequences on urban quality and daily lives of citizens, therefore the void is the structuring public and private spaces in which the citizen interacts an perceives the city.

Consequently are proposed a sequence of controlled public spaces along Mosen Pedro Dosset Street, as sequence of differen and interconnected voids. The spaces are grouped providing
privacy and diversity in different levels according to the environment in each case. The spaces are designed in the same sense as Camilo Sitte thought it, establishing a sequence based on the concatenation of spaces.

Through doorways and steps, the concatenation of places contracts and filters the prospects, which are gradually

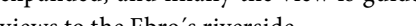

Indistion, concatenation articulates of the blocks. Appears here the spaces "in-between" of Aldo val Eyck, which articulate continuous and different spaces at the same time.

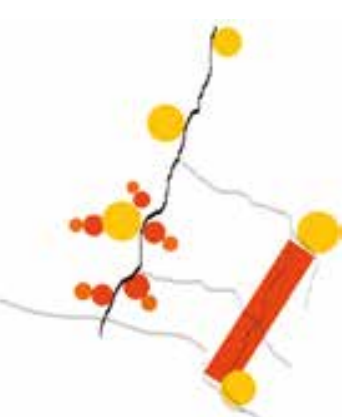

1. Concatenación de vacios
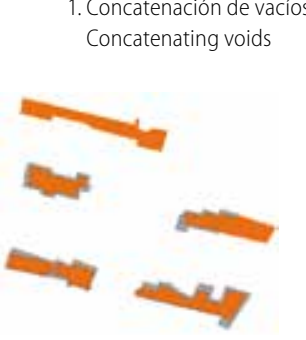

4. Corredores en el patio
Court's corridors

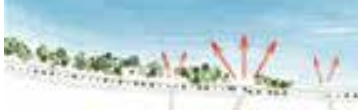

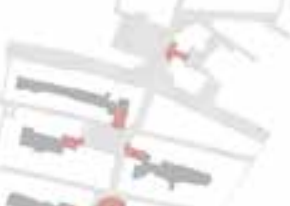

$\rightarrow$

2.Conexiones patios-plaza
Court-places conexion

$\frac{5}{7}$

다

ᄂ

$\square \quad \square$

七઼

$\neg \square$

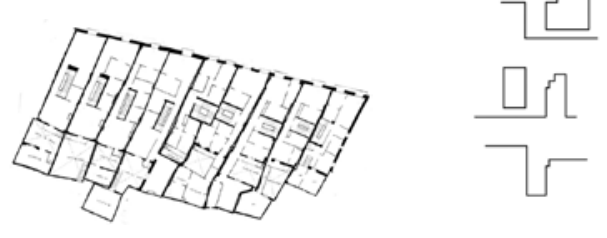

5. Mantenerer tipo
Keeping the type

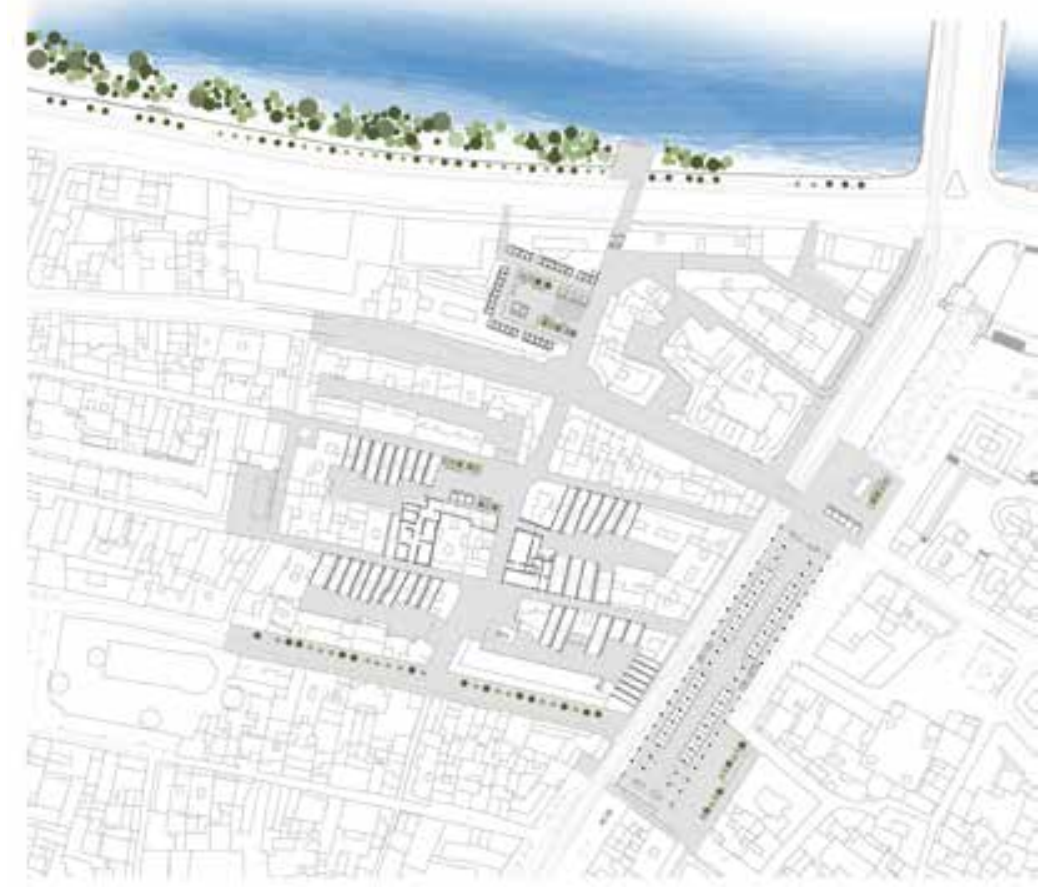

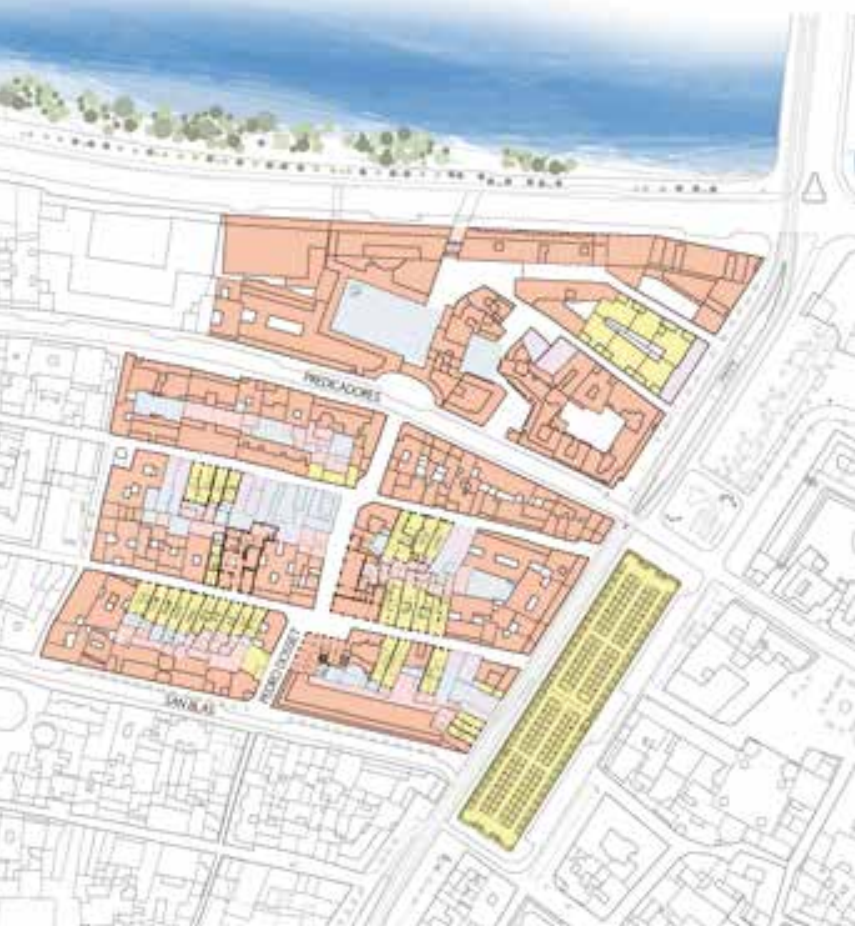

Plano de actuación| |ntervention plan

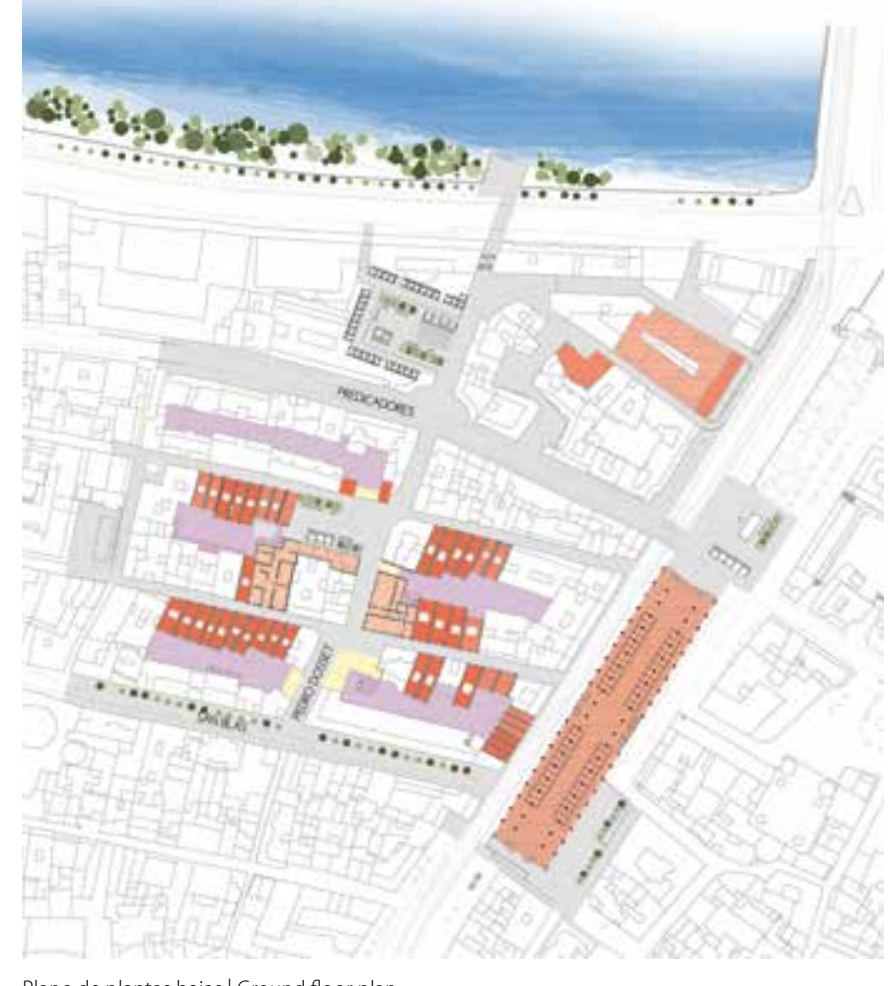

Plano de plantas bajass Ground floor plan

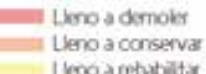

V Vacio a corstive

Plano de plantas bajas | Ground floor plan

E- Plesautsis

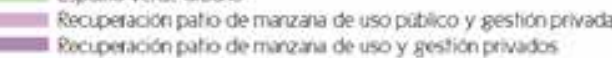

- Gamje pibico

E Equpmementoutaro

- Local passite

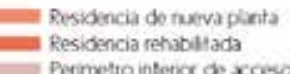

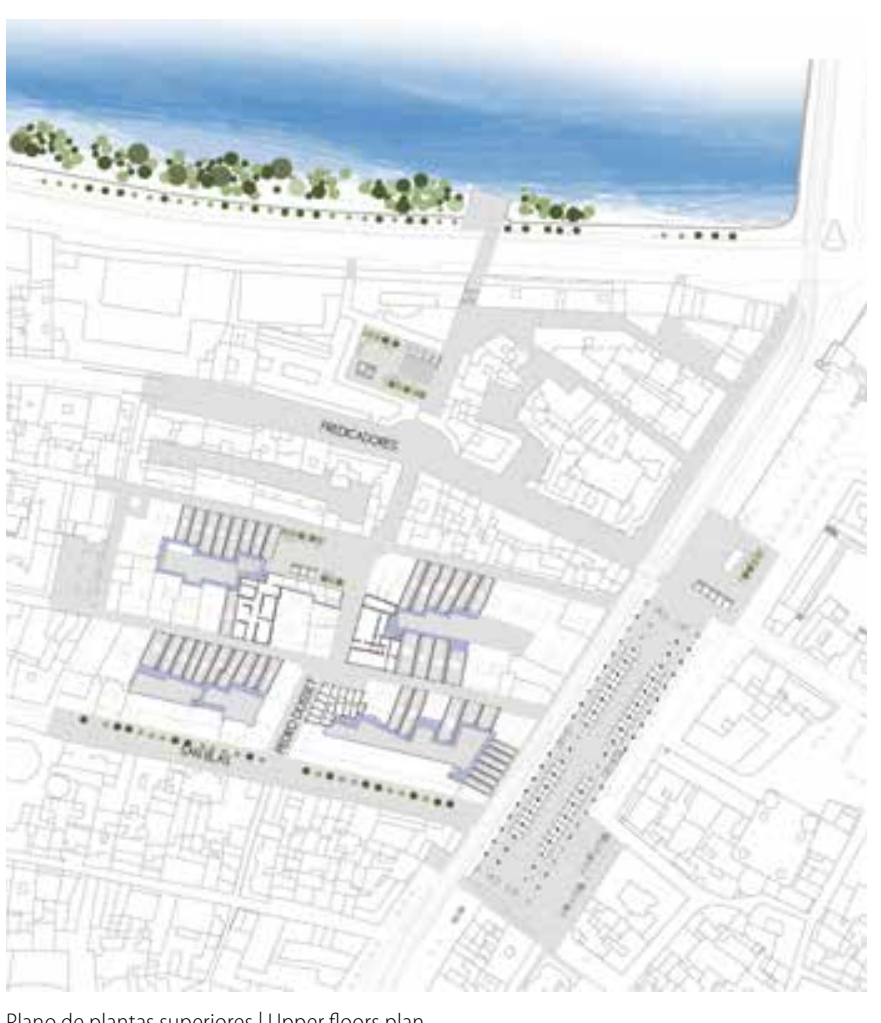




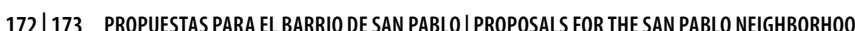
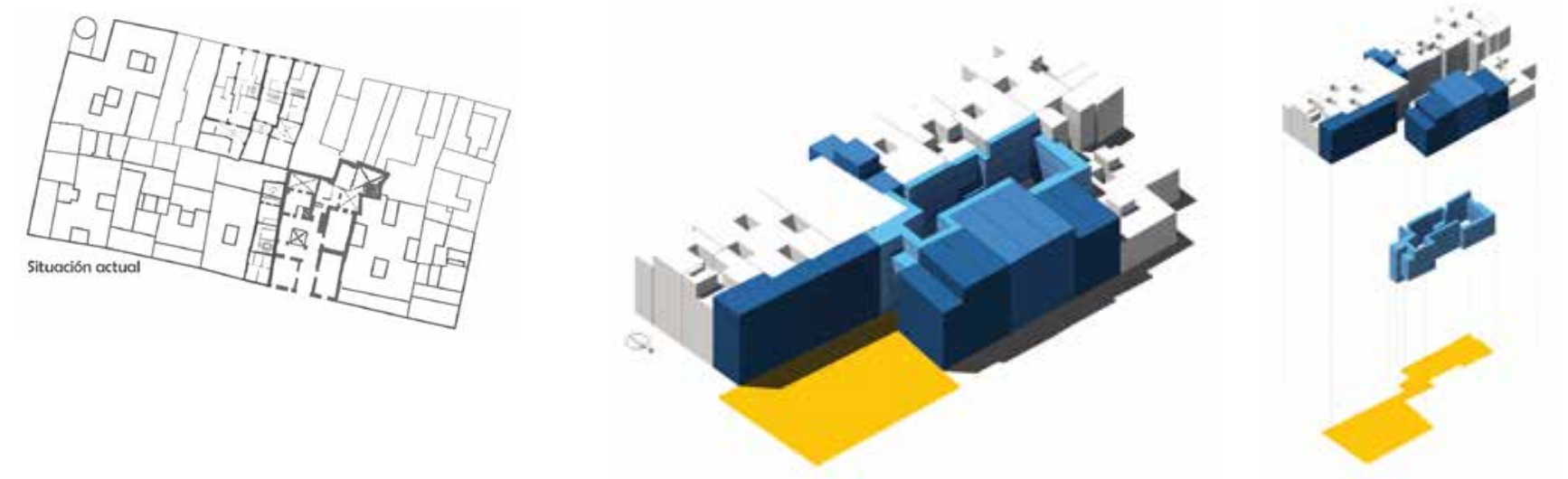

$$
\begin{aligned}
& \frac{11111}{\left[\begin{array}{l}
0 \\
7 \\
71
\end{array}\right]} \\
& \text { HIIIIIII) } \\
& \text { Plontes }
\end{aligned}
$$

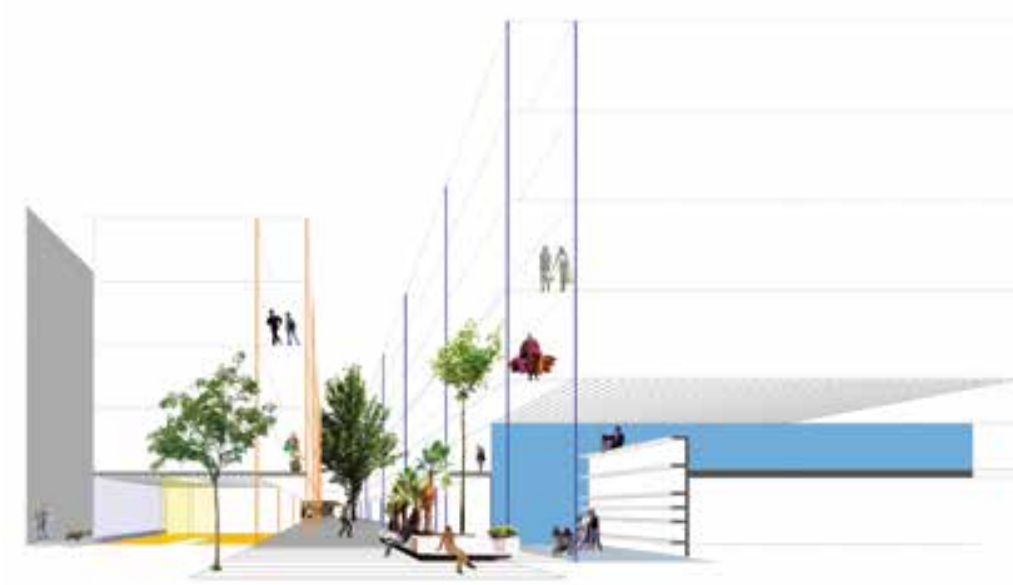

$$
\begin{aligned}
& \text { AfHIIII) } \\
& \text { Pronta } 1
\end{aligned}
$$

$\frac{411112}{47}$

$$
\rightarrow \text { m }
$$
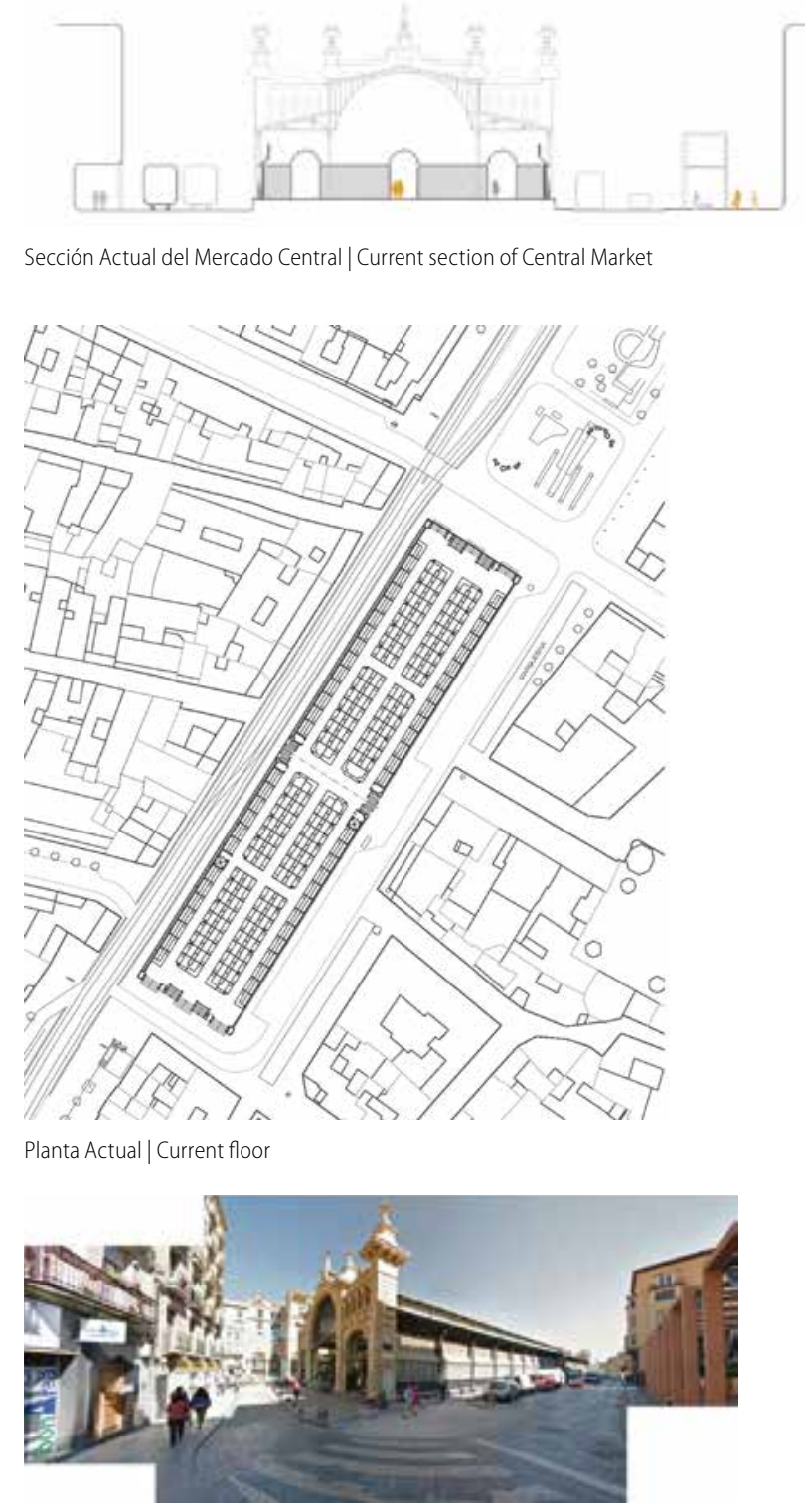
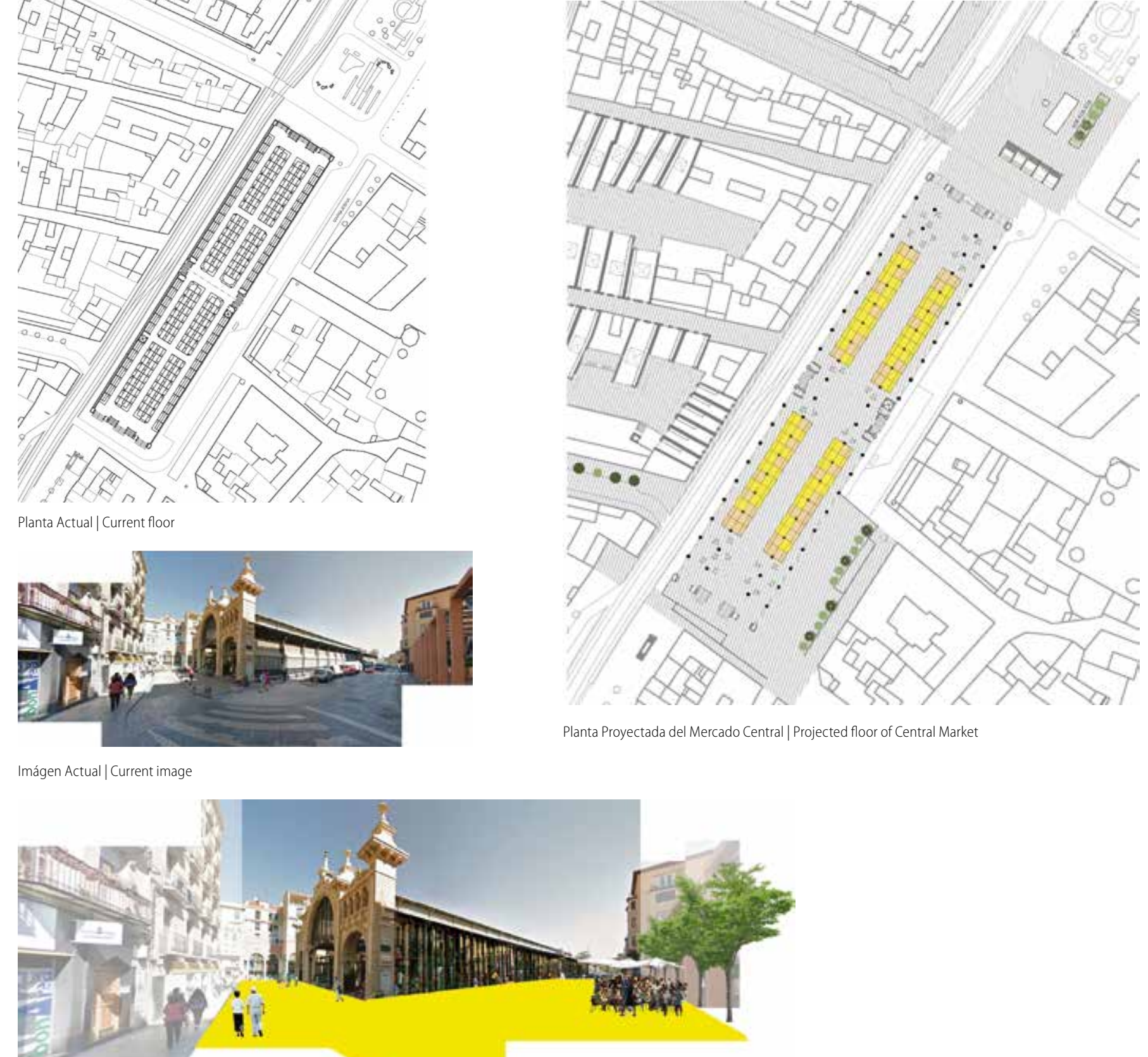


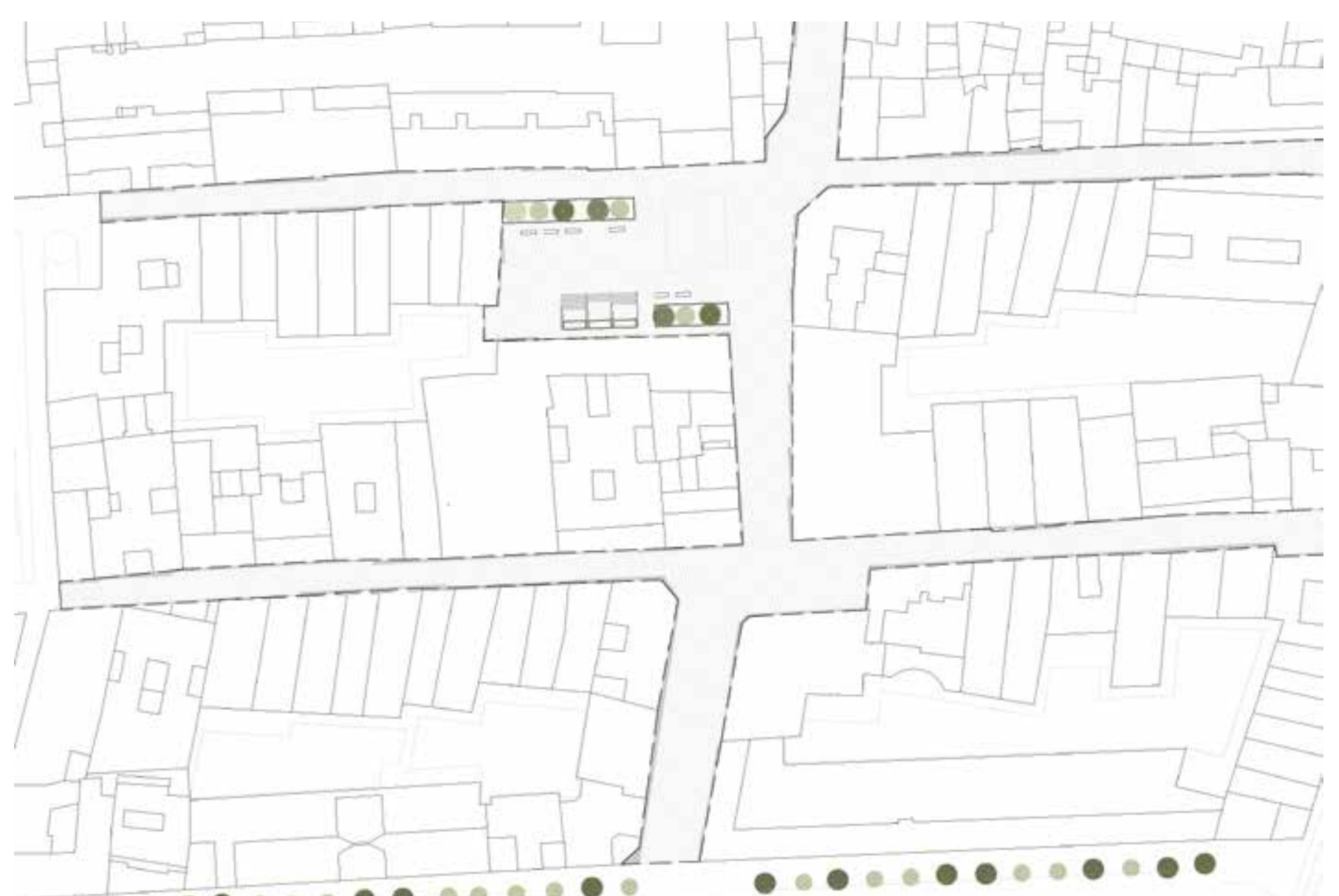

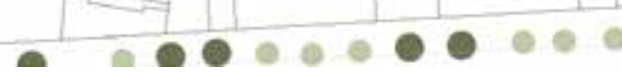

Flano de planta de la plaza propuesta junto a la calle Pedro Dosset | Ground floor plan of the place next to Pedro Dosset street

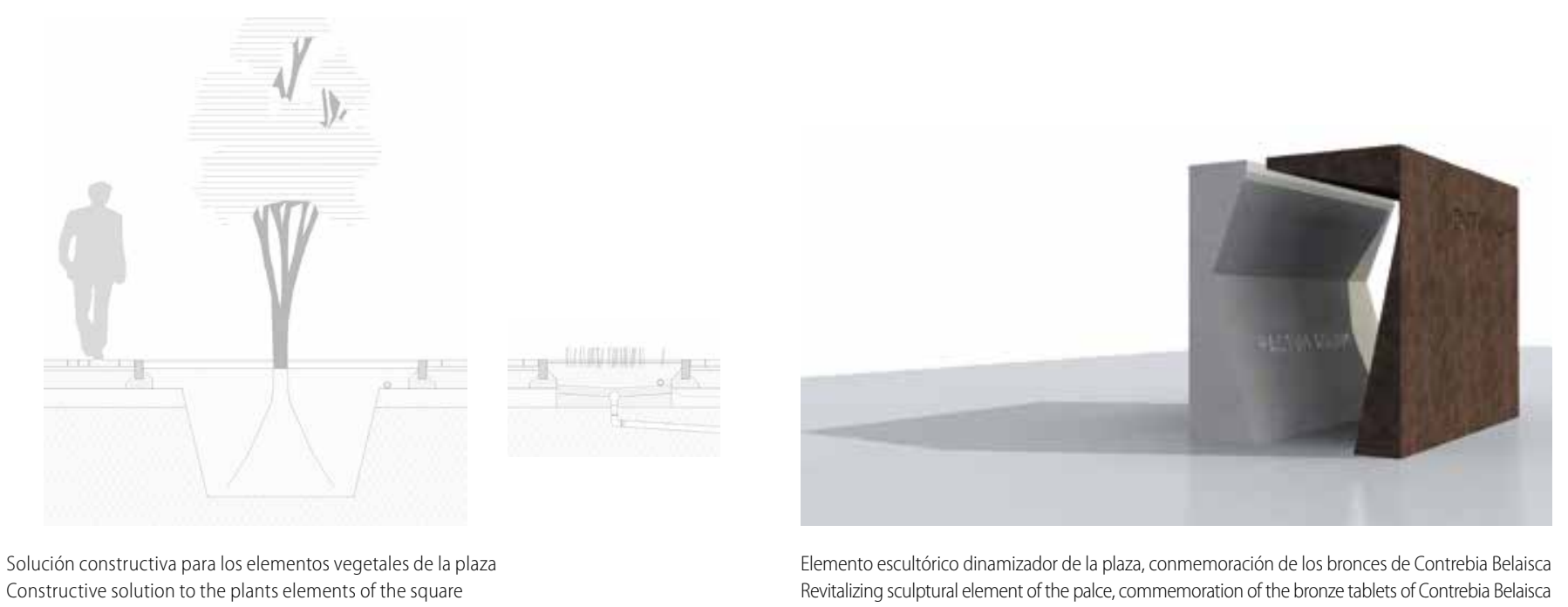

$2 \%$

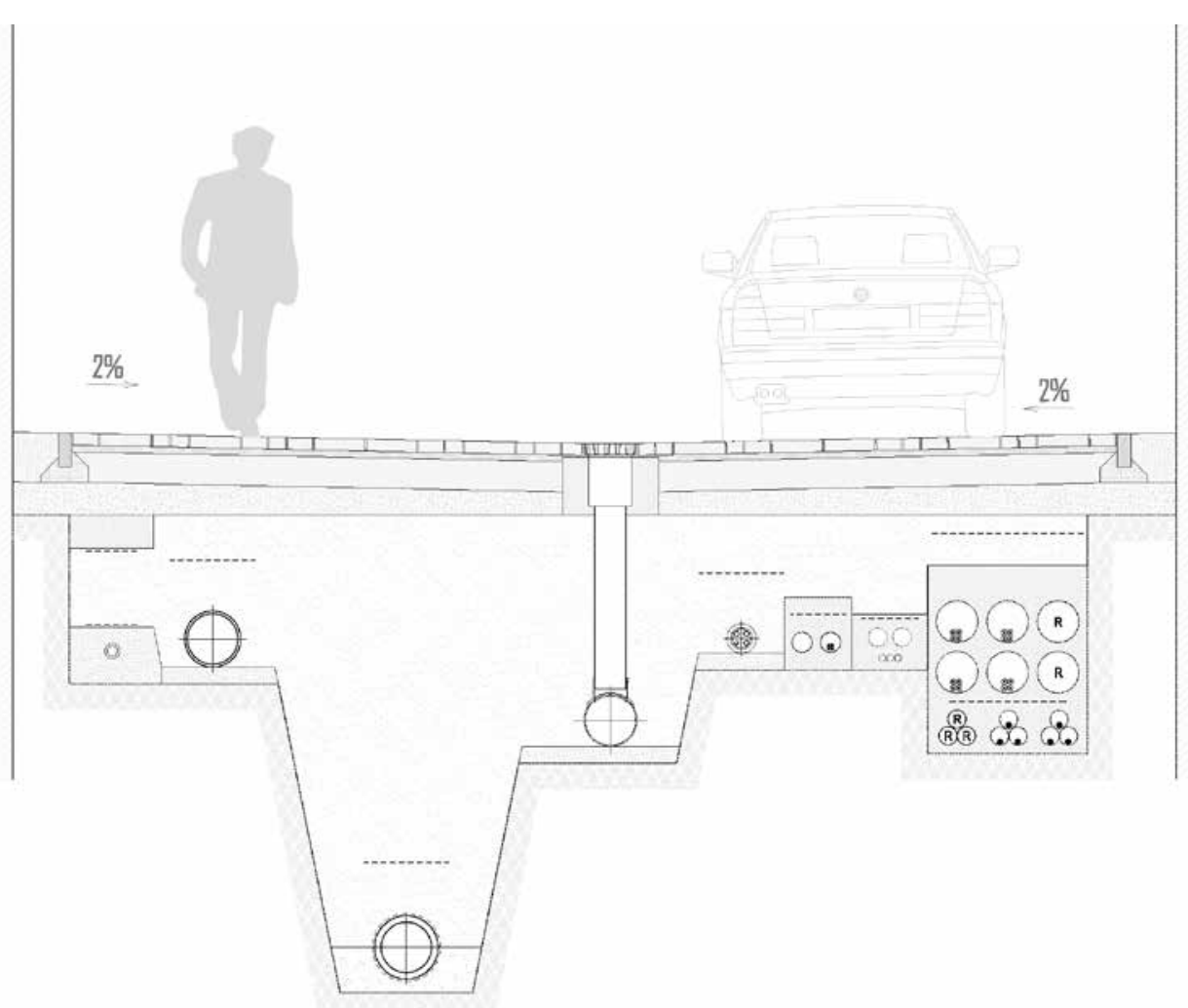

Sección tipo del la calle Pedro Dosset| Type section of Pedro Dosset Street

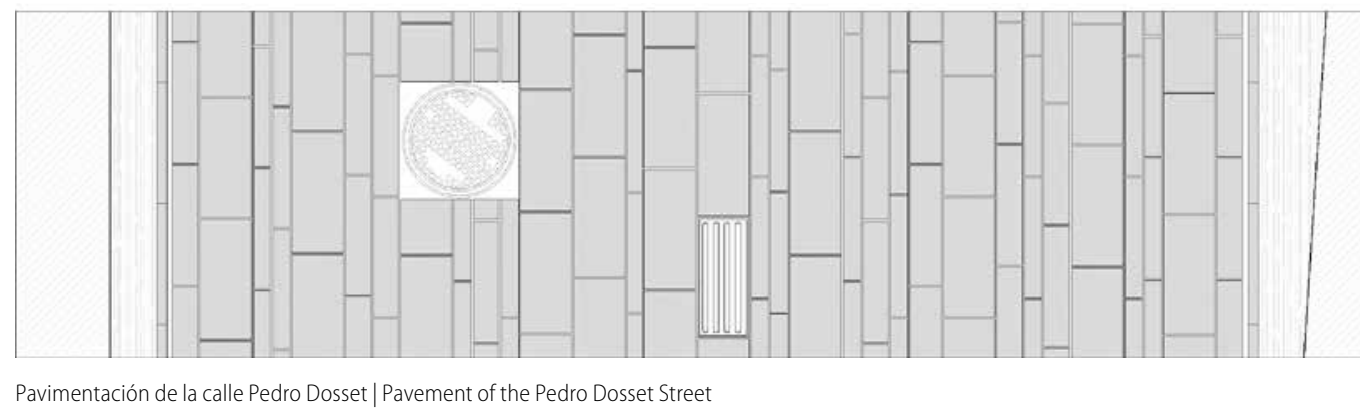



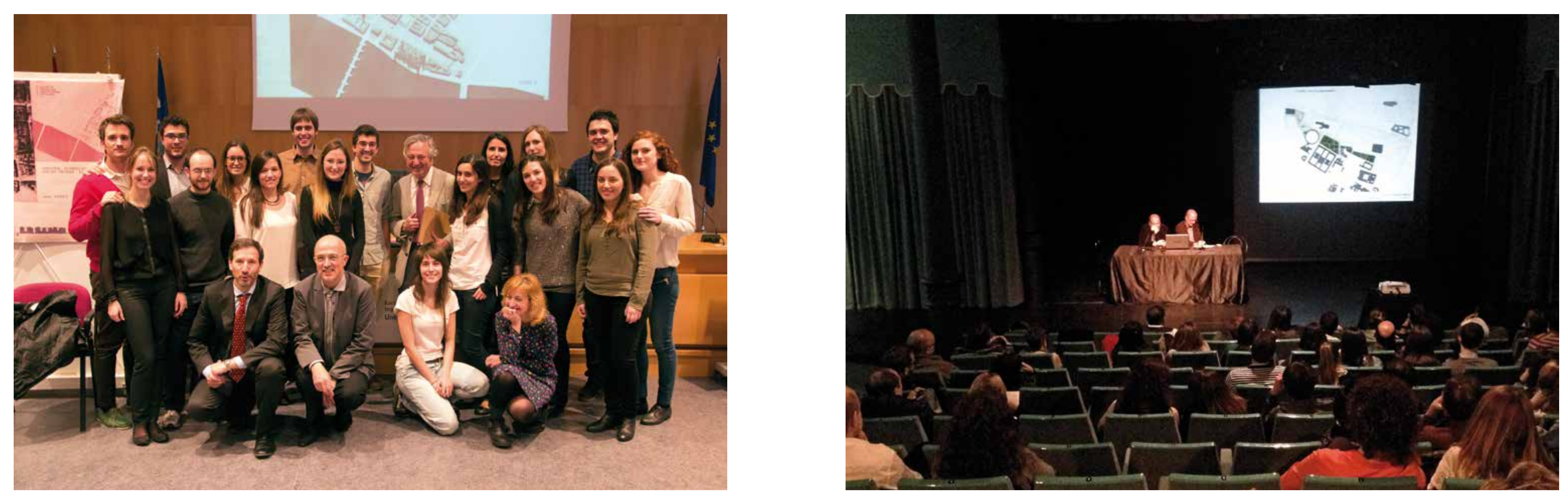

de Zaragoza, tanto de la sociedad Zaragoza Wivienda como de la Oficina del Plan Integral del Casco Historico de Zaragoza (PCH). Creemos que las dos partes, Universidad y Administracion, salen reforadas de esta intensa relación. Los destudlantes de arquatectura deben conocer cómo esta organizada la Admistracion, cóno se adoptan las decisiones de las cuestiones publicas. Y tambien es deseable que la gestion pubica, muy condicionada por las necesidades de corlo plazo, de da a da, a Y Y

Fruto precisamente de la intensa relación desarrollada entre el Ayuntamiento y la Unidad Departamental de Arquitecura de la Universidad de Zaragoza, ya en las fases finales del curso, se desencadenó en el Ayuntamiento un interesante debate centrado en la consideración de algunas de las propuestas lanzadas por estudiantes y profesores, cuyo comentario bien puede servir como colofón a esta publicación

En el pleno celebrado el 15 de Abril de 2014, el concejal del grupo municipal de Izquierda Unida, D. José Manuel Alonso, destacó, entre los trabajos presentados, la propuesta de Paula Gordo y Azucena Guerrero consistente en abrir público los jardines del ed ificio Pignatelli, sede del Gobierno de Aragón. D. José Manuel Alonso trasladé esta propues-

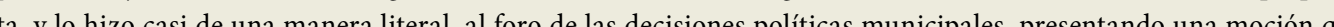
ta, y lo hizo casi de wa cine . ciudadanía un nuevo espacio público". El siguiente párrafo recoge parte de su intervención "Miren, entre los problemas que presenta cualquier casco histórico en una ciudad estála dificultad para reservar en el zonas verdes. No es una cosa sencilla. Por eso, pensamos, al hilo de algunas propuestas de arquitectos, que podría ser interesante aprovechar cualquier posibilidad de añadir zonas verdes al casco histórico. Hemos asistido -también algü otro concejal de los que está hoy en el pleno- a la exposición de los trabajos de los alumnos de un Máster de Arquitectura. Esos trabajos eran interesantes, pero creo que, sobre todo, eran atrevidos. Se expusieron ante una audiencia notable. Fu por esta razón, y por mover también un poquito el debate, la discusión y la dialéctica en el barrio, por la que invitamos a esos mismos alumnos a exponer sus trabajos a la ciudadanía del Casco histórico del resto de la ciudad. Asílo hicimos en el Teatro del Mercado. Creemos que se trata de una discusión interesante, a veces posible, a veces utópica, a veces real. Pero evidentemente sirve para impulsar el debate sobre posibles alternativas en el casco histórico. Tengo en las manos un proyecto que sellama "Rehabilitar San Pablo. Un parque interior", de dos alumnas, Paula Gordo Gregorio y Azucena Guerrero Sobreviela (que va a ser publicado en breve), que se plantean completar el tejido urbano del casco histórico, y recuperar un espacio interior. Plantean un proyecto de estructura longitudinal, de parque interior, que permita enlazar el casco histórico en primer lugar con la zona del Caixa Forum, también con la zona de la Plaza del Portillo, a través de un parque interior. Bajo la filosofía de otorgar un nuevo espacio público para San Pablo, se propone la implantación de un proyecto a escala de ciudad que consiga la permeabilidad de la trama urbana y que lo conecte desde la ribera del Ebro con el Caixa Forum y la Plaza del Portillo. Creo que es un proyecto bonito e interesante. Como, además, creo que la filosofía del edificio Pignatelli ha sido, durante tres siglos, estar abierta a la ciudad. Creo, también, que la separación entro politicos, gestoresy ciudadania no es nunca buena. Y como creo además, que es necesario un espacio verde que abra esos pasillos en el seno del casco historico, me comprometi con dichos alumnos a presentar en forma de moción su propuesta. Creo que es posible, creo que es fácil, creo que tiene cabida en la filosofía del modelo de ciudad que proponemos, y que ellos proponen. Y creo que, además, es perfectamente factible, porque lo ha sido en otros sitios, en otros lugares. Y, ademas, estoy convendid de que permitiria escenificar de forma simbolica una posición de rechazo a la habitual separación ptre policos y ciudadania, algo que, en estos tiempos en los que vivios por todos estos motivos, por lo que presentamos esta moción a debate."

Tras esta presentación, intervino el concejal D. Juan Martín, de la Chunta Aragonesista, introduciendo dos factores más a tener en cuenta en el debate: la consideración de los jardines como elementos vinculados a los edfin y la atención a la dimensión de los mismos. En su discurso reconoció que es difícil estar en contra de una moción que lo que pide es "que se derrumben las vallas que separan un jardín de la vía pública para que el pueblo soberano acceda a los mismos." Pero propuso evaluar la situación en su conjunto, es decir, en el contexto más amplio del barrio de Sa Pablo: "Hemos ganado en esta ciudad, en las inmediaciones de San Pablo también, todos los jardines que tienen que ver con la zona de la Aljafería. Hemos ganado elementos importantes de zonas verdes en el conjunto del casco histórico. En este caso yo no me atrevería ni siquiera a llamar zonas verdes a estos jardines, porque lo que hay detrás del Pignatelli no es más, si me permiten el tono jocoso, que una gran maceta. Y no es una cuestion de seguridad, se trata de que estos

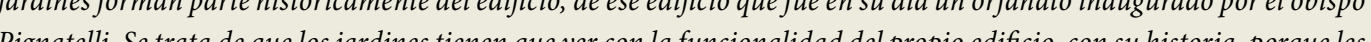

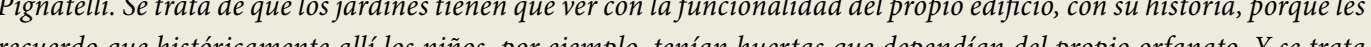

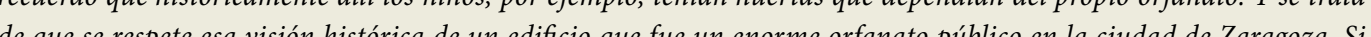
de que se respete esa vision historica de un edffio que fue un enorme offanalo publico en la ciudad de Zaragoza. Si

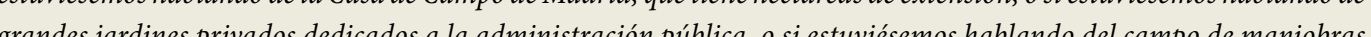
ge Sen Gre de San Gregros, que ileno un poco de jard puesto pro

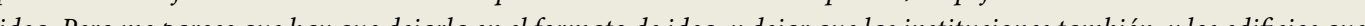
idea. Pero me parcec que hay que dejarla en el formato de idea, y dejar que las insilndionestambién, y los edificios que

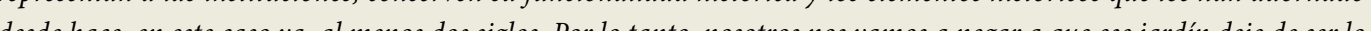

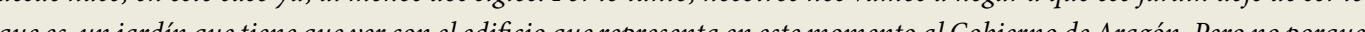
no nos guste que hava más zonas verdes en la zona de San Pablo."

El concejal del Partido Socialista Obrero Español, D. Jerónimo Blasco, manifestó en su intervención su total acuerdo el planteamiento de fondo de la propuesta, "la idea de conseguir mas zonas verdes para San Pablo". Pero, al mismo tiempo, puntaalizo que esta mocion se ha presentado para que no saga, porque en la redacción misma, decir que abran las puertas sin más, me da la impresión de que está abocada al rechazo". En su análisis del barrio expuso que se trata de un barrio bastante constrinido, que ha mejorado sin embargo en algunos aspectos, como en el tratamiento de las riberas, y con alguna otra actuación, como la plaza de José María Forqué, con la escultura ecuestre de Palafox, si bien reconoce que sigue habiendo carencias de zonas verdes.

Pero, yendo al contenido concreto de la moción presentada, Jerónimo Blasco expuso su opinión de que abrir sin más la veria sería casi una provocación: "Pedir a la DGA que abra la verja, sabiendo que es un lugar donde hay que trabajar la verja seria casi una provocacion: "Pedir a la DGA que abra la verja, sabiendo que es un lugar donde hay que trabajar
con cuidado, donde el tema de la seguridad es tan importante, es arriesgado. De todas maneras, la idea no es del todo con cuidado, donde el tema de la seguridad es tan importante, es arriesgado. De todas maneras, la idea no es del todo
desdeñable, yo creo que se puede reformular, se puede estudiar. Creo que la seguridad de la DGA se puede reconsiderar de desdeñable, yo creo que se puede reformular, se puede estudiar. Creo que la seguridad dela DGA se puede reconsiderar de
otra manera. Pero claro, no podrá ser nunca abriendo la veria. Porque, además, para que haya una continuidad - como otra manera. Pero claro, no podrá ser nunca abriendo la verja. Porque, además, para que hay a una continuidad - como
se ha dicho, y me parece una idea excelente de este equipo de arquitectura-, evidentemente habría que hacer otras conse ha dicho, y me parece una idea excelente de este equipo de arquitectura-, evidentemente habria que hacer otras con-
sideraciones, y otras modificaciones sustanciales respecto el trannsito en el interior del edificio del Gobierno de Aragón. En fin, nosostros no la podemos apoyar, pero si que estamos abiertos a estudiar la idea y, por supuesto, en consenso con En fin, nosotros no la podemos apoyar, pero si que estamos abiertos a estudiar la idea y, por supuesto, en consenso con creo que la denuncia de que esa zona verde tiene muy poco uso es real. Es verdad, yo he trabajado en Ia DGA yel uso creo que la denuncia de que esa zona verde tiene muy poco uso es real. Es verdad, yo he trabajado en la DGA yel uso
institucional que se hace de esa zona es casis simbólico. Nosotros la usábamos, en el mejor de los casos, una vez al año o dos, y creo que se sigue utilizando incluso menos ahora, hasta se utiliza para aparcar coches, lo cual tampoco me parece muy positivo. Pero es verdad que a la brava no se debe de transformar el uso de los jardines."

Como conclusión final, Jerónimo Blasco manifestó que esta idea debería tramitarse y estudiarse más detenidamente, y que la Junta de Distrito debería elaborar una propuesta, armada con estudios técnicos y, por supuesto, en colaboración 作 condiciones de "apoyar la idea".

El concejal del Partido Popular, D. Pedro Navarro, apoyó también la idea, e incluso hizo referencia a otras propuestas que se habían propuesto en el Taller de regeneración urbana: "Es una idea de unos alumnos, una entre muchas otras que se presentaron ante un padrino de excepción, el señor D. Rafael Moneo, arquitecto de renombre que dijo muchas cosas interesantes, por cierto. Pero alli se propusieron muchas otras cosas, ésta fue solo una propuesta, efectivamente centrada en que se abriera la zona verde que rodea la sede del Gobierno de Aragón. Pero alli se expuso también un proyecto estupendo de otros alumnos, que planteaba que se abriera la planta baja del instituto de educación secundaria Luis Buñuel para que los vecinos pudieran pasear tranquilamente por el patio del Luis Buñuel." 


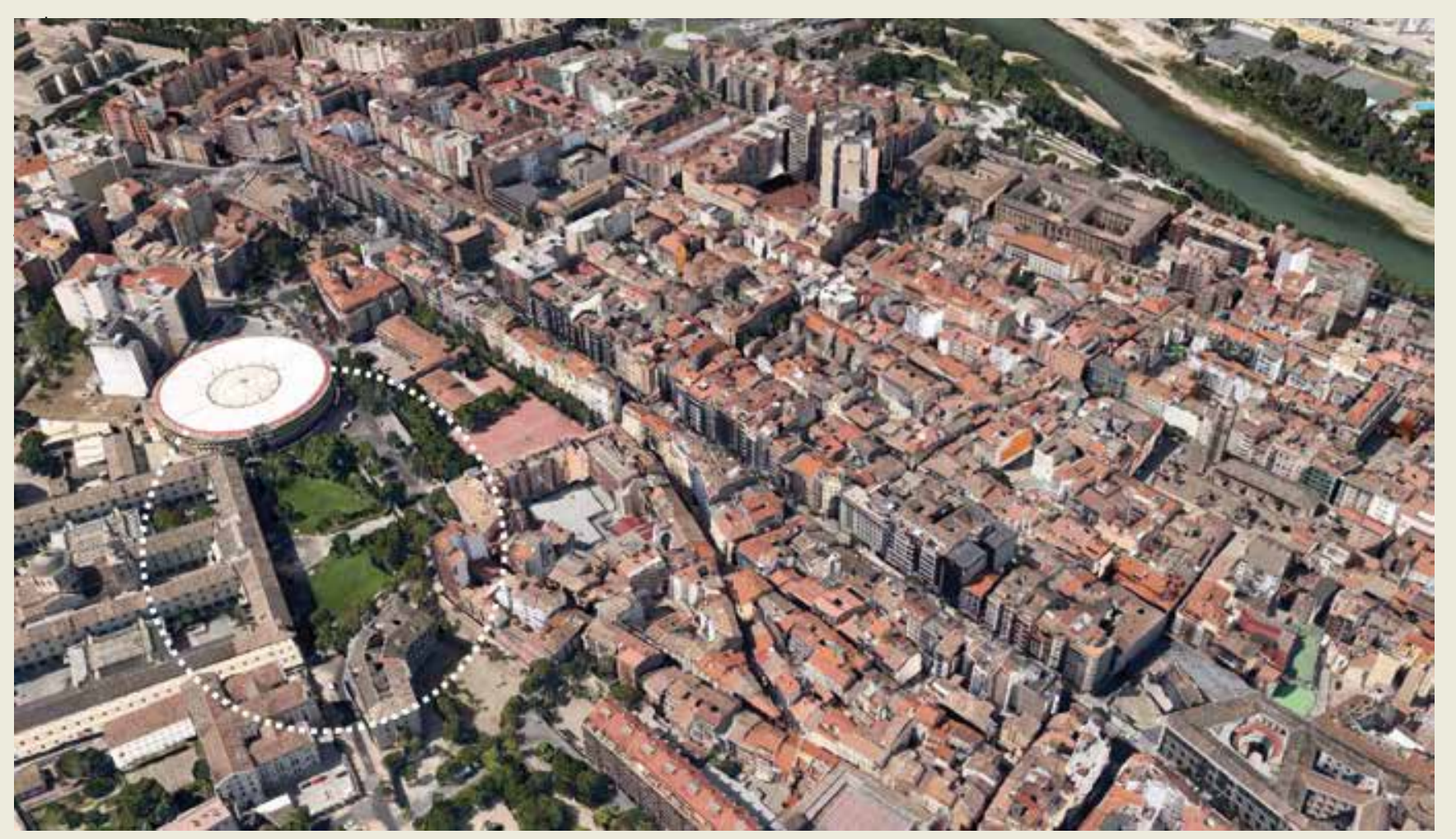

Imagen aérea del barrio de San
Pablo, con el edificio Pignatele sede del Gobierno de Aragón
en el extremo inferiorizquierd

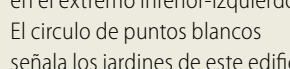
señala los jard
institucional.

En su segunda intervención, el concejal D. José Manuel Alonso replicó a D. Juan Martín, argumentando que no se trataba de un espacio pequeño, ya que estamos hablando de 5.000 metros cuadrados de parque y en una zona que carece de zonas verdes, ésta es una superficie considerable. Puntualizó también que en ningún caso este provecto propone derribar las vallas, sino tan solo dejarlas abiertas en un horario coincidente con el de visitas al edificio Pignatelli. D. Iosé Manuel Alonso planteó, además, otras opciones de carácter intermedio: "Yo quiero que se apruebe esta moción en un sentido on otro, y quiero defender, al menos por ahora, el uso público de estos espacios durante el tiempo que está abierto el Pignatelli, para que la gente pueda entrar alli a pasear. Claro que quiero, propónganme ustedes cualquier fórmula. Por cierto, no solamente vecinos del Casco, sino para todos los vecinos de Zaragoza que tengan a bien pasear por alli, donde hay unos cuantos equipamientos abiertos."

Finalmente, en la votación de esta moción presentada por Izquierda Unida, únicamente se obtuvieron los tres votos favorables de este grupo municipal. La moción fue, por tanto, rechazada. Evidentemente, nos habría gustado más que
esta propuesta hubiera tenido mayor recorrido político, ya que, por un lado, todos los concejales estaban de acuerdo con el fondo del planteamiento por el interés general del mismo y, por otro, la Universidad estaba dispuesta a profundizar, afinar y definir mejor estas primeras aproximaciones. Sin embargo, lejos de pensar que esta iniciativa pueda califcarse como un fracaso, entendemos que se este episodio puede considerarse como un significativo punto de inflexió os trabajos de la Escuela de Arquitectura han estimulado por primera vez un interesante debate en el pleno municipal sobre ciudad y espacio público. Posiblemente haya sido el primero, pero sin duda no será el último.

La conveniencia de que la gestión de la ciudad esté depositada en manos de personas competentes y con criterio es indiscutible. Pero no debemos olvidar que para actuar con buen criterio es necesario, en primer lugar, identificar $y$ analizar a fondo los problemas, tener en consideración diferentes alternativas, estudiar casos que aborden problemáticas similares y tener en consideración referencias de "buenas prácticas" aplicables a situaciones semejantes. Es, precisamente, esta actitud implicada y sensible ante las cuestiones que la ciudad plantea, la que muestra los trabajos que se presentan en esta publicació

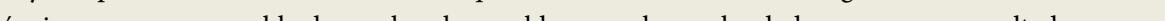

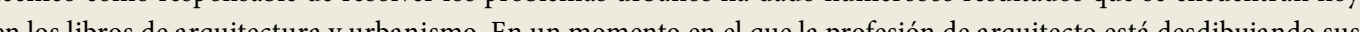

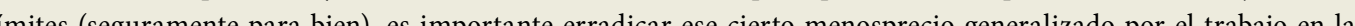
la a n The via... por poner solo el ejemplo de los arquitectos alemanes en el periodo entreguerras.

Considerando un contexto más cercano, podemos reproducir las afirmaciones de Oriol Bohigas -que podrían aplicararquitectura y el urbanismo en la configuración de las nuevas ciudades. La forma de la ciudad es un tema a discutir desde puntos de vista politicos y atendiendo a las proximidades más realistas y, al mismo tiempo, más utópicas."1

Sin duda, las buenas decisiones políticas deben apovarse en buenas propuestas arquitectónicas y urbanísticas. Los planteamientos y los resultados que se muestran en esta publicación dedicada a la regeneración urbana del barrio de
San Pablo de Zaragoza avanzan en esta línea y tratan de apostar por que Zaragoza en general, y el barrio de San Pablo en particular tengan un futuro mejor un plan una hoja de ruta, que dibuje un barrio más integrado desde el punto de vista urbanístico y social. 
TEXXOS| TExTS

Javier Monclús, Massimo Fortis, Julio Tejedor, Juan Rubio y Sergio García, José Javier
Gallardo, Carmen Diezy Ricardo Lampreave, Begoña Genua y Belinda López-Mesa,

Pablo de la Cal, Miriam Garcíay Y Francisco Berruete, Enrique Cano y Juan Antonio Ros FOTOGRAFIAS|PHOTOGRAPHS

Paco Cuenca

TraduCCONESS|TRANLLATIONS

TRASLUZ SL: 6-9, 62-77, 88-97, contraportada (traducción); 106-113, $118-151$ (revisión

TRASLUZ SLL: 6-9, 62-177,

Carmen Díz: $32-53$

DISEÑO Y MAQUEEACIÓN| DESIGN AND LAYOUI

Manuel García Alfonso

IMPRESIONY ENCUADERNACOÓN| PRRINTING AND BINDING

Prensas de la Universidad de Zaragoza

EDITA|PUBLISHED BY

Prensas de la Universidad de Zaragoza

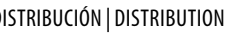

Prensas de la Universidad de Zaragora

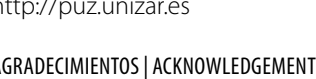

nimo Blasco, Rafael Moneo, Ana Sanromán

edro Santisteve, Nardo Torguet

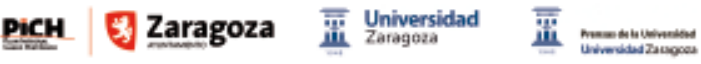

series ZARCHpupc/Urban Workshops n.4

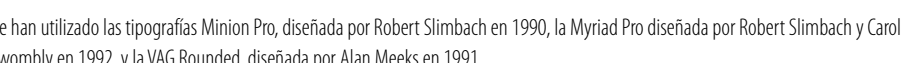

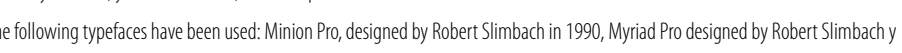

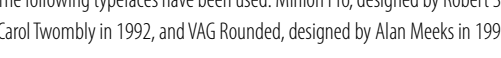

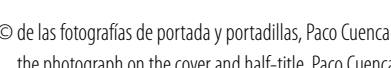

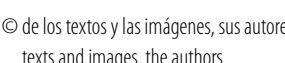

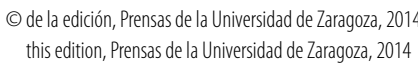

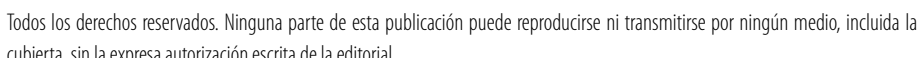

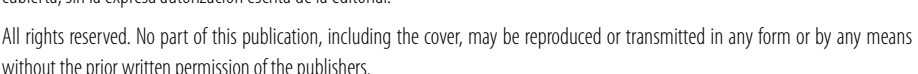


